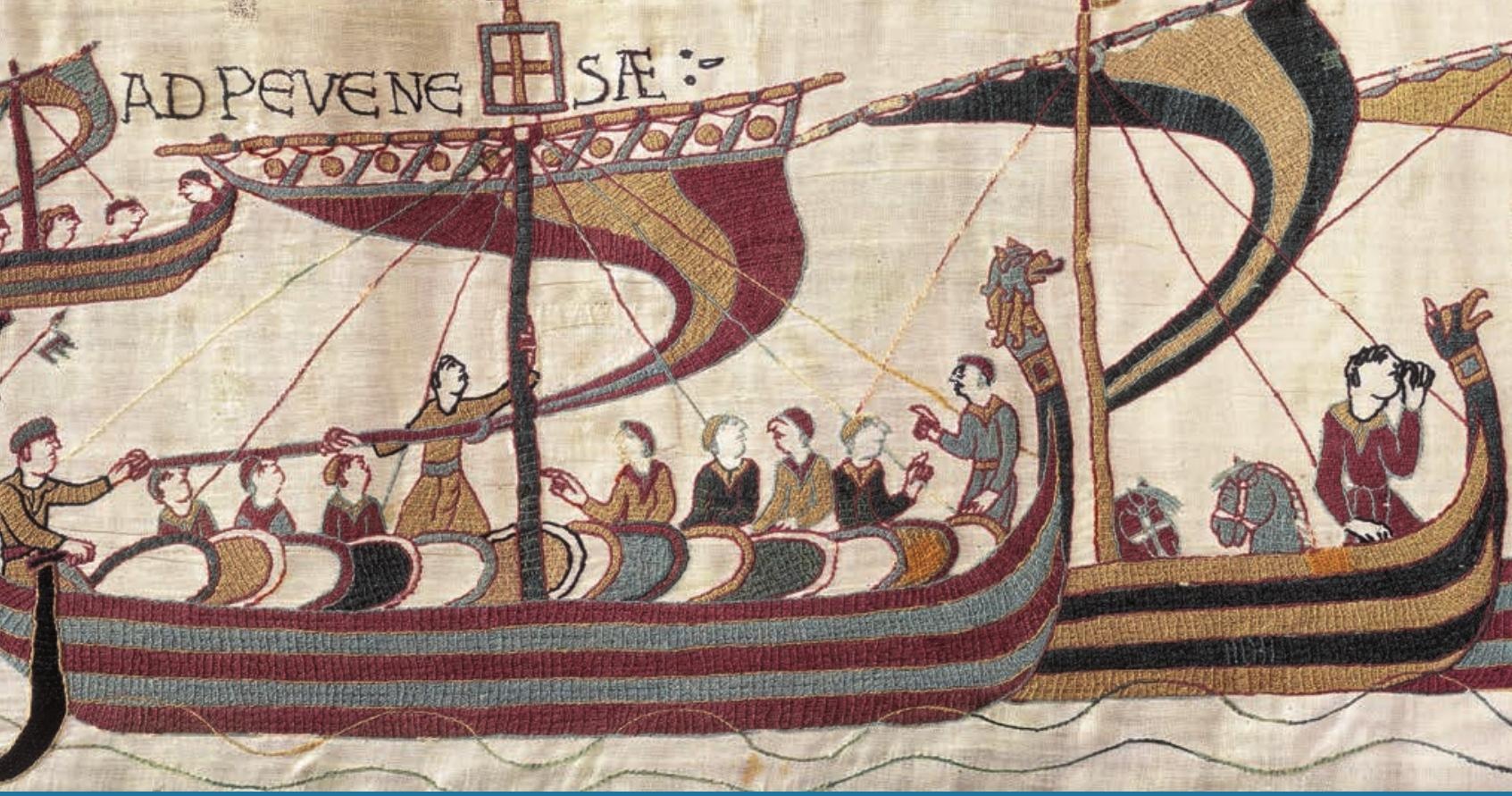

\title{
MIL ANOS DA INCURSÃO NORMANDA AO CASTELO DE VERMOIM
}

COORD.

MÁRIO JORGE BARROCA

ARMANDO COELHO FERREIRA DA SILVA 


\section{MIL ANOS DA INCURSÃO NORMANDA AO CASTELO DE VERMOIM}

COORD.

MÁRIO JORGE BARROCA

ARMANDO COELHO FERREIRA DA SILVA 


\section{Título: Mil Anos da Incursão Normanda ao Castelo de Vermoim}

Coordenação: Mário Jorge Barroca, Armando Coelho Ferreira da Silva

Design gráfico: Helena Lobo | www.hldesign.pt

Imagem da capa: "Tapisserie de Bayeux - XIème siècle". Avec autorisations spéciale de la Ville de Bayeux.

Edição: CITCEM - Centro de Investigação Transdisciplinar Cultura, Espaço e Memória

Via Panorâmica, s/n I 4150-564 Porto I www.citcem.org I citcem@letras.up.pt

ISBN: 978-989-8351-97-5

Depósito Legal: 450318/18

DOI: https://doi.org/10.21747/9789898351975/mil

Porto, dezembro de 2018

Paginação, impressão e acabamento: Sersilito-Empresa Gráfica, Lda. | www.sersilito.pt

Trabalho cofinanciado pelo Fundo Europeu de Desenvolvimento Regional (FEDER) através do COMPETE 2020 Programa Operacional Competitividade e Internacionalização (POCI) e por fundos nacionais através da FCT, no âmbito do projeto POCI-01-0145-FEDER-007460. 


\section{SUMÁRIO}

NOTA DE ABERTURA

Amélia Polónia

DESVENDAR A HISTÓRIA

Paulo Cunha

\section{INTRODUÇÃO}

Mário Jorge Barroca, Armando Coelho Ferreira da Silva

Viking Scandinavians back home and abroad in Europe: and the special case of Björn and Hásteinn

Stefan Brink

Armed bands on both sides of the Channel (865-899):

can we track individual viking gangs?

Alban Gautier

Los vikingos en la Península Ibérica: Nuevas perspectivas sobre piratas y mercenarios en la segunda mitad del siglo $\mathrm{X}$

Irene García Losquiño

La navegación e itinerario del ejército normando de Gunderedo (968-969)

Fernando Alonso Romero

Os Madjus através do espelho: algumas glosas em torno da incursão de 844

Hermenegildo Fernandes

De norte para sul: os vikings em Portugal

Hélio Pires

Incursão normanda ao Castelo de Vermoim: O espírito do tempo e do lugar

Armando Coelho Ferreira da Silva

As incursões vikings no Norte de Portugal

André Evangelista Marques, Mário Jorge Barroca, Luís Carlos Amaral

O Castelo de Vermoim, notas sobre a sua estrutura e implantação

Francisco M. V. Reimão Queiroga 



\title{
NOTA DE ABERTURA
}

\author{
AMÉLIA POLÓNIA*
}

$\mathrm{O}$ evento científico que deu origem à obra que agora se publica, o colóquio internacional comemorativo dos Mil Anos da Incursão Normanda ao Castelo de Vermoim, que decorreu em 17 de setembro de 2016 no Auditório da Casa de Camilo/ Centro de Estudos Camilianos, em S. Miguel de Ceide, assume, para o CITCEM, um duplo significado: o primeiro decorre do seu valor científico intrínseco; o segundo do facto de materializar uma política estratégica do CITCEM (Centro de Investigação Transdisciplinar Cultura, Espaço e Memória, sedeado na Faculdade de Letras da Universidade do Porto), da qual decorrem parcerias estratégias com comunidades e entidades, nomeadamente do Norte de Portugal. O que se convenciona hoje chamar de «Terceira Missão» das Universidades transforma-se para o CITCEM na sua «Primeira Missão»: a de criar e potenciar condições para uma transferência ativa de conhecimentos entre a Universidade e a Sociedade; a de dar valor e significado social ao conhecimento produzido segundo os mais elevados parâmetros científicos.

A realização do evento que deu origem a esta publicação explicita esse desiderato. O evento, coorganizado pelo CITCEM e pela Câmara Municipal de Vila Nova de Famalicão, contando com o apoio da Faculdade de Letras da Universidade do Porto (FLUP) e do Departamento de Ciências e Técnicas do Património (DCTP), teve a coordenação de dois investigadores do CITCEM, os Professores Armando

\footnotetext{
* Coordenadora Científica do CITCEM.
} 
Coelho Ferreira da Silva e Mário Jorge Barroca, cuja iniciativa se enaltece, e permitiu trazer a Portugal os maiores especialistas internacionais nos estudos sobre vikings (ou normandos), com os quais ombrearam especialistas nacionais de renome, que se debruçaram sobre uma matéria que tende a ser negligenciada pela historiografia portuguesa. Um sincero agradecimento é, pois, devido aos organizadores, conferencistas, membros do Secretariado e Bolseiros do CITCEM envolvidos na organização do evento.

O CITCEM apoia, agora, conforme acordado pela minha predecessora, Maria Cristina Cunha, a publicação desta obra, com a convicção do seu tríplice valor: científico, enquanto instrumento de disseminação de conhecimento de ponta; académico, pois esperamos que venha a funcionar como alavanca para posteriores trabalhos de investigação sobre a matéria; e social, enquanto registo de uma memória que pertence a um território, a uma comunidade, e a uma região: a do Vale do Ave.

Esta última função é, sem dúvida, partilhada com o copatrocinador desta edição, a Câmara Municipal de Vila Nova de Famalicão, a quem agradeço o apoio concedido à iniciativa, e agora a esta publicação, e a quem desafio, na pessoa do seu Presidente, Vereadores e Técnicos dos Serviços Culturais, para outras iniciativas conjuntas, capazes de potenciar missões partilhadas por ambas as instituições.

Porto, 17 setembro de 2018 


\title{
DESVENDAR A HISTÓRIA
}

\author{
PAULO CUNHA*
}

Em setembro de 2016, o município de Vila Nova de Famalicão agarrou o tema das incursões vikings na região Norte e lançou uma conferência internacional pioneira no país, reunindo alguns dos mais conceituados especialistas mundiais no período viking e despertando a comunidade científica para estes acontecimentos históricos.

Marcávamos, desta forma, os mil anos passados desde o ataque ao Castelo de Vermoim, tal como está relatado na Chronica Gothorum, o registo mais antigo da história da fundação do reino português.

Dada a brevidade da fonte, desconhecem-se os contornos exatos do ataque. No entanto, presume-se que, naquele fim de verão, os vikings - como hoje popularmente lhes chamamos - subiram o rio Ave nas suas embarcações apelidadas de drakkar e atacaram o Castelo de Vermoim, numa incursão demolidora que destruiu por completo a fortificação, provocando a morte do Conde de Portugal, Alvito Nunes, que governava o Condado Portucalense no século XI.

Independentemente do que aconteceu naqueles dias, o certo é que o Castelo nunca mais recuperou e as consequências desta passagem pela região perduraram durante vários séculos, deixando marcas irreparáveis nas populações e instituições daqueles tempos.

\footnotetext{
* Presidente da Câmara Municipal de Vila Nova de Famalicão.
} 
Durante muito tempo, os historiadores desvalorizaram, talvez por desconhecimento - como se admite agora - esta vaga de incursões normandas pela nossa região. A verdade é que os vikings estiveram no Vale do Ave durante nove meses e a sua presença foi marcante a vários níveis para a evolução da região.

A organização da conferência internacional em 2016 veio trazer uma nova luz sobre estes acontecimentos históricos, estimulando uma onda de interesses e investigações sobre o tema.

E isso muito se deve aos nossos parceiros do evento, com créditos firmados na investigação científica e da história, como é o caso do CITCEM - Centro de Investigação Transdisciplinar da Faculdade de Letras da Universidade do Porto e dos investigadores Armando Coelho Ferreira da Silva e Mário Jorge Barroca.

A pertinência e o interesse suscitado pelo tema resultam agora na edição deste livro que é um dos primeiros efeitos visíveis da conferência internacional, com a publicação das comunicações do encontro que contou com a presença de mais de uma dezena de historiadores nacionais e internacionais.

Como dizia o filósofo romano Marcus Cícero, «a história é testemunha do passado, é luz da verdade e mestra da vida», mas é também um farol que nos guia, pois, acredito que para construirmos o nosso futuro, temos de conhecer e compreender o passado.

Convido, por isso, todos os famalicenses a lerem esta publicação e espero que este livro seja um contributo para novas investigações e para novas descobertas sobre a nossa história coletiva. 


\section{INTRODUÇÃO}

MÁRIO JORGE BARROCA*

ARMANDO COELHO FERREIRA DA SILVA*

Em setembro de 2016 completaram-se mil anos sobre uma incursão militar normanda que atacou o Castelo de Vermoim, no coração do Entre-Douro-e-Minho, um acontecimento que ficou memorizado numa curta passagem da Chronica Gothorum. Apesar do caráter lacónico desta notícia, este foi o evento mais visível e significativo de uma incursão que se prolongou durante vários meses, entre 1015 e 1016, e que afetou o espaço entre os rios Ave e Douro. Para assinalar essa efeméride foi organizado um colóquio internacional, intitulado Mil Anos da Incursão Normanda ao Castelo de Vermoim. Colóquio Comemorativo, que decorreu no dia 17 de setembro de 2016 no Auditório da Casa de Camilo/Centro de Estudos Camilianos, em S. Miguel de Ceide. Tratou-se da primeira reunião científica realizada em Portugal dedicada exclusivamente ao tema das incursões vikings ou normandas no espaço ibérico. A coordenação científica ficou a cargo dos signatários desta Apresentação e a organização foi patrocinada pelo CITCEM - Centro de Investigação Transdisciplinar Cultura, Espaço e Memória (Unidade de I\&D 4059 da FCT) e pela Câmara Municipal de Vila Nova de Famalicão, contando com o apoio da Faculdade de Letras da Universidade do Porto (FLUP) e do Departamento de Ciências e Técnicas do Património (DCTP).

* DCTP/FLUP - CITCEM. 
Nesse colóquio participaram diversos investigadores, entre os quais alguns dos maiores especialistas nos estudos sobre vikings ou normandos: Gareth Williams (do British Museum, Londres), Stefan Brink (da University of Aberdeen, Escócia), Alban Gautier (da Université du Littoral, Boulogne, França), Irene García Losquiño (investigadora da University of Aberdeen, Escócia), Fernando Alonso Romero (da Universidad de Santiago de Compostela, Espanha), Hermenegildo Fernandes (da Faculdade de Letras da Universidade de Lisboa), Hélio Pires e André Evangelista Oliveira Marques (ambos investigadores do Instituto de Estudos Medievais da Faculdade de Ciências Sociais e Humanas da Universidade Nova de Lisboa), Armando Coelho Ferreira da Silva, Luís Carlos Amaral e Mário Jorge Barroca (todos da Faculdade de Letras da Universidade do Porto e do CITCEM) e Francisco Reimão Queiroga (da Universidade Fernando Pessoa). O volume que agora sai do prelo é o resultado dessa reunião científica. Nele apenas falta o contributo apresentado por Gareth Williams (The Viking World), que infelizmente não foi possível incluir em tempo útil.

Enquanto organizadores do colóquio gostaríamos de deixar expresso o nosso reconhecimento às entidades que patrocinaram este evento, nomeadamente:

- ao CITCEM, na pessoa da sua coordenadora de então, a Professora Doutora Maria Cristina Almeida Cunha, e da sua atual coordenadora, Professora Doutora Amélia Polónia da Silva, bem como ao seu vice-coordenador, de então e de agora, Professor Doutor Luís Alberto Marques Alves, que desde a primeira hora deram todo o apoio a esta nossa iniciativa;

- à Câmara Municipal de Vila Nova de Famalicão, na pessoa do seu Presidente, Dr. Paulo Cunha, e na pessoa do Chefe de Divisão da Cultura e Turismo, Dr. Nelson Pereira, por todo o apoio logístico dado, fundamental para o sucesso do colóquio;

- à extraordinária equipa de colaboradores do CITCEM - o Dr. Vasco Sistelo, a Dr. ${ }^{a}$ Marlene Cruz e a Dr. ${ }^{a}$ Vanessa Sousa -, pelo incansável e eficaz apoio em todas as fases de preparação do Colóquio e da edição das suas atas;

- e a todos os funcionários da Casa de Camilo/Centro de Estudos Camilianos, que tão calorosamente nos acolheram.

Por fim, um agradecimento especial a todos os Autores que aceitaram o nosso convite de, a pretexto dos mil anos da incursão ao Castelo de Vermoim, virem refletir connosco sobre os Vikings e a Idade Viking, em contexto atlântico e ibérico, e que tiveram a paciência de aguardar pela edição destas atas. Elas são, afinal, o testemunho perene do que aconteceu naquele dia que, em nosso entender, foi a vários títulos memorável. 


\title{
VIKING SCANDINAVIANS BACK HOME AND ABROAD IN EUROPE: AND THE SPECIAL CASE OF BJÖRN AND HÂSTEINN
}

\author{
STEFAN BRINK
}

The for European early history so famous (or notorious with a bad reputation) vikings start to make a presence of themselves around ad 800 in the written sources, i.e. the Frankish, Anglo-Saxon and Irish annals and chronicles. Today we know that the raiding and trading by these Scandinavians started much earlier. The way this kind of external appropriation was conducted by the vikings was - if we simplify - that if they could get hold of wealth and silver for free, they took it (robbed, stole and if necessary killed off the people), if they met overwhelming resistance, they traded. The precious commodity the raiding and trading vikings was looking for was silver, and the way they achieved this was mainly by taking part in a slave trade on a large scale.

The viking culture and society in Scandinavia was linked to the emergence of proto-towns (emporia), such as Ribe, Hedeby, Kaupang, Birka etc., and they can be dated to as early as around AD. $700^{1}$. This has of course to do with the trading aspects of the vikings. As for the raiding culture of the vikings, a fairly recent discovery of two burials on the island of Saaremaa in today's Estonia in the Baltic has revealed two buried ships into which have been thrown down 34 respectively 7 men, obviously heavily armed warriors, many with serious weapon trauma noticeable on the skeletons ${ }^{2}$. Thanks to the archaeological and osteological analyses and by analysing isotopes it has been concluded that these men originate from central Sweden, possible to be

\footnotetext{
${ }^{1}$ FEVEILE, 2008; HILBERG, 2008; AMBROSIANI, 2008; SKRE, 2008.

2 PEETS, 2013.
} 
narrowed down to the area around Uppsala in the province of Uppland. This is hence to be identified as an unsuccessful 'viking' raiding party. However, the ${ }^{14} \mathrm{C}$ analyses from the excavation give us a dating to $c$. AD. 750, hence well before the traditional start of the Viking Age. The new knowledge gain from Archaeology forces us to see the start of the viking expansion to at least one hundred years or so earlier, something that has been argued for before ${ }^{3}$.

The new picture that emerges is that we perceive the period c. AD. 550-1050 as culturally and societally fairly homogeneous. In Sweden, we have archaeologically divided these centuries into two periods, the Vendel Period (c. AD. 550-800) and the Viking Age (c. AD. 800-1050), where the former can be understood as a preamble to what is then coming, the viking period. (The Vendel Period is in Danish archaeological tradition called Later Germanic Iron Age, yngre germansk jernalder, and in Norwegian archaeological tradition The Merovingian Age, merovingertid). After the fall of Rome and the following turbulence in Europe during the Migration Period ${ }^{4}$, a new kind of society is emerging in Scandinavia. New central places seem to emerge dispersed in the landscape, and a new power structure seems visible. If the assumed tribal society during the Roman Period and the Migration Period continues into this second half of the first millennium, this probably has a new dimension to it. From archaeology and toponymy we can intimate new social classes emerging, a differentiation of society, with a new kind of kings and chieftains, with a new warrior 'aristocracy', with retinues and specialised craftsmen and so on ${ }^{5}$. The emergence of a new ruling class was observed already by Patrick Wormald ${ }^{6}$ :

The Viking Age saw Scandinavian kingship grow from Volkskönigtum [tribal kingship] to Heerkönigtum [military kingship], as that of other Germanic peoples had earlier, and this growth was both cause and effect of Viking activity.

And today we, hence, are starting to see this emergence of a new ruling class already taking place in the pre-viking period. The power base in this early period is obviously still a personal one, not based on territorial supremacy. Power was intimately linked to personal abilities, and power was conducted only where the king/ chieftain and his retinue were present. It is possible to identify the centres for these chieftains and kings with the help of archaeology and place names. The central places, with names on -tuna, -sal etc., with, in some cases, identified hall buildings and with

\footnotetext{
${ }^{3}$ MYHRE, 1992.

${ }^{4}$ For anyone interested in this turbulent period of European history, I can refer to the important collaborative project, Transformation of the Roman world, and the volumes produced in this project (http://www.brill.com/publications/ transformation-roman-world).

${ }^{5}$ Cf. for example BRINK, 1999; LJUNGKVIST, 2006.

${ }^{6}$ WORMALD, 1982: 147.
} 


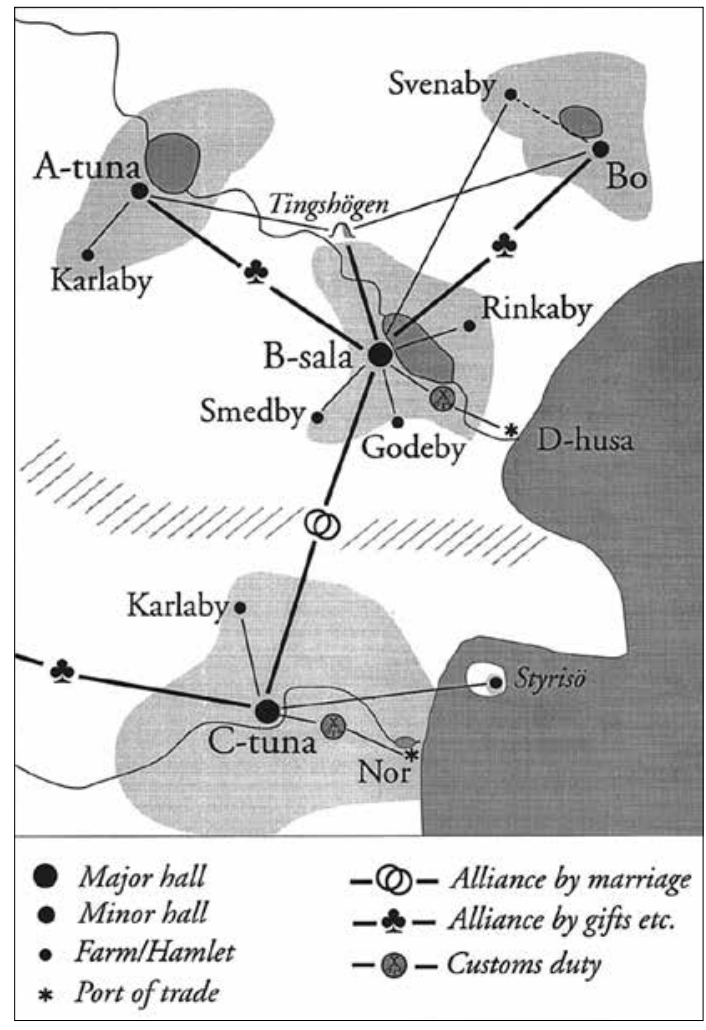

Fig. 1.

A model of the Vendel Period/Early Viking Age society in Scandinavia, regarding power centres. From BRINK, 1999: 434.

often extraordinary archaeological finds and rich burials, are spread out in the landscape. According to poems such as Beowulf, this society was a warrior society with a kind of endemic warfare, trying to control these halls. The picture that emerges is of a society where power constantly was shifting according to the personal abilities of the chieftains and kings of making allies and building up a power base (see Fig. 1).

To build up such a power base in this early period you had to have three assets: a reputation (of a strong leader), allies (which you could rely upon) and richness (with which you could 'buy' allies). To claim a kingship, you most certainly had to come from a royal family, and we must reckon with several such families in society. There were hence many potential candidates for claiming to be a king (konungsefni), and there could also be several kings, not only one, in a realm. The way a young konungsefni prepared himself with the prospect of being a king, you had to gain wealth and reputation. Wealth you could inherit, but fame and reputation as an able and strong leader you had to prove yourself in battle as a warrior. Therefore, we find many young Scandinavians in this period going abroad and taking up a role as a mercenary in some king's army in Anglo-Saxon England, in Ireland or on the Continent. By doing so - and survive! - you were compensated handsomely and 
gained reputation and fame. After such a turn to the south or west you could go back home, tie up allies by presenting them with extraordinary gifts, such as a Frankish sword, or silver or exclusive jewellery, and then claim to be accepted as a king. This was, for example, the way two of the more famous kings in the Viking Age came to power, the Norwegian kings Óláfr Tryggvason (r. 995-1000) and Óláfr Haraldsson (r. 1015-28) $)^{7}$.

The societal base for Scandinavian life during this period was the farm. All vikings were farmers. The first proto-towns seem to have been seasonally inhabited, and tradesmen that exclusively traded must have been extremely few. The seasonal cycle during the Viking Age seems to have been that many men left home with their ships, raiding and trading during the summer season. In a slightly later phase, we know that viking armies and war band wintered at winter camps in England and in Francia. When the man was away from the farm, the wife took responsibility of running it. At a farm for a well-to-do farmer, there were the close family, man, wife and children, with elderly and close relatives, farmhands and maids, and unfree thralls. We don't know how many thralls there were, hence what proportion the slaves made of the total population. There have been many guesses, 10, 25 or 40 percent of the total viking population in Scandinavia. The bottom line is that we don't know and it is impossible to even get a qualified guess. What we can say is that many farmers must have had thralls at their farms. We also start to intimate a regional difference, in so far as southern Scandinavia seem to have had a larger slave-population than further north. This has been suggested by Mats Roslund, after analysing pottery in different societal contexts ${ }^{8}$. It is also possible that this difference indicates that in southern Scandinavia we had large 'manorial estates', run by slave labour, whereas further north in Scandinavia, these did not exist and instead the family farm was the normal unit ${ }^{10}$.

Until the 10th century the viking Scandinavians had a 'religion' which they themselves called forn siðr (old custom $)^{11}$. This is a very apt definition of that kind of 'religion', which was embedded into everyday life for people; you were confronted with higher and lower deities from the moment when you woke up in the morning until you went to bed. There were different kind of deities and supernaturals on the farm, on the land, living in rocks and trees and so on, and you had to relate to them and keep them happy or protect people, farm, crop and cattle from the malicious ones $^{12}$. Then there were the gods and the goddesses, which had different functions:

\footnotetext{
${ }^{7}$ BAGGE, 2006; RUMAR ed., 1997; RØTE, 2004.

${ }^{8}$ ROSLUND, 2007; ROSLUND, 2013.

${ }^{9}$ Cf. TOLLIN, 1999; MYRDAL \& TOLLIN, 2003.

${ }^{10}$ For an overview and discussion of thralls and slavery in viking Scandinavia, see BRINK, 2008 and 2012.

${ }^{11}$ HULTGÅRD, 2008.

12 RAUDVERE, 2008.
} 
Pórr, the god of thunder and lightning, and of war; Óðinn, the mighty one, god of kings and chieftains, the wise one who also gave to people the runes, and to his hall, Valhöll, you went to as a fallen warrior; Freyr, the god of fertility and prosperity, and the goddess Freyja, with the same functions and so on ${ }^{13}$. Around these gods and goddesses there were many myths which create the Old Norse mythology ${ }^{14}$, which we can read about in a unique collection of mythological and heroic poems, the so called Poetic Edda. In the most famous one, Völuspá (the seeress' prophecy), we get an insight into the cosmogony, cosmology and eschatology of this mythology ${ }^{15}$.

This 'religion' was thus not an intellectual one, but instead a siðr, a custom. The two fundamental ways you conducted and took part in this custom were with rituals and cult ${ }^{16}$. We learn about sacrificial meals (blót), of worshipping ancestors, of offerings of animals (and perhaps also humans) to gods at special cult sites, and so on. Still today we have place names in the Scandinavian landscape reminding of these pagan cult sites, with names including the words vi, voe, vé, hof, hörg, harg, lund, etc., which all can be shown having a meaning of 'pagan cult site'17.

As was intimated above, I would like to, regarding Scandinavia, divide the second half of the first millennium into three phases or periods (with 'blurred' ambits):

The first one (c. 550-700) takes place in proper Scandinavia, with the emergence of the new kind of 'aristocracy' and leadership and the changes in the societal structure. We can see this new society in the form of emerging central places during the Vendel Period, with a distinct burial custom in the form of rich chamber and ship burials. The archaeological period called the Vendel Period takes its name from a small parish in central Uppland, Sweden, where some unique and rich boat burials, dated to around AD. 700, were discovered and excavated at the end of the nineteenth century ${ }^{18}$. In the boats (7-9 $\mathrm{m}$ long) were buried together with the dead weaponry, glass, and jewellery, and outside of the boats horses and dogs were thrown down. The most famous objects from these burials are the Vendel helmet, which resembles in an astonishing way a helmet found in a princely boat burial in Sutton Hoo, Norfolk, England, to be dated to the same time as the Vendel helmet. Famous are also the small bronze sheet metal plates from Vendel helmets (Fig. 2), with scenes from the Old Norse mythology. Later similar rich furnished boat graves from the Vendel Period were found at i.a. Valsgärde outside the city of Uppsala, Sweden ${ }^{19}$ (Fig. 3). Many of these boat burials have been excavated and dated to $c$. AD. 600-1000. The finds in these boats are extraordinary,

\footnotetext{
${ }^{13}$ SCHJØDT, 2008.

${ }^{14}$ CLUNIES ROSS, 2008.

${ }^{15}$ GUNNELL \& LASSEN eds., 2013.

16 PRICE, 2014.

${ }^{17}$ BRINK, 1999; VIKSTRAND, 2001.

18 SEILER, 2001.

${ }^{19}$ GRÄSLUND \& LJUNGKVIST, 2011.
} 


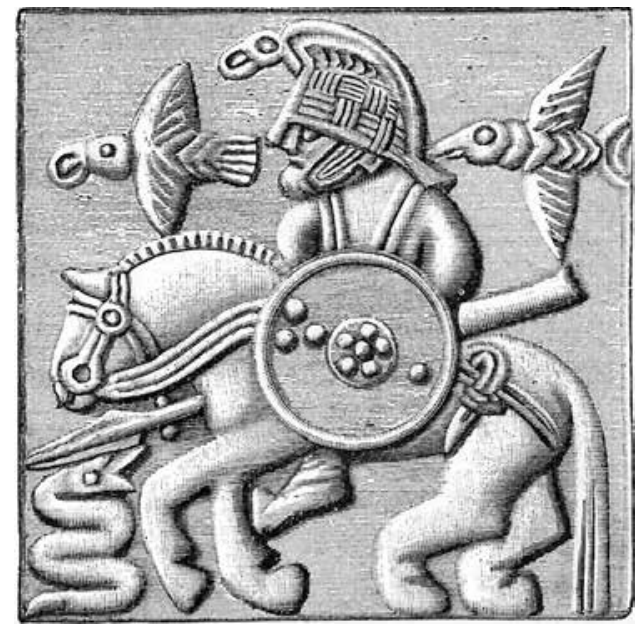

Fig. 2.

A bronze metal sheet from a Vendel helmet perhaps depicting the god Óðinn sitting on his horse Sleipnir and with his two ravens Huginn and Muninn.

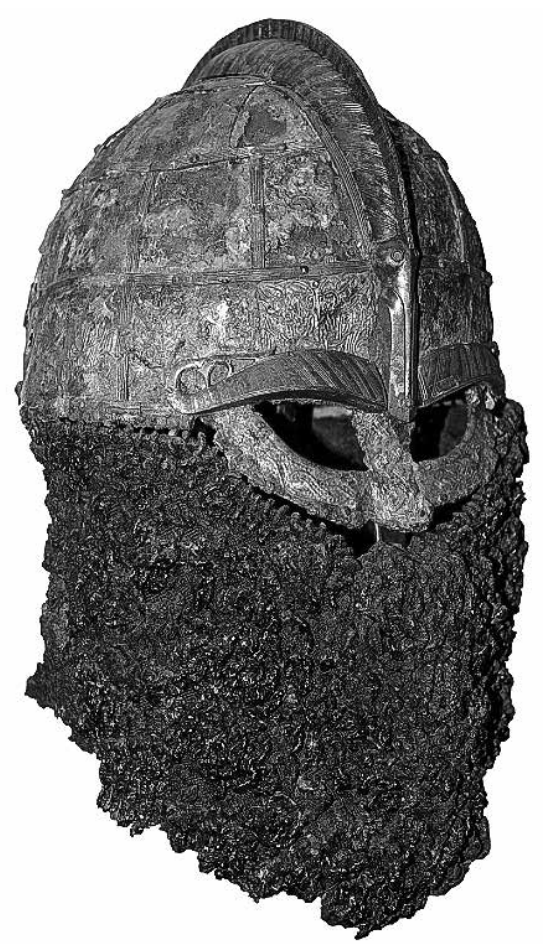

with weapons, exclusive garments, cooking utensils, horses and dogs, birds of prey etc., placed in the boat together with the dead to obviously accompany him to and to be used in the next world. What we see in these burials is an accumulation of wealth and an emergence of a princely warrior class, displayed in these luxury burials. It is these princely families of this warrior class, which are the predecessors of kings and chieftains we meet in the Viking Age. From the iconography and the intended purpose of the buried objects, we understand that the Viking Age 'religion' and its mythology were in existence already in this period, and we also understand that the warrior mentality, which is defining the Viking Age ${ }^{20}$, originated in the Vendel Period.

The second phase (c. 700-950) is when the Scandinavians start to go abroad en masse, with raiding and trading to the east and west, swarming around and colonizing in the North Atlantic, raiding in England and Ireland, raiding in western Europe all down to the Iberian Peninsula (which shall be expanded upon below), raiding and trading to the east, in Russia and the Baltics. The aim with these raids and trading was obviously to get hold of richness in the form of silver, which could be brought back to Scandinavia to build up a power base, and the means of getting hold of this silver 
was - we believe today - primarily to engage in the slave trade. It is my belief that obtaining and selling slaves were the main commodity Viking Scandinavians were engaged with in their trading and raiding during this period ${ }^{21}$. This engagement with the polities and kingdoms in the British Isles and on the Continent together with the accumulation of wealth by Scandinavian chieftains and kings, led to the first attempts to establish larger (potentially also territorial) kingdoms in Scandinavia, something we can see takes place in Denmark in the ninth century and in Norway around c. 900. It is also during this period that a colonization takes place in Iceland, Greenland and the Faroes, and the establishment of a Scandinavian controlled Danelaw in central England, and the emergence of the first proto-towns in Ribe, Hedeby and Birka.

It is in this period when we are told in the annals and chronicles of viking war band and small armies raiding and devastating England and Francia. In British historiography, this phase is called the First Viking Age. In 865 what is called The Great Heathen Army, led by the brothers Ivar the Boneless, Halfdan and Ubba, sons of the legendary king Ragnar Lodbrok, and Guthrum, who was to become a Danish king in the Danelaw, landed in East Anglia and made their way up to Northumbria, captured York, and established the viking community of Jorvik. They took tributes, by i.a. Mercia, and had several battles in several kingdoms along their travels ${ }^{22}$. These kinds of raidings by war band and small armies are defining this phase, and we meet that also in Francia, which was frequently harassed in the ninth century, which finally led to the Frankish king Charles the Simple to ask one of the leaders of a notorious war band, Rollo (Hrólfr), to settle in northeast of Francia and gave him the title of Duke of Normandy, as a protection from other viking war bands ${ }^{23}$.

In the third phase (c. 950-1100) we enter a period where Viking Scandinavia adopts the kind of society and power structure Scandinavians have met on the Continent and on the British Isles. The old religion is slowly dismantled and replaced by the Christian religion. The first proto-towns are in most cases abandoned and new towns emerge. Territorialized 'state'-like kingdoms emerge: Norway, Denmark and Sweden ${ }^{24}$. The small-scale raiding of war bands is replaced by larger viking armies, often organised by royal leaders, and this is the background for in British historiography calling this phase The Second Viking Age. This is the period when the Anglo-Saxons are paying huge tributes to the vikings, called Danageld, for leaving them alone and to go home. This episode is mentioned on one famous runestone from Yttergärde (U 334), Orkesta, in the province of Uppland, Sweden, where we are told (fig. 4): in ulfr hafiR o onklati pru kialt takat pit uas fursta pis tusti ka-t p(a)

\footnotetext{
${ }^{21}$ BRINK, 2012.

${ }^{22}$ SAWYER, 1962; DOWNHAM, 2008.

${ }^{23}$ RENAUD, 2008.

${ }^{24}$ BEREND ed., 2007; KRAG, 2008; ROESDAHL, 2008; LINDKVIST, 2008.
} 
The Runestone from Yttergärde in Orkesta, Uppland, Sweden, mentioning how Ulf took part in three raids in England taking tributes (gæld).

Fonte: Wiki Commons.

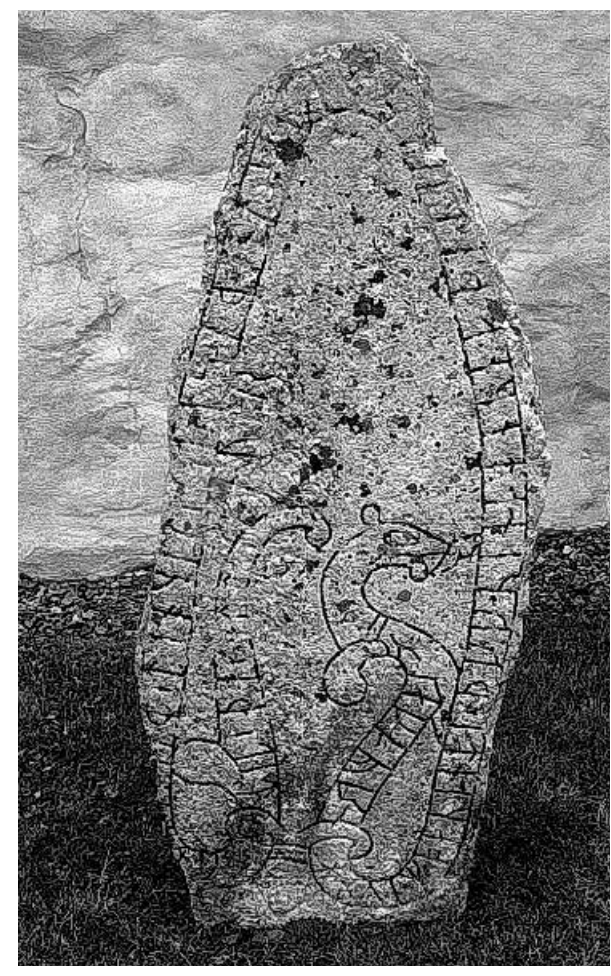

---- (p)urktil pa kalt knutr (And Ulfr has taken three tributes in England. That was the first that Tosti took. Then Porketill took. Then Knútr took). This Ulf had hence taken part in three raids in England and had shared some of the tribute (goeld). The first was under the leadership of Tosti (probably a Skoglar-Tosti around the year 1000), the second under the leadership of Thorkel the High in 1012, and finally a huge tribute that was handed over to the vikings under the leadership of the Danish king Knútr in 1018, the Knútr that later became king of the Anglo-Saxons as well as the Danes, and remembered as Canute the Great.

Slowly the Church is during this phase starting to put its stamp on these societies, implementing its institutions in the form of churches and bishops in bishop towns ${ }^{25}$. We have a steady growth of churches in the eleventh century, mainly built by kings on their royal estates, or 'aristocrats' and well-to-do farmers on their estates and farms. We call this phase the Europeanization of Scandinavia; Scandinavia is adapting the culture and societies of Europe. Around 1050 the old 'Viking' society has terminated, with its seasonally raiding and trading during the summer periods. The old 'fluid' and itinerant society becomes more static. The kings all have a bishop or some

${ }^{25}$ BRINK, 1990; BRINK, 2013; NILSSON ed., 1996. 
well-educated clergyman as their close councillor. And in 1103 an Archbishopric is established in Scandinavia, for Scandinavia, in Lund. From then on Scandinavia follows the societal development of the rest of Europe, where the Church becomes the prime force in society.

\section{THE LEGENDS OF BJÖRN AND HÁSTEINN}

One story taking place in Spain, Portugal and in western Mediterranean, which has become legendary, popular and reiterated over the centuries, is the story of the Swedish brothers Björn and Hásteinn, said to be sons of the legendary Swedish (or Danish) king Ragnar Lodbrok (mentioned above), and their misadventure when sacking Rome in Italy. It is occasionally mentioned in Old Norse sagas, but the main information comes from Norman sources, backed up by Arabic sources ${ }^{26}$. In the Frankish and Norman literature Hásteinn is often known as Alstingius or Hastingus, and is actually a rather dim figure in history.

According to the legend the events took place in the year 859 and the following years. In that year two brothers, Björn Ironside and Hastingus (Hásteinn), sometimes said to be the 'tutor' to Björn, navigated and ravaged along the river Seine in northwest France, and then stayed for winter on the island of Oissel, just north of the city of Rouen. Charles the Bald, not daring to attack the marauding Vikings himself, hired another Viking chieftain, Weland, to attack them and chase them away. Weland was offered 300 pounds of silver, but demanded 5000, plus expenses, which was agreed upon. So the besiege of the island started. The shrewd Björn, however, topped Charles' 6000 pounds in return for safe passage from the island. Hence, instead of ravaging and making himself a nuisance in France, he came up with a bright idea: to conquer Rome. This heroic act would give him a glorious reputation back home, for certain.

Said and done; Björn and his men sailed south from northern France with 62 ships, ravaging the Spanish west (and north?) coast, fighting the Moors on the Guadalquivir, or to use its Arabic name, Wadi al-Kabir 'the big river', possibly getting as far as Seville. After passing the Strait of Gibraltar they plundered the town of Algeciras in southern Andalusia, and then turned south for the north African coast. Here they plundered, raided and took black slaves. After a short spell in Africa they turned north for Murcia and the Balearic Islands. When finished they set sails to the north and after a long journey during the summer and autumn, they decided to make a winter camp at Camargue, near the mouth of the Rhône river, on the Côte d'Azur. While in Provence they took the opportunity to raid and plunder also

\footnotetext{
${ }^{26}$ PRICE, 2008: 465; SIMEK, 2014. The following discussion on Björn and Hásteinn relies heavily on the excellent and exhaustive presentation and discussion of the Continental written sources on this topic by Prof. Rudolf Simek (2014). For more exhaustive bibliographical notes and comments, I refer any interested to Prof. Simek's article.
} 
Arles and Nîmes, and all the way up the Rhône river to Valance, where they met overwhelming resistance, and therefore turned south again.

When spring arrived in 860 they continued the journey, with raiding and plundering along the Côte d'Azur and into Liguria in Italy. According to the legend they then ransacked the town of Luna (Lucca today) in Liguria, just south of La Spezia, assuming it was Rome! Whether this is actually true is a question of discussion, because the Norman sources are rather quiet on this matter. In any way they obviously raided and plundered Pisa later on, and after that felt quite content of what they had achieved and therefore gave up Rome and further conquest.

Finally, according to the legend, the vikings under the leadership of Björn and Hásteinn are once again the next year, 861, involved in fighting with Moorish pirates in the Mediterranean, being able to escape into the Atlantic and on their way back plundering the city of Pamplona in the kingdom of Navarra, before they actually, with only 20 ships remaining, being able to return to the Loire in 862 .

The first historical record of this famous journey is to be found in Annales Bertiniani (The Annals of St-Bertin), which for the year 859 describes the Björn and Hásteinn journey but omits the sacking of Luna. It is then picked up by several other historians, such as Dudo of Saint-Quentin in his History of the Normans, and is even further elaborated by William of Jumièges in his Gesta Normannorum Ducum. Finally, the story is picked up by Benoit de Sainte-Maure in his 12th century chronicle Chronique des ducs de Normandie, which seems to have been the foundation for later retelling and rewriting of this legend, also in Old Norse, Scandinavian writings, such as Ragnars saga lodbrokar and other sagas and poettir.

Hence, this legend found its way into an Icelandic fornaldarsaga (Legendary saga), Ragnars saga lodbrokar, where the Luna episode is mentioned:

XIV. Now they held course from there until they came to the town called Lúna. By then they had broken nearly every town and every castle in all the Southern Kingdom, and they were then so famous in all that region that there was no child, however young, that did not know their name. Then they planned not to let up until they had come to Rómaborg, because that town was then both very mighty and full of men, and famous and rich ${ }^{27}$.

So who was this Ragnar Lodbrok ${ }^{28}$ ?

\footnotetext{
27 «XIV. Nú halda peir í brott paðan, par til er peir koma í pá borg, er Lúna hét. Pá höfu peir hverja borg ok hvern kastala brotit náliga í öllu Suðrríki, ok nú eru peir svá frægir of allan heim, at ekki var svá lítit barn, at eigi kynni nafn peira. Nú ætla peir at létta eigi fyrr en peir koma til Rómaborgar, af pví at sú borg var peim bæði sögð mikil ok fjölmenn ok ágæt ok auðig», Ragnars saga lóðbrokar ok sona hans, ed. Valdimir Ásmundarson, chap. 14.

${ }^{28}$ McTURK, 1991.
} 
This legend of these two Scandinavians, Björn and Hásteinn, the sons of the Swedish, sometimes said to be a Danish king, Ragnar Lodbrok, ravaging in southern Europe, where the climax in the story is the mistake of sacking Luna instead of Rome, is testified in both Frankish and Norman contemporary annals and chronicles, and later on in Norman historiography. The story had obviously all the qualities to make it popular with the Norman rulers. Björn and Hásteinn were for them excellent prototypes for Norman dukes with a Scandinavian ancestry. But, as we have seen, the story also found its way into Scandinavia and the Icelandic literature, especially the Legendary sagas.

So what can we make of this? Are we dealing with 'history' or a fictitious legend? Well, the Continental contemporary sources force us, what I can see, to reckon with a historical core, around which the annalists, chroniclers and historians have used and expanded upon. That Scandinavian vikings have around 850 s been raiding and harassing people in southern Europe is more than probable and an uncontroversial statement. If these vikings where led by two men, Björn and Hásteinn, is probable, but impossible to prove. Who they were, and if they were the sons of the famous Ragnarr lodbrok, is utterly uncertain, and again, impossible to prove.

So we end up, as so often, with a situation, where we can rely upon some historical facts, which have been used by authors, down in Europe as well up in Scandinavia, to fabricate legends and exiting stories, involving brave but merciless vikings.

All in all, the Björn and Hásteinn legend links Portugal, Spain, France and Italy to Scandinavia in a most dramatic way, and the story has been told and retold over centuries in the whole of Europe at the time and the following centuries, and the bold characters of these two vikings, Björn and Hásteinn, so much linked to Normandy in France, was also used as prototypes of the kind of strong, ruthless and victorious leaders the Norman dukes wanted to have as their ancestors.

\section{REFERENCES}

\section{Primary Sources}

The Annals of St-Bertin. Trans. by Janet L. Nelson. Manchester: Manchester University Press, 1991. (Ninth-Century Histories 2).

Benoît de Sainte-Maure - Chronique des ducs de Normandie. Publiée d’après le manuscrit de Tour avec les variantes du manuscrit de Londres. Ed. by C. Fahlin, Ö, Södergård and S. Sandqvist. Uppsala: Almqvist \& Wiksell, 1951-79. (Acta Universitatis Lundensis I: 29).

Dudo of Saint-Quentin, History of the Normans. Trans. by Eric Christiansen. Woodbridge: Boydell and Brewer, 1998.

The Gesta Normannorum Ducum of William of Jumièges, Orderic Vitalis, and Robert of Torgini, 1: Introduction and Book I-IV. Ed. and trans. by Elisabeth M. C. van Houts. Oxford: Oxford University Press, 1992. 
The Poetic Edda. Translated with an introduction and notes by Carolyne Larrington. Oxford: Oxford University Press, 2014.

Ragnars saga lóðbrokar ok sona hans. Ed. by Valdimir Ásmundarson. Reykjavík: Kristjánsson, 1886-91. (Fornaldarsögur Norðrlanda 1).

$\mathrm{U}=$ Upplands runinskrifter 1-4. Stockholm: Almqvist \& Wiksell international 1940-58. (Sveriges runinskrifter, 6-9).

\section{Secondary Sources}

AMBROSIANI, Björn (2008) - Birka. In BRINK, Stefan; PRICE, Neil (in coll. with), ed. - The Viking World. London \& New York: Routledge, p. 94-100.

BAGGE, Sverre (2006) - The Making of a Missionary King: The Medieval Accounts of Olaf Tryggvason and the Conversion of Norway. "The Journal of English and Germanic Philology», 105(4), p. 486-87.

BEREND, Nora, ed. (2007) - Christianization and the rise of Christian monarchy: Scandinavia, Central Europe and Rus' c. 900-1200. Cambridge: Cambridge University Press.

BRINK, Stefan (1990) - Sockenbildning och sockennamn. Studier i äldre territoriall indelning $i$ Norden. Stockholm: Almqvist \& Wiksell International. (Acta Academiae Regiae Gustavi Adoplhi 57). (1999) - Social Order in the Early Scandinavian Landscape. In FABECH, Ch.; RINGTVED, J., eds. - Settlement and Landscape. Højbjerg: Jutland Archaeological Society, p. 423-39. (2008) - Slavery in the Viking Age. In In BRINK, Stefan; PRICE, Neil (in coll. with), ed. - The Viking World. London \& New York: Routledge, p. 49-56.

(2012) - Vikingarnas slavar. Stockholm: Atlantis.

(2013) - Early Ecclesiastical Organization of Scandinavia, especially Sweden. In SALONEN, Kirsi; JENSEN, Kurt Villads; JØRGENSEN, Torstein, eds. - Medieval Christianity in the North. New Studies. Turnhout: Brepols, p. 23-39. (Acta Scandinavica 1).

CLUNIES ROSS, Margaret (2008) - The Creation of Old Norse Mythology. In BRINK, Stefan; PRICE, Neil (in coll. with), ed. - The Viking World. London \& New York: Routledge, p. 231-34.

DOWNHAM, Claire (2008) - Vikings in England. In BRINK, Stefan; PRICE, Neil (in coll. with), ed. The Viking World. London \& New York: Routledge, p. 341-49.

FEVEILE, Claus (2008) - Ribe. In BRINK, Stefan; PRICE, Neil (in coll. with), ed. - The Viking World. London \& New York: Routledge, p. 126-30.

GRÄSLUND, Anne-Sofie; LJUNGKVIST, John (2011) - Valsgärde revisited. In Sachsensymposium: Det 61. Internationale Sachsensymposion 2010 Haderslev, Danmark. Neumünster: Wachholtz, p. 12340. (Archäologie in Schleswig. Sonderband).

GUNNELL, Terry; LASSEN, Anette, eds. (2013) - The Nordic Apocalypse: Approaches to Völuspa and Nordic Days of Judgement. Turnhout: Brepols. (Acta Scandinavica 2).

HILBERG, Volker (2008) - Hedeby: An Outline of its Research History. In BRINK, Stefan; PRICE, Neil (in coll. with), ed. - The Viking World. London \& New York: Routledge, p. 101-11.

HULTGÅRD, Anders (2008) - The Religion of the Vikings. In BRINK, Stefan; PRICE, Neil (in coll. with), ed. - The Viking World. London \& New York: Routledge, p. 212-18.

KRAG, Claus (2008) - The Creation of Norway. In BRINK, Stefan; PRICE, Neil (in coll. with), ed. - The Viking World. London \& New York: Routledge, p. 645-51.

LINDKVIST, Thomas (2008) - The Emergence of Sweden. In BRINK, Stefan; PRICE, Neil (in coll. with), ed. - The Viking World. London \& New York: Routledge, p. 668-74.

LJUNGKVIST, John (2006) - En hiar atti rikR: om elit, struktur och ekonomi kring Uppsala och Mälaren under yngre järnålder. Uppsala: Institutionen för arkeologi och antik historia, Uppsala universitet. (Aun 34). 
McTURK, Rory (1991) - Studies in Ragnars saga loðbrókar and Its Major Scandinavian Analogues. Oxford: Society for the Study of Mediaeval Languages and Literature. (Medium Aevum Monographs, New Series 15).

MYHRE, Björn (1992) - The beginning of the Viking Age - some current archaeological problems. In FAULKES, Anthony; PERKINS, Richard, eds. - Viking Revaluations. London: Viking Society, p. 182-204.

MYRDAL, Janken; TOLLIN, Clas (2003) - Brytar och tidigmedeltida huvudgårdar. In LINDKVIST, Thomas; MYRDAL, Janken - Trälar: ofria i agrarsamhället från vikingatid till medeltid. Stockholm: Nordiska museets förlag, p. 133-68. (Skrifter om skogs- och lantbrukshistoria 17).

NILSSON, Bertil, ed. (1996) - Kristnandet i Sverige: gamla källor och nya perspektiv. Uppsala: Lunne. (Sveriges kristnande. Publikationer 5).

PEETS, Jüri (2013) - Salme Ship Burials, «Current World Archaeology», 58, p. 18-24.

PRICE, Neil (2002) - The Viking Way. Religion and War in Late Iron Age Scandinavia. Uppsala: Uppsala University Press. (Aun 31).

(2008) - The Vikings in Spain, North Africa and the Mediterranean. In BRINK, Stefan; PRICE, Neil (in coll. with), ed. - The Viking World. London \& New York: Routledge, p. 458-61.

(2014) - Nine paces from Hel: time and motion in Old Norse ritual performance, «World Archaeology», 46(2): 178-91.

RAUDVERE, Catharina (2008) - Popular Religion in the Viking Age. In BRINK, Stefan; PRICE, Neil (in coll. with), ed. - The Viking World. London \& New York: Routledge, p. 235-43.

RENAUD, Jean (2008) - The Duchy of Normandy. In BRINK, Stefan; PRICE, Neil (in coll. with), ed. The Viking World. London \& New York: Routledge, p. 453-57.

ROESDAHL, Else (2008) - The Emergence of Denmark and the Reign of Harald Bluetooth. In BRINK, Stefan; PRICE, Neil (in coll. with), ed. - The Viking World. London \& New York: Routledge, p. 652-64.

ROSLUND, Mats (2007) - Guests in the house: cultural transmission between Slavs and Scandinavians 900 to 1300. Trans. by Alan Crozier. Leiden: Brill. (The Northern World 33). (2013) - Trälars tysta kunskap - keramikproduktionens sociala kontext. In HEDVALL, Rikard; KARIN, Lindeblad; MENANDER, Hanna, eds. - Borgare, bröder och bönder : arkeologiska perspektiv på Skänninges äldre historia. Stockholm: Arkeologiska uppdragsverksamheten (UV), Riksantikvarieämbetet, p. 119-32.

RØTE, Gunnhild (2004) - Helt, konge og helgen: den hagiografiske tradisjon om Olav den hellige i Den legendariske saga, Heimskringla og Flateyjarbók. Oslo: Unipub. (Acta Humaniora 201).

RUMAR, Lars, ed. (1997) - Helgonet i Nidaros: Olavskult och kristnande. Stockholm: Riksarkivet. (Skrifter utgivna av Riksarkivet 3).

SAWYER, Peter (1962) - The Age of the Vikings, 1st edn. London: Edward Arnold.

SCHJØDT, Jens Peter (2008) - The Old Norse Gods. In BRINK, Stefan; PRICE, Neil (in coll. with), ed. - The Viking World. London \& New York: Routledge, p. 219-22.

SEILER, Anton (2001) - I skuggan av båtgravarna: landskap och samhälle $i$ Vendels socken under yngre järnålder. Stockholm: Arkeologiska forskningslaboratoriet, Stockholm University, 2 vols. (Theses and papers in archaeology 7-8).

SIMEK, Rudolf (2014) - Memoria Normannica. In HERMANN, Pernille; MITCHELL, Stephen A.; ARNÓRSDÓTTIR, Agnes S. - Minni and Muninn. Memory in Medieval Nordic Culture. Turnhout: Brepols, p. 133-54. (Acta Scandinavica 4).

SKRE, Dagfinn (2008) - Kaupang - «Skíringssalr». In BRINK, Stefan; PRICE, Neil (in coll. with), ed. The Viking World. London \& New York: Routledge, p. 112-20. 
TOLLIN, Clas (1999) - Rågångar, gränshallar och ägoområden : rekonstruktion av fastighetsstruktur och bebyggelseutveckling i mellersta Småland under äldre medeltid. Stockholm: Stockholms universitet. (Meddelanden från Kulturgeografiska institutionen vid Stockholms universitet 101).

VIKSTRAND, Per (2001) - Gudarnas platser: förkristna sakrala ortnamn i Mälarlandskapen (Acta Academiae Regiae Gustavi Adolphi 77). Uppsala: Gustav Adolfs Academi.

DE VRIES, Jan (1928) - Die westnordische Tradition der Sage von Ragnar Lodbrok. "Zeitschrift für deutsche Philologie», 53, p. 257-302.

WORMALD, C. Patrick (1982) - Viking studies; whence and whither? In FARRELL, R. T., ed. - The Vikings. London: Phillimore, p. 128-53. 


\title{
ARMED BANDS ON BOTH SIDES OF THE CHANNEL (865-899): CAN WE TRACK INDIVIDUAL VIKING GANGS?
}

\author{
ALBAN GAUTIER*
}

In the last third of the ninth century, a number of large viking armies were active on both sides of the English Channel, either in Northern Frankia or in the Anglo-Saxon kingdoms ${ }^{1}$. As opposed to previous viking gangs who had been raiding the coasts of Gaul and the British Isles over the previous century, these vikings threatened the very existence of established powers and conquered vast areas both in the Isles and on the Continent: in Frisia, in East Anglia, in Mercia, in Northumbria, and finally in Normandy in the early tenth century, newcomers were able to establish important and often lasting power bases. Since the early twentieth century at least, there has been a consensus in historiography that these «new» vikings were broadly the «same» people, who operated on either side of the Channel, depending on the circumstances $^{2}$. If they met strong resistance or even failure in one sector, those highly mobile people would be ready to move away, crossing the sea in order to harry and/or try to conquer another, less prepared, region. It has also often been said that these vikings «of western Europe» originated more precisely from Denmark, that

\footnotetext{
* Université de Caen Normandie - CRAHAM UMR 6273. alban.gautier@unicaen.fr

${ }^{1}$ For general accounts of the vikings, see among many other titles: HAYWOOD, 1995; ROESDAHL, 1998; BAUDUIN, 2004; HALL, 2007. I write "vikings» with a low-case initial, because the Norse and Anglo-Saxon words víkingr and wicing did not refer to a people, but to an activity, even a way of life: we would not write «the Pirates» or «the Sailors». See JESCH, 2002.

${ }^{2}$ The seminal work here is VOGEL, 1906. See also, for a more detailed regional account, D'HAENENS, 1967, and for a short summary, D'HAENENS, 1970.
} 
they were Danes rather than Norwegians or Swedes: that would set them apart from other Scandinavian pirates and settlers, who at the same time would have sailed to the coasts of the Southern and Eastern Baltic and to what would in time become Russia (in the case of Swedes), or to Northern Britain, Ireland and the islands of the North Atlantic (in the case of Norwegians).

I do not think it would be wise to challenge completely these two main received ideas - that most of them "came from Denmark» and that they were «the same vikings» in England and in Frankia - but I believe it is still useful to question them not as a broad vision of «what really happened then", but by considering more specific points. I will not be bringing here brand new ideas on what happened around the southern half of the North Sea and in the English Channel in the late ninth century, but I would like to question some methodological assumptions which until recently were common in the historiography of the viking invasions in the West. Of course, there is nothing illegitimate in the ambition to write a «master narrative» of that phenomenon, but if the «big picture» of Danish invaders operating indifferently on both sides of the Channel is partly true, it is nevertheless deeply misleading when it is not explained and qualified properly.

Hence the main question I would like to ask: can we actually track viking gangs as they moved along the seaways, up and down rivers, and across land? If we want to answer that, we really have to ask at least three different sub-questions, the answers to which will not be the same. 1/ Can we really perceive vast movements of large viking armies? That is: where did those «new» conquering armies come from, and did they actually move back and forth across the Channel? 2/ Can we follow individual vikings? That is: are there people, whom we can identify as vikings, whose «international» career we may be able to follow over the years? 3/ Can we track specific viking gangs? This question is, I think, the hardest but potentially the most rewarding one. As we will see, viking armies seem to have been composed of smaller units, which we may call «gangs» or «armed bands»: those units joined and congregated to form larger armies, such as the "Great Army» that appeared off the coasts of East Anglia in the autumn of 865 . The question of whether we can follow those smaller components in their moves is a difficult one, because it means we must understand how they were created and how they worked. Indeed, I will not be drawing a very encouraging conclusion: the very structure of these groups, on which recent work has been shedding much light, makes it very difficult to track them in their travels ${ }^{3}$.

\footnotetext{
${ }^{3}$ For recent descriptions of such gangs, see RAFFIELD et al., 2015, and RAFFIELD, 2016. I use the notion of «armed bands» in the way I defined it in earlier publications: e.g. GAUTIER, 2012, and GAUTIER, 2013.
} 


\section{VIKING ARMIES}

Let us begin with the vaster movements of «armies». For more than a century (indeed, since Walther Vogel published in 1906 his masterful study on Northmen and the Frankish Empire), historians have used written sources, especially annalistic sources, in order to follow the track of «the vikings» in the areas where they operated as raiders and conquerors. In England, those sources are the Anglo-Saxon Chronicle together with its associated texts (for example Asser's Life of King Alfred), but also later works such as the Historia de Sancto Cuthberto (tenth-eleventh century). In Frankia, the main written sources are the many sets of annals which might be described as spin-offs from the earlier Royal Frankish Annals: that is, Annales Vedastini, Annales Bertiniani, Annales Fuldenses, Annales Xantenses, and their numerous analogues and continuations.

The «big picture» which arises from culling those sources is indeed rather obvious, and it explains the common wisdom on the subject. We may rely here on the very useful chronology established by Albert d'Haenens in his great little book on the viking invasions in northern Frankia, complemented by Pierre Bauduin's recent study on "the Frankish world and the vikings» ${ }^{4}$. Between 850 and 866, viking raids were frequent in the Seine valley, but after that date, they ceased altogether for more than a decade, with the exception of a single action in the winter of 876-7. In the meantime, vikings were active on the Loire, and the Anglo-Saxon Chronicle tells of a «Great Army» (micel here) of «Danes» (Dene) or «pagans» (høðen), who roamed over England from 865 to 878, when they were finally beaten and forced to make peace with King Alfred of Wessex ${ }^{5}$. The following year, that is in the spring of 879 , vikings appeared again north of the Somme and south of the Meuse (that is, in today's Belgium and Northern France), a region which until then had known only sporadic raids. Viking operations there lasted until they were beaten by King Arnulf of the East Franks at Leuven in 891. As for the Loire vikings, they seem (at least according to a later source, Richer's History) to have been defeated by king Odo of the West Franks at Montpensier in the Auvergne in 892. Finally, in the autumn of the same year, a large viking fleet set sail from Boulogne, on the Frankish side of the Straits of Dover. This is precisely when the Anglo-Saxon Chronicle tells of the arrival of large viking here in Kent, which Alfred had to tackle in the following years ${ }^{6}$.

So, if we follow that chronology, the picture appears limpid: «the vikings» had been attacking the Seine and Loire valley in the 850s and early 860 s; they «came

\footnotetext{
${ }^{4}$ D'HAENENS, 1970: 11-14; BAUDUIN, 2009. There are (broadly valid) cartographic representations of these movements of «larger» vikings armies in HAYWOOD, 1995: 60-9.

${ }^{5}$ A classic description of the movements of the «Great Army» may be found in STENTON, 1971: 246-57. For a more recent and controversial view, see McLEOD, 2014.

${ }^{6}$ For detailed accounts of Alfred's wars against vikings, both before 878 and 892, see SMYTH, 1995 and ABELS, 1998. For the text of the Anglo-Saxon Chronicle, I used BATELY, 1986.
} 
to England» in the autumn of 865 , and stayed there until the spring of 879 ; at that date, having been beaten by Alfred, they «sailed to Frankia» and ravaged the regions between the Somme and the Meuse until 892; after (and because of) their defeat in Leuven, they "went back» to England, where Alfred had to deal with them all over again. We should add that the Anglo-Saxon Chronicle often calls them Danes (Dene), while Frankish texts dwell on the family links between some of its leaders and Danish dynasts. This seems to vindicate the received opinion: those vikings came from Denmark, and once they had arrived in the West, their movements over the English Channel reflected the capacity of Christian kings to oppose them effectively: when kings were good and strong, the vikings left.

Unfortunately, such a «big picture» is fraught with difficulties. To begin with, it has long been recognized that, in Anglo-Saxon sources at least, «Danes» is a generic name for all kinds of Scandinavians: we cannot assume that all «Danes» were from today's Denmark ${ }^{7}$. It is true that Frankish sources mention figures such as Godfrid, Sigfrid or Rodulf - all of them kinsmen of Roric, a well-known Danish dynast of the mid-ninth century, and of Harald Klak, a Danish king who had concluded an alliance with the Franks in the $820 \mathrm{~s}^{8}$. But even if the leaders were Danes, what of the men? The close entourage of such leaders may have been composed of kinsmen and clients from their home region, but that does not mean that the whole army was. Moreover, we must admit that over such a long period the armies simply cannot have been composed of the same men. About thirty years elapsed between the arrival of the «Great Army» in England in 865 and the renewed viking activity there in the mid-890s. Basically, a very simple observation must be made: a middle-aged warrior who participated in the 865 invasion was probably dead thirty years later, and many of the men who invaded Kent in 892 cannot have been part of the army which had left in 879 , let alone the one that invaded in 865 . In the meanwhile, armies kept moving, splitting and merging. New groups kept appearing and reinforcing armies (chroniclers are always aware of that), and existing groups kept recruiting men.

So, where did the new recruits come from? Some of them may have indeed come from Denmark or other Scandinavian lands, some may have been turncoat Franks or Anglo-Saxons, runaway slaves and discontented peasants, but many of them were probably the sons of vikings who had been operating in the West over the last decades. The Historia de Sancto Cuthberto, written in the late tenth and eleventh century, gives the 865-879 invaders the name of Scalding $i^{9}$. One common understanding of

\footnotetext{
${ }^{7}$ Similar observations have been made for other regions, particularly Ireland. For a detailed discussion of the (mis) use of ethnic and national labels in some modern studies of the vikings, see DOWNHAM, 2009.

${ }^{8}$ Several studies focus on some of those characters, especially because some of them later developed into half-legendary heroes in Icelandic sagas. See BAUDUIN, 2009; ROWE, 2012; and recently LEWIS, 2016.

${ }^{9}$ Historia de Sancto Cuthberto, ch. 7, 11 and 12: see JOHNSON SOUTH, 2002: 49-53.
} 
that word has been that is refers to the Danish dynasty of the Skjöldungar, in Old English Scyldingas, who were mentioned in Beowulf and in several much later Norse sources. But an alternative explanation (proposed since the nineteenth century, but more recently and cogently defended by Alex Woolf) has it that the name refers to the river Scheldt (in Latin Scaldis) ${ }^{10}$ : Scaldingi were «the vikings of the Scheldt», just as there were "vikings of the Seine» and «of the Loire». If that interpretation is right, they were probably a portion of the vikings who had been present in Frisia for some decades then, since one of their leaders, Roric, had been granted dominion there by Emperor Lothar I in the early $840 \mathrm{~s}^{11}$. If we follow Shane McLeod's suggestion, it means that many of the warriors who landed in East Anglia in 865 had never actually lived in Denmark (or, come to that, in any Scandinavian country), but had grown up (at least from a very young age) in a Western environment with which they were quite familiar ${ }^{12}$. This goes a long way towards explaining why they converted so quickly to Christianity in the 880 s and 890 s, and why they adapted so easily to their new English terrain.

Indeed, we know that many men stayed in England in the 870s, as surely many did in Frankia in the 890s. So the commonly held idea that vikings only went when they were defeated by Christian kings must be challenged, or at least qualified. We know very well that, in 878, Alfred arranged for the viking leader Guthrum and his army to stay in England (more exactly in East Anglia), and many of them did. More surprisingly, it seems that after his victory in the summer of 891, Arnulf did not exploit the situation: he went back to Bavaria (his main power base), leaving the vikings at their Leuven camp, where they stayed and from which they conducted expeditions for another year and a little more. Finally (if it indeed happened ${ }^{13}$ ) Odo's victory in 892 at Montpensier was not against the vikings of the Seine and the Somme who had "come from England» thirteen years before, but against vikings of the Loire basin, who had been conducting independent expeditions over the last decades from bases near Nantes and Angers, and on the island of Noirmoutier. Viking armies kept splitting and merging. Did those defeated vikings of the Loire area join their colleagues from the Leuven and Amiens camps who sailed from Boulogne towards England in 892? It is indeed possible, but it means that the army which set sail in that year was, again, something quite new.

\footnotetext{
${ }^{10}$ WOOLF, 2007: 72; see also LEWIS, 2016: 22-5.

${ }^{11}$ BAUDUIN, 2009: 181-2. For a general view of vikings in Frisia, see LEBECQ, 2005.

${ }^{12}$ McLEOD, 2014: 168-9. Other vikings in the «Great Army» probably had strong connections with Ireland, and may have been operating there for some decades. I do not have space here to include a discussion of those Irish connections, but they should definitely be included in the «big picture» as much as in the life-stories of individual vikings. DOWNHAM, 2007, tries to make sense of what we know of a particular kin-group, active both in Ireland and in England within the "Great Army»; ROWE, 2012, follows the same vikings in their own time and in later legend.

${ }^{13}$ See below for a discussion of the historicity of that episode.
} 


\section{VIKING LEADERS AND WARRIORS}

Will our task become easier once we turn to the question of the moves of individual vikings? Here of course, the paucity and the very nature of the written sources only allow us to follow «kings» and «jarls». Men such as Inguar, Healfdene, Guthrum, Godfrid, Sigfrid, Rodulf, Hæsten and Rollo seem to have been quite famous in their own time, and Christian chroniclers did not hesitate to mention their names. Indeed, in the following centuries, medieval authors themselves tried to track the movements of those viking heroes (or anti-heroes), and sometimes they did it with a lot of imagination ${ }^{14}$.

The example of Hasting (also known as Hæsten, probably Hásteinn in Norse) is revealing ${ }^{15}$. He is mentioned in a handful of mid and late-ninth century annals entries (most significantly in the Annals of Saint Vaast and in the Anglo-Saxon Chronicle), but his literary fortune came much later, with Dudo of Saint-Quentin's Ways and Deeds of the Earliest Norman Dukes, written around the year 1000, where his adventures represent the main argument of Book I. Dudo described him as a wily and clever viking, and included the famous episode (inspired by motif of the Trojan horse) in which he sacked an Italian city by pretending he had died and by hiding in a coffin ${ }^{16}$. If we follow Dudo, Hasting's career seems to have been a very long one: beginning in the mid-830s, he roamed over the whole of western Europe until he died in England in the mid-890s. This would mean that he died at the age of 80 (at the very least), still leading an army. Of course it is not strictly impossible, but it is rather unlikely. Could there be in fact several Hastings (even only two, for example a father and a son)? Who knows? But this case shows that we should not trust Dudo or any other late author blindly: Janet Nelson, for one, is very prudent, and she limits what we know of his career to little more than the one last decade (that is, after 880).

Now if we consider only his moves in that shorter period, we see that Hasting operated in three successive regions: on the Loire before 882; between Seine and Scheldt until 892; and finally in south-eastern England, where he died in or shortly after 893. It means that Hasting, who had appeared north of the Seine in 882 after some previous activity further south, was probably not among the vikings who had come over from England after Alfred and Guthrum had reached an agreement four years before, particularly if he was the son or a kinsman of an earlier Hasting, who had been raiding on the Loire in the 850s and 860s. If it was indeed the case (which I think likely), the "younger Hasting» of the years 880-893 was actually not «from Denmark», and not even «from Scandinavia»: he was probably born in Frankia, and had lived all of his life there. So his individual movements were not those of the «big picture»: not a complex

\footnotetext{
${ }^{14}$ ROWE, 2012.

${ }^{15}$ For new assessments of Hasting's career and literary fortune, see NELSON, 2004; BAUDUIN, 2009: 358-9; BOUET, 2012; and SIMEK, 2014.

${ }^{16}$ Dudo, De moribus, book I: see LAIR, 1865 for Latin text, and CHRISTENSEN, 1998, for an English translation.
} 
back-and-forth movement from Denmark to Frankia, then to England, then back to Frankia, and finally back to England, but a much more straightforward south-north career, from the Loire to the Seine to Picardy to Boulogne to Kent - end of story.

The example of Hasting shows that our sources barely allow us to try and reconstruct the life and career of a viking leader ${ }^{17}$, but what of the movements of ordinary viking warriors? Here of course, texts prove totally useless: they are too elite-oriented to help us follow the fortunes of the rank and file of armies. One interesting alternative has recently come from the analysis of stable isotopes in the teeth and bones of buried vikings: it aims to inform us, through the establishment percentages of some isotopes (particularly those of strontium) on the place where an individual grew up, and it has become frequent in discussions of migration ${ }^{18}$. Unfortunately, currently there are very few individual burials which can be identified with some degree of certainty as those of viking raiders, invaders or settlers ${ }^{19}$, and whose bones have also been the object of isotope analyses. I know of no example in France or Belgium, and there are still very few in the United Kingdom. In the last synthetic article published on that topic, Ben Raffield was only able to consider a dozen individuals (interestingly, both male and female); the figure is similar to that in Shane McLeod's earlier paper on «Warriors and women», which retained only thirteen burials ${ }^{20}$. So we must remain very prudent here, because of a great risk of circular reasoning. Still, one conclusion we may draw from this very limited sample is that those buried people, who in their lifetime were probably viking warriors or settlers, were not all from Denmark, or even from what today we call Scandinavia. For example, one woman who was buried at Repton when the "Great Army» was there in the winter of 873-4 had grown up in the Baltic region of the European continent, or even further south: it does not mean she was not of Scandinavian origin - there were Scandinavian settlements on the southern coast of the Baltic Sea - but she did not come from what we call Denmark. During the same winter, a man who had probably grown up in Sweden was buried at Repton, near another man who was actually from the west coast of Denmark ${ }^{21}$.

We should add that isotope analyses are useful if we want to know where people grew up, but that they cannot tell us anything about where they had been traveling and raiding once they had become adults. If a viking's waring life could last as long as thirty years (and I think it is safe not to postulate much longer careers), one individual

\footnotetext{
${ }^{17}$ Many other attempts have been made in that direction. Most recently, LEWIS, 2016, reconstructed the career of Rodulf «of Frisia», whom he thinks should be equated with Ubba of the "Great Army». If that is correct, again we have a leader who, like Hasting, was probably born in Frankia within a lineage of Scandinavian origin, and whose career encompassed both sides of the Channel (as well as Ireland).

${ }_{18}$ The principles of isotope analysis are explained in POLET \& ORBAN, 2001.

${ }^{19}$ What would make a skeleton «viking»? «Pagan» elements in the perceived burial rite? «Scandinavian» grave-goods? The presence of a barrow? There is no simple answer to that question. See HARRISON, 2015, for a sensible discussion. ${ }^{20}$ RAFFIELD, 2016; McLEOD, 2011.

${ }^{21}$ McLEOD, 2011: 346.
} 
could have raided or even tried to settle a variety of places before dying. If we return to our example of Hasting, the Norman historian William of Jumièges (who wrote in the mid-eleventh century) claims that in 882 , the viking had been granted land and authority in Chartres by a king of the Franks (probably Louis III) ${ }^{22}$, if that is true, he quickly changed his mind and travelled north to Picardy, where he went a-viking again.

\section{VIKING GANGS}

The Repton cemetery, with both male and female individuals of rather different geographical backgrounds buried not far from each other, suggests that the «vikings» in one particular group may have come from a variety of places. This brings me to my last point, the question of viking gangs. Ben Raffield in particular has recently explored the structure and functioning of these communities of warriors, and I myself have tried in other publications to understand it in the wider context of early medieval Europe. Viking armies were composed of smaller, much tighter bands, composed of a few ships and crews which could probably be counted in hundreds of men: their members were united by oaths, common life, comradeship, and (to some extent) fidelity to their leader ${ }^{23}$, which does not mean that internal competition and even treason never happened ${ }^{24}$. This institution was probably called lið (or maybe hirð) in Old Norse ${ }^{25}$, and a few contemporary written sources refer to them.

For example, the Annals of St-Bertin mention that, in the winter of 861-2, a large viking army had to overwinter in North-Western Frankia: in order to make the most of the local resources in what was probably a difficult situation for the invaders themselves, «they split up according to their brotherhoods into groups allocated to various ports from the sea-coast right up to Paris» - this is Janet Nelson's translation, but the Latin text reads suas sodalitates, literally «their companies», «their teams», "their sworn gangs», «their bands of comrades» ${ }^{26}$. Of course, «brotherhoods» is not a bad translation at all, but there is no concept of kinship in the word sodalitas: this is why I prefer the phrase «bands of comrades» to Raffield's (admittedly more elegant) «bands of brothers». Indeed, the very idea of sworn groups of men, based on oaths rather than kinship, had a notorious profile in Frankish texts of that time, particularly in legal texts, both royal and ecclesiastical, as in several capitularies of Archbishop Hincmar of Rheims, the very author of this section of the Annals. Formal associations such as

\footnotetext{
${ }^{22}$ William of Jumièges, Gesta Normannorum ducum, I, 10 and II, 5, quoted by BAUDUIN, 2009: 290; see also BOUET, 2012: 217.

${ }^{23}$ RAFFIELD et al., 2015; RAFFIELD, 2016.

${ }^{24} \mathrm{I}$ insist on that dimension in GAUTIER, 2012 and GAUTIER, 2013.

25 «Probably», because the texts which mention them are either contemporary, but in Latin, or in Old Norse, but much later.

${ }^{26}$ Annales Bertiniani, year 861: see WAITZ, 1883: 56, for the Latin text; and NELSON, 1991: 95-6, for the English translation. See also RAFFIELD, 2016: 324-5, for a commentary.
} 
guilds and other sworn fellowships, established in defiance of a superior authority (the king's or the bishop's) or at least perceived to have been established in that way, were condemned as conjurationes (literally «oath-taking groups»), conventicula («little gatherings») or «commessationes» ( «table-sharing groups») $)^{27}$. The entry for 861 in the Annals of St-Bertin was indeed the first one written by Hincmar after the death of the previous writer, Bishop Prudentius of Troyes. The presence of those sodalitates, referring here to viking groups operating within the kingdom in defiance of the king's peace, in the very first description the new author made of the vikings, is very telling ${ }^{28}$. Just before that, Hincmar had explained how sixty viking ships had gone up an unidentified tributary of the Seine to a fortress already besieged by other Northmen, with whom they had «bound in association» (in societate iunguntur). In the eyes of the Frankish authorities (and, probably, equally in the eyes of their Anglo-Saxon counterparts), the vikings appeared like illegal gatherings, bound by illegal oaths and common mischief, which could occasionally bind with other gangs in order to create larger armies and work more mischief, before splitting again into their original components.

How were those gangs created? It is a difficult question. Our problem here is that their basic instability makes it almost impossible for us to follow them. We should not imagine that those gangs were homogeneous groups who «naturally» followed their leaders because they were (for example) their kinsmen or their fellow countrymen. The ethnic (or at least geographic) variety of viking gangs is confirmed by the analysis of the skeletons of a later (probably late tenth century) mass grave, found in 2008 in Weymouth, on the coast of Dorset. Isotope analyses showed that the men who were killed there (probably a whole gang, or at least a substantial part of it) had grown up in a great variety of places in Northern Europe, from the Southern Baltic and Russia to North of the Arctic Circle ${ }^{29}$.

So following the moves of one leader may not always give us clues as to the whereabouts of «his» gang. Let us take for one last time the example of Hasting. It seems that he abandoned his earlier southern terrain in the Loire basin in 882: at that date, maybe following an agreement with King Louis III of the Franks, he moved north to the Seine basin, and then into Picardy. But did all his gang follow him? I have no answer to that, but it is rather striking to observe that, after their seemingly crushing defeat at Montpensier in 892, viking gangs stopped harrying the Loire area (where they had been active almost without a break for the last five decades). In the same year, a huge army set sail from Boulogne for England, under the leadership

\footnotetext{
${ }^{27}$ See the classic study by OEXLE, 1982: 3-6.

${ }^{28}$ Admittedly, the connotations of sodalitas were not as negative as those of conjuratio, conventiculum or comessatio: it could for example refer to «legitimate» monastic groups. But I think its use in this particular context (referring to vikings) does echo Hincmar's condemnation of sworn association in several of his other works.

${ }^{29}$ LOE et al., 2014; BOYLE, 2016.
} 
of Hasting. Did former members of his Loire gang join him then? Did other gangs (maybe former allies of his) leave the Loire region (where their raiding would have become more hazardous and less profitable) and join up with him in that new venture? The problem is that the chronology is not easy to reconstruct, and actually it does not seem right. The contemporary Annals of St Vaast do mention Odo's expedition in Aquitaine, which would provide the right context for a battle at Montpensier; but they record the king's presence in the South only after telling of Hasting's departure of from Boulogne. That seems rather reasonable: we may infer that the king went south only after he had seen the Northmen off. But to add to the confusion, there are proofs (from diplomas) that the expedition to Aquitaine began in June 892-330, whereas the Annals of St Vaast say that the vikings left Frankia «in autumn» (tempore autumni) ${ }^{31}$. Probably the author of the Annals was working geographically, and not chronologically... So when could the battle have taken place? Maybe we could squeeze it in August or September of 892, in the course of Odo's campaign (he had first gone to Poitou, then to the Auvergne). But if that is the right chronology, it does not leave much time for the defeated vikings to reorganize and join other gangs (including one led by the "younger Hasting», possibly a kinsman of one of their former leaders) in Boulogne. Maybe the right answer to that conundrum is that the battle, which is not mentioned by any contemporary source, never happened: a conclusion which was already reached by Édouard Favre in the late nineteenth century ${ }^{32}$.

That particular case of the battle of Montpensier, and of the possible insular destiny of the viking gang (or gangs) that met defeat there, is a good example of the many problems that beset historians whenever they are trying to track individual viking bands. Contemporary writers in Frankia and Anglo-Saxon England were well aware of the specific structure of viking armies, with their numerous and highly divisive components; they knew about their sodalitates, but they were not interested in keeping track of them. What really mattered to them was either the formation of the much more dangerous large armies, or the fate of individual leaders with whom local powers might be negotiating. They were ready to tell how two armies met to create a larger one, which a year later split into three groups, but they never bothered to record which original component went this or that way after the army had dissolved. They would tell how one particular leader died in battle, but they would not mention who led his men, or what his particular gang did after that leader's death.

\footnotetext{
${ }^{30}$ FAVRE, 1893: 146-9.

${ }^{31}$ Annales Vedastini, year 892: see SIMSON, 1909: 70-3, for the Latin text.

32 The story of the battle of Montpensier (Mons Panchei) was told by Richer of Reims (who was writing just before 1000), in his Histories, I, 6-8: Latin text and English translation in LAKE, 2011: 24-7. FAVRE, 1893: 232, considered the whole episode a fabrication. On the other hand, FAVRE, 1893: 146-9, shows very well that Odo was in Aquitaine and Auvergne from the summer of 892 and until sometime in 1893: so the possibility remains that the battle did take place. On that (too?) ornate story, see also BAUDUIN, 2009: 29-30.
} 
So I'm afraid any conclusion is bound to be rather inconclusive. Following «large armies» has proved partly misleading, for ninth-century vikings did not move in stable large gatherings; following leaders is fraught with many difficulties of identification; and following individual rank soldiers has proved impossible (at least given our current archaeological data). In order to reconstruct the actual moves of vikings, the ideal solution would be to track the seemingly more coherent «armed bands»: but it seems that our sources, written and archaeological, are just inadequate for that.

\section{REFERENCES}

ABELS, Richard (1998) - Alfred the Great. War, Kingship and Culture in Anglo-Saxon England. London: Longman.

BATELY, Janet, ed. (1986) - The Anglo-Saxon Chronicle. Cambridge: D. S. Brewer. («The Anglo-Saxon Chronicle: A Collaborative Edition», vol. 3).

BAUDUIN, Pierre (2004) - Les Vikings. Paris: Presses universitaires de France. («Que sais-je?», vol. 1188). (2009) - Le monde franc et les Vikings (VIII - $X^{e}$ siècle). Paris: Albin Michel.

BOUET, Pierre (2012) - Hasting, le Viking pervers selon Dudon de Saint-Quentin. «Annales de Normandie», vol. 62/2, p. 2015-233.

BOYLE, Angela (2016) - Death on the Dorset ridgeway: the discovery and excavation of an early medieval mass burial. In LAVELLE, Ryan; ROFFEY, Simon, coord. - Danes in Wessex. The Scandinavian Impact on Southern England, c. 800-c. 1100. Oxford: Oxbow Books, p. 109-121.

CHRISTENSEN, Eric, introd. and transl. (1998) - Dudo of St Quentin: History of the Normans. Woodbridge, Boydell.

D'HAENENS, Albert (1967) - Les invasions normandes en Belgique au IXe siècle. Le phénomène et sa répercussion dans l'historiographie médiévale. Leuven: Publications universitaires de Louvain («Recueil de travaux d'histoire et de philologie», $4^{e}$ série, vol. 28). (1970) - Les invasions normandes, un catastrophe? Paris: Flammarion.

DOWNHAM, Clare (2007) - Viking Kings of Britain and Ireland. The Dynasty of Ívarr to A.D. 1014. Edinburgh: Dunedin. (2009) - «Hiberno-Norwegians» and «Anglo-Danes»: anachronistic ethnicities and Viking-Age England. «Mediaeval Scandinavia», vol. 19, p. 139-169.

FAVRE, Édouard (1893) - Eudes, comte de Paris, roi de France (882-898). Paris, Bouillon («Bibliothèque de l'École des Hautes Études. Sciences historiques et philologiques», vol. 99).

GAUTIER, Alban (2012) - Les activités compétitives au sein des bandes armées de l'Europe du Nord au haut Moyen Âge. In BOUGARD François; LE JAN, Régine; LIENHARD, Thomas, coord. - Agôn. La compétition, $V^{e}-X I I^{e}$ siècle. Turnhout: Brepols, p. 75-91. («Haut Moyen Âge», 17). (2013) - La competición en bandas armadas en Europa del Norte durante la Alta Edad Media, «Sociedades precapitalistas», vol. 3/1. Available at http://www.sociedadesprecapitalistas.fahce.unlp.edu.ar.

HALL, Richard (2007) - Exploring the World of the Vikings. London: Thames \& Hudson.

HARRISON, Stephen (2015) - "Warrior graves»? The weapon burial rite in Viking Age Britain and Ireland. In BARRETT, James H.; GIBBON, Sarah Jane, coord. - Maritime Societies of the Viking and Medieval World. London: Society for Medieval Archaelogy («Society for Medieval Archaelogy Monographs», vol. 37), p.299-319.

HAYWOOD, John (1995) - The Penguin Historical Atlas of the Vikings. London: Penguin.

JESCH, Judith (2002) - Old Norse víkingr: a question of semantics. In HOUGH, Carole; LOWE, Kathryn A., coord. - Lastworda betst. Essays in memory of Christine E. Fell with her unpublished writings. Donington, Shaun Tyas, p. 107-121. 
JOHNSON SOUTH, Ted, ed. (2002) - Historia de Sancto Cuthberto: A History of Saint Cuthbert and a Record of His Patrimony. Cambridge: D. S. Brewer. («Anglo-Saxon Texts», vol. 3).

LAIR, Jules, ed. (1865) - De moribus et actis primorum Normanniae ducum auctore Dudone Sancti Quintini decano. Caen: Le Blanc-Hardel.

LAKE, Justin, ed. and transl. (2011) - Richer of Saint-Remi: Histories, Books 1-2. Cambridge: Harvard University Press («Dumbarton Oaks Medieval Library», vol. 10).

LEBECQ, Stéphane (2005) - Les Vikings en Frise. Chronique d'un échec relatif. In BAUDUIN, Pierre, coord. - Les fondations scandinaves en Occident et les débuts du duché de Normandie. Caen: Publications du CRAHM, p. 97-112.

LEWIS, Stephen (2016) - Rodulf and Ubba. In search of a Frisian-Danish king. «Saga-Book», vol. 40, p. 5-42.

LOE, Louise; BOYLE, Angela; WEBB, Helen; SCORE, David (2014) - «Given to the Ground»: A Viking Age Mass Grave on Ridgway Hill, Weymouth. Oxford: Oxford Archaeology and Dorset Natural History and Archaeological Society.

McLEOD, Shane (2011) - Warriors and women: the sex ratio of Norse migrants to eastern England up to 900. «Early Medieval Europe», vol. 19/3, p. 332-353.

(2014) - The Beginning of Scandinavian Settlement in England. The Viking "Great Army» and Early Settlers, c. 865-900. Turnhout: Brepols. («Studies in the Early Middle Ages», vol. 29).

NELSON, Janet L., introd. and transl. (1991) - The Annals of St-Bertin. Manchester: Manchester University Press.

(2004) - Hoesten [Hásteinn, Hasting] (fl. 882-893). In Oxford Dictionary of National Biography. Available at http://www.oxforddnb.com/.

OEXLE, Otto Gerhard (1982) - Conjuratio et ghilde dans l'Antiquité et le haut Moyen Âge. Remarques sur la continuité des formes de la vie sociale. «Francia», vol. 10, p. 1-19.

POLET, Caroline ; ORBAN, Rosine (2001) - Les dents et les ossements humains: que mangeait-on au Moyen Âge ? Turnhout: Brepols. («Typologie des sources du Moyen Âge occidental», vol. 84).

RAFFIELD, Ben; GREENLOW, Claire; PRICE, Neil; COLLARD, Mark (2015) - Ingroup identification, identity fusion and the formation of Viking war bands, "World Archaeology», vol. 48/1, p. 35-50.

RAFFIELD, Ben (2016) - Bands of brothers: a re-appraisal of the Viking Great Army and its implications for the Scandinavian colonization of England. «Early Medieval Europe», vol. 24/3, p. 308-337.

ROESDAHL, Else (1998) - The Vikings. $2^{\text {nd }}$ ed. London: Penguin.

ROWE, Elizabeth Ashman (2012) - Vikings in the West: The Legend of Ragnarr Loðbrók and His Sons. Vienna: Fassbaender. («Studia Medievalia Septentrionalia», vol. 18).

SIMEK, Rudolf (2014) - Memoria Normannica. In HERMANN, Pernille; MITCHELL, Stephen A.; ARNÓRSDÓTTIR, Agnes S. coord. - Minni and Muninn. Memory in Medieval Nordic Culture. Turnhout: Brepols, p. 133-154. («Acta Scandinavica», vol. 4)

SIMSON, Bernard von (1909) - Annales Xantenses et Annales Vedastini. Hanover: Hahn («Monumenta Germaniae historica», SS rer. Germ., vol. 12).

SMYTH, Alfred P. (1995) - King Alfred the Great. Oxford: Oxford University Press.

STENTON, Frank M. (1971) - Anglo-Saxon England. 3rd ed. Oxford: Oxford University Press («Oxford History of England», vol. 2).

VOGEL, Walther (1906) - Die Normannen und das fränkische Reich: bis zur Gründung der Normandie, 799-911, mit einer Karte. Heidelberg: C. Winter.

WAITZ, Georg, ed. (1883) - Annales Bertiniani. Hanover: Hahn («Monumenta Germaniae Historica», SS rer. Germ., vol. 5).

WOOLF, Alex (2007) - From Pictland to Alba, 789-1070. Edinburgh: Edinburgh University Press («The New Edinburgh History of Scotland», vol. 2). 


\section{LOS VIKINGOS EN LA PENÍNSULA \\ IBÉRICA: NUEVAS PERSPECTIVAS SOBRE \\ PIRATAS Y MERCENARIOS EN LA \\ SEGUNDA MITAD \\ DEL SIGLO X}

IRENE GARCÍA LOSQUIÑO*

Desde que Reinhart Dozy compilase muchas de las fuentes históricas que mencionan el paso de los vikingos por la península ibérica en el siglo XIX, el estudio sobre los vikingos en Portugal y España se ha focalizado en estas fuentes escritas ${ }^{1}$. Se han realizado grandes obras de compilación y análisis de los distintos tipos de documentos medievales que retratan este período de la historia peninsular'2: las fuentes cristianas del norte, los documentos árabes provenientes en su mayoría de $\mathrm{Al}$ Ándalus, y algunas sagas y documentos historiográficos compuestos en Escandinavia que también mencionan las relaciones de líderes vikingos con, por ejemplo, Galicia. Es cierto que sí existen otras evidencias además de las fuentes escritas del paso vikingo por la península, como son, por ejemplo, la cajita vikinga en la Basílica de San Isidoro de León, los topónimos Lordemão en Coimbra y Lordemanos en León, o restos arqueológicos como las fortificaciones defensivas construidas en la costa gallega para proteger de la piratería o las iglesias afectadas por las razzias vikingas. Sin embargo, sí es cierto que ha dominado la monodisciplinariedad en este campo de estudio, y que, con respecto al paso de los vikingos por España (que es el foco de mi proyecto de investigación), no se ha avanzado mucho desde el trabajo de Eduardo Morales Romero. Quizá esto se deba porque hemos dado por hecho que nada más

\footnotetext{
*i.garcialosquino@gmail.com.

${ }^{1}$ DOZY, 1987.

${ }^{2}$ Cabe destacar, entre otros, ALMAZÁN, 1986; MORALES ROMERO, 1997; MORALES ROMERO, 2004; CHRISTYS, 2015.
} 
se podía encontrar, y que lo que ya habíamos concluido de las fuentes escritas es la totalidad de lo que podríamos concluir. Sin embargo, observar este pedazo de la historia peninsular desde las lentes de muchas disciplinas puede ofrecer mucha y más rica información, y espero que el estudio interdisciplinar del tema ayude a poner a la península en el panorama de la diáspora vikinga, así como ya lo es Francia, Irlanda, Inglaterra, Polonia o los países bálticos, por poner algunos ejemplos.

En este artículo me gustaría demonstrar cómo utilizando nuevas perspectivas y un enfoque interdisciplinar, en este caso combinando toponimia e historia, se puede ahondar en nuestro entendimiento de diversos aspectos del contacto vikingo. Considero que uno de los principales problemas a la hora de tratar este tema es hacerlo de manera generalizada y abarcando grandes áreas geográficas y temporales, siendo posible desarrollar nueva información analizando con profundidad casos o evidencias muy concretas. En el caso que aquí nos ocupa, analizaré un extracto de un documento medieval que nos habla de una redada vikinga en Galicia en el año 968, y procederé a trazar el recorrido de ese grupo de vikingos de Galicia a León, donde propondré que se asientan, en el año 970, como una fuerza mercenaria a favor del rey de León.

La llegada de un grupo de vikingos a las costas gallegas en el año 968 ocurre tras más de un siglo de intensos contactos. Los vikingos llegan a la península por primera vez, aunque no se descarta primeros aproximamientos antes, en el año 844, fecha recogida en los Annales Bertiniani que cuentan cómo un grupo de Nordomanni asedió Gijón y Galicia tras partir de Toulouse ${ }^{3}$. Esta razzia también impactará a las comunidades en los alrededores de Lisboa y Sevilla, y trazará un circuito que se repetirá durante los siguientes dos siglos, que es lo que dura el contacto «propiamente vikingo ${ }^{4}$. El siguiente asedio registrado, en el 859 , trae a un gran grupo de piratas que atacan toda la costa peninsular bajo el mando de las figuras míticas Hastéinn y Björn Järnsida. Este asedio tendrá un gran impacto en Galicia, pues la destrucción del obispado de Iria Flavia llevará a trasladar la sede obispal a Santiago, que desde ese momento crecerá como centro eclesiástico y político ${ }^{5}$. Tras este asalto, se reducirán el número de menciones documentales sobre ataques durante los próximos cien años, aunque en 910, algunos habitantes de Lugo parecen haber sido conscientes de la posibilidad de nuevas amenazas, pues pidieron al rey Ordoño de que fortificases sus casas contra los vikingos ${ }^{6}$. Es asumible, pues, que existieron muchas otras escaramuzas que no fueron registradas. Galicia fue atacada de nuevo en el año 951, y a partir de

\footnotetext{
${ }^{3}$ MORALES ROMERO, 1997: 89-90.

${ }^{4}$ Aunque 1066 marca el final de la Era Vikinga nominalmente, las relaciones violentas o pacíficas (de mercenariazgo) con Escandinavia continuarían durante el resto del siglo XI y el XII.

${ }^{5}$ MORALES ROMERO, 1997: 109.

${ }^{6}$ RISCO ed., 1796: 403-404.
} 
ese año fue sus defensas fueron reforzadas para evitar futuros ataques, aunque estos se producirán de manera casi anual durante el comienzo de la segunda mitad del siglo X. Al menos, serán estos ataques mejor registrados, pues la presencia de grandes figuras eclesiásticas en la lucha contra los vikingos y el interés historiográfico en el ensalzamiento de estas figuras resultan en entradas más detalladas y frecuentes en los anales y crónicas. Después de estos ciclos de ataques, Galicia seguirá recibiendo visitas durante los siguientes años, algunas aún bastante violentas, hasta bien acabada la Era Vikinga.

Los vikingos entran en la península en medio de un siglo lleno de tensiones y cambios. Su llegada se corresponde con los tiempos del emirato, que hasta el 929 no se convertirá en el califato, el cual traerá un gran incremento de la presencia musulmana en Iberia ${ }^{7}$. A su vez, a partir de mitad del siglo IX ocurre una expansión del Reino de Asturias que llevará consigo el fin de las relaciones semi-pacíficas con el sur. Galicia se transforma en un reino independiente, aunque subordinado al Reino de León, hacia el año 910, con la muerte de Alfonso III y la división del reino entre sus tres hijos $^{8}$. García ocupa el trono de la nueva capital en León y Ordoño II se convierte en rey de Galicia9 ${ }^{9}$ Galicia mantendrá un elevado aislacionismo para con el Reino de León, estando las fronteras del Bierzo altamente defendidas durante esta época ${ }^{10}$. Ya en el año 913, Galicia será integrada en el Reino de León y Ordoño II se convertirá en el nuevo rey, comenzando un costoso proceso de unificación de las diversas áreas ahora yuxtapuestas bajo su mandato ${ }^{11}$. Será este el comienzo de unos años de gran cambio político, con la oposición de condes gallegos y castellanos a los cambiantes reyes de León, el reino fraccionado durante períodos y la presión en las fronteras y en la costa, donde hay una presencia constante de piratas árabes y vikingos.

Es durante la segunda mitad del siglo XI, en medio de una oleada de ataques vikingos casi anuales, que la razzia que aquí nos concierne tiene lugar. A principios del año 967 (de acuerdo con el Chronicon Sampiri ${ }^{12}$ ) comienza a reinar un nuevo rey en León con solo cinco años de edad: Ramiro III ${ }^{13}$.

El padre de Ramiro III, Sancho I, sufrió gran oposición durante su reinado, hasta el punto de perder el trono en favor de Ordoño IV hasta que lo consiguió retomar en $959^{14}$. Esta oposición vino en gran parte de los poderes condales gallegos, que argumentaron que la gran gordura de Sancho I le inhabilitaba para atender sus

\footnotetext{
${ }^{7}$ GONZÁLEZ FERRÍN, 2006: 337.

${ }^{8}$ MONTEJO, 1799: 251.

${ }^{9}$ MARTÍNEZ DÍEZ, 2005: 232.

${ }^{10}$ MONTEJO, 1799: 265.

${ }^{11}$ CARRIEDO TEJEDO, 2006: 21.

${ }^{12}$ FLÓREZ ed., 1786: 471.

${ }^{13}$ RISCO, 1952: 72-73.

${ }^{14}$ MARTÍNEZ DÍEZ, 2005: 413.
} 
responsabilidades reales. Tras aliarse con el califa y pasar un período de cura de su obesidad en el califato, Sancho regresará y gobernará hasta su muerte. Debido a la corta edad de Ramiro III, su tía Elvira, educada como monja y ya con gran poder político antes de la muerte de Sancho I, actuará como regente ${ }^{15}$. Los vikingos aprovecharon la inestabilidad política traída por la muerte de Sancho I y el acceso al trono del joven rey, así como las tensiones entre poderes eclesiásticos a través de las figuras de dos obispos enfrentados ${ }^{16}$, para atacar Galicia en el año 968. Estos obispos, llamados Sisnando Menéndez y Rosendo Gutiérrez ${ }^{17}$, representaban un poder intermedio entre la aristocracia gallega y el rey, y el acceso al poder de uno u otro estaba fuertemente ligado a la cambiante ocupación del trono leonés ${ }^{18}$. Gracias a la fama adquirida en este caso por Sisnando (el cual jugó un gran rol en la defensa gallega contra los vikingos) como una figura a ensalzar durante los siglos posteriores, podemos acceder a una mención del paso de los vikingos por Galicia en el 968 que es mucho más informativa de lo normal en este tipo de fuentes, relatando la famosa Batalla de Fornelos. El extracto proviene del Chronicon Sampiri que después se recoge en la Historia Silense.

Año segundo de su reinado. Cien naves vikingas llegaron a las poblaciones de Galicia bajo el mandato de su rey Gunderedo e hicieron mucho daño alrededor de Santiago. El obispo de Santiago, de nombre Sisnando, pereció por la espada, y toda Galicia saquearon hasta llegar a los Pirineos montes Ezebrarii. Tras tres años, cuando se volvían a su patria, Dios, para el que nada hay oculto, tomó venganza. Y así como ellos habían tomado cristianos en cautiverio y habian pasado a muchos por la espada, tanto sufrimiento cayó sobre ellos que tuvieron que marcharse de Galicia. El conde Guillelmus Sancionis... salió con un gran ejército a su encuentro y peleó contra ellos, dándole Dios la victoria, y con su espada los mató a todos, incluido su rey, y quemó sus naves [... ${ }^{19}$.

Primeramente, este documento es de gran interés por ser la primera referencia a tan larga estancia en Galicia, pues normalmente las entradas son tan cortas que

\footnotetext{
${ }^{15}$ CARRIEDO TEJEDO, 2001.

${ }^{16}$ PORTELA SILVA, 2009: 217.

${ }^{17}$ Para más información sobre San Rosendo: CARVALHO CORREIA, 2007.

${ }^{18}$ PORTELA SILVA, 2009: 218.

19 Traducción de la autora del Latín, de SANTOS COCOS ed., 1921: 56-7: «Anno secundo regni sui c classes Normannorum cum rege suo nomine Gunderedo ingresse | sunt urbes Gallecie, et strages multas facientes in giro sancti lacobi, episcopum loci illius gladio peremerunt nomine Sisinandum, ac totam Galleciam depredaverunt, usquequo pervenerunt ad Pireneos montes Ezebrarii. Tertio vero anno, remeantibus illis ad propria, Deus quem occulta non latent, retribuit ultionem. Sicut enim illi plebem christianam in captivitatem miserunt, et multos gladio interfecerunt, ita et illi priusquam a finibus Gallecie exirent, multa mala perpessi sunt. Comes namque Guillelmus Sancionis ... exivit cum exercitu magno obviam illis, et cepit preliari cum illis; dedit illi Dominus victoriam, et omnem gentem ipsam simul cum rege suo gladio interfecit, atque classes eorum igne cremavit $[\ldots] »$.
} 
sólo anuncian la llegada de un grupo de vikingos, pero no dan detalles sobre la duración de los ataques ${ }^{20}$. También interesante es que estos tres años de saqueos no son solamente de presencia costera, próxima a sus barcos, sino que se trata de una presencia interior en la zona de un área denominada «Pirineos montes Ezebrarii». Se ha sugerido con anterioridad, siempre de forma no concluyente, que el topónimo Ezebrarii podría estar relacionado con el actual O Cebreiro, en la Sierra de Ancares lucense, aunque esto se ha hecho por estar las dos palabras relacionadas de manera obvia. Sin embargo, esta no es una conexión que se puede realizar sin mayor análisis, pues además del «O Cebreiro» ya mencionado existen en Galicia actualmente veintinueve topónimos que contienen la forma "Cebreiro» ${ }^{21}$, cada uno refiriéndose a diferentes accidentes terrestres, ríos o poblaciones. ¿A qué «Cebreiro» se refiere pues el Chronicon?

Si buscamos variantes del topónimo «Ezebrarii» en documentos medievales gallegos y leoneses, es posible ver que también existían diferentes entidades a las que este topónimo se refería, siendo utilizado para montañas, ríos, fuentes o poblaciones (e.g. «Zebrario $»^{22}$, «Zebrarium» ${ }^{23}$, «Ecebrario» ${ }^{24}$, «Cebrario» ${ }^{25}$, «Ezebral $\left.{ }^{26}\right)$, incluyendo la zona del actual «O Cebreiro» en Sierra de Ancares. Así pues, resulta imposible determinar el área geográfica en la que los vikingos se movieron durante la razzia en cuestión solamente utilizando el topónimo «Ezebrarii». Sin embargo, el documento nos provee de otro topónimo relacionado con «Ezebrarii»: Pirineos. La aparición de la palabra «Pirineos» aquí ha causado confusión a algunos autores ${ }^{27}$, puesto que la distancia con los Pirineos es tan significativa que podría parecer esta mención un error del autor de la crónica. Sin embargo, el topónimo «Pirineos» se utilizó en la Galicia y el León medievales para referirse a localizaciones montañosas en zonas concretas de Galicia y León ${ }^{28}$, y nunca para referirse a los Pirineos actuales. Por ejemplo, tres menciones pueden ser encontradas en documentos de los siglos IX-XI donde el topónimo señala áreas en la parte sur de la Cordillera Cantábrica.

\footnotetext{
${ }^{20}$ Aunque un documento medieval ahora perdido menciona la «civitas Lodimanos» en el río Ulla, que ya en 998 había sido abandonada.

${ }^{21}$ Datos recogidos por la autora.

${ }^{22}$ Documento gallego de circa 970 en LOSCERTALES DE GARCÍA DE VALDEAVELLANO ed., 1976. El nombre también se puede encontrar en un documento de Coimbra del año 964 RODRIGUES \& DA COSTA, eds.,1999: 223. ${ }^{23}$ Zebrarium Montem aparece en un documento del año 572, recogido en LÓPEZ SANGIL \& VIDÁN TORREIRA eds., 2011: 44 .

${ }^{24}$ Entre otras menciones, aparece en un documento del 992 refiriéndose a una población en el área del actual O Cebreiro. Este documento se compila en LUCAS ÁLVAREZ ed., 1986: $24-5$.

${ }^{25}$ En un texto del año 882, «Ecebrario» se refiere a un río, cerca del actual Cete, no lejos de Porto (FLORIANO CUMBREÑO, 1949: 332).

${ }^{26}$ En el mismo documento que Zebrarium Montem (pie de página 18) aparece «Monte Ezebral», no lejos de O Cebreiro. Hoy en día existen aún seis microtopónimos en el área: «Cebreiro», «Os Cebreiros», «Acebreiros», «Os Acebreiros» (two instances) $\mathrm{y}$ «O Cebreiro».

${ }^{27}$ CHRISTYS, 2015: 84.

${ }^{28}$ También cabe resaltar la existencia de diversos topónimos «Pirineos» en la actualidad en Galicia y el norte de Portugal.
} 
Ejemplos serían la mención de «Pirineos montis» en 853 cerca de Amaya, Burgos ${ }^{29}$ y en 950 «Pirineum» en León, no lejos de Amaya ${ }^{30}$. Así pues, «Pirineos» se refería a la Cordillera Cantábrica en la alta edad media gallego-leonesa, siendo la Sierra de Ancares parte de este sistema montañoso. La única yuxtaposición de instancias del topónimo «Ezebrarii» $\mathrm{y}$ «Pirineos» se produce solo en la Sierra de Ancares, en la actual aldea de $\mathrm{O}$ Cebreiro, Lugo. Así pues, con esta información podemos asumir con certitud que el grupo de vikingos que entró en Galicia en el 968 se adentró hasta O Cebreiro, en El Bierzo, que durante la época que nos ocupa era la frontera natural, y muy bien defendida, entre Galicia y León.

La entrada en anales o crónicas más próxima a este período de estancia en Galicia se produce en los Annales Complutenses, circa dos años después de la Batalla de Fornelos, en el año 970: «Sub Era MVIII. (...) Venerunt Lordomani ad Campos» ${ }^{31}$. Esta entrada es importante, porque revela la presencia de vikingos justamente tras la pérdida de la batalla contra el Gullielmus Sancionis del Chronicon Sampiri. De igual modo que con «Ezebrarii», la localización de «Campos» ha causado cierta confusión, apostándose por relacionar, de manera muy general, el topónimo con "Compostela» o con «Tierra de Campos» ${ }^{32}$. Sin embargo, se ha de proceder a un análisis cuidadoso de este topónimo para poder certificar con exactitud a qué lugar llegaron los vikingos tras su derrota. Primeramente, la relación de «Campos» con «Compostela» se debe a la supuesta etimología de Compostela como proveniente de «Campus Stellae», la cual es una etimología popular, pues hay muchas menciones medievales del nombre «Compostela», y ninguna aparición de «Campus Stellae» ${ }^{33}$. Con respecto a la posible relación con «Tierra de Campos», un análisis exhaustivo de documentos medievales latinos demuestra que sí es esta una etimología correcta, proviniendo su nombre de los «Campi Gallaeciae» mencionados ya en el siglo $\mathrm{V}^{34}$ luego denominados «Campi Gothorum», nombre atestado en el siglo IX ${ }^{35}$. Desde el siglo VIII al siglo XI, hay una variedad de documentos gallegos y leoneses que se refieren a la Tierra de Campos simplemente como «Campos», como por ejemplo, «in Campis Gotorum» ${ }^{36}$, «tam in Campis, e in Castella» ${ }^{37} \mathrm{o}$ "in territorio Campis» ${ }^{38}$, existiendo también como

\footnotetext{
${ }^{29}$ FLORIANO CUMBREÑO, 1949: 332.

${ }^{30}$ SÁEZ, 1987: 308.

${ }^{31}$ FLÓREZ ed., 1767: 311.

${ }^{32}$ MORALES ROMERO, 1997: 125.

${ }^{33}$ De hecho, existe una discusión etimológica en el Chronicon Iriense que relaciona "Compostela» con compositum tellum. Ver más en GARCÍA TATO, 2006: 794.

${ }^{34}$ DE SANDOVAL, 1634: 38.

35 «Campos quos dicunt goticos», recogido en BONNAZ, 1987: 20.

${ }^{36}$ SÁEZ, 1987: 61.

${ }^{37}$ FALQUE REY ed., 1988: 169.

${ }^{38}$ RECUERO ASTRAY, GONZÁLEZ VÁZQUEZ \& ROMERO PORTILLA, 1998: 93.
} 
denominación de aldeas dentro del territorio ${ }^{39}$. Tanto «Tierra de Campos» como «Campos» se utilizan durante los siglos XI y XII para referirse a esta región.

Además de la clara relación del topónimo de los Annales Complutenses con el «Campos» de documentos similares, el uso del verbo «venerunt» es también significativo, pues indica un movimiento hacia la Tierra de Campos y el autor del documento. Al haber sido compuestos los Annales en Castilla, y además al utilizar el autor el verbo «venerunt» frecuentemente en el documento, siempre significando un movimiento hacia las tierras de Castilla y León ${ }^{40}$, se puede confirmar que la cohorte de vikingos que habían arrasado Galicia pasaba en el 970 a tierras de León y llegaba a Tierra de Campos.

El paso de O Cebreiro actúa como único puerto de montaña viable en la Edad Media para cruzar la Sierra de Ancares, pues ahí se encontraba un hospital de peregrinos que permitía realizar esa difícil parte del Camino de Santiago con seguridad $^{41}$. De hecho, el Camino de Santiago se presenta como la única vía de paso desde Galicia a León, cruzando la frontera natura que es la sierra y la zona de El Bierzo, e internándose en Tierra de Campos a través de Astorga ${ }^{42}$. Una vez en Astorga, el Camino se desvía hacia León o conecta con la Vía de Plata en dirección a Benavente. Es esta última dirección la que los vikingos tomaron, pues aún hoy podemos encontrar en gran cercanía a Benavente, en plena Tierra de Campos, la única población restante en España con un topónimo que indica un asentamiento permanente vikingo: Lordemanos ${ }^{43}$.

El hecho de que Lordemanos está situado tan al oeste de la península y de que la única mención documental de un paso de vikingos a esta área es la de los Annales hace suponer que la fundación de Lordemanos y la entrada del 970 están relacionadas. Esto queda confirmado también por el hecho de que ya a partir del siglo XI aparece Lordemanos en documentos recogiendo donaciones de aldeas e iglesias. Por ejemplo, Lordemanos aparece en 1064 como Lordomanos $^{44}$, en 1117 como Lordomanus $^{45}$ y en 1206 como Lordomanos $^{46}$. En todas las instancias la aldea está totalmente integrada en el contexto rural leonés, sin mención alguna de su origen, con lo que ya para mitad del siglo XI Lordemanos había sido fundado, había crecido, se había normalizado en un área ya poblada y había pasado a ser propiedad de un donante. El nombre de Lordemanos corresponde con exactitud al nombre utilizado para los vikingos en las

\footnotetext{
39 «Villa vocitata Campos» (año 747) en RISCO ed., 1796: 358.

${ }^{40}$ FLÓREZ ed., 1767: 310-1.

${ }^{41}$ RUIZ MONTEJO, 2004: 115.

${ }^{42}$ La ruta de el Camino Francés ya queda detallada en un documento del siglo XII, el Codex Calixtinus, de cuyo Liber Peregrinationis se puede ver más en ARQUERO CABALLERO, 2011.

${ }^{43}$ Único ejemplo peninsular junto con Lordemão en Portugal y la ya mencionada 'civitas Lodimanos' en el Ulla.

${ }^{44}$ RUIZ ASENCIO ed., 1990: 346.

${ }^{45}$ VALCARCE, 1985: 32.

${ }^{46}$ GAVILANES LASO, 2003: 74; GARCÍA MARTÍNEZ, 1992: 210-1.
} 
crónicas y anales del norte cristiano, que combinan Lordomanni y Nordomanni (y un gran número de variaciones de estos dos términos). Estos dos nombres son en realidad el mismo término, siendo el intercambio entre $n$ y $l$ algo posible en gallego y portugués medieval en mitad y principio de la palabra ${ }^{47}$. El topónimo Lordemanos es también un tipo de topónimo muy común en esta etapa de población de la Tierra de Campos, donde los gentilicios de los pobladores se utilizan como nombres de asentamiento $^{48}$.

Para poder comprender la naturaleza del asentamiento de Lordemanos es importante prestar atención a varios factores: la presencia humana en el lugar, la existencia de centros de poder en las cercanías y la localización geográfica de Lordemanos.

En el año 970 el área donde Lordemanos se forma no estaba despoblada. En la historiografía española ha habido un gran cambio en el entendimiento de las poblaciones rurales de Tierra de Campos durante los siglos IX y X. Donde antes dominaba la idea de repoblación o colonización total de un área despoblada, ahora se impone la idea de que la región había mantenido una población rural constante desde los tiempos visigodos, la cual sí se expande durante los siglos que nos ocupan y con el desarrollo del Reino de León con capital homónima ${ }^{49}$. Lordemanos no estaba completamente despoblado, pues ya en el siglo X existía al menos una construcción en gran proximidad: el santuario de la Virgen de la Vega ${ }^{50}$, cuyos cimientos datan de este siglo ${ }^{51}$. Existe también una iglesia integrada en el pueblo de Lordemanos, pero al no poder certificar las autoridades locales si se trata de una iglesia del siglo X o el XI, no daremos por senada su presencia en el 970.

Resulta significativo que no exista registro alguno de daños realizados al santuario durante el paso vikingo, pues este es el caso en muchos de los centros eclesiásticos en Galicia que tuvieron contacto alguno con los escandinavos. Aún más significativo es que no exista evidencia de actividad hostil en un gran centro del poder eclesiástico que la cohorte vikinga hubo de cruzar para adentrarse en Tierra de Campos: Astorga. Astorga ya era un obispado importante en el siglo VI, y aunque su poder no creciese tanto como el de las diócesis de Oviedo y León en el siglo $\mathrm{IX}^{52}$, la urbe había acogido el trono real durante el reinado de García I, y continuaría considerándose anexa a la capital de León tras el traslado de la sede real ${ }^{53}$. Además, sería el lugar escogido por

\footnotetext{
${ }^{47}$ PIEL, 1989: 34.

${ }^{48}$ MARTÍNEZ SOPENA, 1985: 99.

${ }^{49}$ Para más información, ver ESCALONA, 2010; MARTÍNEZ SOPENA, 1993. De especial interés es MARTÍNEZ SOPENA, 1985.

${ }^{50}$ LLAMAS, 1962: 4.

${ }^{51}$ Datos ofrecidos por la Consejalía de Cultura de Cimanes de la Vega.

52 GARÍN, 1998: 232.

${ }^{53}$ CARRIEDO TEJEDO, 2006: 21.
} 
los monarcas del siglo X como panteón real ${ }^{54}$. De esta manera, los vikingos hubiesen entrado en Astorga a través del Camino Francés, cruzando el paso de O Cebreiro, para luego desviarse en Tierra de Campos hacia Lordemanos. Todo este traslado fue un proceso visible y no hostil interactuando con un centro de actividad tan importante como lo era Astorga. Tras abandonar Astorga, el cambio paisajístico es manifiesto, pues el fin de la escarpada Sierra de Ancares da paso a las vastas planicies de Tierra de Campos.

Lordemanos es hoy una pequeña aldea casi deshabitada, con una memoria folclórica muy reducida, aunque existente, de su pasado vikingo. Otra evidencia de la naturaleza no hostil del asentamiento es la existencia de grandes núcleos de poder político-militar al norte del mismo, entre Lordemanos y León. Estos castra y fortificaciones crecieron en importancia y fuerza durante el siglo $\mathrm{X}$ y, después de ser atacados por Almanzor en el 986, fueron reconstruidos y siguieron creciendo hasta convertirse en grandes poderes feudales ${ }^{55}$. De entre las fortificaciones más próximas a Lordemanos cabe destacar Toral de los Guzmanes y Valencia de Don Juan (cuyo nombre en la Edad Media era Coyanza), que ya aparece a principios del siglo diez (año 906) como "Castrum de Coyanca» ${ }^{56}$. Sin embargo, sin duda alguna, el centro urbano y político más importante en la proximidad de Lordemanos es León, que había crecido en importancia durante el siglo $\mathrm{X}$ y se había convertido en sede real ${ }^{57}$. No existen gran variedad de indicios arqueológicos que nos muestren la existencia de estructuras diferenciadas de las murallas romanas durante el siglo $\mathrm{X}$, aunque el interior de la torre del castillo real sí ha sido datada del siglo que nos ocupa ${ }^{58}$. Además, ya en el siglo $\mathrm{X}$ aparecen nombradas partes de la urbe relacionadas con la administración y defensa del reino ${ }^{59}$, así como importantes centros eclesiásticos intrínsecamente ligados al poder real, como es la actual Basílica de San Isidoro de León. Esta basílica tiene su base en el monasterio construido por Ramiro II durante la mitad del siglo X para albergar a su hija Elvira ${ }^{60}$, que veinte años más tarde se convertiría en regente de la corona. En el año 966, Elvira y el rey Sancho I trasladaron las reliquias de San Pelayo a León, fundando cerca del monasterio un templo para albergarlas, el cual también actuaría como monasterio ${ }^{61}$. Así pues, el León real en el periodo del 950-70 se dibujaba como una ciudad con una fuerte presencia política,

\footnotetext{
${ }^{54}$ RODRÍGUEZ DÍEZ, 2008: 162; SEVILLANO FUERTES \& VIDAL ENCINAS, 2001: 29.

${ }^{55}$ Para más información sobre Almanzor, ver BARIANI, 2003.

${ }^{56}$ SÁEZ, 1987: 34.

${ }^{57}$ Este crecimiento forma parte de un proceso complejo para dotar al Reino de León de una capital unificadora con la que identificarse. Para más información, ver CARVAJAL CASTRO, 2014.

${ }^{58}$ Comunicación personal con Eva Merino Flecha, Directora del Archivo Histórico Provincial de León. Los resultados de este análisis arqueológico aún no han sido publicados.

${ }^{59}$ MORAIS VALLEJO, 2005: 143.

${ }^{60}$ PÉREZ LLAMAZARES, 1927: 7.

${ }^{61}$ FRANCO MATA, 1991: 44.
} 
defensiva y administrativa y una creciente potencia religiosa. Teniendo en cuenta la preexistencia humana en el asentamiento, la permanencia de la población y la alta presencia circundante de urbes y centros de actividad militar y la capital real, la naturaleza del asentamiento de Lordemanos sólo se puede entender como una colonización realizada bajo el beneplácito real y sin ninguna tensión hostil para con el territorio cristiano colindante. Esta relación de no hostilidad ${ }^{62}$ no es, sin embargo, sorprendente, pues existen varios otros documentos que dan fe de la actuación de grupos de vikingos como mercenarios en favor de poderes condales en Galicia desde la primera mitad del siglo $\mathrm{XI}^{63}$. Además, otros signos de relaciones permanentes, diplomáticas o de beneficio mutuo están presentes, entre crecientes evidencias, en los demás topónimos similares a Lordemanos y la existencia de la cajita vikinga ${ }^{64}$ en la colección diplomática de la Basílica de León.

El emplazamiento de Lordemanos en el contexto geográfico-político de la segunda mitad del siglo $\mathrm{X}$ aporta un mejor entendimiento de las razones para escoger el lugar de asentamiento y el servicio prestado al rey. La aldea está situada en la punta más meridional de la provincia de León, haciendo frontera con Zamora al sur y al oeste, y con el río Esla, frontera natural en la Edad Media, al este. Esta frontera con Zamora es de gran importancia, pues durante el siglo IX y X se produce una expansión de la población preexistente que marca la frontera del reino en el río Duero, que cruza Zamora. Como frontera con el califato omeya, Zamora es objeto de ataques constantes durante el periodo que nos ocupa, pues es la zona de tensión de los intentos califales de extender la frontera hacia el norte y de sus persistentes tentativas de paso hacia León, a veces en alianza con líderes gallegos, castellanos o leoneses contra Sancho I y Ramiro III ${ }^{65}$. El posicionamiento de Lordemanos en el límite con Zamora convierte a Lordemanos en una zona de amortiguamiento entre Zamora, convertida en ciudadcampamento en el siglo $\mathrm{X}^{66}$, y los castra del sur de León, que a su vez protegen el paso a la sede real. Las tensiones condales durante el reinado de Sancho I tendrán un gran impacto en el reinado de Ramiro III, que ya desde el comienzo de su mandato focalizará gran energía en el desarrollo de las comunidades fronterizas y en aplacar la amenaza del califato ${ }^{67}$. Así pues, nos encontramos en Lordemanos con un asentamiento

\footnotetext{
${ }^{62}$ Reitero aquí la importancia de la falta de registro de actividad violenta en cualquiera de las localizaciones pasado El Bierzo que estuvieron en contacto con los vikingos.

${ }^{63}$ Como es el caso de un documento gallego relatando cómo en 1032 un grupo de vikingos ayudaron a los poderes condales locales a destruir una fortificación vasca.

${ }^{64}$ Esta cajita, hecha en Escandinavia a finales del siglo X o principios del XI, aparece en un contexto de regalos diplomáticos junto con muchas otras cajitas de diferentes orígenes. El estudio más actualizado de la cajita es el realizado por FRANCO VALLE, 2016.

${ }^{65}$ MARTÍNEZ DÍEZ, 2005: 462.

${ }^{66}$ REPRESA, 1972: 525.

${ }^{67}$ CEBALLOS-ESCALERA Y GILA, 2000: 132.
} 
de naturaleza mercenaria actuando a favor del rey de León para proteger una zona descubierta de la frontera con Zamora.

El análisis exhaustivo de tres topónimos y otros elementos importantes en dos textos medievales latinos y su combinación con la información histórica y arqueológica disponible sobre Galicia y el sur de León en la segunda mitad del siglo X, me ha permitido trazar el itinerario que siguió un grupo de vikingos en el año 968 desde el interior de Galicia a las planicies de Tierra de Campos. Lo que comenzó como una razzia violenta en Galicia, de aparición común en las fuentes latinas, acabó con una batalla en la que los vikingos salieron derrotados. Tras esta batalla, una parte de aquellos que habían llegado a O Cebreiro tomó rumbo a Tierra de Campos bajo consentimiento real a través del Camino de Santiago y se asentaron en el actual Lordemanos. Una vez allí, actuando como mercenarios (lo cual ya era común en otras partes de la diáspora vikinga $)^{68}$, y establecidos en una posición estratégica para la defensa fronteriza, se debieron amalgamar con la población local, pues menos de un siglo más tarde ya aparecía Lordemanos integrada, como cualquier otra aldea, en los dominios rurales de la Tierra de Campos ${ }^{69}$.

\section{BIBLIOGRAFÍA}

ALMAZÁN, Vicente (1986) - Gallaecia Scandinavica: introducción ó estudio das relacións galaicoescandinavas durante a Idade Media. Vigo: Galaxia.

ARQUERO CABALLERO, Guillermo Fernando (2011) - El Liber Peregrinationis como Fuente para la Historia del Camino de Santiago y de las Sociedades Medievales del Norte Peninsular. "Ab Initio: Revista digital para estudiantes de historia», 4. Madrid: Ab Initio, p. 15-36.

BARIANI, Laura (2003) - Almanzor. San Sebastián: Nerea.

BLÖNDAL, Sigfús (2007) - The Varangians of Byzantium. Cambridge: Cambridge University Press.

BONNAZ, Yves, ed. (1987) - Chroniques asturiennes (fin IXe siècle). Paris: Éditions du Centre National de la Recherche Scientifique.

CARRIEDO TEJEDO, Manuel (2001) - Una reina sin corona en 956-976: La infanta Elvira, hija de Ramiro II. «Tierras de León: Revista de la Diputación Provincial», 39. León: Diputación de León, p. 117-38.

(2006) - León, «Urbe Regia». Año 910 (cronología del rey García). «Tierras de León: Revista de la Diputación Provincial», 44. León: Diputación de León, p. 15-21.

CARVAJAL CASTRO, Álvaro (2014) - La construcción de una sede regia: León y la identidad política de los reyes asturleoneses en la crónica de Sampiro y en los documentos. «e-Spania: Revue Interdisciplinaire d'Études Hispaniques Médieváles et Modernes», 18. Disponible en http://e-spania.revues.org/23714 (fecha de consulta 14/12/2016).

CARVALHO CORREIA, Francisco (2007) - Algunas Notas sobre San Rosendo. «Estudios mindonienses: Anuario de estudios histórico-teológicos de la diócesis de Mondoñedo-Ferrol», 13. Salamanca: Imprenta Kadmos, p. 13-47.

\footnotetext{
${ }^{68}$ Como es el caso de la guardia varega en el Imperio Bizantino: BLÖNDAL, 2007.

${ }^{69}$ Como muestra la mención de Lordemanos en el documento, arriba mencionado, de 1064.
} 
CHRISTYS, Ann (2015) - Vikings in the South - Voyages to Iberia and the Mediterranean, Studies in Early Medieval History. London \& New York: Bloomsbury.

DE CEBALLOS-ESCALERA Y GILA, Alfonso (2000) - Reyes de León: Ordoño III (951-956), Sancho I (956-966), Ordoño IV (958-959), Ramiro III (966-985), Vermudo II. Burgos: La Olmeda.

DE SANDOVAL, Prudencio (1634) - Historias de Idacio Obispo, que escrivio poco antes que España se perdiese. De Isidoro Obispo de Badajoz, que escriuiò en los tiempos que se perdiò España, treynta y ocho años despues, De Sebastiano Obispo de Salamanca, que escriuiò desde el Rey don Pelayo, hasta don Ordoño Primero deste nombre, De Sampiro Obispo de Astorga, que escriuiò desde el Rey don Alonso el Magno, Tercero deste nombre, hasta el Rey don Vermudo el Gotoso, De Pelagio Obispo de Ouiedo, que escriuiò desde el Rey don Vermudo el Gotoso, hasta don Alonso Septimo deste nombre, Emperador de España. Pamplona: Nicolas de Assiayn.

DOZY, Reinhart (1987) - Los Vikingos en España. Madrid: Polifemo.

ESCALONA, Julio (2010) - Aproximación a un análisis comparativo de la territorialidad en los siglos IX-XI: el Territorium legionensis y el Condado de Castilla. In DE LA IGLESIA DUARTE, José Ignacio, coord. - Monasterios, espacio y sociedad en la España cristiana medieval, XX Semana de Estudios Medievales. Logroño: Instituto de estudios Riojanos, p. 271-291.

FALQUE REY, Emma, ed. (1988) - Historia Compostellana. Turnholt: Brepols. (Corpus Christianorum, Continuation Medievalis 70).

FLÓREZ, Emilio, ed. (1767) - Annales Complutenses. In España Sagrada: Teatro geográfico-histórico de la Iglesia de España. Madrid: Antonio Marín. Vol. XXIII, p. 310-4.

FLÓREZ, Enrique, ed. (1786) - Chronicon Sampiri. In España Sagrada: Teatro geográfico-histórico de la Iglesia de España. 2nd edn. Madrid: Pedro Marín. Vol. XIV, p. 452-72.

FLORIANO CUMBREÑO, Antonio (1949) - Diplomática española del periodo astur. Estudio de las fuentes documentales del reino de Asturias (718-910), Oviedo: Instituto de Estudios Asturianos, vol. 1.

FRANCO MATA, Ma Ángela (1991) - El Tesoro de San Isidoro y la Monarquía Leonesa. «Boletín del Museo Arqueológico Nacional», 9. Madrid: Museo Arqueológico Nacional, p. 35-68.

FRANCO VALLE, Rebeca (2016) - Viking Art in the Church: A Scandinavian Casket in San Isidoro de León, Spain. Oslo; Reykjavik: University of Oslo; University of Iceland. Master thesis.

GARCÍA MARTÍNEZ, Francisco Javier (1992) - El significado de los pueblos de León. León: Celarayn, D.L.

GARCÍA TATO, Isidro (2006) - Campus stellae, caminos estelares y otros mitos medievales. "Estudios mindonienses: Anuario de estudios histórico-teológicos de la diócesis de Mondoñedo-Ferrol», 22. Salamanca: Imprenta Kadmos, p. 779-800.

GARÍN, Alberto (1998) - Economía y religiosidad: clérigos propietarios en la diócesis de Astorga en los siglos $X$ y XI. «Espacio, Tiempo y Forma», Serie III: Historia Medieval, 11. Madrid: Facultad de Geografía e Historia. UNED, p. 231-242.

GARRIDO, José Luis, coord. (1993) - Repoblación y Reconquista: Actas del III Curso de Cultura Medieval: Aguilar de Campoo, Septiembre de 1991. Madrid: Fundación Santa María la Real, p. 57-64.

GAVILANES LASO, José Luis (2003) - ¿Hubo asentamiento vikingo en tierras de León? «Tierras de León: Revista de la Diputación Provincial», 41. León: Diputación de León, p. 57-82.

GONZÁLEZ FERRÍN, Emilio (2006) - Historia General de Al Ándalus. Córdoba: Almuzara.

LLAMAS, Amador (1962) - Santuario de la Virgen de la Vega, Cimanes de la Vega. León: Imprenta Católica.

LÓPEZ SANGIL, José Luis; VIDÁN TORREIRA, Manuel, eds. (2011) - Tumbo Viejo de Lugo (complete transcription). «Estudios mindonienses: Anuario de estudios histórico-teológicos de la diócesis de Mondoñedo-Ferrol», 17. Salamanca: Imprenta Kadmos, p. 11-373.

LOSCERTALES DE GARCÍA DE VALDEAVELLANO, Pilar, ed. (1976) - Tumbos del Monasterio de Sobrado de los Monjes. Madrid: Archivo Histórico Nacional. 
LUCAS ÁlVAREZ, Manuel, ed. (1986) - El tumbo de San Julián de Samos, siglos VIII-XII. Santiago de Compostela: Caixa de Galicia.

MARTÍNEZ DÍEZ, Gonzalo (2005) - El Condado de Castilla (711-1038): la historia frente a la leyenda. Valladolid: Marcial Pons, vol. 2.

MARTÍNEZ SOPENA, Pascual (1985) - La Tierra de Campos Occidental: Poblamiento, Poder y Comunidad del Siglo X al XIII. Valladolid: Institución Cultural Simancas.

(1993) - Las repoblaciones de Castilla y León: organización del espacio y cambios sociales entre los siglos X y XIII. In HERNANDO GARRIDO, José Luis, coord. - Repoblación y Reconquista: Actas del III Curso de Cultura Medieval: Aguilar de Campoo, Septiembre de 1991. Madrid: Fundación Santa María la Real, p. 57-64.

MONTEJO, Benito (1799) - Disertación sobre el principio de la independencia de Castilla y soberanía de sus Condes desde el célebre Fernán González. «Memorias de la Real Academia de la Historia», 3. Madrid: Imprenta de Sancha, p. 245-316.

MORAIS VALLEJO, Emilio (2005) - El Castillo de León. Breve historia de un valor patrimonial. «De Arte», 4. León: Facultad de Filosofía y Letras, Universidad de León, p. 135-160.

MORALES ROMERO, Eduardo (1997) - Os Viquingos en Galicia. Santiago de Compostela: Universidade de Santiago de Compostela. (2004) - Historia de los Vikingos en España: Ataques e incursiones contra los reinos cristianos y musulmanes de la Península Ibérica en los siglos IX-XI. Madrid: Miraguano Ediciones.

PÉREZ LLAMAZARES, Julio (1927) - Historia de la Real Colegiata de San Isidoro, de León. León: Imprenta moderna.

PIEL, Joseph Maria (1989) - Estudos de linguística histórica galego-portuguesa. Lisboa: Imprensa Nacional Casa da Moeda.

PORTELA SILVA, Ermelindo (2009) - El rey y los obispos: Poderes locales en el espacio galaico durante el periodo astur. In FERNÁNDEZ CONDE, Francisco Javier; GARCÍA DE CASTRO VALDÉS, César, eds. - Symposium Internacional Poder y Simbología en Europa, siglos VIII-X. Gijón: Trea, p. $215-226$.

RECUERO ASTRAY, Manuel; GONZÁLEZ VÁZQUEZ, Marta; ROMERO PORTILLA, Paz, eds. (1998) Documentos Medievales del Reino de Galicia: Alfonso VII (1116-1157). A Coruña: Xunta de Galicia.

REPRESA, Armando (1972) - Génesis y evolución urbana de la Zamora medieval. «Hispania: Revista Española de Historia», 122. Madrid: Consejo Superior de Investigaciones Científicas, Instituto de Historia, p. 525-545.

RISCO, Manuel, ed. (1796) - Odoarii Episcopi Lucensis testamentum. In España Sagrada, Antigüedades de la ciudad y Santa Iglesia de Lugo: memorias de los insignes monasterios de San Julián de Samos, y San Vicente de Monforte; examen crítico de los Concilios Lucenses; noticias inéditas del códice de los Concilios. Madrid: Viuda é hijo de Marín, vol. XL, p. 356-61.

RISCO, Vicente (1952) - Historia de Galicia. Vigo: Galaxia.

RODRIGUES, Manuel Augusto; DA COSTA, Cónego Avelino de Jesús, eds. (1999) - Livro Preto: Cartulario da Sé de Coimbra. Coimbra: Arquivo da Universidade de Coimbra.

RODRÍGUEZ DÍEZ, Matías (2008) - Historia de la muy noble, leal y benemérita ciudad Astorga. 2nd edn. Valladolid: Maxtor.

RUIZ ASENCIO, José Manuel, ed. (1990) - Colección documental del archivo de la Catedral de León (775-1230). León: Archivo Histórico Diocesano, vol. IV, p. 1032-1109.

RUIZ MONTEJO, Inés (2004) - El Camino a Santiago: Andares de un Peregrino en la España del Siglo XII. Madrid: Tres Cantos.

SÁEZ, Emilio, ed. (1987) - Colección documental del archivo de la Catedral de León (775-1230). León: Archivo Histórico Diocesano, vol. 1, 775-952. 
SANTOS COCO, Francisco, ed. (1921) - Historia Silense. Madrid: Sucesores de Rivadeneyra.

SEVILLANO FUERTES, María Ángeles; VIDAL ENCINAS, Julio M. (2001) - Arqueología del entorno de la catedral de Astorga: la primitiva iglesia de Santa Marta como testimonio de la configuración de un área sacra. In Actas del simposio 'La catedral de Astorga. Astorga: Centro de Estudios Astorganos, p. 25-47.

VALCARCE, Ma Amparo (1985) - El Dominio de la Real Colegiata de S. Isidoro de León hasta 1189. León: Institución Fray Bernardino de Sahagún. 


\section{LA NAVEGACIÓN E ITINERARIO DEL EJÉRCITO NORMANDO DE GUNDEREDO (968-969)}

FERNANDO ALONSO ROMERO*

\section{LOS ANTECEDENTES}

Hasta el descubrimiento de América en el año 1492, todos los viajeros que seguían los itinerarios terrestres para llegar al Noroeste de la Península Ibérica, creían que Galicia era «el límite de la tierra y el mar», como podemos leer en el Códice Calixtino redactado en el siglo XII ${ }^{1}$. Sin embargo, para los que llegaban por mar desde territorios muy lejanos: tanto del Norte de Europa, como del Este del Mediterráneo, Gallaecia ya era desde muchos siglos antes un territorio de enlace entre los lejanos pueblos del Mediterráneo y los del Norte de la Europa Atlántica. Los navegantes vikingos que empezaron a llegar a las costas gallegas a principios del siglo IX, no tenían miedo a perderse en el Océano porque ya estaban muy bien informados de la existencia del territorio galaico que tenían que rebasar para continuar la navegación hacia el Sur, rumbo a los países del Mediterráneo, del que procedían los exóticos productos que tanto se apreciaban en el Norte de Europa.

Debido a la llegada de vikingos y de normandos a Galicia, varios topónimos gallegos aparecen mencionados en catorce sagas nórdicas. Los vikingos utilizaban el nombre de Galizuland y Jakobsland para referirse a Galicia; y para referirse a España decían Spanland, Spania, Spaníaland e Yspania². En las sagas aparecen también Galiz

\footnotetext{
* Universidad de Santiago de Compostela. fernando.alonso@usc.es.

${ }^{1}$ «Galicia, donde está el límite de la tierra y el mar» (Liber Sancti Jacobi. Codex Calixtinus, VII, 111).

${ }^{2}$ IZQUIERDO DÍAZ, 2009: 73.
} 
y Galizland, así como Span ${ }^{3}$. Pero en el poema de Einárr Skúlason, del siglo XII, se menciona el topónimo Jákòbs-land; porque en esa época la ciudad de Santiago de Compostela ya era conocida internacionalmente debido al descubrimiento del sepulcro del Apóstol entre los años 820-830, bajo el reinado de Alfonso II el Casto (791-842)

Los vikingos llegaron a finales del siglo VIII a las Islas Británicas y también al norte de Francia, en donde Carlomagno, el rey de los francos (768-814 d. de C.), se había visto obligado a levantar emplazamientos defensivos en diferentes lugares de la costa debido a las repetidas incursiones de piratas nórdicos; e incluso tuvo que construir numerosos puentes en los ríos franceses navegables para evitar que los vikingos penetraran con sus naves hacia el interior ${ }^{5}$. Pero a pesar de esas precauciones, los vikingos saquearon en el año 835 un monasterio de la isla de Noirmoutier, en la desembocadura del río Loire, porque era un importante centro relacionado con el comercio de la sal y del vino. El poco calado de sus naves les permitió después navegar río arriba y atacar la ciudad de Nantes, obtener botines y regresar posteriormente a sus bases en Noirmoutier. Se conserva un testimonio que se fecha en el año 860, de un monje de ese monasterio, en el que se dice que los vikingos saquearon no solamente las ciudades de Bordeaux, Périgueux, Limoges, Angoulême, Toulouse, Angers, Tours y Orléans, sino que también llegaron hasta Paris y a otras localidades en las que perecieron muchas personas ${ }^{6}$.

De las incursiones violentas de los piratas vikingos y del temor que estas suscitaban en el estamento religioso, queda también el testimonio muy breve, pero muy significativo, de una cuarteta que escribió un monje irlandés del siglo IX en una página del manuscrito Institutiones gramaticae; obra de un gramático del siglo VI llamado Priscian, que se conserva en Sankt Gallen, Stiftsbibliothek (Suiza). Dicha cuarteta dice así:

El viento sopla esta noche con violencia, sacude la blanca cabellera del mar;

hoy no temo a las correrías por un mar en calma de los feroces guerreros de Lothlind.

El territorio de Lothlind se refiere a la Escocia vikinga, que comprendía parte del territorio del norte y de sus islas, así como también las del oeste ${ }^{7}$.

\footnotetext{
${ }^{3}$ ALMAZÁN, 1982: 2.

${ }^{4}$ LÓPEZ ALSINA, 2013: 117.

${ }^{5}$ IZQUIERDO DÍAZ, 2009: 67.

${ }^{6}$ GRAHAM-CAMPBELL, 1989: 31.

7 «Is acher in gaith in-nocht/fu-fúasna fairggae findfolt;/ni ágor réimm mora minn/dond láechraid lainn úa Lothlind». (MS 904). En: Ó CORRÁIN, 1998: 302-303.
} 
Los cauces fluviales siempre fueron desde la Prehistoria una de las principales vías de penetración hacia los territorios alejados del mar, y las embarcaciones de los vikingos al ser muy ligeras y provistas de remos, además de una vela, podían fácilmente penetrar por los ríos hacia el interior del país. Gracias a ellas pudieron navegar en el año 840 hasta la ciudad de Burdeos; y en el año 844 continuar penetrando río arriba por el Garonne hasta Toulouse, es decir, a más de trescientos kilómetros de la costa; aunque ya antes, en el año 840, habían llegado también al suroeste de Francia para apoderarse de la ciudad de Bayona en la desembocadura del río Adour; ciudad que permaneció en poder de los vikingos hasta el año 980. Es decir, hasta once años después de la batalla en la que murió el normando Gunderedo, cuando los supervivientes de su ejército tuvieron que abandonar Galicia en el año 969, después de haber navegado hasta las cercanías de Padrón siguiendo el cauce del río Ulla para realizar saqueos en varios lugares del interior de Galicia, como vamos a ver.

La llegada de los primeros vikingos al Norte de España se produjo probablemente desde sus asentamientos en la costa atlántica del sur de Francia; los pilotos de sus naves conocían perfectamente las características de los vientos del mar Cantábrico y las corrientes marinas que bordeaban la costa de la Península Ibérica. Sabían que los vientos predominantes en los meses de verano solían ser vientos del norte; lo cual les facilitaba las rutas hacia el sur. Por eso, en el mes de agosto del año 844, es decir, durante el mismo año en el que habían llegado hasta Toulouse, los vikingos que ya hacía tiempo que estaban asentados en la isla de Noirmoutier, en la desembocadura del Loire, llegaron con sus naves hasta la ciudad de Gijón, que disponía de un puerto de abrigo de origen romano en el que solían recalar las naves mediterráneas rumbo al Norte de Europa. Se sabe que los vikingos llegaron a la costa asturiana gracias a la noticia que sobre este acontecimiento histórico nos ofrece Prudencio, el obispo de Troyes, que escribe en los Annales Bertiniani entre los años 843 y $862^{8}$; por lo tanto, es contemporáneo con los hechos que describe. Dice Prudencio que unas embarcaciones vikingas penetraron por el río Garonne y llegaron a la región de Toulouse. Después arribaron a la costa española a causa de un temporal ${ }^{9}$. Parte de esa flota navegó hasta Galicia. La Crónica de Alfonso III (siglo IX) relata que los vikingos llegaron a Gijón y después a Farum Brigantium (A Coruña), donde fueron rechazados por un ejército de Ramiro I (842-850). Sin embargo, los vikingos supervivientes huyeron navegando rumbo al Sur, y debían de ser muchos porque llegaron hasta Sevilla, derrotaron a los musulmanes y conquistaron la ciudad ${ }^{10}$.

\footnotetext{
${ }^{8}$ Las referencias cronológicas de estos Annales llegan hasta el año 882. Troyes se encuentra a orillas del Sena a unos $130 \mathrm{~km}$ al sureste de Paris. Por su desembocadura en el puerto de Le Havre penetraron en diversas ocasiones las naves vikingas.

${ }^{9}$ MORALES ROMERO, 1997: 79.

${ }^{10}$ PIRES, 2012: 99.
} 
El ataque normando a las costas asturianas y gallegas del año 844 fue probablemente el que dio lugar a la leyenda de San Gonzalo, obispo de la iglesia de Britonia (Lugo) fundada en el siglo VI. Su argumento relata que este obispo evitó con sus milagrosos gestos que las naves normandas consiguieran arribar a las cercanías de la desembocadura del río Masma (Foz, Lugo). El obispo subió a la cima del monte Alto da Grela, en Mourente (Foz, Lugo), desde donde, según la tradición popular, realizó el milagro. Todavía hoy, en conmemoración de este episodio, se celebra una romería el sábado anterior al lunes de Pentecostés ${ }^{11}$ hasta la capilla do Milagre, situada en lo alto de ese monte ${ }^{12}$.

La proximidad de los asentamientos vikingos en la Bretaña y en el sur de Francia facilitaba la frecuente llegada de sus incursiones por las costas del noroeste de la Península Ibérica; sobre todo en los lugares donde se concentraba la riqueza: que solían ser las iglesias y los monasterios. Lo que determinó que en el año 880, bajo el episcopado de Sisnando I (880-920), la sede episcopal de Santa Eulalia de Iria se trasladase a Santiago de Compostela; por estar esta ciudad más alejada de los lugares de arribada de las naves vikingas ${ }^{13}$, que solían ser las rías gallegas y sus ríos.

A partir del siglo X, casi cien años después del descubrimiento del sepulcro de Santiago, el conocimiento de su existencia empezó a difundirse por el norte de Europa ${ }^{14}$; circunstancia que muy probablemente fue también la causa de que la mayoría de los ataques vikingos se incrementaran a partir del año 900, pues en torno a esa fecha, bajo el episcopado de Sisnando I (880-920), los cristianos y concretamente el pueblo de San Martín de Tours, ya estaban bien enterados de la existencia del camino de peregrinación hacia Santiago de Compostela, porque había sido la Iglesia compostelana la que los había informado sobre la ruta para acceder navegando hasta las cercanías de Iria, y continuar después por tierra hasta Compostela ${ }^{15}$. Es evidente que esta ruta la conocían también los vikingos que habían navegado ya a principios del siglo IX por el Loire hasta las cercanías de Tours, atraídos por los objetos valiosos que esperaban encontrar en las iglesias; y después de apoderarse de esa ciudad «redujeron a cenizas el famoso templo de San Martín» ${ }^{16}$. Desde la desembocadura del Loire los vikingos podían navegar hasta Galicia en menos de cuatro días, en ruta directa facilitada por los vientos del verano. Precisamente los nórdicos denominaban «la ruta occidental» a la ruta que seguían las naves de los peregrinos y comerciantes para llegar hasta la

\footnotetext{
${ }^{11}$ Esta fecha la celebraban los israelitas 50 días después de la Pascua de Resurrección como fiesta de acción de gracias por las primicias de la cosecha. Los primeros testimonios sobre Pentecostés como fiesta cristiana son del siglo II (MARTÍNEZ SÁIZ, 1969: 10, 14).

12 IZQUIERDO DÍAZ, 2009: 79.

${ }^{13}$ LÓPEZ ALSINA, 2013: 174-175.

${ }^{14}$ PIRES, 2012: 268.

${ }^{15}$ LÓPEZ ALSINA, 2013: 196.

${ }^{16}$ LÓPEZ FERREIRO, 1899: tomo II, 204.
} 
Tierra de Santiago, pues según un documento que se conserva en la Biblioteca Real de Estocolmo, al que se denomina Navigatio ex Dania per mare occidentale orientem versus circa 1270, las naves salían del puerto de Ribe (Dinamarca) y navegaban hasta Portsmouth en el sur de Inglaterra, y después al puerto de Sanctum Mathiam (Saint-Matthieu, Bretaña), y en tres días y tres noches más de navegación llegaban finalmente a La Coruña ${ }^{17}$.

Las incursiones que realizaron los vikingos por Galicia no solamente las condicionó la posibilidad de apoderarse de tesoros, sino también «el rapto y el consiguiente rescate o la venta como esclavos de los prisioneros». Práctica semejante a la que realizaban los musulmanes ${ }^{18}$. Pero otro de los motivos fue la necesidad de obtener sal, para utilizarla como condimento y también para conservar sus alimentos y los curtidos. De ahí que la sal fuera otro aliciente de sus incursiones por la ría de Arousa, donde las salinas de Noalla ya eran importantes en el siglo IX, así como otras de las rías bajas. Precisamente el topónimo Salnés de esa comarca arousana es una corrupción de la palabra salinero ${ }^{19}$. Sin embargo, el atractivo más importante de la ría de Arousa es el hecho de que en ella desemboque el río Ulla, que ya desde la Prehistoria era una importante vía de penetración hacia el interior de Galicia, aunque fue durante la Edad Media cuando más se utilizó para acercarse a Santiago de Compostela.

También las creencias y las tradiciones relacionadas con Santiago Apóstol tienen que ver con el río Ulla, pues el descubrimiento de su sepulcro se produjo en la primera mitad del siglo IX (820-830), es decir, mil años después de la llegada de los romanos a ese territorio, y precisamente por vía marítima y fluvial, al igual que había llegado, según la tradición, la mítica barca que transportaba el cuerpo de Santiago desde las lejanas tierras del Mediterráneo oriental. Tampoco debemos ignorar que antes de que las galeras y las naves de carga romanas penetraran por ese río hasta sus lugares de atraque en Pontecesures, muy cerca de Iria, ya otros pueblos habían navegado por el Ulla en busca de nuevos territorios en los que asentarse o para comerciar con sus gentes. En sus naves venían nuevos productos, ideas y conocimientos que dejaron también sus huellas entre nosotros; vestigios tangibles algunos, que se convirtieron con el paso del tiempo en testimonios arqueológicos, mientras que otros se fueron diluyendo poco a poco, transformándose en nuevas creencias y actitudes frente a la vida y al Otro Mundo, y dejando también huellas en la lengua que hoy hablamos y en los nombres de nuestros pueblos ${ }^{20}$.

\footnotetext{
${ }^{17}$ Ms. 41, fols. 127-128. ALMAZÁN, 1982: 8.

${ }^{18}$ ISLA FREZ, 1992: 102.

${ }^{19}$ IZQUIERDO DÍAZ, 2009: 82.

${ }^{20}$ ALONSO ROMERO, 2014: 94.
} 
Fig. 1.

Uno de los torreones que formaban parte de las Torres de Catoira, construidas en la orilla izquierda del río Ulla, muy cerca del lugar llamado A Vacariza, donde se supone que fondearon las naves de la flota de Gunderedo en el mes de marzo del año 968.

Fonte: Foto del autor.

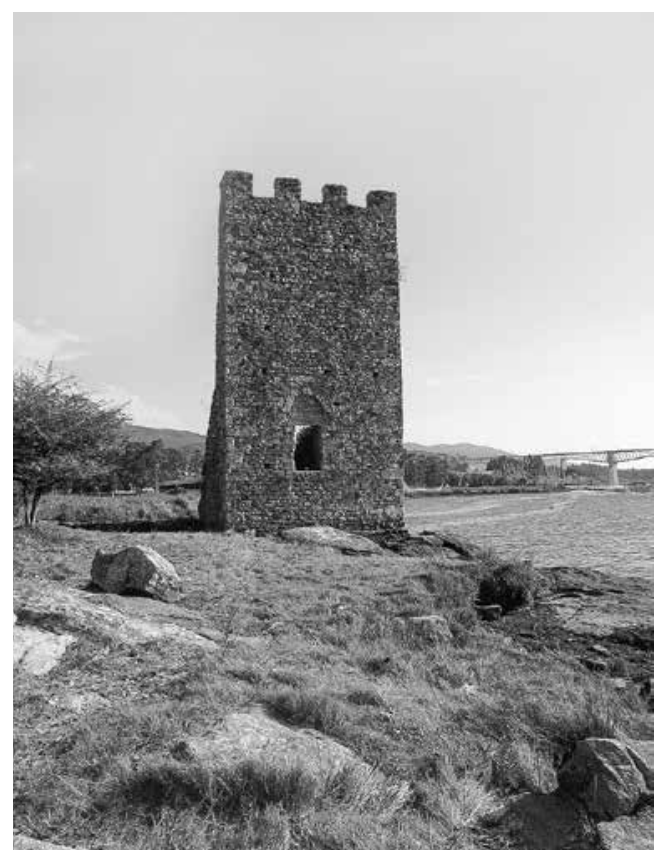

Uno de los topónimos cercanos a Catoira, en la orilla izquierda del Ulla, que sin duda surgió como consecuencia de la navegación fluvial por ese río, fue el lugar de Porto, en Pontecesures, que se encontraba frente a la antigua desembocadura del Sar. En la ladera del monte en donde está Porto, se descubrieron a finales del siglo XIX diversos restos de origen romano: vidrios, tégulas, fragmentos de cerámica diversa y monedas romanas fechadas entre los siglos I y $\mathrm{V}$ d. de C., y es significativo que a finales de ese siglo existiera aún en ese lugar un pequeño atracadero ${ }^{21}$. Hasta esas orillas llegaban las grandes naves de carga romanas y, por supuesto, diversos tipos de embarcaciones menores.

Todos estos datos indican que las Torres del Oeste que había construido a finales del siglo IX el obispo Sisnando I (880-920) en la orilla izquierda del río Ulla, bajo el reinado de Alfonso III el Magno, se levantaron sobre los cimientos de una antigua fortaleza romana muy relacionada con esa vía fluvial, por la que navegaron embarcaciones no sólo del Mediterráneo, sino también del Atlántico (Fig. 1).

Las incursiones de los vikingos y de los musulmanes determinaron que en la década del año 960 el obispo Sisnando II (951-968), ante el comportamiento de «la furiosa gente de los normandos», se viera obligado a fortificar la sede compostelana con la construcción de muros, fosos y torreones, como podemos leer en el Chronicon

${ }^{21}$ LÓPEZ FERREIRO, 1898: I, 220 y ss. 
Iriense (siglo X) ${ }^{22}$. Y entre los años 950 y 960 y el primer tercio del siglo XI se construyen varios castillos: como el de Aveancos, Aranga, San Xurxo, Canetum, Cedofeita, Casaldarado (en Sernadas (Pontevedra), de cuya existencia ya se tiene conocimiento a partir del año 916), Lobeira, A Lanzada ${ }^{23}$... Pero también se construyeron castillos tierra adentro pues los vikingos solían penetrar hacia el interior de Galicia cuando no obtenían en los lugares cercanos a la costa las riquezas que esperaban encontrar.

La existencia de los enclaves defensivos de la ría de Arousa demuestra también la preferencia que tenían los invasores por encontrar fondeaderos en aguas tranquilas del interior, rodeadas de territorios fértiles, donde abundaba la caza y la pesca, y donde tenían más posibilidades de encontrar riquezas, de hacer prisioneros y de saquear iglesias; pues además de las que estaban en los alrededores de la costa, la Iglesia de Santiago durante el obispado de Sisnando I (880-920) era propietaria también de las iglesias que había en las islas de Ons, Sálvora, San Vicente, Tambo e islas Cíes ${ }^{24}$. Eran establecimientos religiosos de monjes, que por vivir aislados estuvieron muy expuestos a los ataques sorpresivos no solamente de piratas nórdicos, sino también musulmanes, turcos e ingleses que saquearon sus iglesias y viviendas en diferentes etapas históricas.

Los piratas sentían preferencia por los fondeaderos de las islas a sabiendas de que no podrían ser atacados por los gallegos, pues hasta los tiempos del arzobispo Gelmirez (1100-1140), Galicia no dispuso de una flota de guerra. Además, desde esos fondeaderos isleños los piratas podían realizar incursiones a lo largo de la costa gallega, y volver impugnes antes del anochecer para depositar en las islas el fruto de sus rapiñas; hasta que satisfechas sus necesidades, decidían regresar a sus tierras.

Las fortificaciones costeras además de servir para la defensa, las utilizaba también la monarquía astur-leonesa para controlar el pago de los tributos, pues sus gobernantes eran nobles locales que desde sus castillos se encargaban de la administración del territorio que pertenecía de la monarquía ${ }^{25}$. Eran castillos levantados en cumbres desde las que se dominaba un amplio espacio del horizonte marino. Desde ellos, por medio de señales de humo y de fuego, se podía transmitir hasta la sede compostelana la noticia de la llegada de naves enemigas, y aprestarse así para la defensa. Fue precisamente el obispo Sisnando II (951-968) el que le dio un gran impulso a la construcción y reconstrucción de estos sistemas defensivos a lo largo de la costa gallega: como la reconstrucción de las Torres del Oeste y la torre de la Lanzada (Sanxenso) construida sobre un antiguo castro ${ }^{26}$. Pero, sobre todo, las murallas de la ciudad de Santiago

\footnotetext{
22 SÁNCHEZ PARDO, 2010: 66.

${ }^{23}$ LÓPEZ ALSINA, 1988: 225.

${ }^{24}$ ANDRADE CERNADAS, 2004: 27-28.

${ }^{25}$ BALIÑAS PÉREZ, 2014: 85.

${ }^{26}$ QUIRÓS CASTILLO, 2012.
} 
de Compostela. Sisnando II obligó a sus habitantes a trabajar duramente lo cual dio lugar a diversas protestas agravadas además por el hecho de que Sisnando II para "pagar y gratificar a los caballeros y campeones», que lo ayudaban en la defensa del territorio, utilizaba los recursos y rentas de la sede compostelana. Pero el dinero no se distribuía entre los siervos de la Iglesia, que trabajaban en esas construcciones, sino entre algunos nobles ${ }^{27}$. Con lo cual, el descontento llegó a oídos del rey Sancho I el Craso, que aprovechó la ocasión para enviar sus tropas a Compostela y detener a Sisnando II; aunque se sabe que detrás de esta detención estaba también el deseo de vengarse del daño que anteriormente le había causado Sisnando II por haberse opuesto a su reinado. Sancho I no sólo detuvo a Sisnando II, sino que en el año 966 también lo destituyó de su cargo; poniendo en su lugar al obispo Rosendo, un monje del monasterio de Celanova que llegaría a convertirse en Santo y que en ese año tendría que enfrentarse a los ataques de los normandos que habían llegado a las costas de Lugo ${ }^{28}$.

La sustitución de Sisnando II en el año 966 contribuyó a aumentar la rivalidad que tenía con el obispo Rosendo, derivada de los enfrentamientos tradicionales entre las cuatro familias gallegas más poderosas, que se repartían entre ellas las propiedades del territorio gallego ${ }^{29}$. Ya en el mes de febrero del año 961 Sisnando II había tenido un pleito con ese obispo motivado por la posesión de unas pesqueras que tenía la Iglesia en la desembocadura del río Tambre en la ría de Noia (A Coruña). Ambos religiosos alegaban ser sus propietarios, por lo que el conflicto hubo de celebrarse en la catedral de Santiago delante de la tumba del Apóstol, ante la cual los defensores de la reclamación del obispo Rosendo no se atrevieron a jurar que verdaderamente ese obispo era su legítimo propietario; con lo que el veredicto de los jueces fue a favor de Sisnando $\mathrm{II}^{30}$. Es comprensible que la personalidad de Sisnando II chocara abiertamente con la de Rosendo. Sisnando había vivido muy relacionado con la corte leonesa, como mayordomo del rey Ramiro II, y poseía desde el año 954 el sorprendente título de Totius orbis antistes, es decir, obispo de todo el orbe, que le había concedido el rey Ordoño III. Tratamiento comparable al de los pontífices de Roma ${ }^{31}$. Lo cual debió de suscitar en muchos miembros de la Iglesia envidias, críticas y comentarios muy negativos, que llevarían a Sisnando II a adoptar una postura propia de una persona que se siente superior y quizá a responder con acciones autoritarias.

\footnotetext{
${ }^{27}$ LÓPEZ FERREIRO, 1899: 336-339.

${ }^{28}$ MORALES ROMERO, 1997: 115-118.

${ }^{29}$ PORTELA \& PALLARES, 1987: 30.

${ }^{30}$ CARRIEDO TEJEDO, 2013: 587-588.

${ }^{31}$ CARRIEDO TEJEDO, 2013: 559.
} 
Pero a los pocos días de la muerte del rey Sancho I, Sisnando II recuperó la sede compostelana la víspera del día de Navidad del año 966 y amenazó con matar al obispo Rosendo, que tuvo que huir al monasterio de Celanova, quedando así confirmado lo que sobre la prisión de Sisnando II relata la Crónica Iriense, la Historia Compostelana y la Vida de San Rosendo ${ }^{32}$.

Los conflictos entre las jerarquías eclesiásticas y las poderosas familias de los nobles gallegos facilitaron la penetración de las huestes normandas hacia el interior de la Península Ibérica. Ambos estamentos eran dueños de terrenos en los que trabajaba una población de labradores y pastores. Es por ello muy probable que algunas de las invasiones normandas que sufrió Galicia las hubieran facilitado las alianzas y acuerdos comerciales entre los invasores y los nobles locales, «con el único fin de defender sus comunes intereses políticos sobre el reino». Como ejemplo de estas alianzas conocemos la realizada en el año 1032, cuando el jefe vikingo Ulf, apodado Ulf el gallego, combatió al lado de la nobleza gallega contra el rey Vermudo III de León ${ }^{33}$. Otro testimonio de estas alianzas con los vikingos lo encontramos en la Orkneyinga Saga compuesta en el norte de Islandia por un autor anónimo de la segunda mitad del siglo XIII. En ella se describe la llegada de la flota del conde Rögnvald desde las islas Orcadas hasta Galicia. Los capítulos 86 y 87 se ocupan de Galicia y mencionan el trato secreto que realizaron los gallegos y la Iglesia con el conde Rögnvald para que los ayudara a derribar el castillo de un extranjero llamado Guðifrey ${ }^{34}$, que en la Historia Compostelana aparece con el nombre de Pelayo Gudesteiz (cap. 47). Pero este relato de la Orkneyinga Saga se copió de la Heimskringla Saga, obra del año 1230 de Snorri Sturluson (1179-1241); de manera que el verdadero autor de ese acuerdo secreto con los vikingos fue en realidad el rey Sigurd, cuando estuvo en Galicia en el mes de otoño del año 1108, pues es el primer escandinavo del que se tiene noticia de su peregrinación a Santiago de Compostela; es decir, en una época en la que los gallegos estaban divididos entre los partidarios de Doña Urraca y los de su marido Alfonso I de Aragón, al que apoyaba Pelayo Gudesteiz; de ahí la ayuda que le pidieron a los vikingos los partidarios de Doña Urraca para derribar el castillo de Pelayo, que, según Almazán, se encontraba en Pontesampaio, en la desembocadura del río Verdugo (Pontevedra) ${ }^{35}$.

\section{LA PROCEDENCIA DEL EJÉRCITO DE GUNDEREDO}

Veíamos anteriormente que a principios del siglo IX los vikingos habían iniciado una serie de incursiones esporádicas por las costas del norte de Francia. Eran vikingos

\footnotetext{
${ }^{32}$ GARCÍA ÁLVAREZ, 1965: 92.

${ }^{33}$ MARTÍNEZ GRUEIRA, 2010: 806.

${ }^{34}$ ALMAZÁN, 1982: 9.

${ }^{35}$ ALMAZÁN, 1997: 426; ALMAZÁN, 1999: 244.
} 
que procedían principalmente de Noruega y de Dinamarca, pero poco a poco empezaron a llegar también desde las Islas Británicas; y con el tiempo y la continuidad de sus contactos con sus países de origen: sobre todo de Dinamarca, los vikingos acabaron en el año 893 por asentarse definitivamente en el ducado de Normandía ${ }^{36}$, fundado ese año por un vikingo de origen noruego llamado Rolf (latinizado como Rollo o Rollón), que había estado en Escocia, y probablemente también en Irlanda ${ }^{37}$.

A pesar de las actividades delictivas de los vikingos, los contactos internacionales que tenían contribuyeron indirectamente a mantener en el siglo IX las relaciones comerciales de Francia con otros territorios; incluso con países del Mediterráneo. Muchos objetos de valor y monedas procedentes de sus robos acababan finalmente en los mercados locales, que solían celebrarse al amparo de algún centro religioso, que obtenía también ganancias comerciales al igual que el rey. Fue así como surgieron algunos mercados franceses en el siglo IX, sobre todo en las localidades próximas a los ríos que facilitaban la navegación fluvial hasta sus proximidades ${ }^{38}$.

Debido a la continuidad de sus vínculos con los países escandinavos, el ducado de Normandía fue adquiriendo más poder, hasta el extremo de que en el año 963, el duque de Normandía Ricardo I decidió aumentar el número de vikingos que componían su ejército con contingentes procedentes de Dinamarca y de Noruega. $\mathrm{Y}$ cuando ya estaban todos preparados para enfrentarse abiertamente con Lotario, el rey de Francia, se llegó a un acuerdo y se firmó la paz. Entonces, Ricardo I se encontró con una serie de conflictos de todo tipo, causados por colaboradores que habían venido de Escandinavia, que no se resistían a estar inactivos y que, además, no estaban aún cristianizados. Ya desde el año 961 el territorio de Normandía venía sufriendo una serie de luchas internas por el poder y de operaciones de pillaje río arriba por el Sena y también hacia las costas bretonas ${ }^{39}$. Por lo que la primera reacción de Ricardo I después de firmada la paz con el rey de Francia fue intentar pacificar a los vikingos con diferentes prebendas y promesas confiando en que así acabaría con los conflictos. Pero estos se incrementaron al llegar el año 965; por lo que Ricardo I, para terminar definitivamente con los problemas que le estaban causando, decidió animarlos a que realizaran sus tradicionales correrías por el occidente de Francia. Fue precisamente esta decisión la que llevó a los vikingos hasta las costas de España en el año $966^{40}$.

Dos años después de esa incursión Normanda del 966, parece ser que en la primavera del año 968, bajo el reinado de Ramiro III (966-984), llegó a las costas de

\footnotetext{
${ }^{36}$ ALMAZÁN, 1986: 97.

${ }^{37}$ DOUGLAS, 1942: 421.

${ }^{38}$ WESTFALL, 1915: 867.

${ }^{39}$ BREESE, 1977: 53.

${ }^{40}$ SÁNCHEZ PARDO, 2010: 68.
} 
Galicia una flota de unas cien naves al mando de un normando de nombre Gunderedo, nombre latinizado probablemente del nórdico Gunrød ${ }^{41}$, Gunnrauðr ${ }^{42}$ o Gudroed ${ }^{43}$. Gunderedo era hijo del rey danés Harald ${ }^{44}$.

El problema principal con el que nos encontramos al analizar la ruta que siguió la flota de Gunderedo para llegar hasta Galicia, así como el itinerario de su ejército, es la falta de testimonios arqueológicos y la brevedad de los relatos históricos; lo cual hace difícil la localización de los topónimos que se mencionan en las Crónicas, e incluso el lugar en el que se celebró la famosa batalla de Fornelos; posiblemente cerca de Santiago de Compostela, en la que perdió la vida el obispo Sisnando II al enfrentarse a los normandos para impedir su avance hacia la sede compostelana.

A pesar de que la penetración del ejército de Gunderedo en el territorio gallego fue una de las incursiones normandas más importantes que sufrió Galicia a mediados del siglo X, no se han encontrado en Escandinavia objetos arqueológicos claramente procedentes de Galicia, aunque se supone que las monedas árabes y otros objetos del mundo musulmán que se hallaron en contextos vikingos de Noruega procedían de la Península Ibérica ${ }^{45}$.

Se supone que la flota de Gunderedo partió de Normandía, aunque también se opina que pudo zarpar de algún lugar de las Islas Británicas ${ }^{46}$. Pues es probable que algunas naves procedieran efectivamente de Irlanda, en donde los vikingos ya se habían establecido a principios del siglo IX y mantenían intercambios comerciales con el Continente. Para el historiador árabe del siglo XI, Umar Al-Udri, de origen almeriense, los normandos que habían llegado hasta Lisboa y Sevilla en el año 844 procedían de Irlanda, en donde, según ese autor, los «Mayus se vestían con abrigos adornados con joyas». Los árabes los llamaban Al-Urdumaniyyum (nordomani) y también Mayus (adoradores del fuego) ${ }^{47}$. La influencia vikinga en Irlanda fue muy marcada, pues fundaron ciudades, como Dublín, y se establecieron también en Cork y en otras poblaciones de la costa sur. De manera que desde principios del siglo $\mathrm{X}$ ya controlaban el comercio marítimo que realizaba Irlanda con otras ciudades de la costa occidental europea. Por este motivo no se puede descartar tampoco la posibilidad de que en la flota de Gunderedo vinieran también naves procedentes de Irlanda; aunque lo más probable es que el grueso de su flota partiera de Normandía en donde se habrían concentrado todas las naves, que, sin duda, eran de diferentes países: como se puede deducir de la noticia que se da en el Cronicón Iriense (del año

\footnotetext{
${ }^{41}$ MORALES ROMERO, 1997: 123.

${ }^{42}$ PIRES, 2012: 139.

${ }^{43}$ GARCÍA ÁLVAREZ, 1968: 234.

${ }^{44}$ IZQUIERDO DÍAZ, 2009: 87.

${ }^{45}$ SCHEEN, 1996: 79.

${ }^{46}$ PIRES, 2012.

${ }^{47}$ ROLDÁN CASTRO, 1987: 153-154.
} 
1080) sobre la procedencia internacional de su tripulación al relatar que encontrándose Sisnando II (951-968) en Santiago de Compostela a mediados de Cuaresma, llegaron emisarios diciendo que normandos y franceses y mucha gente enemiga venían de «uncaria» con la intención de acercarse a Iria («Normani, \& Frandenses, \& gens multa inimicorum»), y que cogían muchos cautivos y saqueaban y devastaban todos los lugares por los que pasaban ${ }^{48}$. Como esta noticia del Cronicón Iriense es la más cercana a los hechos que se relatan, vamos a ver el supuesto derrotero que siguió la flota de Gunderedo desde el norte de Francia; una costa por la que igualmente, también tendría que haber pasado en caso de proceder de cualquier lugar de las Islas Británicas; a no ser que esa flota normanda hubiera seguido un rumbo directo desde Irlanda o desde Cornualles en la costa occidental británica. Pero como esta posible alternativa es también una suposición, me voy a limitar a analizar el itinerario marítimo partiendo de Normandía, por donde pasaban las expediciones escandinavas rumbo a las costas de la Península Ibérica.

\section{LA RUTA MARÍTIMA DE LA FLOTA DE GUNDEREDO}

Los piratas normandos sabían que en las pequeñas poblaciones no encontrarían grandes riquezas; y como a ellos les interesaba adquirir valiosos botines, procuraban fondear sus naves en los lugares más próximos a las ciudades; como podemos leer en la Crónica de Sampiro en la que se dice que «los normandos penetraron en las ciudades de Galicia». Lo cual plantea la posibilidad de que la flota de Gunderedo, antes de su llegada, como cuentan las Crónicas, al puerto de «Juncaria», hubiera penetrado en otras rías de la costa Norte: como la de Vivero ${ }^{49}$, o quizá la de Betanzos, con el fin de navegar por el río Mandeo para después saquear el monasterio de Curtis ${ }^{50}$. E, igualmente, es posible que antes de su entrada en la ría de Arousa lo hubiera hecho en la de Noia, en donde en el siglo X ya existía una importante población a la que solían arribar naves comerciales y de peregrinos. Pero atengámonos a lo que nos dicen las Crónicas y con su escueta información intentaremos reproducir lo que pudo haber ocurrido.

Como los datos históricos no nos dicen nada sobre esas probables arribadas en la costa norte de Galicia, partimos del supuesto de que la flota de Gunderedo, aunque pudo haber fondeado en varios lugares, su punto de destino era la ría de Arousa; en

\footnotetext{
${ }^{48}$ FLÓREZ, 1747-1775: X, 606. MORALES ROMERO, 1997: 126.

${ }^{49}$ Juncaria, y sus derivados, son topónimos frecuentes en Galicia. En un documento del año 1540 sobre determinados bienes de la iglesia de San Martín de Mondoñedo, se menciona el puerto de «Junqueyro», de la ría de Viveiro (MARTIÑO, 1540: fol. 41 y 42. En: FERNÁNDEZ PACIOS, 2008: 94, 173). Supongo que estaría en el lugar que actualmente se llama Xunqueira, donde se encuentra el convento de Valdeflores, que perteneció a monjas o beatas mendicantes y después a monjas dominicas. Le leyenda dice que su fundación se debió al hallazgo de la imagen de Nuestra Señora de Valdeflores. Por lo que se construyó una ermita en ese lugar, que en el año 1128 se llamaba «Juncaria» (LÓPEZ ALSINA, 1976: 42. Cita de RODRÍGUEZ NÚÑEZ, 1993: 454).

${ }^{50}$ BALIÑAS PÉREZ, 2014: 97.
} 


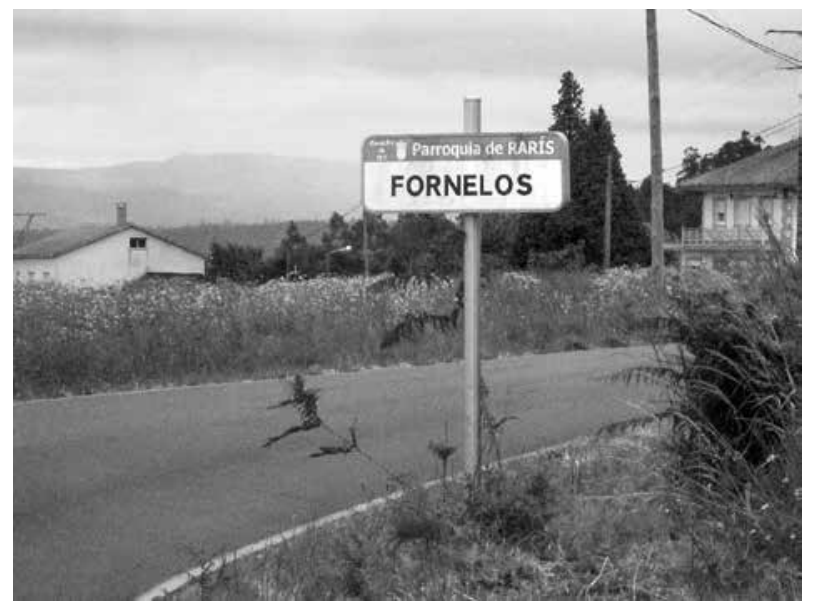

Fig. 2.

La aldea de Fornelos, en la parroquia de Rarís, se encuentra al sur de Santiago de Compostela y a 23 kilómetros de A Vacariza en donde desembarcaron los normandos.

Fonte: Foto del autor.

donde, al ser avistada, se transmitió la noticia a Santiago de Compostela; de facho a facho por medio de las señales de humo, que se hacían cuando se divisaba una flota enemiga. Después, según el Cronicón Iriense, se comunicó verbalmente al obispo Sisnando II, que salió rápidamente de Santiago para enfrentarse a los normandos en la batalla de Fornelos: un lugar a unos diez kilómetros al sur de Santiago de Compostela (Fig. 2).

Cien años después de la navegación de Gunderedo, los peregrinos nórdicos del siglo XI que venían a Galicia seguían las viejas rutas de navegación vikingas, como nos cuentan los testimonios que se conservan de sus viajes, que nos sirven para conocer el itinerario que pudo seguir la flota de Gunderedo desde Normandía. Las Crónicas dicen que su flota llegó a Galicia en la primavera del año 968 y que después de desembarcar en «Juncaria», los normandos se dirigieron a Santiago de Compostela. Sobre la exactitud de esa fecha de arribada está de acuerdo la mayoría de los estudiosos; aunque no se descarta el hecho de que pudo haber alguna incursión vikinga en alguna fecha próxima anterior ${ }^{51}$. Del análisis de los datos históricos, deducimos que el ejército de Gunderedo desembarcó en un lugar del interior de la ría de Arousa, cerca de Pontecesures, y con Gunderedo al frente, los normandos emprendieron el camino hacia la sede de Iria, como se relata en el Cronicón Iriense, que es una de las fuentes más antiguas en la que nos podemos basar, pues se fecha alrededor del año $1080^{52}$. Es decir, se redactó unos cien años después de ese episodio. Por lo tanto, los hechos violentos que realizaron los normandos es probable que todavía los recordara la memoria popular.

\footnotetext{
${ }^{51}$ SÁNCHEZ PARDO, 2010: 66.

${ }^{52}$ GARCÍA ÁlVAREZ, 1963: 85-90. PIRES, 2012: 31.
} 
La llegada de Gunderedo a Galicia se produjo a finales del mes de marzo del año 968; en plena la Semana Santa. Lo cual quiere decir que debió de salir de Normandía a principios de ese mes. La fecha elegida para zarpar muy probablemente la condicionó el buen tiempo y el viento adecuado para navegar hacia el oeste, porque no era habitual que los vikingos navegaran antes del mes de abril.

Para zarpar de Normandía había que prestar atención al estado de las mareas que cubrían las playas en las que se varaban las naves, pues en esa latitud el nivel de las aguas varía varios metros. En la obra Konungs Skuggsjá (El espejo del Rey), redactada en antiguo nórdico alrededor del año 1250, se aconseja a los navegantes que presten atención a las fases de la Luna para conocer el estado de las mareas, pues «con la Luna llena la pleamar es muy alta y muy baja la bajamar» ${ }^{53}$. Conocimiento que debían tener los pilotos para poder salir de los varaderos de bajos fondos y también para navegar por los estuarios de los ríos. Cuando las naves estaban a flote, se solía ir bordeando la costa francesa hasta la Bretaña, en donde el impacto de la influencia vikinga era también considerable pues en ese territorio levantaron diversos asentamientos y construyeron fortificaciones circulares, como la de Camp de Péran, en la costa norte ${ }^{54}$. La flota de Gunderedo intentaría mantenerse a la vista de la costa para evitar perder el rumbo. Cuando los vikingos se perdían porque la niebla no les permitía ver la costa, no tenían más remedio que recurrir al uso de la sonda, para orientarse por la profundidad de las aguas y también por su color.

Es lógico suponer que los pilotos de la mayoría de las naves de Gunderedo estuvieran familiarizados con las aguas del Canal de la Mancha, pues sus embarcaciones procedían de Normandía y necesariamente tenían que conocer perfectamente las características de sus aguas y los rumbos que había que seguir. Muy probablemente dispondrían también de algún tipo de cartas de marear o de portulanos con información sobre los puertos, los lugares de abrigo y la señalización de las rompiente; y conocerían quizá algún mapa en el que se mencionase la existencia de Galicia, pues este territorio aparece ya en un mapa del siglo XI, que se conserva en la Bodleian Library de Oxford ${ }^{55}$; aunque es muy esquemático pues, como en todos los primeros mapas, el mundo conocido se representa con un gran círculo terrestre rodeado por el mar, en cuyo interior se mencionan los nombres de algunos países; como ocurre también con otro mapa del año 1047 que se conserva en la Biblioteca del Escorial en el que aparecen mencionadas Galicia y Asturias ${ }^{56}$. En el mapa del códice del beato de Osma, del año 1086, además del nombre de «Gallaecia» aparece representada la Torre de Hércules. Sin embargo, ninguno de ellos servía para orientarse; aunque son

\footnotetext{
${ }^{53}$ LARSON, 1917: 93-94.

${ }^{54}$ PRICE, 1989: 54, 57.

${ }^{55}$ Canon. Misc. 560, fol. 3. En: CHEKIN, 2006: 62.

${ }^{56}$ Biblioteca San Lorenzo \&. I.3, fol. 177v. En: CHEKIN, 2006: 80.
} 
un importante testimonio de los vínculos de Asturias y de Galicia con las vías de navegación del norte de Europa.

Antes de que los navegantes italianos empezaran en el siglo XIII a realizar los portulanos de algunas rutas de la costa atlántica, ya los navegantes anglosajones, que procedían del sur de Dinamarca, prestaban atención a los principales resaltes de la costa; hasta incluso y con el fin de orientarse, se fijaban en las elevaciones artificiales de los túmulos funerarios que podían divisarse desde el mar; como podemos deducir del siguiente párrafo del siglo VIII del poema Beowulf: «entonces el pueblo géata levantó un túmulo espacioso y de gran altura en el promontorio, visible para los hombres del mar desde lejos» ${ }^{57}$. Los vikingos también solían fijarse en los pequeños túmulos de tierra y de piedras con los que cubrían sus enterramientos, y al igual que sus vecinos los anglosajones, los utilizaban como referencias para orientarse al entrar en los puertos y en los canales ${ }^{58}$.

También tenían en cuenta la velocidad que podían alcanzar sus naves y la distancia que podían recorrer en un día, que podía variar entre 30 y algo más de 100 millas náuticas: hasta 150 millas podía recorrer una nave vikinga en un día si navegaba a unos seis nudos de velocidad con viento favorable ${ }^{59}$. E incluso podían rebasar los diez nudos con buenas condiciones de la mar y viento de popa ${ }^{60}$. Pero tenían que estar constantemente pendientes de la dirección del viento, pues cuando éste cambiaba había que maniobrar adecuadamente: recoger rizos en las velas, cambiar su posición y afianzar cabos y escotas, transformándola casi en una vela latina para poder navegar de bolina.

Otro aspecto importante en el que debían fijarse los pilotos de una gran flota para evitar la dispersión de sus naves cuando navegaban con poca visibilidad, era seguir la dirección de la estela que dejaban las naves, como se recomendaba todavía en el siglo XVI: «una de las cosas en que debe tener el piloto aviso, cuando va navegando, es la vía o camino que la nao lleva, la cual conoce por la estela o rastro que deja en el agua la cual, aunque sea de noche, se muestra como una manera o lumbre que el agua allí hace» ${ }^{61}$.

Después de salir del Canal de la Mancha los normandos tuvieron que rebasar la costa bretona de Saint-Matthieu; por la que ya antes del siglo X pasaron también las naves en las que iban los monjes que cristianizaron las Islas Británicas ${ }^{62}$. Desde ese lugar los navegantes nórdicos tenían dos posibilidades: seguir rumbo al sur en una navegación de cabotaje o esperar la llegada de los vientos de componente norte,

\footnotetext{
${ }^{57}$ Beowulf, XXXIII. BRAVO GARCÍA, 1987.

${ }^{58}$ HUTCHINSON, 1994: 170.

${ }^{59}$ MCGRAIL, 1987: 282. Una milla náutica es igual a 1.852 metros.

${ }^{60}$ CAMERON, 1982: 327.

${ }^{61}$ DE MEDINA, 1563: IV, III, aviso III.

62 TANGUY, 1995: 31.
} 
que los llevarían directamente hasta las costas de Galicia o a las de Asturias en tres o cuatro días; sobre todo en verano, que es cuando con más frecuencia suelen soplar esos vientos. En el siglo XI Adam de Bremen cuenta que desde Saint-Matthieu las naves de los peregrinos que iban a Santiago de Compostela tardaban en llegar poco más de tres días ${ }^{63}$. Lo cual es muy posible pues desde el sur de Bretaña hasta la costa asturiana hay unas 300 millas náuticas; y a unas 50 millas de esa costa ya se empiezan a distinguir las cumbres de 2680 metros de los Picos de Europa, a menos de diez y ocho kilómetros de la costa ${ }^{64}$. Los normandos sabían que al oeste de esas montañas se encontraba el puerto de Gijón, de enorme importancia ya en época romana por sus relaciones comerciales y marítimas en los siglos III y IV d. de $\mathrm{C}^{65}$. Tras rebasarlo, la navegación de cabotaje seguía hacia el oeste: rumbo a Galicia, pues en esa latitud la costa es muy recortada, con numerosos cabos que fácilmente se pueden confundir con islas ${ }^{66}$.

El puerto de Gijón fue en el siglo IX frecuentemente utilizado como punto de arribada de las naves de los normandos que hacían la travesía directa desde Bretaña, pues ya mencionamos la arribada de una flota Normanda a la ciudad de Gijón el año 844. En su puerto es muy probable que Gunderedo se detuviera algún tiempo en espera de la llegada de las naves que pudieran haberse separado del grueso de la flota. Desde esa ciudad hasta la ría de Foz los normandos pudieron llegar en poco más de un día de navegación, y penetrar en su interior hasta el lugar conocido con el nombre de "Juncaria», igual que el de la ría de Arousa. Aunque también pudieron detenerse en la ría de Ortigueira en espera del tiempo adecuado para rebasar el cabo Ortegal y cambiar el rumbo hacia el sur de Galicia, pues bordear ese cabo con embarcaciones dotadas de vela cuadra no resultaba nada fácil con vientos contrarios. En el fondo de la ría de Ortigueira hay también junqueras, e incluso el topónimo punta Fornelos (en San Adrián de Veiga) en el que quedan restos de un castro atribuido a los «mouros» y de una antigua fortificación que se utilizaba para la defensa de la ría. Es de suponer que la flota de Gunderedo se hubiera detenido también en Farum Brigantium (A Coruña), aunque las Crónicas lo único que dicen es que arribaron a "Juncaria».

No es nada fácil bordear la Costa de la Muerte para alcanzar las Rías Bajas, y es posible que muchas de las naves se dispersaran y que la flota se dividiera, recalando en los puertos de abrigo más convenientes según el estado de la mar, las necesidades de avituallamiento o el deterioro de las naves que hubieran tenido que capear algún temporal. Pero como todo esto son solamente conjeturas, tenemos que concentrarnos

\footnotetext{
${ }^{63}$ GUILLOTEL, 1995: 133.

${ }^{64}$ URÍA RIU, 1955: 372.

${ }^{65}$ FERNÁNDEZ OCHOA \& MORILLO CERDÁN, 1994: 96

${ }^{66}$ CASARIEGO, 1965.
} 
en su arribada al puerto de «Juncaria» de la ría de Arousa, donde la mayoría de los investigadores opinan que ancló la flota de Gunderedo.

Los normandos realizaban sus incursiones desde el puerto en el que se concentraba la flota, al que regresaban después cargados de botines. Pero siempre se quedaba al cuidado de las naves parte de las tripulaciones en previsión de un posible ataque por sorpresa. Alrededor de unas cien naves componían la flota de Gunderedo; lo cual quiere decir que transportaban un gran contingente de tropas; como mínimo 3000 hombres, suponiendo que en cada nave fueran solamente treinta tripulantes, aunque se sabe que en el siglo $\mathrm{X}$ algunas naves normandas tenían dimensiones suficientes para llevar hasta sesenta personas, pues en ese siglo los vikingos disponían de naves de unos 30 metros de eslora que se manejadas con 60 remos. Y sus conocimientos de navegación eran tan grandes que desde el año 860 , ya vivían en Islandia y trabajaban en los terrenos que podían ser cultivados en ese territorio ${ }^{67}$. No conocemos exactamente cuántos normandos se quedarían al cuidado de las naves mientras sus compañeros realizaban sus correrías por el interior de Galicia; pero, aunque se quedase solamente la mitad de ese conjunto de tres mil hombres, el grupo restante era más que suficiente para imponerse sobre el diseminado ejército gallego, repartido entre las varias fortalezas que defendían la costa y cogido además por sorpresa, sin tiempo suficiente para concentrar sus fuerzas. Esta situación la conocían los normandos, por eso sus correrías solían realizarse con rapidez con la finalidad de regresar lo antes posible a sus naves, para después zarpar rumbo a otros puertos en los que repetir la misma táctica.

Aunque admitamos que en la flota de Gunderedo iban solamente tres mil hombres; sin embargo, eran suficientes para plantear problemas de subsistencia en cualquier punto del territorio gallego en el que desembarcaran, pues sus habitantes estaban muy repartidos en pequeños núcleos de población en los que los normandos difícilmente podrían encontrar alimentos para todos. Es este un dato importante a considerar para tener una visión lo más acertada posible del itinerario terrestre que siguió el ejército de Gunderedo hasta llegar a Santiago de Compostela. La necesidad de obtener alimentos daba prioridad a las actividades de la intendencia encargada del abastecimiento de las tropas. Pero los normandos sabían que tanto los alimentos como los botines que buscaban se concentraban en los lugares donde hubiera iglesias y grandes mansiones de nobles. A esta realidad hay que unir el hecho de que una flota que ascendía a unas cien naves, necesitaba un amplio espacio para efectuar el desembarco; y no todos los posibles lugares de arribada en la costa gallega ofrecían las condiciones adecuadas a las necesidades de una flota tan grande; a pesar de las

${ }^{67}$ CRUMLIN-PEDERSEN, 2010: 81-82, 107. 
Fig. 3.

Representación en el tapiz de Bayeux de una de las naves normandas de la flota de Guillermo el Conquistador, que en el año 1066 arribó a las costas de Inglaterra. En ella se podían transportar caballos.

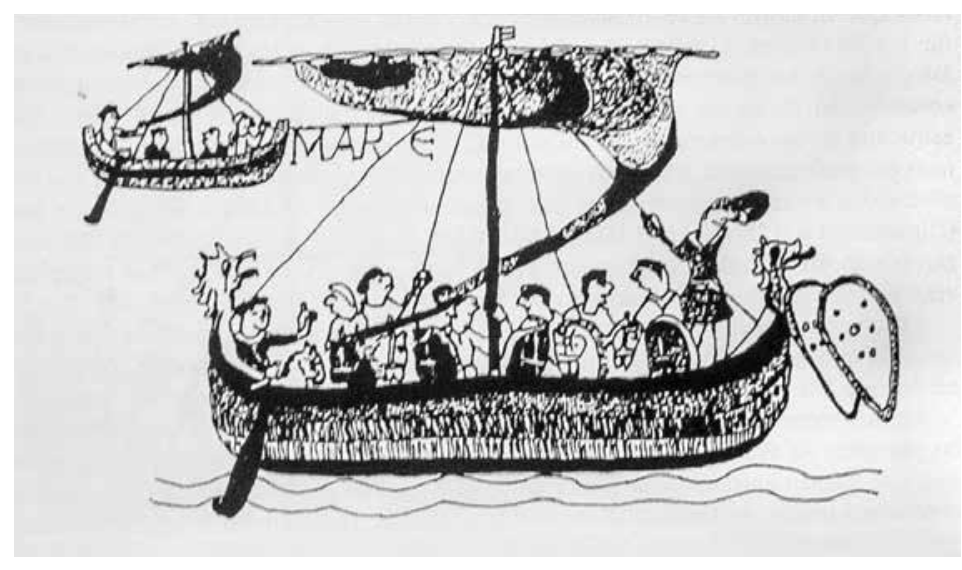

Fonte: Dibujo del autor.

pequeñas dimensiones de las naves normandas del siglo $\mathrm{X}$, cuyas características poseían una evidente influencia vikinga ${ }^{68}$.

Cuando todos los remos iban armados con los remeros en sus puestos, el espacio libre que quedaba para otros tripulantes y para el equipaje era muy reducido, por lo que se dificultaban las maniobras que hubiera que hacer para salir de una situación imprevista. Generalmente los bultos mayores se solían colocar cerca del mástil en donde se dejaba un espacio libre para la carga ${ }^{69}$. Las embarcaciones que utilizaron los normandos para invadir Inglaterra en el año 1066 descendían de las vikingas y en ellas se podían transportar caballos y una tripulación de hasta sesenta hombres ${ }^{70}$ (Fig. 3). Algunas de las embarcaciones que se muestran en el famoso tapiz de Bayeux, en el que se representa la flota de Guillermo el Conquistador de Inglaterra el año 1066, estaban preparadas para transportar caballos; por eso se construían con la borda más baja para facilitar la carga y el desembarco de los animales al arribar en las playas. Eran embarcaciones que descendían de las naves danesas que al mando de Rollo se habían establecido en Normandía en el siglo X. Hay que recordar que las naves de los vikingos daneses del siglo $\mathrm{X}$ eran más estrechas y bajas que las de los noruegos, pues las construían para navegar por las aguas poco profundas de las playas de Dinamarca, a diferencia de las noruegas que se utilizaban para navegar en los profundos fiordos ${ }^{71}$. Pero tanto el casco de las naves danesas como el de las noruegas o las normandas se construían con planchas de madera en tingladillo (solapadas) (Fig. 4).

\footnotetext{
${ }^{68}$ McGRAIL, 1981: 19.

${ }^{69}$ CHRISTENSEN, 1985: 219.

${ }^{70}$ MUCKELROY, 1978: 89.

${ }^{71}$ OLSEN \& CRUMLIN-PEDERSEN, 1978: 108, 112.
} 


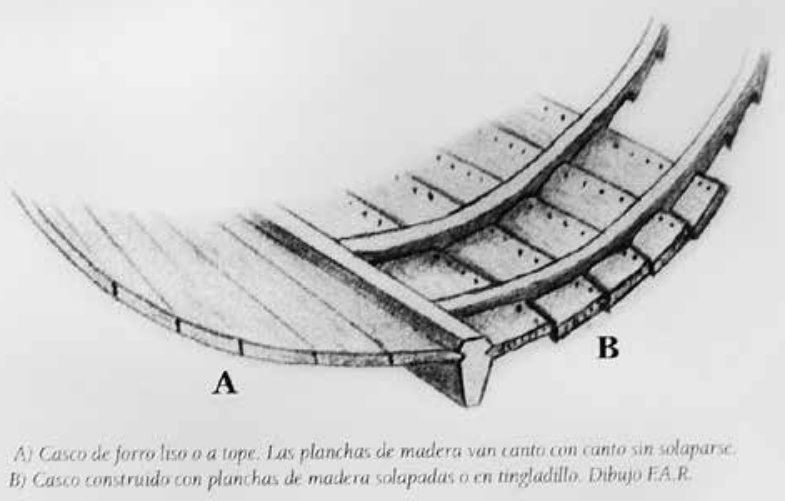

Fig. 4.

Los dos sistemas que se utilizan en la construcción del casco de una embarcación: A) Las planchas de las naves mediterráneas van unidas canto con canto, sin solaparse. B) Las naves escandinavas y las normandas se construían con las planchas de madera en tingladillo (solapadas).

\section{LA INTENDENCIA}

A pesar del énfasis que con frecuencia se pone en el comportamiento violento de los vikingos, no se suele prestar atención a las dificultades que tenían para conseguir alimentos, sin tener en cuenta que el factor de la alimentación tenía prioridad sobre el de las riquezas; motivo por el cual los vikingos procuraban disponer siempre de un asentamiento en lugares en los que abundara la caza y la pesca, y que, además, estuviera cerca de sus naves. Esta realidad nos lleva a ocuparnos de la logística que se necesitaría para el avituallamiento del ejército normando de Gunderedo durante su estancia en Galicia. Cuando se organiza una campaña bélica, se atiende a tres factores principales: el peso del soldado, la carga que puede transportar cada uno y el tiempo de una jornada de marcha. En base a estos datos se puede hacer una estimación aproximada de la cantidad de alimentos que se necesitarían para cubrir las necesidades básicas de la alimentación. Sabemos que los normandos realizaron diferentes incursiones por el interior de Galicia, aunque desconocemos exactamente cuantos soldados participaron en ellas y cómo estaba estructurado su ejército. Sin embargo, su comportamiento en una marcha y sus necesidades básicas eran las mismas que las de cualquier ejército que se desplazara a pie por unos caminos que en el siglo X no eran mejores que los que habían tenido que recorrer también los romanos en el siglo I. Lo cual nos permite realizar una estimación aproximada de la cantidad de alimentos que necesitó el ejército de Gunderedo durante sus campañas por el interior de Galicia. Si tomamos como punto de referencia la composición del ejército romano, sabemos que su unidad básica la formaba un contubernium, es decir, un grupo de 8 hombres que durante una campaña militar dormía dentro de una misma tienda. Un conjunto de 10 contubernia casi formaba una centuria de 100 hombres. El grupo siguiente se llamaba manipulo y lo formaban 2 centurias. Tres manipulos constituían una cross de alrededor de 500 soldados. Por último, con 10 
cohors ya se podía disponer de una legión compuesta de unos 5000 hombres $^{72}$; que era un número muy superior al de los componentes del ejército de Gunderedo, que no pasaría de los tres mil, es decir: el equivalente a 6 cohors. Si suponemos que cada uno de los hombres que componían un contubernium pesaría alrededor de 70 kilos, y que transportaba una carga de 30 kilos entre armamento y vituallas, el conjunto total del contubernium tendría que haber consumido al cabo de quince días de seis horas diarias de marcha, unos 180 kilos de comida sólida. Pues si cada soldado consumía 1,5 kg. de comida sólida cada día, en 15 días el conjunto total eran 22,5 kilos; entre pan, carne y otros alimentos que hubiera podido conseguir para cubrir sus necesidades básicas. Y si multiplicamos 22,5 por 8 soldados, vemos que los 8 hombres de ese grupo necesitaron 180 kilos de alimentos para comer durante 15 días de marcha. Si esa caminata la hubiera realizado una cohors, para alimentar a sus quinientos componentes se hubieran necesitado 10800 kilos de alimentos ${ }^{73}$. Lo cual, y tomando como referencia el interesante estudio de Losada sobre el ejército romano $^{74}$, nos permite saber que necesariamente Gunderedo tuvo que prestarle atención prioritaria a la obtención de comida para el mantenimiento de su ejército durante su estancia de un año en Galicia; aunque en las Crónicas no se mencione este aspecto, pues se limitan a resaltar de un modo general los daños y expolios que realizaban los normandos en las iglesias y en las ciudades en las que hacían prisioneros; como la Crónica de Sampiro, que dice que «Gunderedo entró en muchas ciudades de Galicia e hizo muchos estragos en toda la redonda de Santiago» ${ }^{75}$; pero sin resaltar que era en ellas precisamente en donde tenían más posibilidades de encontrar comida.

\section{EL ITINERARIO TERRESTRE DEL EJÉRCITO DE GUNDEREDO}

Ahora vamos a intentar de averiguar qué es lo que pudo haber hecho el ejército de Gunderedo después de desembarcar en el puerto de Juncaria de la ría de Arousa; y en lo primero que debemos fijarnos es en el número de embarcaciones que tenía la flota normanda. Suponiendo que ésta estuviera compuesta de unas cien naves, como relatan las Crónicas, una armada tan numerosa necesitaba un gran espacio para fondear, y a esta realidad debemos añadir el hecho de que durante el proceso de entrada hasta el fondeadero del interior de la ría de Arousa, las naves necesariamente tenían que manejarse a remo no solamente para contrarrestar la corriente del río, sino también para introducirlas en la orilla dentro de una formación adecuada para proceder al desembarco de los, por lo menos, tres mil hombres que iban a bordo. Si tenemos en cuenta que la manga de esas embarcaciones medía unos cuatro metros de anchura y

\footnotetext{
${ }^{72}$ LOSADA, 2014: 202.

${ }^{73}$ LOSADA, 2014: 206.

${ }^{74}$ LOSADA, 2014.

${ }^{75}$ FERREIRO ALEMPARTE, 1999: 37.
} 
que cada remo solía medir un poco más de cinco metros ${ }^{76}$; cada nave con los remos armados ocuparía un espacio de unos 14 metros de anchura; y cien naves ancladas frente a la costa costado contra costado y con los remos recogidos abordo ocuparían una línea costera de 400 metros de longitud. Pero esta formación no debía adoptarse nunca, pues no dejaba espacio para armar los remos en caso de tener que zarpar precipitadamente ante la amenaza de un ataque repentino por parte de los habitantes de la costa gallega. Con lo cual, es evidente que se necesitarían muchos más metros de orilla fluvial para que los normandos pudieran anclar las cien naves de la flota y desembarcar. Esas naves con los remos armados colocadas en formación de fila militar, es decir, costado contra costado, y fondeadas frente a la orilla, ocuparían un espacio de alrededor de mil quinientos metros; es decir, una distancia que sobrepasa en unos quinientos metros a la que existe entre las Torres del Oeste (en Catoira) y A Vacariza; lugar en el que según la Crónica de Santa María de Iria, fue el punto final en el que atracó la flota de Gunderedo. Es por ello muy probable que Juncaria fuera lo que todavía es actualmente A Vacariza; en cuyas cercanías aún se recuerdan varios lugares que llevan el nombre de Xunqueira. En la parroquia de Dimo, en Catoira, existen los siguientes topónimos: A Fonte da Xunqueira, O Cruceiro da Xunqueira, A Carballeira da Xunqueira e O Rego da Xunqueira ${ }^{77}$. Con lo cual, una observación detenida de los posibles lugares de anclaje en las orillas fluviales de ese lugar de A Vacariza nos permite descubrir que necesariamente las naves tendrían que ocupar ambas orillas desde las Torres del Oeste, o incluso varar en otros fondeaderos río arriba (Fig. 5).

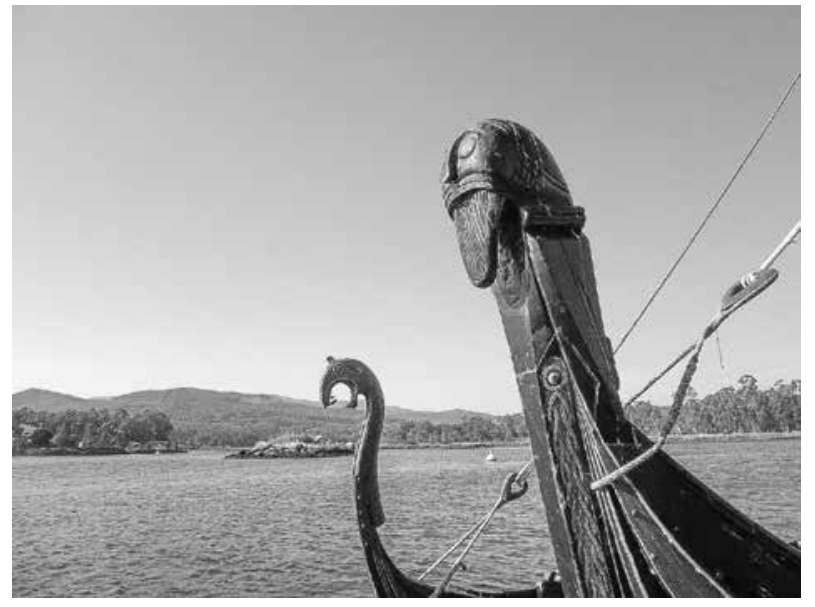

Fig. 5.

Reproducción de dos naves vikingas ancladas en el fondeadero de las Torres del Oeste, en Catoria. En el amplio espacio fluvial que existe entre este lugar y A Vacariza, al pie del monte que se divisa en la fotografía, pudo perfectamente fondear toda la flota Normanda de Gunderedo.

Fonte: Foto del autor.

\footnotetext{
${ }^{76}$ UNGER, 1980: 88. Los de la proa y popa al ir sobre una borda más elevada eran algo más largos.

${ }^{77}$ NAVAZA BLANCO, 2007: 116.
} 
La Historia Compostelana y la Crónica de Sampiro dicen que arribaron a un lugar llamado Juncaria, posiblemente con la intención de acercarse a Iria; suposición que queda confirmada con lo que menciona La Crónica de Sampiro cuando dice que «Gunderedo entró en muchas ciudades de Galicia e hizo muchos estragos en toda la redonda de Santiago» ${ }^{78}$. A las cercanías de Santiago de Compostela llegaron los normandos en la Semana Santa del año 968. Lamentablemente en ninguna de las Crónicas se dice en qué lugar exactamente estaba Juncaria. Olvido muy comprensible debido a que este topónimo significa «lugar donde hay juncos», una planta muy abundante en muchos lugares de la ría; sin embargo, en las Crónicas no tiene el significado de lugar común, sino que es un topónimo insigne con valor histórico como fondeadero tradicional; como lo era ya en época romana el entorno fluvial de las Torres del Oeste en cuyas cercanías: aproximadamente a un kilómetro río arriba pero en la orilla opuesta, está A Vacariza, puerto de desembarco para coger el camino que llevaba hacia Padrón e Iria.

La Historia Compostelana, redactada por encargo de Gelmirez (1100-1140), dice que los normandos vinieron «desde el puerto que se llama Juncaria» y se dirigieron a Iria «saqueando esta zona» ${ }^{79}$. El Cronicón Iriense sitúa el lugar del desembarco también en Juncaria: [...] «normani et frandeses et gens multa inimicorum, veniens de Iuncariis volentes ire ad Hyriam $»^{80}$. Sin embargo, en la obra redactada a mediados del siglo XV: la Crónica de Santa María de Iria, se sitúa Juncaria en Vacariça: que se supone que es el actual A Vacariza en la orilla derecha del río Ulla, en la parroquia de Santa María de Isorna: «et en este ano, enna dominica mediante de Coreesma, vieron moitas naves de normanos, et frandeses et moita gente de enemigos da fe ao porto de Vacariça et entraron a Ilia. Et por toda a terra roubaron omes et molleres, et poinan fogo e destroiron a terra ata Compostella» ${ }^{81}$.

El Cronicón Iriense (siglo X) se conserva en la Crónica Compostelana y sus noticias llegan hasta el año 982, y por su proximidad cronológica con los hechos que se relatan, es al que creo que se le debe dar más veracidad. En él se dice que una vez desembarcados, los normandos se dirigieron hacia Iria pero les salió al encuentro el obispo Sisnando II al frente de sus tropas, que habían salido precipitadamente de Santiago de Compostela al enterarse de la proximidad de los normandos. Sisnando II pertenecía a la más alta aristocracia gallega, con grandes propiedades, con lo cual era un poderoso señor con medios suficientes para disponer de un ejército privado a su servicio y con evidente interés personal por defender sus posesiones; entre las que estaban también las Torres del Oeste.

\footnotetext{
${ }^{78}$ FERREIRO ALEMPARTE, 1999: 37.

${ }^{79}$ Historia Compostelana, I, 2, 6. (Edición de Emma Falque Rey. Madrid, 1994).

${ }^{80}$ El Cronicón Iriense. Edición de García Álvarez, M.R. 1963.

${ }^{81}$ Crónica de Santa María de Iria. (Edición de Souto Cabo, J. A. 2001, 4.10).
} 
López Ferreiro dice que en la fecha en la que la flota de Gunderedo llegó a las costas gallegas, Sisnando II vivía retirado en Sobrado dos Monxes, pero que cuando se produjo el desembarco ya estaba en Compostela, adonde había ido probablemente para asistir a los oficios de Cuaresma en la catedral. Para llegar hasta Compostela, Sisnando II tuvo que seguir una calzada romana secundaria que desde Lugo iba en dirección a Santiago ${ }^{82}$. En aquellos tiempos, en realidad igual que actualmente, la jornada de viaje de un caminante raramente sobrepasaba los 30 kilómetros; y la misma distancia si se iba a lomos de caballerías pues los reyes de León en el siglo X cuando tenían que viajar no avanzaban más de 30 kilómetros diarios ${ }^{83}$.

Es evidente que el ejército de Gunderedo era muy superior pues en el encuentro entre las dos fuerzas, en una batalla que tuvo lugar en Fornelos ${ }^{84}$, los normandos acabaron con la vida del obispo Sisnando II el 29 de marzo del año 968; como dice el Cronicón Iriense: «Quo audito episcopus Sisnandus, ut insanus armis indutus, cucurrit post eos usque Fornelos, et intrans per medias acies occiditur ${ }^{85}$. En esa fecha se estaba celebrando la Cuaresma ${ }^{86}$. Sobre estos hechos la Historia Compostelana relata que Sisnando II salió de la ciudad de Santiago de Compostela para enfrentarse a los normandos: «el propio Sisnando salió de la ciudad y, protegido por la fuerza de su ejército, un día de Cuaresma, los siguió hasta el predio de Fornelos», donde muere al ser atravesado por una flecha el 29 de marzo del año $968^{87}$. La Crónica de Santa María de Iria dice que Sisnando salió de Santiago para perseguir a los normandos «[...] et correu enpos deles ata o lugar de Fornelos» ${ }^{88}$.

Como la muerte de Sisnando se produjo en plena Cuaresma, sabemos que en ese año la Pascua había caído el 19 de abril ${ }^{89}$; lo que quiere decir que la Cuaresma había empezado el 10 de marzo, pues la Cuaresma empieza el Miércoles de Ceniza y termina en el Jueves Santo, día de la Pascua. Es en esta Pascua cuando se celebra la Semana Santa, que debe coincidir con la primera Luna llena después del equinoccio de primavera. Por ello, el Jueves Santo del año 968 hubo Luna llena. Sin embargo, el 29 de marzo de ese año la Luna estaba ya en fase menguante; muy próxima a la Luna nueva, fenómeno que ocurrió el 31 de marzo ${ }^{90}$. Es este un dato importante para reforzar la opinión de que la batalla de Fornelos tuvo que celebrarse en un lugar próximo a Santiago, a menos de 30 kilómetros de $A$ Vacariza, que es la distancia que se suele recorrer caminando en una jornada. Después de la batalla los normandos

\footnotetext{
${ }^{82}$ GARCÍA ÁLVAREZ, 1965: 32-33.

${ }^{83}$ GARCÍA ÁLVAREZ, 1971: 432.

${ }^{84}$ LÓPEZ FERREIRO, 1899: 352.

${ }^{85}$ El Cronicón Iriense. García Álvarez, M.R. (Edición). 1963, 11, p. 119.

${ }^{86}$ Historia Compostelana, Libro I. cap. 2, 6.

${ }^{87}$ Historia Compostelana, I, 2, 6. (Edición de Emma Falque Rey. 1994).

${ }^{88}$ Crónica de Santa María de Iria, 4. 10. (Edición de Souto Cabo, J. A. 2001).

${ }^{89}$ LÓPEZ FERREIRO, 1899: 352-356.

${ }^{90}$ Agradezco al profesor astrofísico Dr. Manuel Cornide Castro Piñeiro esta información.
} 
hicieron muchos prisioneros y cargados de botines necesariamente tendrían que regresar a sus naves antes de que llegara la noche. Pero como ésta ya estaba próxima, la débil luz de la Luna en esa fecha no les hubiera permitido desplazarse con seguridad llevando prisioneros y teniendo que volver a caminar casi 30 kilómetros hasta sus naves, exponiéndose además a ser atacados por sorpresa en territorio enemigo. A esta suposición hay que unir también la posibilidad de que esa noche el cielo estuviera cubierto de nubes, con lo cual la ausencia total de luz habría aumentado los riesgos. Esta situación nos obliga a examinar la ruta que debió de seguir el ejército de Gunderedo para llegar hasta Fornelos y regresar después a sus naves.

Veamos pues el itinerario que pudo haber seguido. Fornelos es actualmente una pequeña aldea al sur de Santiago de Compostela, pero alejada doce kilómetros del camino tradicional de Iria hasta la ciudad compostelana. Lo cual quiere decir que el ejército de Gunderedo utilizó otro itinerario; posiblemente con la intención de no ser descubierto; pues en las Crónicas no se menciona que llegara a atacar esa ciudad, que como estaba muy bien fortificada es muy probable que la intención de Gunderedo fuera atacar otros lugares en los que esperaba encontrar menos resistencia. Tras la llegada de los normandos a Iria, nos encontramos con la posibilidad de que una parte del ejército regresara a las naves para recluir a los prisioneros y depositar a buen recaudo el fruto de los expolios realizados en las iglesias y en las poblaciones cercanas a Iria. Mientras que el resto del grueso del ejército continuó avanzando hacia Santiago de Compostela pero por un camino distinto del tradicional, hasta que llegó al lugar de Fornelos, que como bien opinan Vicetto ${ }^{91}$ y Carré Aldao, se refiere a un lugar de la aldea de San Miguel de Rariz, en Teo, al sur de Santiago de Compostela ${ }^{92}$.

Desde A Vacariza los normandos avanzaron hacia Iria siguiendo la antigua calzada que coincidía con los itinerarios de las vías romanas de la ría de Arousa, pues debido a los restos arqueológicos encontrados, «se puede asegurar sin dificultad que estas vías se utilizaron a lo largo de toda la Edad Media ${ }^{93}$. Desde $A$ Vacariza la vía seguía por Bejo, Imo, San Julián de Laiño, Dodro, Lestrove y Padrón ${ }^{94}$. Cubriendo así una distancia de 9 kilómetros. Después desde Iria a Fornelos pasaron otra vez por Padrón para continuar por Herbón, Juane, Pousada, Berjaos, Rialdomato y Fornelos. Un recorrido total de unos 14 kilómetros, que unidos a los 9 kilómetros anteriores suman 23 kilómetros. Con lo cual es probable que los normandos después de la batalla de Fornelos hubieran decidido pasar la noche en algún lugar, para evitar tener que volver a caminar otros 23 kilómetros más hasta sus naves; aunque tampoco se puede

\footnotetext{
91 VICETO, 1871: IV, 206.

${ }^{92}$ CARRÉ ALDAO, 1936: II, 813-814.

${ }^{93}$ FERREIRA PRIEGUE, 1988: 143.

${ }^{94}$ FERREIRA PRIEGUE, 1988: 143.
} 
descartar la posibilidad de que así lo hubieran hecho, en caso de haber contado con la ayuda de caballerías para llevar la carga.

La muy probable entrada de flota de Gunderedo en la ría de Arousa para desembarcar en el puerto de Juncaria se demuestra también por el hecho de ser esta ría la vía principal de acceso hacia el interior de Galicia. Circunstancia que debía de ser muy bien conocida por los navegantes ya desde tiempos anteriores, y que había determinado la construcción de diversas fortificaciones costeras; sobre todo las Torres del Oeste cerca del nacimiento de esa ría. El tradicional temor a las invasiones que pudieran venir por mar se agudizó en la época de Gelmírez pues, como se cuenta en la Historia Compostelana: «ciertamente temían los hispanos que los pueblos ingleses o los normandos u otros pueblos bárbaros atacaran por esta parte Galicia por mar, pues Oeste es como la llave y el sello de Galicia. Porque si pueblos extranjeros se apoderaran de este lugar, desde allí mismo, aprestada la fortificación, tendrían a su alcance atacar Galicia y devastarla» ${ }^{95}$.

Aunque en las Crónicas no se nos dice cuántos hombres se quedaron al cuidado de la flota, sabemos que se necesitarían por lo menos diez remeros en cada una de las naves para poder salir precipitadamente de los atracaderos en caso de necesidad. Pues hay que tener en cuenta que los gallegos habrían intentado destruir sus naves si éstas hubieran quedado abandonadas. Esta lógica suposición nos permite calcular que de un total de tres mil hombres que vendrían en la flota de Gunderedo, mil se quedaron vigilándolas y que el resto, o gran parte del resto pues exactamente es imposible saber el número de sus componentes, emprendió el camino hacia Iria; siendo conscientes de que en Iria y en las localidades por las que iban a pasar, la población ya estaría enterada desde por lo menos varias horas antes de la entrada de la flota en la ría de Arousa. Ahora bien, la anchura del río Ulla en el lugar donde fondearon las naves podría haber sido insuficiente; lo cual facilitaría el que fueran atacadas, y posiblemente incendiadas, desde la orilla opuesta, sin necesidad de llegar a un enfrentamiento cuerpo a cuerpo. Pero los normandos, al igual que sus antepasados vikingos, eran muy expertos en la navegación fluvial y en la planificación de las campañas bélicas, y sabían que el factor sorpresa facilitaba mucho sus victorias, ya que impedía que los enemigos pudieran reunir un ejército suficiente para hacerles frente. Eran conscientes de que para proteger sus naves en los fondeaderos fluviales se necesitaba ocupar ambas orillas. Por estos motivos, lo más probable es que la flota normanda desde el momento en que entró en la ría de Arousa rumbo a $A$ Vacariza se hubiera dividido en dos secciones: una navegó a lo largo de la orilla norte de la ría, y la otra hizo lo mismo por la orilla sur, con el fin de realizar incursiones en todos los centros habitados en los que podía encontrar resistencia u obtener algún botín.

${ }^{95}$ Historia Compostelana, II, 23, p. 343. (Edición de Emma Falque Rey. Madrid, 1994). 
Por las noticias históricas que conocemos, sabemos que antes de llegar a $A$ Vacariza los normandos devastaron el convento de monjas benedictinas de San Esteban de Boiro, en la ría de Arousa ${ }^{96}$, cuyos restos todavía no se han localizado, aunque se supone que se encuentran hacia el interior en algún monte ${ }^{97}$. También arrasaron la iglesia de San Cibrán de Calogo, en Vilanova de Arousa ${ }^{98}$, fundada por San Fructuoso en el siglo VII y reconstruida en el siglo IX ${ }^{99}$. Ambos centros religiosos situados en puntos opuestos de la ría. De este modo, y destruyendo los lugares por donde iban pasando, la flota siguió navegando hacia el interior de la ría hasta alcanzar el puerto de A Vacariza por encontrarse muy cerca de las Torres del Oeste, en el que previamente se habría acordado que debería fondear la totalidad de la flota; tras asegurarse de que las fuerzas enemigas procedentes de los lugares de retaguardia que habían arrasado no podrían atacarles porque habían quedado destruidas.

Después de una victoria bélica y de las consecuentes acciones de rapiña y expolio de los bienes de los vencidos, el comportamiento que solían seguir los normandos consistía en regresar lo más rápidamente posible a sus naves, cargados con los botines y llevando prisioneros. Sin embargo, aunque ésta era la táctica bélica tradicional, la larga estancia del ejército de Gunderedo en Galicia, un año según los cálculos de la mayoría de los investigadores, nos obliga a pensar en otro tipo de comportamiento; sobre todo, como cuentan las Crónicas, porque cogieron muchos prisioneros en los alrededores de Compostela, cuyo apresamiento les impediría continuar avanzando por el territorio gallego; de ahí la necesidad de llevarlos a las embarcaciones, en caso de que pensaran retornar a sus países del norte, o para recluirlos en un poblado en espera de su rescate o venta; como tenían por costumbre hacer, pues ésta era otra de las principales fuentes de ingresos que tenían los vikingos. Si esto realmente sucedió así, los normandos debieron de construir algún poblado fortificado cerca de sus embarcaderos en previsión de una estancia indefinida, y también porque la proximidad de sus naves les facilitaba la huida y las esporádicas singladuras necesarias para el control del territorio costero en el que se asentaban.

Sobre la localización de dicho supuesto poblado solamente podemos hacer una conjetura, aunque fundamentada en la existencia del topónimo Lodimanos: un lugar cerca de la desembocadura del río Ulla, que se menciona en un pergamino del 2 de enero del año $996^{100}$. Se sitúa ese lugar en los limites de una propiedad de la villa de Campaña, que estaban delimitados por el río Louro y con Cordeiro y Valga, y hasta

\footnotetext{
${ }^{96}$ LÓPEZ FERREIRO, 1899, 397.

${ }^{97}$ RÍOS PÉREZ, 1984: 93.

${ }^{98}$ ALMAZÁN, V, 1986: 102.

${ }^{99}$ SÁNCHEZ PARDO, 2010: 62.

${ }^{100}$ LÓPEZ ALSINA, 1988-2013: 234, n. 340. En: MORALES ROMERO, 1997: 78.
} 


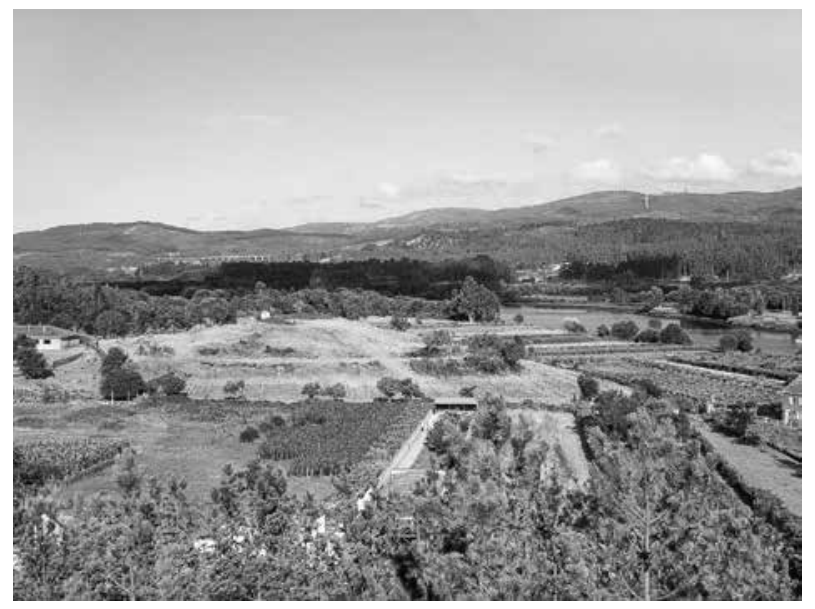

Fig. 6.

Lugar en el que suponemos que estaba «la ciudad de los Lodimanos». Es una pequeña colina en la orilla izquierda del río Ulla, muy cerca del monte do Porto y del antiguo puerto romano de Pontecesures. Tras su reciente limpieza con motivo de una plantación, quedó al descubierto el terreno escalonado en dos terrazas alrededor de la colina.

Fonte: Foto del autor, Verano de 2016.

en donde estuvo la ciudad de los Lodimanos ${ }^{101}$. El río Louro desemboca en el Ulla después de pasar por la parroquia de Cordeiro; y Valga se encuentra a poco más de dos kilómetros en línea recta desde Cordeiro. Mientras que la parroquia de Campaña está al norte de esas dos localidades, a poco más de dos kilómetros de Cordeiro y de Valga. Con lo cual resulta fácil delimitar el perímetro del territorio de esa propiedad de la villa de Campaña por su zona sur. El otro punto de referencia es la ciudad de Lodimanos, que tendría que estar situada al norte de Campaña en las cercanías de la orilla izquierda del río Ulla (Fig. 6). La comarca de Cordeiro, en la que suponemos que estaba la ciudad de Lodimanos, pertenecía también al amplio territorio de la denominada Tierra de Santiago que estaba bajo el dominio de la Iglesia de Santiago de Compostela.

Todos esos lugares están en la margen izquierda del río Ulla en la que también desembarcaría parte de la tripulación de la flota de Gunderedo, que tuvo que ser la que se ocupó de construir ese campamento o ciudad de Lodimanos hasta la que habrían conducido a sus prisioneros. Ciudad que debió de abandonarse tras la derrota del ejército normando de Gunderedo en el año 969, pues en ese pergamino, datado 27 años después, se dice que "estuvo la ciudad de los Lodimanos"; con lo cual se da a entender que en enero del año 996 ya no existía; probablemente debido a que fue destruida por los gallegos deseosos de venganza, al igual que quemaron muchas de las naves de Gunderedo y destruyeron gran parte de su ejército, obligando a huir a los supervivientes.

Las Crónicas no nos dan información sobre lo que pasó después de la victoria de Fornelos. Algunos historiadores suponen que los normandos siguieron avanzando

${ }^{101}$ MORALES ROMERO, 1997: 77, 132. LÓPEZ ALSINA, 1988: 225, n. 340. 
por el territorio gallego: que debieron de ocupar varios lugares y que casi consiguieron crear una nueva Normandía ${ }^{102}$; es posible que desde la impunidad de su base a orillas del río Ulla hubieran realizado varias acciones de rapiña: no sólo por las costas de Galicia, sino también por el interior del territorio. Pero siempre teniendo como campamento base el lugar de Lodimanos pues el río Ulla, además de facilitarles la comunicación con el mar, era una importante vía de penetración hacia el interior; así como también fuente de caza y pesca.

En el archivo de la catedral de Ourense se conserva un manuscrito, redactado alrededor del año 979, es decir, diez años después de la muerte de Gunderedo, en el que se dice que los normandos también destruyeron el monasterio de San Xoan da Cova, precisamente a orillas del río $\mathrm{Ulla}^{103}$. Los restos del cenobio de San Xoan da Cova se encuentran en la orilla derecha del río Ulla en una garganta delimitada por dos montes de laderas casi verticales que descienden hasta la orilla del río. Fue levantado en el siglo IX por monjes benedictinos, y en la época de Sisnando I, Alfonso III entregó el monasterio de San Juan de Cova al abad Panosindo: «quod est fundatum in ripa fluvii Ulie in caverna montis quan dicunt Montemsacrum» ${ }^{104}$. A unos tres kilómetros río arriba, también en la margen derecha, hubo una iglesia consagrada a los mártires San Verísimo, Máximo y Julia. A mediados del siglo IX era un monasterio dúplice pero posteriormente fue sólo de monjas, llamado San Breixo (Verísimo) de Donas. En la actualidad únicamente se conserva la iglesia parroquial de San Pedro de Donas, pero sin restos de esa época ${ }^{105}$. Es posible que también hubiera sido expoliado por los normandos pero no he encontrado testimonios que así lo confirmen.

En otra de sus incursiones también destruyeron las iglesias de Santiago de Boente (Arzúa) y la de Santa Eulalia (Baia) de Curtis ${ }^{106}$; que quedó en ruinas. De la Huerta comenta que estando el cenobio de Santa Eulalia de Curtis «a nueve leguas distante de La Coruña, se reconoce como los Bárbaros se internaron mucho en el País, lo que pudieron executar fácilmente, por hallarse los Naturales desprevenidos, e ignorantes de tan impensable invasión» ${ }^{107}$. Algunos años después, concretamente el 1 de julio de 995, la iglesia de Santa Eulalia la restauró San Pedro de Mezonzo, el obispo de Iria ${ }^{108}$.

\footnotetext{
102 ALMAZÁN, 1986: 100.

${ }^{103}$ MORALES ROMERO, 1997: 130 apud ALMAZÁN, 1986: 100. (Pergamiños monacais c 120).

${ }^{104}$ LÓPEZ ALSINA, 2013: 184, n. ${ }^{\circ} 220$.

${ }^{105}$ LÓPEZ FERREIRO, 1899: II, 256-257.

${ }^{106}$ IZQUIERDO DÍAZ, 2009: 91-92.

${ }^{107}$ DE LA HUERTA Y VEGA, 1736: II, 360-361.

${ }^{108}$ GONZÁLEZ PAZ, 2007: 360.
} 
Según la Crónica de Sampiro, que fue escrita en el siglo X por Sampiro, el obispo de Zamora, parece ser que los normandos llegaron hasta las montañas del Cebrero, y que posteriormente en el año 969 se acercarían hasta la costa con la intención de cargar en sus naves todos los tesoros y los bienes que habían obtenido durante sus correrías ${ }^{109}$. Pero cuando estaban embarcándose para regresar a sus tierras, el conde llamado Guillermo Sánchez (Gundisalvus, según Sampiro), posiblemente de Gascuña que había venido en peregrinación a Santiago de Compostela ${ }^{110}$, consiguió detenerlos y derrotarlos en una batalla que, según la Crónica de Sampiro, tuvo lugar en el año 969 durante el tercer año del reinado de Ramiro III. En esa batalla los gallegos mataron a Gunderedo e incendiaron gran parte de su flota; con lo cual se supone que este episodio supuso el final de esta importante incursión normanda que había empezado el año anterior. Almazán, siguiendo el relato de la descripción de esa batalla en España Sagrada (XIV, 471), dice que el conde se llamaba Gonzalo Sánchez ${ }^{111}$, igual que opina Morales Romero y García Álvarez, este último añade, además, que a ese conde lo ayudó San Rosendo ${ }^{112}$. Aunque Pires dice que dicho conde se llamaba Guillermo y que las fuentes posteriores cambiaron su nombre por el de Gonzalo $^{113}$. Sea uno u otro el nombre verdadero de ese conde, es un tema que no altera la realidad de los hechos, pues efectivamente las correrías de los normandos de Gunderedo terminaron tras la victoria de los gallegos comandados por ese conde. Lo que sucedió después no lo sabemos. López Ferreiro opina que por esas fechas los musulmanes intentaron penetrar en Galicia por el sur, pero fueron rechazados por San Rosendo ${ }^{114}$; mostrándonos así que fueron realmente los obispos gallegos, más que los reyes de León, los que defendieron el territorio gallego de los ataques normandos; teniendo que convertirse en aguerridos prelados, «señores de horca y cuchillo más que de mitra e hisopo», hasta que acabaron con sus acostumbradas incursiones ${ }^{115}$. Victoria que consiguió finalmente el arzobispo Gelmírez cuando bajo su dirección, los gallegos dispusieron de una flota de galeras mediterráneas con las que se defendieron con más efectividad las costas de Galicia, aunque posteriormente y por desidia de los gallegos, acabaron abandonadas en un fondeadero muy cerca de Padrón ${ }^{116}$. Pero esto es ya otra historia.

\footnotetext{
${ }^{109}$ MORALES ROMERO, 2004: 191.

${ }^{110}$ DÍAZ Y DÍAZ et al., 1990: 131, nota 42.

111 ALMAZÁN, 1986: 107.

112 MORALES ROMERO, 2004: 191. GARCÍA ÁLVAREZ, 1965: 100.

113 PIRES, 2012: 146.

${ }^{114}$ LÓPEZ FERREIRO, 1899: II, 356-357.

115 GONZÁLEZ LÓPEZ, 1957: 90.

${ }^{116}$ Historia Compostelana, Libro I, CIII; Libro II, XXI; LXXV.
} 


\section{AGRADECIMIENTO}

Con las siguientes personas tengo una deuda de gratitud por su ayuda y colaboración en la localización de varios lugares del itinerario terrestre de Gunderedo: Antón Bouzas Sierra, Cristina Mourón Figueroa, Baltasar Insua García ( $†$ ), Elena Martínez Muerza, María Castroviejo Bolibar, José Miguel Pérez Dieste, Natividad Deán Suárez y Manuel Cornide Castro Piñeiro, el cual me ayudó en el estudio de la fecha de la batalla de Fornelos.

\section{BIBLIOGRAFÍA}

ALMAZÁN, Vicente (1982) - Galiza nas sagas nórdicas. «Grial», n. ${ }^{\circ}$ 75, p. 1-17.

(1986) - Gallaecia Scandinava. Vigo: Editorial Galaxia.

(1995) - Las vías marítimas de peregrinación a Santiago de Compostela de los países escandinavos. In Actas del Congreso de Estudios Xacobeos. Santiago de Compostela: Xunta de Galicia, p. 19-27. (1997) - Earl Rögnvald's Journey from the Orkney Islands to Galicia in 1151-52. In Proceedings of the 4th International Conference on Galician Studies. S/l: Centre for Galician Studies; University of Oxford, vol. II, p. 421-429.

(1999) - The North of Europe and the Tradition of St. James. In VV. AA. St. James. Xacobeo' 99. Santiago de Compostela: Xunta de Galicia, p. 243-249.

ALONSO ROMERO, Fernando (2014) - La embarcación de la jarra romana del río Ulla (Galicia). "Anuario Brigantino», n. ${ }^{\circ}$ 37; p. 93-102.

ANDRADE CERNADAS, José. Ma (2004) - La Iglesia de Iria-Santiago, el mar y las fortalezas costeras de la Galicia Medieval. In ALMAZÁN, V., coord. - Padrón, Iria y las tradiciones Jacobeas. Santiago de Compostela: Xunta de Galicia, p. 21-35.

ARMADA PITA, Xose-Lois (2003) - El culto a Santa Eulalia y la cristianización de Gallaecia: algunos testimonios arqueológicos. «Habis», n. ${ }^{\circ} 3$, p. 365-388.

BALIÑAS PÉREZ, Carlos (2014) - El Territorium Saliniense y los orígenes altomedievales de la comarca de Arousa. In I Simposio de historia y patrimonio cultural de Vilagarcía de Arousa. Concello de Vilagarcía de Arousa, p. 70-103.

BRAVO GARCÍA, Antonio (1987) - La épica anglosajona. Oviedo: Universidad de Oviedo.

BREESE, Lauren Wood (1977) - The persistence of Scandinavian connections in Normandy in the tenth and early eleventh centuries. «Viator», 8, p. 47-61.

CAAMAÑO GESTO, José Manuel (1991) - O campamento romano de Cidadela (Sobrado dos Monxes. A Coruña). «Larouco», vol. 1, p. 119-122.

CAL PARDO, Enrique (2003) - Episcopado Mindoniense. «Cuadernos de Estudios Gallegos», anexo XXVIII.

CAMERON, P. N. (1982) - Saxons, Sea and Sail. «The International Journal of Nautical Archaeology and Underwater Exploration», vol. II, n. ${ }^{\circ} 4$; p. 319-332.

CARLSSON-BRANDT FONTÁN, Erik (2011) - El material constructivo latericio en el campamento romano de Cidadela (Sobrado dos Monxes, A Coruña). «Gallaecia», 30, p. 167-180.

CARRÉ ALDAO, Eugenio (1936) - Geografía del Reino de Galicia. Provincia de La Coruña. II. Barcelona: Alberto Martín.

CARRIEDO TEJEDO, Manuel (1996) - El segundo pontificado mindoniense de San Rosendo (955958) y su posterior influencia en la transmisión de su pontificado compostelano. "Estudios mindonienses», 12; p. 191-229. 
(2013) - Sisnando II de Santiago (951-968): «Totius orbis antistes». «Compostellanum: revista de la Archidiócesis de Santiago de Compostela», vol. LVIII, n. ${ }^{\circ} 3-4$; p. 543-599.

CASARIEGO, Jesús Evaristo (1965) - La costa Astur-Galaica a mediados del siglo XII. «Boletín del Instituto de Estudios Asturianos», n. ${ }^{\circ}$ LVI, p. 197-213.

CHEKIN, Leonid S. (2006) - Northern Eurasia in Medieval Cartography. Inventory, Text, Translation and Commentary. Turnhout: Brepols Publishers.

CHRISTENSEN, Arne Emil (1985) - Boats Finds from Bryggen. In The Bryggen Pappers. Oslo: Universitetsforlaget as. Bergen, vol. I, p. 47-280.

COSTA GARCÍA, José Manuel; VARELA GÓMEZ, David (2011) - A Cidadela después de Roma: introducción al estudio del yacimiento y su entorno durante el periodo medieval. «Gallaecia», 30, p. 181-194.

CRÓNICA de Santa María de Íria. Edición de José Antonio Souto Cabo. A Coruña: Cabido da S.A.M.I. Catedral. Seminario de Estudos Galegos. Ediciós do Castro. Sada.

CRUMLIN-PEDERSEN, Ole (2010) - Archaeology and the Sea in Scandinavia and Britain: A Personal Account. Roskilde: The Viking Ship Museum.

DE LA CRUZ DÍAZ MARTÍNEZ, Pablo (1983) - Los distintos «grupos sociales» del noroeste hispano y la invasión de los suevos. «Studia Historica», vol. I, n. ${ }^{\circ}$ 1, p. 75’87.

DE LA HUERTA Y VEGA, Francisco Javier Manuel (1736) - Anales de el Reyno de Galicia. Santiago de Compostela: en la Imprenta de D. Andrés Frayz, tomo II.

DE MEDINA, PEDRO (1964 [1563]) - Regimiento de navegación. Edición facsímile. Madrid: Instituto de España.

DÍAZ Y DÍAZ, Manuel. Cecilio; PARDO GÓMEZ, María Virtudes; VILARIÑO PINTOS, Daría, eds. (1990) - Ordoño de Celanova. Vida y milagros de San Rosendo. A Coruña: Fundación Pedro Barrié de la Maza.

DÍAZ MARTÍNEZ, Pablo C. (1992) - El alcance de la ocupación sueva de Gallaecia y el problema de la germanización. In VV. AA. - Galicia: da romanización á xermanización. Santiago de Compostela: Museo do Pobo Galego, p. 209-226.

DOMÍNGUEZ FONTÁN, Manuel (1987) - La Puebla del Caramiñal. La Coruña: Diputación Provincial. DOUGLAS, David C. (1942) - Rollo of Normandy. «The English Historical Review», vol. 57, n. ${ }^{\circ} 228$, p. $417-436$.

FERNÁNDEZ OCHOA, Carmen; MORILLO CERDÁN, Angel (1994) - De Brigantium a Oiasso. Una aproximación al estudio de los enclaves marítimos cantábricos en época romana. Madrid: Foro.

FERNÁNDEZ PACIOS, Juan Ramón (2008) - San Gonzalo bispo mindoniense. Santiago de Compostela: Consellería de Innovación e Industria; Dirección Xeral de Turismo; Xunta de Galicia.

FERREIRA PRIEGUE, Elisa (1988) - Los caminos medievales de Galicia. «Boletín Auriense». Ourense: Museo Arqueolóxico Provincial, anexo 9.

FERREIRO ALEMPARTE, Jaime (1999) - Arribadas de normandos y cruzados a las costas de la Península Ibérica. Madrid: Sociedad Española de Estudios Medievales.

FLÓREZ, Enrique (1747-1775) - España Sagrada. Theatro geográfico-histórico de la Iglesia de España. Madrid.

FRANCO MASIDE, Rosa María (2001) - La Via per loca Maritima: un estudio sobre vías romanas en la mitad noroccidental de Galicia. "Gallaecia», vol. XX, p. 217-248.

GALBÁN MALAGÓN, Carlos J. (2013) - En ese país que por siglos fue el final de la tierra. Una aproximación a los orígenes del sistema castral del obispado de Iria-Santiago (ss. IX-XI). «Territorio, Sociedad y Poder», n. ${ }^{\circ}$ 8, p. 85-104. 
GARCÍA ÁLVAREZ, Manuel Rubén (1963) - El Cronicón Iriense. Estudio preliminar, edición crítica y notas históricas. In Memorial Histórico Español. Madrid: Real Academia de la Historia, vol. L, p. 1-240.

(1965) - San Pedro de Mezonzo. Madrid: Industrias Gráficas Magerit.

(1968) - Sisnando Menéndez, mayordomo real y obispo de Santiago. «Compostellanum», vol. XIII, n. ${ }^{\circ}$ 2, p. 199-239.

(1971) - Galicia al filo del año mil. «Compostellanum», vol. XVI., n. ${ }^{\circ} 1-4$, p. 425-565.

GONZÁLEZ LÓPEZ, Emilio (1957) - Grandeza y decadencia del Reino de Galicia. Editorial Citania. Buenos Aires.

GONZÁLEZ PAZ, Carlos Andrés (2007) - Catro exemplos de fortificacións altomedievais galegas do século X: Castellum de Aranga, Castellum Minei, Castellum Berreti $e$ Castellum de Citofacta. In Rudesindus. «San Rosendo. O seu tempo e o seu legado». Congreso Internacional. Mondoñedo. Santo Tirso (Portugal) e Celanova. Santiago de Compostela: Consellería de Innovación e Industria, S.A. de Xestión do Plan Xacobeo, p. 359-368.

GRAHAM-CAMPBELL, James (1989) - The Viking World. Leicester: Windward.

GUILLOTEL, Hubert (1995) - Les vicomtes de León sont-ils les fondateurs de l'abbaye de Saint-Mathieu? In TANGUY, Bernard; CLOÎTRE, Marie-Claire, ed. - Saint Mathieu de Fine-Terre: Actes du colloque de Plougonvelin, 23-24 septembre 1994. Brest: Centre de Recherche Bretonne et Celtique, p. 131-151.

HERNÁNDEZ FIGUEIREDO, José Ramón (2007) - San Rosendo. Obispo de Mondoñedo, fundador de Celanova y pacificador de la Gallaecia. Madrid: Biblioteca de Autores Cristianos.

HISTORIA Compostelana. Edición de Emma Falque Rey. Madrid: Editorial Akal, 1994.

HUTCHINSON, Gillian. (1994) - Medieval Ships and Shipping. London: Leicester University Press.

ISLA FREZ, Amancio (1992) - La sociedad gallega en la Alta Edad Media. Madrid: Consejo Superior de Investigaciones Científicas. Madrid.

IZQUIERDO DÍAZ, Jorge Simón (2009) - Os Vikingos en Galicia. Santiago de Compostela: Edicións Lóstrego.

LIBER Sancti Jacobi. Codex Calixtinus. Traducción de Abelardo Moralejo, Casimiro Torres; Julio Feo. Reedición de Xosé Carro Otero. Santiago de Compostela: Xunta de Galicia, 1992.

LÓPEZ ALSINA, Fernando (1976) - Introducción al fenómeno urbano medieval gallego, a través de tres ejemplos: Mondoñedo, Vivero y Ribadeo. Santiago de Compostela: Universidad de Santiago de Compostela.

(1988 / 2013). La ciudad de Santiago de Compostela en la Alta Edad Media. Santiago de Compostela: Universidad de Santiago de Compostela. Consorcio de Santiago.

LÓPEZ FERREIRO, Antonio (1898-1899) - Historia de la Santa A. M. Iglesia de Santiago de Compostela. Santiago de Compostela: Seminario Conciliar Central.

LOSADA, Miguel (2014) - Viaxe ó castelo de Cerveira. Parte primeira. «Fol de Veleno», n. ${ }^{\circ}$ 4, p. 193-212.

LUCAS ÁlVAREZ, Manuel (1998) - Tumbo A de la Catedral de Santiago. Santiago de Compostela: Seminario de Estudios Gallegos. Cabildo de la S.A.M.I. Catedral.

MARTÍNEZ GRUEIRA, Heitor (2010) - La marina del Atlántico. «Revista General de Marina», p. 805-812.

MARTÍNEZ SÁIZ, Pablo (1969) - El tiempo pascual en la liturgia hispánica. Madrid: Instituto Superior de Pastoral.

MCGRAIL, Sean (1981) - Medieval Boats, Ships and Landing Places. In MILNE, G. et. al. Waterfront Archaeology in Britain and Northern Europe: a review of current research in waterfront archaeology in six European countries, based on the papers presented to the First International Conference on Waterfront Archaeology in North European Towns held at the Museum of London on 20-22 April 1979. London: Council for British Archaeology, p. 17-23.

(1987) - Ancient Boats in N.W. Europe. London: Longman. 
(1989) - Pilotage and navigation in the times of St. Brendan. In DE COURCY IRELAND, John; SHEEHY, David. C., eds. - Atlantic Visions. Dublin: Boole Press, p. 25-35.

(1993) - Prehistoric Seafaring in the Channel. In HEALY, Frances; SCARRE, Chris, eds. - Trade and Exchange in Prehistoric Europe. Oxford Oxbow Books, p. 199-210).

MÍNGUEZ, José María (1985) - Los hombres del Norte invaden el Imperio. "Cuadernos Historia», n. ${ }^{\circ} 16$, p. $4-12$.

MORALES ROMERO, Eduardo (1997) - Os vikingos en Galicia. Santiago de Compostela: Universidade de Santiago de Compostela.

(2004) - Historia de los vikingos en España. Madrid: Miraguano, S. A. Ediciones.

MUCKELROY, Keith (1978) - Maritime Archaeology. Cambridge: Cambridge University Press.

NAVAZA BLANCO, Gonzalo (2007) - Toponimia de Catoira. Catoira: Concello de Catoira.

Ó CORRÁIN, Donnchadh (1998) - The Vikings in Scotland and Ireland in the ninth century. «Peritia», vol. 12, p. 296-339.

OLSEN, Olaf; CRUMLIN-PEDERSEN, Ole (1978) - Five Viking Ships from Roskilde Fjord. Copenhagen: The National Maritime Museum.

PIRES, Hélio Fernando Vitorino (2012) - Incursões no Ocidente Ibérico (844-1147): Fontes, História $e$ Vestigios. Lisboa: Faculdade de Ciências Sociais e Humanas da Universidade Nova de Lisboa. Tese de Doutoramento en História Medieval.

PORTELA SILVA, Ermelindo y PALLARES, María del Carmen (1987) - Elementos para el análisis de la aristocracia alto-medieval de Galicia: parentesco y patrimonio. «Studia Histórica», vol. V, p. 17-32.

PRICE, Neil S. (1989) - The Vikings in Brittany. London: Viking Society for Northern Research. University College.

QUIRÓS CASTILLO, Juan Antonio (2012) - Los castillos altomedievales del cuadrante noroccidental de la Península Ibérica. In QUIRÓS CASTILLO, J. A. y TEJADO SEBASTIÁN, eds. - Los castillos altomedievales en el Noroeste de la Península Ibérica. Vizcaya: Universidad del País Vasco, p. 17-27.

RÍOS PÉREZ, Juan Manuel (1984) - Boiro, Concejo Gallego. Boiro: Ayuntamiento de Boiro.

RODRÍGUEZ NÚÑEZ, Clara (1993) - El monasterio de Nuestra Señora de Valdeflores de Viveiro. «Estudios Mindonienses», n. ${ }^{\circ}$ 9, p. 441-539.

ROLDÁN CASTRO, Fátima (1987) - Los Mayus. A propósito de un texto atribuido a Al-Udri. «Philologia hispalensis», n.o 2, p. 153-158.

SÁNCHEZ ALBORNOZ, Claudio (1981) - Estudios sobre Galicia en la temprana Edad Media. A Coruña: Fundación Pedro Barrié de la Maza.

SÁNCHEZ PARDO, José Carlos (2010) - Los ataques vikingos y su influencia en la Galicia de los siglos IX-XI. «Anuario Brigantino», n. ${ }^{\circ} 33$, p. 57-86.

SCHEEN, Rolf (1996) - Viking Raids on the Spanish Peninsula. «MILITARIA. Revista de Cultura Militar», n. ${ }^{\circ}$ 8; p. 67-88. Madrid: UCM.

TANGUY, Bernard (1995) - Saint-Mathieu. Le haut Moyen Age: Légende et histoire. In TANGUY, Bernard; CLOÎTRE, Marie-Claire, eds. - Saint Mathieu de Fine-Terre: Actes du colloque de Plougonvelin, 23-24 septembre 1994. Brest: Centre de Recherche Bretonne et Celtique, p. 31-48.

UNGER, Richard, W. (1980) - The Ship in the Medieval Economy. 600-1600. London: Croom Helm Ltd. URÍA RIU, Juan (1955) - Los normandos en las costas del reino de Asturias en el reinado de Ramiro I (844). «Boletín del Instituto de Estudios Asturianos», año IX, n. ${ }^{\circ}$ XXVI, p. 356-381.

VICETO, Benito (1865-1873) - Historia de Galicia. Ferrol: Nicasio Taxonera.

WESTFALL THOMPSON, James (1915) - The Commerce of France in the Ninth Century. "Journal of Political Economy», vol. 23, n. ${ }^{\circ}$ 9, p. 857-887. 



\title{
OS MADJUS ATRAVÉS DO ESPELHO: ALGUMAS GLOSAS EM TORNO DA INCURSÃO DE 844
}

\author{
HERMENEGILDO FERNANDES*
}

\section{I.}

A história das incursões vikings, a quem os árabes do al-Andalus chamaram Madjus $^{1}$, teve na historiografia uma repercussão talvez maior do que o seu real impacto na Hispânia dos séculos IX e X poderia justificar. Tal destaque poderá ficar tanto a dever-se às marcas psicológicas imediatas provocadas pela violência dos ataques e, sobretudo, pela estranheza suscitada pelos seus perpetradores, o que justificará o largo destaque a eles dado pelas narrativas históricas do período, como ao espaço dedicado por Dozy ao tópico no tomo II das Recherches ${ }^{2}$. Muito inspirado pela erudição desenvolvida no quadro do romantismo nórdico sobre as raízes das construções nacionais, assim como pelo papel desempenhado pelos ataques vikings na crise do império carolíngio depois da batalha de Fontenai (841), a perspectiva que Dozy deduz das fontes poderá ser vista como khalduniana, no sentido em que parece ser sensível ao carácter sistémico das incursões, enquanto fenómeno que globalmente atinge os estados de natureza imperial que estão no lugar do império romano, quer eles sejam cristãos, como o carolíngio, ou parte do «bilad al-Islam», como o emirado

\footnotetext{
* FLUL/Centro de História da Universidade de Lisboa.

1 Sobre o sentido do conceito de Madjus, (ou ainda de Al-Madjus al-Urdumaniyyun) dominante entre os historiadores do Magrebe e al-Andalus para designar os vikings, e a analogia com o zoroastrismo, cf. MELVINGER, A., "al-Madjus", s.v. Encyclopédie de l'Islam, $n$. ed..

2 DOZY, 1881: 250-371.
} 
de Córdova. Dito de outra forma, entre as neo-Romas civilizadas e as longínquas periferias pagãs. Como sempre a operação de Dozy assenta em bases estritamente textuais: assim, parafraseia longamente textos de Nuwairi, Ibn Idhari, Ibn al-Qutiya, Ibn Dihya e um fragmento de Ibn Hayyan (publicando no apêndice XXXIV os textos em árabe de todos eles, excepto de Ibn Idhari), que lhe servem para reconstruir uma narrativa possível, mas assumidamente desconexa, devido às contradições internas dos textos, sobre a história das incursões dos Madjus no al-Andalus. A descoberta em Fês da segunda parte do Muqtabis de Ibn Hayyan ${ }^{3}$, publicado apenas há uma vintena de anos pela dupla Corriente/Makki, haveria de servir a E. Lévi-Provençal, cuja síntese domina o panorama da história andalusi de meados do século XX, para dar novo fôlego aos estudos sobre as incursões dos Madjus. Tudo o que desde então se escreveu repousa de forma mais ou menos próxima na leitura do Muqtabis por ele feita, centrando-se na determinação da cronologia e do impacto directo das incursões, assim como no estudo da relação destas com o nascimento de uma rede de ribatat ao longo da costa. No que respeita ao Ocidente do al-Andalus, em particular visado pelos ataques, será difícil acrescentar às sínteses de C. Picard, quer na sinopse de história do Gharb ${ }^{4}$ quer na história do Atlântico muçulmano ${ }^{5}$, ou de $\mathrm{H}_{\text {. Pires }}{ }^{6}$, em tese recente onde se sistematiza o estado actual dos nossos conhecimentos sobre a história das incursões vikings na costa ocidental andaluza.

A minha perspectiva será aqui outra: menos do que a história - muito conhecida - das incursões dos Madjus interessa-me restituir um ponto de vista, o dos andaluzes, através do discurso oficial ou das elites espelhado nas crónicas, assim como o impacto real da interacção. Em causa está avaliar como as incursões e os processos defensivos que elas despoletam, permitem observar sistemas organizados de comunicação política e de governo no interior do emirado, assim como activar vínculos entre o poder central e as periferias e entre aquele e outros poderes autónomos de facto como aqueles que controlam a marca superior. Em segundo lugar, perceber como as incursões dão uma oportunidade para revelar a rede de comunicação diplomática do emirado, que constitui, por assim dizer, o seu espaço, através da rede de dependências que mantém no Magrebe, desvelando escalas de intervenção aliás progressivamente mais diáfanas, como se percebe pela embaixada enviada ao rei dos Madjus suscitada logo pela primeira intervenção de 844. Por último, creio que as incursões suscitam a revelação de alguns indícios sobre os mecanismos de integração social no al-Andalus, num momento em que o processo de criação de uma sociedade andaluza está numa fase crítica, correspondendo a cronologia das incursões

\footnotetext{
3 Uma síntese da história do ms. em PENELAS \& MOLINA, 2011: 229, n.1.

4 PICARD, 2000: 209.

5 PICARD, 1997.

6 PIRES, 2012: 90 e ss.
} 
do século IX à fase imediatamente anterior e contemporânea da crise dos mártires de Córdova e da primeira Fitna. Não creio, porém, que, ao contrário do que sucedeu na Europa de além Pirenéus, a presença cíclica dos Madjus tenha desempenhado um papel central na crise da sociedade andaluza. Isto por razões que importará observar.

\section{II.}

A primeira observação implica reconhecer que, ao invés do que se estava a passar pela mesma altura na Britânia dos reinos anglo-saxões e do que se passaria na costa atlântica da Francia Ocidental durante o século X, no al-Andalus nunca as incursões dos Madjus deram lugar a assentamentos permanentes, se exceptuarmos a residual implantação no Baixo Guadalquivir de elementos deixados para trás depois da expedição contra Sevilha de 844. A sua rápida integração na sociedade andaluza, pela dupla via da islamização e da especialização agropecuária, que os transformará em pacíficos fornecedores de queijos à cidade do Guadalquivir, não deve no entanto fazer esquecer a excepcionalidade deste percurso. A ausência de colonização é particularmente eloquente nas costas atlânticas do al-Andalus e da Hispânia cristã a norte, pelo contraste que evidencia com as potencialidades oferecidas pelas condições naturais. De facto, tanto a densidade da hidrografia, potenciada pelo número de estuários com boa acessibilidade e possibilidade de navegação fluvial, do rio Minho para sul, como a existência de profundos entalhes naturais na costa, criando condições análogas às dos fiords de onde uma parte importante dos Madjus eram originários, pareciam suscitar a sua instalação permanente. Se a isso somarmos outra interessante condição, a existência de uma rede urbana desenvolvida de matriz antiga, teremos verificado todos os factores - e mais alguns - que estão por detrás das colonizações vikings em ambos os lados do canal da Mancha e do mar do Norte, o que torna ainda mais reveladora a ausência de vestígios dessa ocupação tanto no al-Andalus como na Hispânia cristã.

Essa mesma excepcionalidade é vincada pela total ausência de vestígios dos Madjus no registo arqueológico só explicável pela mesma falta de instalação permanente, ao invés do que sucede com os abundantes testemunhos da presença viking na costa leste da Inglaterra. Assim, em nenhum outro lado da Hispânia se registando notícia de instalação estável, as incursões, episódicas durante os séculos IX e X, e retomadas depois já de os Madjus se terem convertido ao cristianismo, hão de ser observadas sobretudo do ponto de vista do impacto que causam na sociedade andaluza, quer em resultado das práticas de saque e tomada de cativos, quer na natureza da reacção organizada que desencadeiam. Nesta última repousam a maior parte dos problemas historiográficos despertados pelas incursões, já no que respeita às medidas de fortificação, urbana e litoral, já na plausível articulação entre elas e o desenvolvimento da rede de ribatats na costa andaluza. No que respeita às costas do Gharb al-Andalus, 
face mais exposta a ataques provenientes do Atlântico, e as primeiras visadas pelas incursões, numa extensão de costa com muitos pontos de articulação fluvial com o interior e que por isso se apresentam como ideais para os processos de penetração habituais nos Madjus, de Lisboa até Sevilha, só uma análise muito fina dos materiais arqueológicos recuperados nos últimos trinta anos permitirá tirar conclusões seguras acerca da ligação entre povoamento fortificado litoral (ou da fortificação das cidades acessíveis por via fluvial) e os ataques dos Madjus registados pelos textos árabes.

Creio, porém, que uma outra via relativa à recepção das incursões dos Madjus na sociedade andaluza foi ainda insuficientemente explorada: refiro-me à activação dos mecanismos defensivos e à oportunidade de concentração da estrutura do estado em torno do emir, particularmente num momento em que se acabava de renovar essa estrutura com base nos modelos centralizados do mundo Abássida, o que acontecera precisamente no período das primeiras incursões, as do emirado de 'Abd al-Rahman II. Por isso mesmo parece central a observação dos mecanismos despoletados pelas incursões, facilitada pela abundância de detalhes narrativos compilados no século XI por Ibn Hayyan. Em foco processos como os da comunicação e circulação de informação, coesão política entre o centro e as periferias e relação com poderes mediterrânicos que reconhecem ao emirado de Córdova preeminência simbólica.

Em suma, interessa-nos menos aqui a história das incursões em si mesmas, do que a das possibilidades que criam de reforço do poder do estado no interior da sociedade andaluza através do jogo de relações políticas a diferentes escalas, desde a esfera local dos governadores de província até à regional, no quadro de uma sociedade islâmica no Ocidente. Inequivocamente, como veremos, os Madjus, são na sociedade andaluza, mais do que eles próprios.

\section{III.}

Uma rápida mas necessária recapitulação da cronologia e do alcance territorial das incursões permitirá desde logo identificar alguns padrões. Primeiramente do ponto de vista cronológico: os ataques agrupam-se em dois momentos relativamente concentrados, um entre a fase final do emirado de 'Abd al-Rahman II, em 229/230 (844) e o começo do governo de Muhammad, em 244 (858-861); outro ao longo do califado de al-Hakam II, em 355 (966) e de novo em 360 (971) e 361 (972). O primeiro situa-se numa fase inicial da expansão viking e deve ser articulado com os ataques devastadoras contra as cidades e mosteiros do mundo carolíngio nos anos subsequentes ao tratado de Verdun. O segundo corresponde a uma fase de consolidação, quando já há assentamentos permanentes em Inglaterra e na costa Normanda. E é precisamente a crise do império carolíngio, assim como a incapacidade de resposta dos reinos anglo-saxónicos que explica o seu sucesso na Europa do norte. Inversamente, 
será necessário encontrar na conjuntura política andaluza razões para o fracasso na transformação das operações de saque em ocupação real do território.

A primeira conjuntura, a de meados do século IX, vem na sequência de um importante reforço da autoridade do emir conseguida por 'Abd al-Rahman II, logo desde o início do seu emirado, em 822, através de um hábil programa de translação dos modelos do califado Abássida - cujo prestígio, por então se estende à própria corte romana de Constantinopla do imperador Teófilo - da administração à cultura material, translação que o Muqtabis simboliza na figura do cantor Ziriyab, e que terá o seu manifesto arquitectónico na ampliação da mesquita aljama de Córdova, obra que parece ter estado em perigo pela mobilização de recursos do tesouro para a fortificação das cidades que as incursões tornavam necessária. $\mathrm{O}$ crescimento que se pode seguir no al-Andalus desse período explica a rapidez da mobilização na primeira incursão e ainda a capacidade para pôr em prática um programa de medidas que implica disponibilidade do tesouro. E a bravata do emir em insistir na manutenção da construção da mesquita em simultâneo com as obras de fortificação é também uma demonstração dessa prosperidade que, de resto, se deverá estender ao conjunto da economia mediterrânica no período, no império bizantino da dinastia amórica (e na subsequente, macedónica), como no oriente Abássida de al-Mảmun e de al-Mutasim, que é o verdadeiro motor económico do momento. A assimetria conjuntural entre o mundo carolíngio e o mediterrânico, com aquele a iniciar a longa recessão que só se virá a inverter pelo ano 1000 e este a prolongar uma fase de crescimento que se iniciara no século VIII, deve ser considerado como um factor explicativo para a diversidade de processos políticos entre as duas regiões durante esse período e, com maioria de razão, também para a recepção das incursões dos Madjus. No al-Andalus esse crescimento quase parece soçobrar durante a Fitna da segunda metade do século, isto é, durante o longo processo de colapso do poder central que se inicia justamente com Muhammad, emir aquando das incursões de 858-861. Não será este o lugar para discutirmos o lugar dos Madjus na debilitação do poder do emir. Chegará no entanto sublinhar que estes ocupam nos registos históricos relativos a este período um lugar relativamente modesto, diríamos secundário, se comparado com o protagonismo das várias duwal (casas) que afirmam por todo o lado um poder de dimensão regional mas de facto autónomo face a Córdova, entre as quais a dos Banu Marwan nesse mesmo Ocidente que fora nas últimas décadas o principal alvo das incursões vindas do Atlântico. Aliás a ameaça dos Madjus pareceria ao emir, nesse começo da década de 60, menos preocupante que a dos «galegos», isto é, os cristãos do norte asturiano, ou dos senhores locais revoltosos. É deles, e não dos Madjus que tratam primordialmente os textos.

A segunda vaga de incursões, da qual não tratarei aqui, acontece numa conjuntura que apresenta muitas analogias com a anterior, do ponto de vista da história 
do al-Andalus. Com efeito, o emirado de al-Hakam II corresponde a uma fase de estabilização, possível graças ao recentramento político e simbólico operado nas décadas precedentes em torno de al-Nasir. Mais do que nunca inspirado em modelos orientais, $\mathrm{o}$ agora califado atingiu uma estabilidade acompanhada por um crescimento económico que o transformara no principal motor da economia do ocidente, tanto islâmico como cristão. Neste quadro as incursões dos vikings não parecem mais significativas que um incómodo passageiro, que não deixa de merecer a atenção de Galib, comandante do exército, a par de outros conflitos nas fronteiras, em particular no Magrib. Os Madjus integram-se assim numa cartografia do conflito mais alargada, num momento em que tem lugar uma reorganização da ordem política mediterrânica, em que se gerem as ameaças vindas da costa atlântica, ao mesmo tempo que se disputa a hegemonia mediterrânica aos Fatímidas que haviam acabado de conquistar o Cairo (969) e aos Ziridas que governam o Magrebe em representação daqueles (972). Em Constantinopla, a dinastia macedónica iniciava o seu período dourado que, com Basílio II, levaria à maior extensão do Império desde Justiniano. Nesta consolidação do mundo em torno de dominações imperiais os Madjus só poderiam ter, por enquanto, um lugar de figurantes.

Importaria ainda observar outras regularidades, aquelas que afectam o alcance territorial das incursões na esfera andaluza. O próprio Muqtabis nos dá uma chave de compreensão geográfica, na frase que serve para marcar a primeira chegada dos vikings: «Nos fins de $229 \mathrm{~h}$. apareceram as naves dos normandos que foram conhecidos no al-Andalus como madjus na costa ocidental do al-Andalus, detendo-se em Lisboa como primeiro ponto de entrada [...]» $»^{7}$. Aqui estará um primeiro padrão do ponto de vista geográfico, a predilecção dos Madjus pelas áreas estuarinas, Lisboa, onde o estuário se alarga em golfo, sendo o verdadeiro porto de entrada no al-Andalus para quem se apresenta vindo do Atlântico Norte. O extremo ocidente, sempre periférico nas contas políticas do poder cordovês, adquire assim, por via destes invasores, um novo protagonismo.

Mas as áreas de impacto, se contabilizarmos o conjunto das incursões, estendem-se muito mais além, abrangendo a quase totalidade da costa meridional da antiga Lusitânia e a da Betica, de Santarém a Múrcia (Tudmir), do Gharb extremo até ao Sharq, numa zona de grande densidade da presença romana e de exposição tradicional, desde antes da romanização, às influências orientalizantes vindas do Mediterrâneo. Como era usual nas incursões dos normandos o critério da acessibilidade a partir de ligações costeiras é determinante como se pode verificar dos casos dos ataques a Lisboa, Saltes ou Sevilha, mas não exclusivo (veja-se a este título o caso da incursão

7 Muqtabis, II-1, 185v. 
a Beja). ${ }^{8} \mathrm{O}$ critério unificador será antes o do peso e da capacidade de atracção das antigas metrópoles romanas que conservariam então muito do seu antigo brilho, quer nas funções centrais, quer na população e riqueza, quer no edificado, capaz por si só de atrair incursões que visam, antes de mais, o saque. Creio, no entanto, que, neste mapa algo difuso, o alvo central nem por isso deixam de ser duas zonas estuarinas, o complexo Tejo/Sado, unido pela península de Setúbal dominada pelo hisn de Balmala, onde tanto Lisboa como Alcácer são visadas, e o Guadalquivir até Sevilha.

Estas últimas observações têm sido determinadas pelo confronto entre as rotas das incursões e os dados da geografia física mas sobretudo entre aquelas e a permanência de estruturas territoriais da antiga Hispânia romana. Seria útil submetê-los também ao que sabemos sobre a organização territorial do al-Andalus. O que nos revelam os episódios das incursões sobre essa organização e em que medida a transformam? Todo o sistema Omíada de administração do território estava, como é sabido, assente na dualidade entre as circunscrições interiores do território (Kuwar), mais pequenas, fortemente urbanizadas e com uma capitalidade genericamente entregue a antigos municípios, nesse sentido herdeiras dos conventii - ainda que se possa discutir a linearidade da filiação - e as marcas (Tughur) que organizavam espaços transicionais, mais militarizados, mas, sobretudo, mantendo com o poder central relações muitas vezes difusas, onde se centrava uma parte importante da absorção da conflitualidade e das relações com os principados cristãos do norte e, mais ainda, com o império carolíngio. Ora, vindo do litoral, atlântico e mediterrânico, as incursões dos Madjus subvertem a ordem natural pressuposta por esta organização territorial. De facto é o litoral da Kura (sahil) que é afectado, o que introduz um elemento de instabilidade em regiões normalmente a salvo de incursões externas ao próprio al-Andalus. Ao invés, as marcas não são afectadas. Esta inversão explica a impreparação da maior parte das cidades para os ataques, como acontece de forma óbvia em Sevilha, onde os vikings se apoderam momentaneamente da cidade sem oposição de monta, nela fazendo o que tinham já feito nos anos anteriores nas cidades e mosteiros carolíngios da área do Loire. Explica ainda a dimensão do choque sentido pelos andaluzes assim como as medidas de fortificação que o emir entende levar a cabo em perímetros fortificados datáveis da crise do império romano e que, desde então, não pareciam ter sofrido obras significativas. Imanente como era ao sistema de organização territorial andaluz, parece admissível que nem mesmo o perigo apesar de tudo passageiro representado pelos Madjus tenha sido suficiente para subverter esta correlação entre as Tughur e as Kuwar, militarizando estas últimas, em parte porque o emir temia que cidades fortificadas pudessem resistir melhor à sua autoridade. O mesmo é dizer,

\footnotetext{
8 Mas uma fonte do século XIII, Ibn Idhari, fala na costa (litoral) de Beja, a propósito da incursão de 858-860, cf. PIRES, 2012: 131.
} 
que a natureza do sistema político andaluz assentava simultaneamente na robustez económica e na debilidade militar do sistema urbano que servia de base ao regime. E é precisamente esta dualidade que o torna uma presa ao mesmo tempo apetecível e fácil para os Madjus, como para outros invasores mais familiares: as condições de ruína das muralhas romanas que irão oferecer Évora, em 913, ao saque de Ordonho II das Astúrias, lembram em tudo os ataques vikings do século anterior. Será necessário esperar por uma mudança radical no equilíbrio de forças no interior da Península Ibérica, a partir de meados do século XI, para se assistir a uma mudança consistente na estrutura de organização territorial, marcada por uma tendência para a militarização, fora dos espaços que tinham conhecido um processo de encastelamento logo desde a Fitna do século IX.

Tudo o que acabámos de dizer remete para uma hipótese, a de que o sistema de defesa face às incursões dos Madjus assentará muito mais numa mobilidade de tropas em que o circuito de informação é vital. Parece-me ser aqui, e não nas fortificações, que reside a essência da capacidade de reacção, pelo que, ao menos neste caso, o velho problema historiográfico da sobrevivência das fortificações romanas, e do mau estado destas, muito visível em inícios do século $\mathrm{X}$, talvez não deva ser sobrevalorizado.

\section{IV.}

São esses mecanismos de circulação de informação que me proponho estudar de seguida, a partir de uma fonte única, o Muqtabis de Ibn Hayyan, compilação do século XI que, na complexidade de fontes primárias que estão na sua base, revela diversos níveis estratigráficos de informações sobre os ataques. Reconheça-se desde logo, o que seria desnecessário para os cultores dos textos árabes do período, que as fontes mais precisas e detalhadas para a história dos Madjus no Mediterrâneo são andaluzas (árabes), tendo estas paralelo apenas em textos nórdicos mais recentes, em particular o Morkinskinna ${ }^{9}$, que se refere exclusivamente a uma grande incursão de inícios do século XII, muito posterior, pois, à cristianização dos Madjus.

$\mathrm{E}$ a fonte mais significativa para este aspecto como para outros da história do al-Andalus deste período é o Muqtabis de Ibn Hayyan, compilação do século XI que, no trecho respeitante aos ataques dos Madjus, recolhe sobretudo autores da centúria anterior ${ }^{10}$. Entre eles estão Ahmad al-Razi ${ }^{11}$, 'Isa b. Ahmad al-Razi ${ }^{12}$, ambos prove-

\footnotetext{
9 Morkinskinna (2000). Cf. sobretudo pp. 316-317, os processos mantendo-se análogos aos das incursões dos séculos IX e X, apesar da cristianização.

${ }_{10}$ Um panorama de historiografia do al-Andalus em MOLÉNAT, 2007. Sobre Ibn Hayyan, filho de um secretário de Al-Mansur que mantém com o califado a mesma relação que os historiadores romanos do alto império dedicavam à memória da República, morto já no final do regime taifa, em 469/1076, cf. IDEM: 28-31.

11 274/888-344/955, cf. PONS BOIGUES, 1898: n 23, p. 62-66 e MOLÉNAT, 2007: 25.

12 Filho e continuador do precedente, morto em data desconhecida, provavelmente durante a segunda metade do século X, cf. PONS BOIGUES, 1898: nº 41, p. 82.
} 
nientes de uma família ligada à corte desde o tempo do emir Muhammad, al-Qurashi $^{13}$, Ashshabinasi ${ }^{14}$ e Ibn al-Qutiyyah ${ }^{15}$, que nos dão das incursões diferentes versões concordes no essencial. A ligação destes autores aos meios áulicos, por laços de parentela, clientelares e de serviço, assim como o saudosismo Omíada do compilador do século XI são aqui um vector a reter, pelo que revelam de intencional na centralidade dos processos de comunicação política e de propaganda dinástica no olhar das próprias fontes.

Assinale-se, por outro lado que o próprio processo de preservação dos registos acaba por explicar muito da evolução da perspectiva historiográfica sobre o tópico. A extensa compilação de fontes sobre as incursões dos Madjus publicada por Dozy em 1881 manteve-se durante quase um século como a referência incontornável. A descoberta por Lévi-Provençal de um manuscrito de uma parte perdida do Muqtabis de Ibn Hayyan viria no entanto permitir rever profundamente a história das incursões, como se evidencia no capítulo de síntese a elas dedicado na obra maior do autor, em que segue de perto, sintetizando-a, a narrativa do Muqtabis. Como Levi-Provençal nunca publicou a fonte que tinha na sua posse, foi só na passagem do milénio que o texto reentrou no circuito dos historiadores, primeiro em fac-simil ${ }^{16}$, depois em tradução ${ }^{17}$. É essencialmente sobre esse texto que aqui me centrarei, pelo que os comentários seguintes dizem todos respeito à primeira incursão, a de 844 , talvez a mais interessante, pela novidade que representa na organização política andaluza, o que a torna num estudo de caso relevante do ponto de vista que me interessa, o da activação dos mecanismos de reacção e daquilo que eles revelam sobre essa sociedade política.

\section{V.}

O primeiro facto a anotar será o do peso relativo das incursões dos Madjus no conjunto da compilação de Ibn Hayyan e, em particular, no volume do Muqtabis (II) que abrange os anos de 796 a 847 e que praticamente termina com a secção sobre as incursões, no ano de 844 (229 H.). Do ponto de vista quantitativo, a repercussão das incursões na fonte é relevante embora secundária se tivermos em consideração o lugar que ocupam na economia da narrativa (185r-188v, 312-322 trad.), sempre menor

\footnotetext{
${ }^{13}$ Hafiz sevilhano, deixou escrita uma história da mesma cidade, vivendo pelos começos do reinado de 'Abd al-Rahman III. Cf PONS BOIGUES, 1898: nº 100, p. 124-125 e Muqtabis II-1, p. 316, n. 671.

14 Mu’awiya b. Hisham al-Shabinasi, autor de uma «História da dinastia Omíada no al-Andalus» (Tarih fi dawla Banu Marwan bi-l-Andalus), que deve ser a obra que serve de fonte a Ibn Hayyan, é ele próprio descendente dos Omíadas e por isso ligado à dinastia reinante, visto ser tetraneto do emir Hisham I. Cf. PONS BOIGUES, 1898: no 102 , p. 125. $15 \mathrm{O}$ melhor conhecido de todos os historiadores citados por Ibn Hayyan na passagem referente aos Madjus, era descendente de Vitiza por linha feminina (de Sara sua neta), facto de que estava bem consciente, e cliente dos Omíadas por via do pacto que permitira a Olemundo, pai de Sara, guardar uma grande concessão territorial aquando da conquista árabe. A sua História da Conquista de Espanha estende-se até ao califado de 'Abd al-Rahman III de que é contemporâneo. Morreu em 367/977. Cf. PONS BOIGUES, 1898: n 45, p. 83 e ss, MOLÉNAT, 2007: pp. 25-26.

${ }^{16}$ VALLVÉ, 1999.

${ }^{17}$ MAKKI e CORRIENTE, 2001.
} 
que o tópico das rebeliões internas, verdadeiro leit-motiv dos historiadores andaluzes, numa sociedade em que a dissidência e a 'asabiyyah ocupam um lugar central. Menor ainda, por exemplo, que a larga passagem dedicada às inovações produzidas na corte de Córdova, nesse mesmo reinado de Abd al-Rahman II que assiste à primeira grande incursão dos Madjus, pela chegada do iraquiano Ziriyab (147v-154v, 193-215 trad.). Assim, se tomarmos a extensão de fólios ocupados como um indício sobre a percepção da importância relativa dos acontecimentos, a singular aparição de Ziriyab na corte cordovesa, proveniente de Baghdad, tem duas vezes mais importância que os meses de incursão normanda no ano de 844 que tantas destruições provocaram no litoral, em particular em Lisboa e Sevilha. Tal constatação, se por si mesma não pode ter valor absoluto, deve no entanto afinar o ângulo de aproximação às fontes recolhidas no Muqtabis e ao olhar particular que as enforma - a perspectiva dos círculos próximos à corte emiral.

Como se disse, é o Muqtabis uma compilação, de resto organizada em época dois séculos posterior a estes eventos. Não pode, nesse sentido, ser abordado como se de uma fonte única se tratasse. Apenas uma arqueologia do texto através da análise dos vários estratos que o compõem poderá ajudar a focar uma imagem, ou talvez antes um conjunto de imagens complementares. Já nos referimos ao conjunto de autores que neste caso servem de fonte a Ibn Hayyan que é, aliás como era prática na historiografia árabe, para quem um texto valia tanto como a autoridade das suas fontes - o processo é em tudo análogo, neste sentido, à construção dos processos de legitimidade textual em torno de uma fatwa - muito escrupuloso na sua identificação. Convém por isso considerar cada um dos relatos.

Todos eles se referem com grau diferente de detalhe e de selecção de eventos à mesma série de acontecimentos. Lévi-Provençal e depois dele H. Pires já deram deles uma tentativa de reconstrução ${ }^{18}$. Como não são os acontecimentos por si que aqui nos interessam alinhemos uma brevíssima analística prévia dos eventos de 844 . No começo do Verão do ano anterior de 843 (Junho), os Madjus tinham tomado Nantes, na embocadura do Loire e atacado depois Bordéus e Toulouse, remontando o Garonne. No Verão de 844, a 20 de Agosto, estão diante de Lisboa, com mais de cem embarcações, seguindo-se treze dias de combates ${ }^{19}$. Em princípios de Setembro a frota abandona Lisboa encaminhando-se para o golfo hispano-magrebino onde encontraram a embocadura do Guadalquivir ${ }^{20}$. Aí, uma parte dos navios continua

\footnotetext{
18 LÉVI-PROVENÇAL, 1967: 146 e ss. PIRES, 2012: 96 e ss.

19 Sobre as diferentes versões do ataque a Lisboa cf. PICARD, 2000: 209.

${ }^{20}$ No ms de Copenhaga, factício e interpolado no século XVII por Gabriel Rodríguez de Escabias, a notícia sobre o reinado de 'Abd al-Rahman II, dado erradamente como "filho de 'Abd al-Rahman", ocupa-se sobretudo da incursão de 844. O conceito de Madjus é aqui traduzido como hereges, o que está talvez próximo do sentido original. Atribui ainda o ataque a Sevilha a forças conjugadas destes hereges, e doutros, "a que chamam nombardos" (provavelmente por Lombardos). Uma pista que nenhuma outra fonte confirma. Cf. AL-RAZI, 1975: fls 107-108, p. 374.
} 
para oriente percorrendo o litoral da kura de Medina Sidonia, explorando o seu interior através do Guadalete e atacando a cidade portuária de Cádis. A outra parte interna-se no Guadalquivir em fins de Setembro e, depois de saquearem a alcaria de Coria del Rio, entram em Sevilha nos primeiros dias de Outubro. Tem início o saque da cidade que dura sete dias, embora uma parte importante da população a tivesse já abandonado, com o governador à cabeça. $\mathrm{O}$ remanescente é levado prisioneiro, incluindo muitas mulheres, para a ilha de Qabtil, a jusante, onde os Madjus tinham a sua base e se haviam fornecido dos cavalos com que tentam, sem grande êxito, raziar o interior. É entre essa ilha e Sevilha, que acabam por ser confrontados pela cavalaria (liderada por três personagens de que já falaremos), entretanto enviada pelo emir, de Córdova, para o al-Sharaf, a ocidente do rio, e, a 11 de Novembro, pelo grosso das tropas mobilizadas para o efeito e comandadas pelo eunuco Nasr. Os Madjus acabarão derrotados com graves perdas, mil homens, mais quatrocentos prisioneiros que foram executados diante das suas embarcações e, trinta navios queimados, o que corresponde a uma parte muito importante da frota e acabam por abandonar o cenário, sendo Sevilha reocupada pelos seus habitantes. Do ataque restavam apenas algumas bolsas isoladas de Madjus nas ilhas do Guadalquivir, que abarão por aceitar o Islão e instalar-se naquele que será o único episódio real de assentamento permanente resultante desta expedição. É provável que o episódio citado por al-Maqqari de um ataque a Beja depois de terem subido o Guadiana se possa situar no regresso, como compensação pelo fracasso em Lisboa e em Sevilha. De qualquer forma as embarcações restantes voltaram à Aquitânia para não mais serem vistas nos 15 anos seguintes.

Este é o fio sumário dos acontecimentos. Genericamente diz-nos aquilo que já sabíamos sobre a forma como os Madjus se movimentam, a escala a que operam e os objectivos das operações: uma rapidez de movimentos que contrasta com as grandes movimentações dos séculos III a V; uma escala de operação que transforma toda a fachada atlântica europeia, partilhada entre as antigas Gálias e Hispânia num único teatro de operações (sem ousar ainda a aventura mediterrânica que virá depois), os grandes estuários dos rios mais importantes, Loire, Garonne, Tejo, Guadiana, Guadalquivir, Guadalete, servindo de marcadores de posição de centros urbanos antigos e ricos ${ }^{21}$; saque metódico desses centros urbanos, não sem encontrarem uma resistência que parece ser bastante mais eficaz na Hispânia que na Gália.

\section{VI.}

Importaria agora decompor e glosar os vários relatos que compõem estratigraficamente a principal fonte para esta sequência de eventos, o Muqtabis de Ibn Hayyan,

\footnotetext{
21 A importância dos estuários no mapa mental pode ser avaliada através do peso que a hidrografia assume na cartografia. Um exemplo para o al-Andalus e o Magrebe, que ilustra um ms. do Kitab Surat al-Ard conservado na Biblioteca Topkapi, pode ser visto em ANTRIM, 2012: 118, fig. 53.
} 
valorizando a complexa trama de níveis de comunicação e de integração no interior da sociedade andaluza que me parece estar por detrás do insucesso da incursão e cuja valorização é provavelmente, mesmo, a sua mais relevante consequência.

\section{Relato $1^{22}$ (Ahmad al-Razi), ou o primado da política}

A ordenação dos relatos dir-nos-á alguma coisa sobre o processo historiográfico de composição do texto por parte do polígrafo cordovês do século XI. Com efeito, começar por Ahmad al-Razi, o «historiador» por excelência para os seus contemporâneos, implica desde logo uma opção na hierarquia das autoridades, ao mesmo tempo que se estabelece na abertura um relato base, sobre o qual os restantes vão operar como se de glosas se tratasse, acrescentando informação e iluminando certos pontos ${ }^{23}$.

Do ponto de vista que aqui escolhemos, o relato de al-Razi permite identificar um detonador para o processo de resposta às incursões, a carta enviada pelo governador de Lisboa, Wahballah b. Hazm, ao emir, dando-lhe conta da chegada dos Madjus à sua costa e detalhes sobre o número de embarcações. É esta missiva que permite ao emir reagir, o que implica o arranque de um processo de circulação de informação que se faz através do envio de cartas. Nesta primeira fase a chancelaria notifica os governadores das costas para que estivessem preparados, o que significa intervir no litoral (sahil), por oposição às marcas (tughur). A chegada dos Madjus a Sevilha faz arrancar a segunda e mais intensa fase do processo. Uma vez notificado acerca do saque de Sevilha, o emir faz arrancar uma força de cavalaria da que estava junto dele, com três dos seus comandantes, 'Abdallah b. Kulayb, Muhammad b. Said b. Rustum e 'Abd al-Wahid b. Yazid al-Iskandarani, logo reforçada por 'Abdallah b. Al-Mundhir e 'Isa b. Shuhayd ${ }^{24}$. O envio da cavalaria é desdobrado por nova carta circular, agora a todos os governadores, ordenando o levantamento geral, o que resultará numa concentração de tropas em Córdova que irão intervir no terreno comandadas pelo eunuco Nasr. É esta mobilização geral que determina o insucesso final da expedição dos Madjus. A derrota destes despoleta um novo processo de comunicação e propaganda, em parte visual, em parte utilizando a comunicação escrita. Dele faz parte a exibição dos restos mortais dos atacantes pendurados em postes e em troncos de palmeiras em Sevilha, assim como a comunicação da vitória às províncias. À exibição directa no local do ataque e à difusão da notícia em todo o al-Andalus vem somar-se um terceiro círculo informativo que abrange «os emires berberes da costa norte-africana (Aflah b. 'Abdalwahhab, senhor de Tahart cliente dos Omíadas

\footnotetext{
22 Fl. 185v, pp. 312-314 (trad.)

23 Anotaria que esta centralidade do relato de Ahmad al-Razi passou para a historiografia contemporânea, sendo ele a servir de base à reconstrução dos eventos por Lévi-Provençal que, à data em que escrevia, lia diretamente do manuscrito hoje na Academia Real de la Historia de Madrid, (1967), pp. 144-150.

24 Sobre 'Isa b. Shuhayd, membro de uma destacada família de origem oriental cliente dos Omíadas e hadjib de 'Abd al-Rahman II, cf. MEOUAK, 1999: 132-133.
} 
e a outros)» ${ }^{25}$. É a esse último círculo que é remetida a cabeça do chefe dos Madjus morto na batalha, assim como a de duzentos outros guerreiros, naquilo que é sem dúvida uma operação massiva de propaganda Omíada no Mediterrâneo ocidental, numa área magrebina que estava tradicionalmente articulada com a Hispânia e que, encontrando-se demasiado longe da esfera de influência Abássida, os Omíadas do al-Andalus sempre pretenderam tutelar ${ }^{26}$. Os despojos sangrentos da vitória permitem afinal à dawla agora andaluza reforçar o seu poder simbólico numa área que extravasa largamente o território por ela directamente controlado. A referência aos «clientes dos Omíadas» aí existentes remete justamente para esse tipo de controle difuso, feito de relações pessoais, por contraste com aquele exercido de forma directa sobre um território através de vínculos de natureza fiscal, militar e judiciária. Facto, aliás, que saía já reforçado pela pertença de pelo menos um dos comandantes citados à dawla magrebina dos Rustémidas.

As incursões dos Madjus são, assim, no relato central de Ahmad al-Razi, um acontecimento que permite revelar o processo de funcionamento do governo Omíada nas suas várias extensões territoriais, da corte de Córdova, às mais remotas províncias - que incluem a Marca Superior governada pelos Banu Qasi, a um deles, Lubb b. Musa, se atribuindo, en passant, a derrota dos invasores na kura de Sidonia - e à sua esfera de influência magrebina. Em causa estão duas esferas concêntricas de comunicação, uma directa, de territórios que obedecem a Córdova e correspondem a um sistema de administração central periférica estritamente peninsular; outra indirecta, que se supõe sob influência política da dinastia Omíada e que inclui um sistema de dominação assente na proximidade geográfica e no sistema clientelar (mawla ${ }^{27}$. Um sistema assente na comunicação escrita, marcada nas fontes como «cartas», entre governadores e emir, mas também visual, a circulação e a exposição de despojos humanos realizando uma poderosa função propagandística que as narrativas tornam perene.

\section{Relato $2^{28}$ ('Isa b. Ahmad al-Razi) ou de Ibn Rustum}

O relato de 'Isa é apresentado como um comentário da notícia anterior, o que faz pensar que a obra do filho não seria uma continuação da de Ahmad al-Razi, senão uma glosa com incorporação de muitos mais elementos. O excerto recuperado aqui por Ibn Hayyan tem precisamente essas características e, começando apenas com o

\footnotetext{
${ }^{25}$ Muqtabis II-1, fl. 185v, p. 314 (trad.). Sobre a relação com o Magrebe e os senhores Rustémidas de Tahart em meados do século IX, ver GAISER, 2013: 57.

${ }^{26}$ Sobre a complexidade político religiosa do Magreb central neste período e a importância dos principados Kharidjitas (os Rustémidas de Tahart) e Álidas no processo de islamização da região, por oposição ao espaço de controle remoto do califado Abássida, representado regionalmente pelos Aglábidas de Cairuão, cf. VALÉRIAN, 2011: 138-139.

${ }^{27}$ Confronte-se, a título comparativo, sobre a natureza descontínua e reticular do território enquanto exercício de poder no universo carolíngio e pós-carolíngio cf. MONNET, 2017: 25-26.

${ }_{28}$ Muqtabis II-1, fl. 186r-186v, pp. 314-316 (trad.).
} 
desembarque em Qabtil, vai centrar-se na conquista e saque de Sevilha, que narra com detalhes e precisão ausentes no texto do pai. Releve-se, por exemplo, a referência à existência de uma rabita em Coria, primeiro lugar saqueado pelos Madjus no Guadalquivir, a passagem sobre o massacre da mesquita que passou a ser chamada Mesquita dos Mártires, deixando traço na toponímia local, ou o ardil dos vikings que, retirados em Qabtil depois do saque, abrem um período de resgate, apenas para poderem massacrar quem lá se dirigisse. Também aqui o processo de comunicação assume relevância, embora menor, reduzindo-se a uma referência à carta circular enviada às kuwar e às tughur, isto é, às kuras e às marcas. Esta especificação merece sublinhado, no que contém sobre a universalidade da mobilização em todo o território andaluz. $\mathrm{O}$ contraste mais significativo com o texto anterior está no entanto no protagonismo dado a uma personagem, o alcaide Muhammad b. Sa’id b. Rustum, que é não só dado como o comandante único do esquadrão de cavalaria saído de Córdova logo após o ataque a Sevilha, como o autor da derrota dos Madjus no recontro final de Talyatah. Teria sido ele, ainda, a mandar cortar as cabeças dos quatrocentos prisioneiros frente aos Madjus que conseguiram fugir para os barcos, acto de guerra psicológica que marca o fim das operações. Sendo o alcaide um dos Rustémidas magrebinos que estava ao serviço dos Omíadas, marca da sua condição de clientes, o centramento do relato de 'Isa na sua figura parece contrastar com a versão áulica de Ahmad, que prefere dissolver a acção do príncipe Ibadita num colectivo de três alcaides e dar a glória da vitória ao eunuco Nasr, favorito do emir 'Abd al-Rahman e personagem poderosa da corte nos anos seguintes precisamente por causa desta vitória. Não se pode deixar de pensar no que a versão do filho tem de revisão da história dinástica oficial contada pelo pai.

\section{Relato $3^{29}$ (al-Qurashi, ou de novo 'Isa al-Razi) entre uma carta e um relatório}

$\mathrm{O}$ terceiro relato, que pertence à obra sobre história de Sevilha do autor, é, em rigor, composto de duas partes, nenhuma delas de al-Qurashi. Na primeira cita por sua vez 'Isa b. Ahmad al-Razi, pelo que, nesta complexa estratigrafia, 3 é parte de 2 (mas citado agora indirectamente por Ibn Hayyan). Por sua vez 'Isa cita a carta enviada ao norte de África dando conta da vitória sobre os Madjus, que complementa com comentários seus. Na segunda parte transcreve uma carta enviada ao emir por um seu emissário que viera reconhecer o território de Sevilha e de Sidonia, naquela que é uma das mais espantosas passagens de todo o texto. De resto a sequência organizada por al-Qurashi é fragmentária, o que se poderá ficar a dever à sua selecção ou à do próprio Ibn Hayyan, mas está em linha com a ausência total de texto próprio, no que contrasta com as outras fontes utilizadas pelo polígrafo cordovês do século XI.

\footnotetext{
${ }^{29}$ Muqtabis II-1, fl. 186v, pp. 316-318 (trad.).
} 
1. A primeira parte de 3, composta por partes da carta enviada para a costa magrebina $^{30}$ e por comentários de 'Isa b. Muhammad sob a forma de fragmentos, acrescenta detalhes e comentários novos a 2, razão que terá levado Ibn Hayyan a interpolá-los nesta parte do relato. Necessariamente muito mais genérica que os relatos 1 e 2 é também muito mais abrangente e explicativa, fornecendo precisões de natureza geográfica, e cronológica: começa por identificar a origem geográfica dos «magos (madjus) chamados normandos (ardamaniyyun)», localizando-os num país "dentro do mar, junto à terra de França», narra o processo de ataque dos invasores assente num ciclo de morte, captura de cativos e saque e acompanha-os até ao Mediterrâneo [sic], onde são travados apenas na kura de Lisboa (não se pode deixar de sublinhar que é Lisboa e não Sevilha que aparece aqui como o ponto focal do ataque); conta por fim a sua retirada e os ataques que nela acabam por fazer à «gente da Djilliqiyyah» (os cristãos do norte da Hispânia) sublinhando a sua pusilanimidade e incapacidade para a guerra. Do ponto de vista geográfico o quadro é amplíssimo, desenhando-se um horizonte político que vai de França ao Mediterrâneo e em que o al-Andalus aparece com uma função de pivot, contrastando com a inanidade dos poderes cristãos a norte. Trata-se, afinal, de convencer os clientes (mawali) magrebinos, dissidentes ibaditas que não podem seguir o califa Abássida de Baghdad/Samarra, de que o poder que conta a ocidente é o dos Omíadas andaluzes. Na conjuntura dos anos 60 do século $\mathrm{X}$ em que provavelmente ${ }^{31}$ 'Isa reproduz a carta do emir 'Abd al-Rahman, os actores tinham mudado, mas o quadro geral era o mesmo, os projectos hegemónicos dos Omíadas no Magrebe chocando agora com a concorrência dos fatímidas. Os Madjus estavam aliás de volta por esses anos, para cumprirem o mesmo papel destruidor de inimigos úteis.

Os comentários de 'Isa que se seguem à transcrição da carta aos emires norte-africanos centram-se num tema que até aqui os outros relatos tinham deixado no silêncio, o do impacto das incursões na política emiral uma vez retirados os invasores: organização da marinha, posicionando embarcações em todas as costas e início da fortificação de Sevilha, logo interrompida pelo receio que a muralha viesse a servir de abrigo a revoltas locais. Esta passagem ajuda a definir o modelo de defesa estabelecido pelos Omíadas depois das expedições dos Madjus assim como as contingências que o limitam. Trata-se muito mais de bloquear o acesso às áreas de penetração estuarinas através de um sistema de patrulhamento naval das costas, do que de estabelecer pontos fortificados, de que seriam exemplo os ribatat. Nenhuma alusão

\footnotetext{
30 É provavelmente a carta citada supra no relato de Ahmad al-Razi, remetida a Aflah b. 'Abdalwahhab, senhor de Tahart cliente dos Omíadas e a outros senhores da costa africana (cf. nota 9). Que 'Isa al-Razi a tenha transcrito talvez possa ser relacionado com o maior papel dado aos Rustémidas no seu relato, e em particular ao alcaide Muhammad b. Rustum. ${ }^{31}$ Não sabemos precisamente quando escreve 'Isa. Porém, uma citação sua talvez indique que escreve antes dos ataques do califado de al-Hakam II (o primeiro de 355/966), uma vez que dá os ataques por terminados aqui, para se repetirem apenas no reinado do emir Muhammad (858-861). Cf. Muqtabis II-1, fl. 186v, p. 317 (trad.).
} 
aqui à guerra santa ou a fazer ribat. Essa defesa à distância deveria ser complementada pela fortificação dos centros urbanos atacados, sendo Sevilha o prioritário por ter sido a principal vítima do ataque e também por se tratar de uma das principais cidades andaluzas. Contudo, era também um centro cronicamente difícil de controlar pelo regime de Córdova (já o havia sido também pela monarquia visigótica, aí tendo deflagrado uma das mais importantes revoltas contra ela, a de Hermenegildo), como durante a Fitna próxima se haveria de ver. E é esse jogo de equilíbrio entre o peso da ameaça externa viking e o da ameaça interna árabe, que determina, segundo 'Isa, a suspensão da fortificação.

2. A segunda parte de 3 é integralmente composta pela carta de 'Abdallah b. $\mathrm{Kulayb}^{32}$, um dos alcaides enviados de imediato de Córdova para combater os Madjus, a 'Abd al-Rahman II, com o relatório das condições de defesa na zona do «rio de Córdova» (Guadalquivir), num território que corresponde ao Gharb dos geógrafos, isto é, à área que se estende a oeste de Córdova, começando em Sevilha. Alguns topónimos âncora citados permitem perceber os contornos do território sob escrutínio, que é também aquele que se encontra mais vulnerável aos Madjus, com exclusão do extremo ocidental que é Lisboa e Santarém: Sevilha, Coria, Sidonia, Cádis, Niebla, Beja, esta última parecendo ser o destino último da expedição. Os contornos da zona abrangida dão-nos um indício acerca do contexto de produção do relatório, apontando para que este não tenha resultado da intervenção militar aquando do ataque, em que Ibn Kulayb participa, mas de uma viagem de reconhecimento, relacionada com um inventário das fortificações realizado após a retirada dos vikings que estaria na base de um programa construtivo que foi efectivamente iniciado ${ }^{33}$. Ao longo do Guadalquivir o relator «viu» (e esta referência à observação directa define o relato) «vestígios de cidades, fortalezas, castelos e atalaias conexas e próximas», que se articulam com Itálica e Coria até Sevilha e daí a Jerez na Kura de Sidonia até Cádis e à zona costeira. A identificação desta rede de fortificações, que abrange todo o antigo golfo que chegava a Sevilha (a área estuarina actual do Guadalquivir), estende-se depois à Kura de Niebla. Para todos estes vestígios e ruínas Ibn Kulayb tem uma explicação que revela uma leitura de antiquário: os antigos fizeram estas fortalezas e atalaias contra os Madjus que deviam ter chegado já em distintas épocas. As incursões são assim vistas como um fenómeno recorrente, capaz de explicar a organização do território numa muito longa duração indefinida. Ao mesmo tempo, todos os vestígios são, a posteriori, militarizados, só as necessidades defensivas podendo explicar a

\footnotetext{
32 Havia sido governador de Toledo no ano de 228, e será depois governador das Marcas (em 232), pelo que se trata de um alcaide empregue sobretudo em áreas de fronteira e com forte intuição territorial, como aliás decorre da sua carta. Cf. Muqtabis II-1, fl. 185r e 188v.

33 Outra hipótese, seria a de a expedição de Ibn Kulayb estar relacionada com o ataque (final?) dos Madjus a Beja, que parece ser o destino último da viagem.
} 
densidade e magnitude das construções. No pórtico de uma militarização anunciada do território, a presença estranha e improvável dos Madjus, serve de instrumento de leitura do passado e, por causa disso, de justificação para os projectos futuros.

\section{Relato $4^{34}$ (al-Shabinasi) ou o primado do eunuco}

A quarta fonte utilizada por Ibn Hayyan é al-Shabinasi, um membro do clã Omíada governante no al-Andalus, facto que explicará a originalidade do relato que produz, dominado pela perspectiva da corte vista de dentro, mais talvez do que os historiadores oficiais como os dois Razi, muito preocupados com a sucessão dos eventos militares. Não surpreende assim a explicação positiva que apresenta à cabeça para a vulnerabilidade do al-Andalus aos ataques: seria a tranquilidade garantida durante muito tempo pelo governo dos «califas Marwanis, regedores da comunidade no al-Andalus» a justificar a impreparação e o descuido da cidade de Sevilha assim como a ausência de estruturas defensivas. Esta visão de uma pax Omíada contrasta com o que sabemos sobre as dissensões internas durante os quase dois primeiros séculos da dinastia, mesmo se observadas do reinado de 'Abd al-Rahman III a cuja geração pertence, assim como com a relutância do emir 'Abd al-Rahman II, declarada noutras passagens deste texto, em fortificar Sevilha de novo por receio de revoltas internas futuras. Parece certo que é aí, e não numa paz permanente, que estão as verdadeiras razões para a vulnerabilidade face aos Madjus. $\mathrm{O}$ carácter fortemente dinástico deste relato está ainda presente na atribuição retroactiva do título califal a 'Abd al-Rahman II, que nunca os emires Omíadas usaram até 929, operação que vinca tanto a continuidade da legitimidade na liderança da comunidade como o contributo desta para um clima de paz dela resultante.

O relato em si mesmo coincide factualmente em muito com o de Razi Pai, embora dê protagonismo a personagens diferentes. Assim a reacção do emir às notícias de Sevilha passa pelo envio sucessivo dos três alcaides, primeiro do já citado 'Abdallah b. Kulayb, com os esquadões de cavalaria de Córdova, depois de 'Abdalwahid b. Yazid al-Iskandarani (um dos vizires) e, finalmente de Muhammad b. Saíd b. Rustum (que foi comandante da Marca Superior), com um poderoso exército resultado do levantamento de infantaria na planície e na montanha de Córdova) e de 'Abdallah b. Almundhir b. 'Abd al-Rahman b. Mu'awiya ${ }^{35}$, um príncipe de sangue Omíada, a quem deu o comando dos quraichitas e clientes, adscrevendo-lhe como alcaide 'Isa b. Suhayd, que era camareiro do emir e continuaria a sê-lo do seu filho Muhammad. Seguir-se-á o exército mobilizado nas Kuwar, liderado pelo eunuco Nasr, favorito do

\footnotetext{
34 Muqtabis, II-1, fl. 186v-188r, 188v, pp. 318-321, 322.

35 A acreditar no nasab (patronímico), neto do fundador do estado Omíada no al-Andalus e portanto tio (primo de uma geração acima) do emir 'Abd al-Rahman II. Cf. o Quadro Genealógico da família Omíada que LÉVI-PROVENÇAL, 1967: 248-249, reconstrói com base na Djamharat de Ibn Hazm.
} 
emir que tem o verdadeiro protagonismo neste relato, a ele se atribuindo o sucesso final da expedição. As cadeias de comando ao serviço do emir revelam desta forma um equilíbrio entre a presença de especialistas da guerra nas fronteiras, tais Ibn Kulayb ou Ibn Rustum, de altos funcionários da própria corte como al-Iskandarani ou Ibn Suhayd, aquele vizir, este camareiro, e do eunuco Nasr, como finalmente da própria família real.

Os procedimentos de defesa expõem assim, de forma muito eloquente, a estrutura da sociedade andaluza dos meados do século IX, quando o estado, com a corte no seu centro, se aculturara aos padrões Abássidas, retendo porém a trama de fidelidades que tinha colocado no poder no al-Andalus a dinastia Omíada, depois de esta o ter perdido no Oriente. Essa centralidade política e simbólica da corte, toda a iniciativa vindo do príncipe, como aliás já se percebera através da carta expedida pelo governador de Lisboa ao emir (nenhum representante local se movimenta de forma autónoma, o que vinca ainda mais a importância do sistema de circulação de informações) reflecte-se no processo concêntrico de recrutamento, que tem início em Córdova para se extender depois às periferias do sistema (segundo o esquema, cidade, distrito, kuwar e marcas) e, também, nos tempos de operacionalização dos contingentes; reflecte-se ainda na importância dos clientes (mawali) Omíadas ${ }^{36} \mathrm{e}$ nas hierarquias de comando, a importância da linhagem de alguns dos alcaides (por exemplo o Rustémida, da família dos emires Ibaditas de Tahart), não se sobrepondo ao favoritismo do eunuco; aliás, se prova suplementar fosse necessária, aí estaria o facto de a este ter sido confiado o comando supremo da expedição, ultrapassando a presença de um príncipe de sangue, neto do emir 'Abd al-Rahman b. Mu'awiyah e por isso mesmo familiar do emir reinante e descendente de figuras tão prestigiosas como os califas Omíadas Hisham II e 'Abd al-Malik.

A importância do eunuco, como vizir e general ${ }^{37}$, está em linha, de resto, com a grande tradição tardo-imperial corporizada nos generais de Justiniano assim como com as práticas da corte Abássida contemporânea e parece ser directamente proporcional à densidade política do estado por eles servido. $\mathrm{O}$ triunfo do eunuco, e através dele do emir, é marcado pela entrega ritual em Córdova das cabeças dos vencidos. É ainda sublinhado pela afluência de cortesãos que acorrem a felicitá-lo, alguns deles produzindo poemas panegíricos, parte central na economia do dom típica da cultura de corte nas sociedades islâmicas do período, como se testemunha pelo exemplo transcrito pelo Muqtabis, uma qasida do poeta 'Uthman b. Al-Muthanna. Nasr, que simboliza aqui uma cultura de corte de matriz orientalizante, é assim o verdadeiro protagonista de um historiador vindo do interior da família real, o que faz crer numa

\footnotetext{
36 Sobre a composição social da entourage dos emires Omíadas, cf. MANZANO, 2006: 224 e ss. Sobre a ligação entre mawali e administração emiral (e califal), cf. MEOUAK, 1999.

37 Sobre o eunuco Nasr, cf. MANZANO, 2006: 236-237.
} 
versão da corte sobre os acontecimentos diferente da dos alcaides, aquela representada por Razi pai e por al-Shabinasi, esta por Razi filho.

\section{Relato $4 a^{38}$ (Ibn al-Qutiyyah) ou da intervenção do emir da marca}

No interior do relato de al-Shabinasi, o Muqtabis faz ainda uma interpolação que introduz em cena uma nova personagem, assim como uma diferente perspectiva. Refiro-me à citação de um fragmento de um dos grandes historiadores e cultores do Adab na corte cordovesa do século X, Ibn al-Qutiyya. Nele o acento tónico muda, para ser posto na mobilização dos contingentes das Kuwar e das marcas, à frente dos quais o emir coloca a Musa b. Musa [Ibn Qasi], principal potentado da marca superior, que acabara de ser provisoriamente submetido à autoridade de Córdova ${ }^{39}$. Não deixa de ser relevante que a narrativa de Ibn al-Qutiyyah, ele próprio de longínqua origem muladi - descendente de Sara e por isso de Vitiza, e parte da alta nobreza visigótica que cedo se islamizara - se centre aqui na acção do chefe do mais importante clã islamizado na península desse período, a dawla dos Banu Qasi, parecendo a incursão dos Madjus um mero lugar onde se podem manifestar as tensões entre os poderes central e regionais. Poder-se-á aliás mesmo pensar, considerando a acção de Musa b. Musa, neste episódio e nos anos subsequentes, se não se tratará mesmo de um terceiro poder na Hispânia, a somar ao do emir e do rei asturiano. Isso explica porque necessita o emir (nesta passagem chamado sultão), de lhe lembrar a relação clientelar entre os antepassados de ambos, tendo-se os Banu Qasi islamizado pela via da clientela do califa al-Walid b. 'Abd al-Malik, sob cujo governo se havia conquistado o al-Andalus. Três elementos convergem aqui para promover a integração da dissidência: clientela, antiguidade da relação, datando esta da época da conquista, patrocínio na islamização. Os Madjus não parecem assim outra coisa que uma oportunidade, permitindo ao emir atribuir o comando do exército a um magnate dissidente e com isso unificar, ainda que momentaneamente, a totalidade do al-Andalus. Este último, porém, não parece demasiado interessado em aproveitá-la, deixando aos vizires a iniciativa - que depois de inícios titubeantes que se traduzem no refúgio do exército emiral em Carmona, acabará numa vitória sobre os Madjus e na retirada destes de Sevilha - e acampando à parte do resto do exército. Nova revolta de Musa b. Musa no ano seguinte torna clara a futilidade dos planos do emir, assim como a incapacidade deste de manter o controlo das marcas para além do estado de emergência provocado pelas incursões do Madjus. Também deste ponto de vista, o do impacto

\footnotetext{
38 Fl. 188r-188v, pp. 320-321.

39 Sobre a participação de Musa Ibn Musa dos Banu Qasi na campanha contra os Madjus cf. LORENZO JIMÉNEZ, 2010: 198 e ss. Veja-se ainda o conflito quase imediato com 'Abdallah Ibn Kulayb, quando este se torna governador, 'Amil, da Marca Superior, o que pode ser uma pista para interpretar as contradições entre os diversos relatos, p. 202.
} 
sobre a organização interna do emirado, isto é, sobre a correlação de poderes, não parece poder reconhecer-se um peso significativo das incursões.

Porém, a citação do relato de Ibn al-Qutiyyah termina com a notícia de uma medida directa causada pelas incursões, a da construção da muralha de Sevilha ${ }^{40}$ e obras de fortificação na cidade, assim como a da reparação das destruições causadas na mesquita aljama e noutras mesquitas, pelos Madjus ${ }^{41}$ : voltando a citar al-Shabinasi, o Muqtabis revela uma carta escrita pelo alfaqueque 'Abd al-Malik b. Habib ao emir, de Sevilha, instando-o a abandonar o seu projecto favorito, as obras de ampliação da mesquita aljama de Córdova, que o seu bisavô e fundador da dinastia no al-Andalus iniciara, já começadas, a fim de colocar todos os recursos na fortificação de Sevilha, por ele consideradas mais urgentes; que o emir, apesar de continuar as obras em Córdova, tenha decidido também executar o projecto sevilhano, diz muito não só sobre a importância da cidade, como sobre a sua vulnerabilidade e a seriedade da ameaça que os Madjus representavam para todas as cidades costeiras do al-Andalus ou abertas ao litoral por via fluvial. Cumpre no entanto notar que 'Isa b. Al-Razi, citado por al-Qurashi, como vimos um autor sevilhano e autor de uma história de Sevilha que é fonte do Muqtabis, e por isso fonte presumivelmente bem informada, diz que a construção das muralhas, uma vez iniciada, foi interrompida pelo temor que o emir tinha das revoltas. É verdade que a fidelidade de Sevilha sempre fora oscilante desde o tempo da monarquia visigótica. Tudo somado a ameaça dos Madjus é talvez preferível aos olhos do emir aos elementos centrípetos que ameaçam internamente o seu poder. Ainda assim, aí, na consolidação a posteriori de um dispositivo militar defensivo, podem estar os resultados materiais mais directos das incursões.

\section{VII.}

A estratigrafia textual que acabámos de estudar permite, creio, reconstruir diferentes níveis de impacto das incursões na sociedade andaluza, ao mesmo tempo que revelam o seu funcionamento. $\mathrm{O}$ mais directo resulta das destruições e da toma de cativos, responsáveis não só pelo grosso do impacto psicológico como também das repercussões materiais e é, poderá dizer-se, uma invariável neste modelo de incursões sem assentamento. Embora contenham narrações mais ou menos detalhadas sobre a pilhagem e as destruições em Sevilha, não é esse o foco das narrativas incorporadas no Muqtabis. O mesmo se poderá dizer em relação a uma das práticas económicas em que assenta a economia do saque, a do resgate. Aliás Ibn al-Qutiyya refere que, depois da derrota dos Madjus, foi fácil e barato resgatar os cativos nas suas mãos

\footnotetext{
40 VALENCIA, 1987: 143, sobre as fortificações refeitas em torno de 848.

41 Sobre 'Abd al-Rahman II diz o Dhikr (1983), que «no ano 230 (844-845) ordenou a reconstrução da aljama de Sevilha e alçar uma muralha por causa das incursões dos Madjus no mar Mediterrâneo», Tomo I, p. 117 e Tomo II (trad.), p.150.
} 
porque eles não queriam nem ouro nem prata, apenas tecidos e provisões ${ }^{42}$, o que contrasta com o impacto provocado na economia do império carolíngio pelas mesmas depredações.

O segundo nível, talvez o mais relevante, é o aproveitamento político que o emirado, vivendo então um importante período de consolidação conseguida por um reforço da centralidade da corte na sociedade e pela importação crescente de modelos abássidas, conseguirá tirar das incursões. Nisso contrasta com as monarquias da Europa trans-pirenaica, onde estas provocam - ou adensam - crises políticas que se prolongam por várias décadas, quase fazendo desaparecer os reinos saxónicos e expondo as debilidades do mundo carolíngio. No al-Andalus as incursões dos Madjus, das quais estudámos a primeira, a de 844, tornam manifesta a capacidade de reacção do centro feita sobretudo pela activação de mecanismos de comunicação com as periferias, o que implica a existência de um circuito activo e eficaz de circulação de cartas e relatórios do qual está pendente a tomada de decisões. Isto significa que em vez do princípio da delegação do processo decisório nos governadores, se verifica a possibilidade de o centralizar, como aliás se pode inferir das rápidas substituições nos governos das províncias que caracterizam os períodos de apogeu do poder central no al-Andalus, tal este ou os meados do século X. No interior deste processo de comunicação as incursões vêm expor anéis em função da proximidade ao centro: a cidade corte de Córdova, de onde sai o contingente inicial; a sua região, onde se faz o primeiro levantamento de tropas; as províncias, com as kuwar (nelas dominando as do litoral, o que é uma novidade suscitada pelas incursões) e as tughur (marcas), nestas últimas preponderando a Marca Superior, neste período na prática uma entidade política autónoma sob o controle dos Banu Qasi; finalmente as costas do Norte de África, onde alguns emires, tais os Rustémidas de Tahart, mantêm com os omíadas uma relação de dependência simbólica.

Nesse sentido podemos ver nas incursões dos Madjus uma oportunidade bem aproveitada pelos emires andaluzes para robustecer os laços entre a sua corte e as várias escalas geográficas em que a sua autoridade se faz sentir, que transcendem, como em todas as dominações de modelo carismático, os limites físicos (territoriais) da sua autoridade, abrangendo áreas, como as Marcas, de controle cinzento e espaços mais remotos, com o Magrebe central, governados por dinastias independentes. Assim, a propósito das incursões, revela-se um teatro do poder ${ }^{43}$, com um centro ritual e actores, todos eles com um papel definido, alcaides, governadores das marcas, vizires, camareiro, eunuco, dramatis personae que constituem um círculo próximo do emir e cujo protagonismo será avaliado de forma diferente pelos vários narradores que

\footnotetext{
${ }^{42}$ Muqtabis II-1, fl. 188v, p. 321(trad.).

43 Sobre os rituais de corte em Córdova no século imediato, cf. CARDOSO, 2018.
} 
formam a compilação de Ibn Hayyan. 'Abd al-Rahman II, que tinha muito sentido da propaganda, parece jogar deliberadamente nesse palco, aproveitando a ameaça dos Madjus, ao mesmo tempo que a repele, para resolver problemas de dissidência nas marcas e para montar uma impressionante operação de propaganda no seu horizonte externo mais próximo e interessante, o Magrebe. Creio que as repercussões das incursões estão muito mais aqui do que numa redefinição da política territorial.

No que a esta diz respeito, é verdade que as incursões permitem observar a organização militar do território em funcionamento. A primeira evidência é a de que a sua maior incidência no Gharb dá uma relevância nova à Marca Inferior, ou talvez mesmo, será responsável pela sua constituição. As décadas seguintes manterão esta tendência para o protagonismo que a dissidência dos Banu Marwan, ao dobrar a dos Banu Qasi na Marca Superior, vem dar à parte ocidental do al-Andalus. Em segundo lugar, dá relevância à fronteira marítima ocidental (a do Gharb) e expõe pela primeira vez a importância vital da zona dos estuários, do Tejo e do Sado, que se tornará mais notória no século XII e terá tão grande impacto na construção do reino português. A segunda evidência prende-se, como vimos, com a debilidade estrutural do povoamento fortificado. Aqui os textos parecem sustentar a definição de uma política de reconstrução dos perímetros amuralhados, apesar da ambiguidade da posição do emir, desconfiado por um lado do robustecimento que cidades fortificadas significam para os poderes locais, interessado por outro em concentrar os níveis de investimento nas grandes obras áulicas do reinado, tal como a mesquita de Córdova ${ }^{44}$. Já quanto à formação de uma rede defensiva assente na fundação de ribatat, será mais difícil apreciar uma potencial ligação com as incursões dos Madjus, a acreditar nos autores representados neste fragmento do Muqtabis. Está a fundação de uma série de ribatat na costa oceânica ligada à acção de 'Abd al-Rahman II e às incursões de 844 e do final da década de 50 ? De facto, os textos não se referem directamente a esse tipo de medidas, insistindo na fortificação das próprias cidades e na organização da marinha ${ }^{45}$.

É aliás como preparação para esse programa de fortificação urbana que se poderá entender o relatório sobre o litoral feito por Ibn Kulayb. Nele os Madjus são a única chave para explicar todos os vestígios do passado suscetíveis de ser interpretados enquanto fortificações, o que diz alguma coisa sobre a ausência de ameaças

\footnotetext{
${ }^{44}$ Cf. MAZZOLI-GUINTARD, 1998: 101-103, para um inventário das transformações urbanas no século IX andaluz. Os dados recolhidos não me parecem demonstrar qualquer relação necessária entre as incursões e o processo de urbanização. Deverá antes seguir-se a pista da acção dos poderes regionais, como aliás já havia feito PICARD, 1993. 45 Sobre a construção de uma dar al-sina’a em Sevilha como resultado das incursões de 844 cf. PICARD, 201: 137. Sobre a repercussão na difusão da instituição ribat no al-Andalus (o que é diferente de uma rede de ribatat), apoiando-se em al-Himyari e no exemplo de Almeria cf. Idem: 138. Poderá aliás questionar-se, a propósito desta passagem, que poderá documentar um nexo entre as incursões dos Madjus e o aparecimento de uma rede de ribatat, se fazer ribat, enquanto acto espiritual e práctica na fronteira equivale de forma automática à definição de uma rede fortificada litoral.
} 
externas, nesse período da História andaluza. Esta universalidade retrospectiva dos vikings, transformada em modelo arqueológico de leitura de um passado difuso, é bem representada na leitura da porta de uma cidade na Kura de Niebla: nela, há "umas estátuas de pessoas que se parecem com os normandos que combatem agora os muçulmanos, assim como reproduções de naves como as suas [...], feitas sem dúvida como talismãs que deviam ajudar a afastá-los do seu país» ${ }^{46}$.

\section{FONTES}

[Dhikr Bilad al-Andalus] (1983) - Una Descripción anónima de al-Andalus. Edição e tradução de Luis Molina. Madrid: CSIC, 2 vols.

AL-RAZI, Ahmad Ibn Muhammad, (1975) - Cronica del Moro Rasis versión del ajbar muluk al-Andalus de Ahmad Ibn Muhammad Ibn Musa al-Razi, 889-955 [...]. Diego Catalan e M. Soledad de Andres. Madrid: Editorial Gredos.

IBN HAYYAN (1999) - Muqtabis II. Anales de los Emires de Córdoba Alhaquém I (180-206 H./796-822) y Abderramán II (206-232/822-847). Vallvé Bermejo, J., ed. Fac-simil. Madrid: Real Academia de la Historia.

IBN HAYYAN (2001) - Crónica de los emires Alhakam I y 'Abdarrahman II entre los años 796 y 847 [Almuqtabis II-1]. Tradução de Mahmud 'Ali Makki e Federico Corriente. Saragoça: Instituto de Estudios Islâmicos y del Próximo Oriente. [cit. no texto como Muqtabis II-1]

IBN KHALDUN (2010) - Histoire Des Berbères Et Des Dynasties Musulmanes de l'Afrique septentrionale. Tradução de W. Mac-Guckin de Slane. Alger: Berti Editions.

Morkinskinna. The earliest Icelandic Chronicle of the Norwegian Kings (1030-1157), (2000). Tradução de Theodore. M. Andersson e Kari Ellen Gade. Ithaca and London: Cornell University Press.

AL-RAZI, Ahmad Ibn Muhammad, (1975) - Cronica del Moro Rasis versión del ajbar muluk al-Andalus de Ahmadx

\section{BIBLIOGRAFIA}

ANTRIM, Zayde (2012) - Routes and Realms. The Power of Place in the Early Islamic world. Oxford, New York: Oxford University Press.

CARDOSO, Elsa (2018) - The scenography of power in al-Andalus and the Abbasid and Byzantine ceremonials: Christian ambassadorial receptions in the court of Cordoba in a comparative perspective. «Medieval Encounters. Jewish, Christian and Muslim Culture in Confluence and Dialogue», vol. 24 , n. ${ }^{\circ}$, p. $390-434$.

DOZY, Reinhart (1881) - Les Normands en Espagne. In Recherches sur l'Histoire et la Littérature de l'Espagne pendant le Moyen Âge. Tomo II, $3^{\text {a }}$ ed. Leiden: [reimp. Amsterdam Oriental Press, 1965], p. 250-371.

GAISER, Adam (2013) - Slaves and Silver across the Strait of Gibraltar: Politics and Trade between Umayyad Iberia and Kharidjite North Africa. «Spanning the Strait: Studies in Unity in the Western Mediterranean». Leiden/Boston: Brill, p. 41-70.

\footnotetext{
${ }^{46}$ Muqtabis II-1, fl. 187r, p. 318 (trad.).
} 
LÉVI-PROVENÇAL, E. (1967) - España Musulmana hasta la caída del califado de Córdoba (711-1031 de J. C.). In MENENDÉZ-PIDAL Ramón, dir. - Historia de España, Tomo IV, $3^{a}$ ed. Madrid: Espasa-Calpe.

LORENZO JIMÉNEZ, Jesús (2010) - La Dawla de los Banu Qasi. Origen, auge y caída de una dinastia muladí en la frontera superior de al-Andalus. Madrid: CSIC.

MANZANO MORENO, Eduardo (2006) - Conquistadores, Emires y Califas. Los Omeyas y la formación de al-Andalus. Barcelona: Crítica.

MAZZOLI-GUINTARD, Christine (1998) - L'Urbanisation d'al-Andalus au IXe siécle. Données chronologiques. In Cressier, Patrice; García-Arenal, M. eds. - Génese de la Ville Islamique en al-Andalus et au Maghrebe occidentale. Madrid: Casa de Velásquez, CSIC, p. 99-106.

MELVINGER, A. - “al-Madjus", s.v. Encyclopédie de l'Islam, nouvelle edition. Leiden: Brill.

MEOUAK, Mohamed (1999) - Pouvoir souverain, administration centrale et elites politiques dans lespangne umayyade (II ${ }^{e}-I V^{e} / V I I I^{e}-X^{e}$ siècles). [s.l.]: Academia Scientiarum Fennica.

MOLÉNAT, Jean-Pierre (2007) - Historiographie d'al-Andalus. Un essai de mise au point. «Clio, Revista do Centro de História da Universidade de Lisboa», n. ${ }^{\circ}$ 16/17, p. 15-40.

MONNET, Jerôme (2017) - Le territoire comme télépouvoir. Bans, bandits et banlieues entre territorialités aréolaire et réticulaire. In BUEHRER-THIERRY, G.; PATZOLD, S.; SCHNEIDER, J., eds. - Genèse des Espaces Politiques (IXe-XIIe siècle). Autour d ela question spatiale dans les royaumes francs et postcarolingiens. Turnhout: Brepols, p. 25-33.

PENELAS, Mayte; MOLINA, Luis (2011) - Dos fragmentos inéditos del volumen II del Muqtabis de Ibn Hayyan, «Al-Qantara», vol. XXXII 1, p. 229-241.

PICARD, Christophe (1993) - Le renouveau Urbain en Occident ibérique aux IX $X^{e} X^{e}$ sièclessous l'impulsion des seigneurs muwalladun. In Actes des congrès de la Société des historiens médiévistes de l'enseignement supérieur public, $23^{e}$ congrès, Brest, 1992. Les princes et le pouvoir au Moyen Age. Paris: Publications de la Sorbonne, p. 49-67.

(1997) - L'Océan Atlantique musulman. De la conquête arabe à l'époque almohade : Navigation et mise en valeur des côtes d'al-Andalus et du Maghreb occidental (Portugal-Espagne-Maroc). Paris: Maisonneuve et Larose.

(2000) - Le Portugal Musulman (VIII -XIII siècle). LOccident d'al-Andalus sous domination islamique. Paris: Maisonneuve et Larose.

(2002) - Les ribats au Portugal à l'époque musulmane: sources et définitions. In FERNANDES, Isabel Cristina Ferreira, coord. - Mil anos de Fortificações na Península Ibérica e no Magrebe (500-1500). Actas do Simpósio Internacional sobre Castelos. Lisboa: Colibri/Câmara Municipal de Palmela, p. 203-212.

(2015) - La Mer des Caliphes. Une Historie de la Méditerranée musulmane (VII ${ }^{e-X I I^{e}}$ siécle). Paris: Éditions du Seuil.

PIRES, Hélio (2012) - Incursões Nórdicas no Ocidente Ibérico (844-1147): Fontes, História e Vestígios. Lisboa: Faculdade de Ciências Sociais e Humanas, Universidade Nova de Lisboa. Tese de Doutoramento.

PONS BOIGUES, Francisco (1898) - Los Historiadores y Geógrafos arábigo-Españoles, 800-1450 A.D. Madrid: [reimp. Amsterdam: Philo Press, 1972].

VALENCIA RODRÍGUEZ, Rafael (1987) - Sevilla Musulmana hasta la caída del califato: contribución a su estudio. Madrid: Universidade Complutense de Madrid. Tese de Doutoramento.

VALÉRIAN, Dominique (2011) - Contrôle et Domination Politique de l'Espace dans le Maghreb Central (VII ${ }^{e}-X{ }^{e}$ siècle). In NEF, Annliese; VOGUET, Élise, eds. - La Légitimation du Pouvoir au Maghreb Médiéval. De l'orientalisation à l'Émancipation Politique. Madrid: Casa de Velázquez, p. 135-143. 


\section{DE NORTE PARA SUL: \\ OS VIKINGS EM PORTUGAL}

HÉLIO PIRES*

Não obstante a escassez de informação, algo que é igualmente verdade para outros temas da História medieval, a presença de vikings naquilo que é hoje território português não deixa de ser um tema extenso e complexo. O que se apresenta aqui é por isso um resumo que não aborda todos os aspetos e, regra geral, ignora episódios ocorridos a norte do rio Minho. Mas antes de se abordar os diferentes ataques e focar brevemente em alguns deles, há que esclarecer um conjunto de noções úteis.

\section{NOÇÕES BÁSICAS}

A primeira são os limites cronológicos da Idade Viking, que se pode definir como uma época de expansão marítima nórdica - uma espécie de Descobrimentos escandinavos, se se quiser, e igualmente multifacetada na diversidade de processos - e que se pode colocar entre 789 , ano do primeiro ataque registado em Inglaterra ${ }^{1}$, e 1086, data da morte do rei Canuto IV da Dinamarca e consequente fim do seu plano de conquista do trono inglês ${ }^{2}$. Claro que estas datas são um pouco simbólicas, motivo pelo qual elas podem variar consoante os estudiosos, e isto acontece porque a História faz-se de processos e não de instantâneos, pelo que a Idade Viking não começou nem acabou num abrir e fechar de olhos, mas teve uma alvorada e crepús-

\footnotetext{
* Membro do Instituto de Estudos Medievais e NEVA. heliovpires@sapo.pt.

${ }^{1}$ GARMONSWAY, 1984: 54.

${ }^{2}$ LUND, 2001: 178-81.
} 
culo progressivos. Para mais, esse processo teve variações regionais: por exemplo, na Península Ibérica ele teve início apenas em 844, ano do primeiro ataque conhecido entre nós, e na Escócia perdurou durante o século XII, pelo menos a acreditar nos capítulos 106 a 108 da Orkneyinga saga ${ }^{3}$; e por essa altura, a partir de 1100, no território ibérico estava-se já na fase de transição pós-viking em que há uma continuidade de práticas, mas com ideias e dinâmicas que indicam outra época.

É por isso que, em rigor, eu não chamaria viking a um rei norueguês que, por volta de 1109, navegou ao longo do que é hoje a costa portuguesa. É certo que ele era nórdico, que veio de barco e atacou povoações costeiras - e nesse sentido há uma continuidade - mas ele fê-lo num contexto e dinâmica já próprios de outra época que não a Idade Viking.

Outra noção a ter em conta é que um viking não é necessariamente o mesmo que um normando. É certo que os portugueses, fruto da tradição latina, tendem a usar as duas palavras como sinónimos, mas isso é problemático por elas terem uma certa polissemia. Isto é, a palavra «normandos» tem o sentido geral de «homens do norte» - os nordmanni, termo que na Península Ibérica surge com variantes como lordmani ou leordomani; mas ao mesmo tempo, «normandos» tem também o sentido estrito de «habitantes da Normandia». E se é verdade que essa região de França deve o seu nome ao facto de ter sido doada a um grupo de vikings e parcialmente colonizada por eles, também é verdade que os nórdicos que se fixaram no reino dos francos foram assimilados no espaço de algumas gerações ${ }^{4}$. Assim, chegados ao século XI e não obstante os vestígios das suas origens setentrionais, os normandos da Normandia eram já um grupo diferente, afrancesado e cristianizado, motivo pelo qual eles eram também distintos dos seus antepassados vikings. Distinção essa que se perde a partir do momento em que se usa os dois termos como simples sinónimos.

Por fim, há que dizer ainda umas palavras acerca das fontes de informação, que são diversas quanto às origens e idade e são esmagadoramente escritas, escasseando dados físicos de outra ordem. Tem-se textos dos séculos IX a XIII, do norte da Península Ibérica em latim, do sul em árabe, do reino dos Francos e da Normandia (também em latim) e ainda da Escandinávia em islandês antigo, em especial as coletâneas de sagas de reis do século XIII, que foram beber informação a poemas mais antigos. E esta distinção entre os dois tipos de fontes nórdicas é importante, porque as narrativas que elas transmitem nem sempre coincidem e por isso há uma discrepância que é relevante em alguns episódios. E nenhum dos textos oferece mais do que resumos, notícias breves ou referências isoladas, porque foi só isso o que se escreveu ou chegou até hoje. $\mathrm{O}$ que quer dizer que se tem apenas fragmentos

\footnotetext{
${ }^{3}$ PÁLSSON \& EDWARDS, 1981: 215-8.

${ }^{4}$ RENAUD, 2010: 456.
} 
de informação sobrevivente que dão uma visão meramente parcial do sucedido. Não existe um registo completo e detalhado da atividade viking no que é hoje território português! O que não é indiferente nem uma mera curiosidade académica, porque obriga a reconhecer os limites do nosso conhecimento. Isto é, a aceitar que há coisas que não se sabe, nunca se saberá - a menos que surjam fontes novas - e por isso nem sempre se pode concluir com certeza ou sequer afirmar que aconteceu isto ou aquilo. Pode-se certamente sugerir ou propor, mas muitas vezes é só isso.

Para dar um exemplo genérico, há uma certa tendência para dizer que dois ou mais episódios dos quais se tem notícias separadas foram protagonizados por um único grupo de vikings com base apenas na proximidade geográfica ou cronológica dos acontecimentos. Mas isso é uma falácia, porque se não se tem a informação toda, então não se pode pura e simplesmente assumir uma relação entre dados fragmentários, ainda que próximos. Talvez os ataques estejam relacionados ou talvez tenham sido levados a cabo por grupos distintos que estavam ativos na mesma região pela mesma altura - e há exemplos disso noutras partes da Europa, conforme se verá mais à frente. A partir do momento em que não se conhece o panorama completo e muito menos todos os seus detalhes, não se pode assumir como certa uma relação entre fragmentos de informação com base apenas na sua proximidade.

\section{ATAQUES DO SÉCULO IX}

O primeiro ataque de que há notícia no ocidente ibérico data de 844 , quando um grupo de vikings atacou a região da Corunha antes de seguir para o sul da península. E pode-se, pelo menos à partida, assumir que era o mesmo grupo porque os textos medievais referem a rota ${ }^{5}$. Segundo a informação preservada no Muqtabis de Ibn Hayyan, os nórdicos entraram no Tejo a 20 de agosto e partiram apenas ao final de treze dias, durante os quais ocorreram três batalhas com tropas locais ${ }^{6}$. Não se sabe exatamente onde nem qual foi o resultado desses combates, tal como também se desconhece se a investida afetou a cidade de Lisboa propriamente dita ou apenas os arredores e até onde.

A mesma fonte árabe descreve a frota viking como tendo cinquenta e quatro navios nórdicos e um número igual de cárabos, informação que pode sugerir que parte dos barcos seriam familiares aos olhos do autor da notícia. E isso permite colocar a hipótese de ter havido ataques adicionais entre a Corunha e Lisboa, o que não é impossível, porque os vikings estavam no norte da península no início de agosto assim o diz a chamada Crónica Profética ${ }^{7}-$, o que quer dizer que entre a investida na região da Corunha e a chegada a Lisboa a 20 do mesmo mês, há um hiato de

\footnotetext{
${ }^{5}$ FERNÁNDEZ et al., 1985: 142-3.

${ }^{6}$ MAKKI \& CORRIENTE, 2001: 312.

${ }^{7}$ FERNÁNDEZ et al., 1985: 188.
} 
cerca de duas semanas para uma viagem que podia ter sido feita em menos tempo. Isto pode ser explicado de várias formas: talvez os nórdicos tenham estado a maior parte desse tempo no norte da Galiza, até porque não se conhece a extensão espacial e temporal do ataque na zona da Corunha; ou talvez tenham encontrado mau tempo e por isso a viagem para sul foi mais lenta; mas também é possível que eles se tenham demorado em ataques a povoações costeiras e tenham capturado vários navios locais. Até porque há notícia de que parte da frota viking foi destruída pelos galegos $^{8}$, motivo pelo qual os nórdicos podem ter tentado recompô-la roubando embarcações ibéricas. E assim, a 20 de agosto, eles estariam em Lisboa com um misto de navios: uns com um aspeto estrangeiro e um número mais ou menos igual de barcos reconhecíveis ou familiares o suficiente para um autor árabe chamar-lhes cárabos. Mas isto, note-se, é apenas e só uma hipótese feita com base em fragmentos de informação. Não é uma certeza!

Para o que se seguiu após os treze dias de saque na região de Lisboa tem-se um hiato cronológico ainda maior, uma vez que os vikings seguiram viagem para sul e só chegaram a Sevilha cerca de um mês depois ${ }^{9}$. Uma vez mais, trata-se de uma viagem que podia ter sido feita em menos tempo, pelo que em algum lugar eles andaram. Não se sabe exatamente onde nem porquê - se pilhagens, mau tempo ou confrontos navais - mas tem-se aqui outro indício de mais episódios para lá dos conhecidos. O que leva de volta ao que se disse no início: não se conhece tudo, mas tem-se apenas fragmentos de informação sobrevivente que dão uma visão parcial do sucedido.

No verão de 858, os vikings estavam de volta e atacaram Lisboa, onde só se sabe que morreu muita gente, mas não em que contexto - se uma vitória ou derrota nórdica, pilhagem da cidade ou dos arredores ${ }^{10}$. No ano seguinte, em 859, houve um pequeno confronto naval ao largo do que será talvez hoje a costa alentejana ${ }^{11} \mathrm{e}$ depois, na década de 860, os nórdicos talvez tenham regressado ao ocidente ibérico, embora sem certezas dada a informação ser escassa e críptica.

A respeito deste último conjunto de ataques, há quem afirme que eles se referem todos a uma única grande expedição viking que durou vários anos, de 858 a 860 ou mais ${ }^{12}$, o que me parece altamente duvidoso. Senão vejamos: segundo a chamada Crónica Profética, os nórdicos regressaram em 858 e atacaram Lisboa; a Albeldense diz que, no reinado de Ordonho I, os vikings voltaram (iterum) à Galiza e foram derrotados por um conde Pedro ${ }^{13}$; a História de Ibn al-Qutyia conta que

\footnotetext{
${ }^{8}$ FERNÁNDEZ et al., 1985: 142-3.

${ }^{9}$ MAKKI \& CORRIENTE, 2001: 312.

${ }^{10}$ FERNÁNDEZ et al., 1985: 188.

${ }^{11}$ FERNÁNDEZ GONZÁLEZ, 1999: 133-4.

${ }^{12}$ É o caso de ALMAZÁN, 1986: 91-5.

${ }^{13}$ FERNÁNDEZ et al., 1985: 176.
} 
os invasores foram derrotados no Guadalquivir no reinado do emir Muhammad ${ }^{14}$, o que é uma referência cronológica vaga, mas, diz a mesma fonte, após a derrota de 844 os vikings regressaram catorze anos depois, o que corresponde a $858^{15}$; a Crónica de Alfonso III também diz que os nórdicos voltaram (iterum) no reinado de Ordonho I, pilharam a costa e navegaram até ao norte de África e às Baleares ${ }^{16}$; Ibn Idhari refere o confronto naval na costa alentejana no ano 245 da Hégira, que começou em abril de 859, e que depois os vikings rumaram ao Guadalquivir, entraram no Mediterrâneo e passaram o inverno no rio Ródano, no sul de França ${ }^{17}$; e essa informação é confirmada pelos Anais de São Bertino, que sob o ano de 859 registam a presença de nórdicos no sul de França e diz que eles passaram o inverno numa ilha no Ródano ${ }^{18}$.

Se se assume que estes acontecimentos fazem todos parte de uma única grande expedição, é-se obrigado a concluir que se tratava de uma frota brutalmente resistente. Afinal, teria de ser capaz de atacar a costa norte-ibérica no verão de 858 , ser derrotada na Galiza, participar apesar disso em novos confrontos em Lisboa, seguir para sul e ser derrotada no Guadalquivir, regressar ao que é hoje a costa portuguesa e por lá ficar vários meses, não se sabe onde, até protagonizar o confronto naval ao largo do Alentejo em abril de 859 ou mais tarde nesse ano, entrar no Mediterrâneo, pilhar as Baleares, chegar ao sul de França, passar lá o inverno com mais ataques pelo meio e depois, já em 860, regressar ao estreito de Gibraltar para mais uma batalha... É muita coisa! É certo que não é rigorosamente impossível que todas estas ações correspondam a uma única expedição, mas parece-me muito mais plausível pensar que se está perante pelo menos dois episódios distintos em anos consecutivos: um em 858 , que terminou com a derrota viking no Guadalquivir durante o reinado do emir Muhammad; e outro em 859-60, esse sim o que inclui a chegada ao sul de França e o regresso à entrada do Mediterrâneo meses depois.

Onde é que está a confusão? No facto de as duas fontes mais usadas para estes acontecimentos serem a Albeldense e a Crónica de Alfonso III, que oferecem apenas uma referência cronológica vaga - no reinado de Ordonho I - e usam o mesmo termo para ambas as expedições - iterum, o que é ambíguo por querer dizer «de novo», mas também "pela segunda vez». É apenas quando se conjuga a informação de todas as fontes, as ibéricas, assim como as árabes e francas, que se percebe que, não obstante os anos de 858 a 860 serem todos no reinado de Ordonho I, nem tudo o que aconteceu nesse período faz parte de uma única expedição.

\footnotetext{
${ }^{14}$ JAMES, 2009: 102.

15 JAMES, 2009: 101.

${ }^{16}$ FERNÁNDEZ et al., 1985: 148.

${ }^{17}$ FERNÁNDEZ GONZÁLEZ, 1999: 133-4.

${ }^{18}$ NELSON, 1991: 90.
} 


\section{ATAQUES DO SÉCULO X}

Há um maior número de notícias de ataques para o século $\mathrm{X}$, embora continue a haver também dúvidas. O primeiro episódio de que há conhecimento ou antes indício é disso mesmo exemplo, uma vez que se tem apenas uma alusão breve num documento de 1112 que foi preservado nos apêndices da España Sagrada ${ }^{19}$. Nele, é dito que um bispo Nausto de Tui foi obrigado a fugir da cidade e a refugiar-se no que é hoje o norte de Portugal devido às investidas nórdicas e muçulmanas nas margens do rio Minho. Mas não é referido ao certo quando e se se está perante um ou mais ataques concentrados num curto espaço de tempo ou distribuídos ao longo de vários anos. Não há sequer certezas quanto à data da morte do referido bispo, havendo quem a coloque em $912^{20}$ e $934^{21}$, pelo que se pode apenas dizer com segurança que Tui foi vítima de pelo menos um ataque nas primeiras décadas do século $\mathrm{X}$, que pode ou não ter resvalado para o que é hoje a fronteira norte de Portugal.

No verão de 966, Lisboa foi alvo de outra investida ${ }^{22}$ que, em hipótese, pode ter sido protagonizada pelos vikings que estiveram ao serviço do conde Ricardo I de Rouen e que seguiram viagem para a Península Ibérica, onde pilharam várias cidades e enfrentaram um exército, não se sabe qual nem onde, embora a descrição refira-se a «etíopes» ${ }^{23}$. Talvez árabes ou berberes, embora sem certezas quanto à relação com o sucedido em Lisboa - porque lá está, tem-se apenas fragmentos de informação - e sem que se possa sequer afirmar com segurança que o relato normando é fidedigno. Mas se os episódios são idênticos, fica-se uma vez mais sem saber o que aconteceu à cidade. Também no verão de 966 , sem que seja claro se se trata do mesmo grupo ou de outro, uma frota viking foi avistada ao largo de Alcácer do Sal e houve uma batalha naval no Algarve, porventura no rio Arade ou na sua foz, ao largo do que é hoje Portimão, uma vez que a fonte árabe refere-se ao rio de Silves ${ }^{24}$. Cinco anos depois, em 971, há notícia de que os nórdicos entraram no rio Douro a 8 de julho desse $a_{n}{ }^{25}$, não sendo, no entanto, conhecido até onde e com que resultado. E nesse mesmo ano, assim como no seguinte, surgem referências a mais atividade viking no que é hoje a costa portuguesa ${ }^{26}$, mas sem que também aqui se saiba onde e com que contornos exatos. De referir ainda a possibilidade de pelo menos um ataque na zona de Guimarães, algures na década de 950 ou 960, pelo menos a julgar pelo testamento

\footnotetext{
${ }^{19}$ FLÓREZ, 1798: 250-3, doc. 2.

${ }^{20}$ ALSINA, 2004: 59.

${ }^{21}$ FLÓREZ, 1798: 49-52.

${ }^{22}$ COELHO, 1972: 123.

${ }^{23}$ CHRISTIANSEN, 1998: 162.

${ }^{24}$ COELHO, 1972: 123.

${ }^{25}$ GARCÍA GÓMEZ, 1967: 50, doc. 11.

${ }^{26}$ GARCÍA GÓMEZ, 1967: 69, doc. 8; 101-2, doc. 64.
} 
de Mumadona Dias ${ }^{27}$ e pese embora o uso do termo «gentios» seja ambíguo, podendo referir-se tanto a vikings como a tropas islâmicas.

\section{ATAQUES DO SÉCULO XI}

Durante a década de 970 e a avaliar pelos dados sobreviventes, a atividade viking no que é hoje território português parece ter atingido um pico e decrescido a partir desse ponto, voltando apenas em força já na segunda década do século XI. É nessa altura que tem lugar um dos maiores ataques no registo existente e que se conhece por via de um documento de $1018^{28}$. Segundo o texto, três anos antes, em julho de 1015, um grupo de nórdicos, descritos como «netos e filhos dos normandos», entraram no rio Douro e durante nove meses pilharam a região até ao Ave, fazendo cativos e libertando-os a troco de resgates. É por via dos esforços de um homem para salvar as suas três filhas que se tem notícia do sucedido.

Embora o relato seja excecional no detalhe geográfico e cronológico - pelo menos quando comparado com outras notícias do ocidente ibérico - deixa muitas questões por esclarecer. Por exemplo, o que é que aconteceu ao Porto? Está junto à foz do Douro, pelo que se os vikings entraram nesse rio, de certeza que andaram perto da cidade. E depois? Pilharam-na ou cercaram-na? Correu bem ou correu mal? Não se sabe. Qual a reação das autoridades portucalenses? Atacaram os vikings ou toleraram-nos? E se toleraram, foi após uma derrota frente aos nórdicos ou por falta de meios para atacá-los de forma decisiva? Alguma coisa aconteceu (ou não aconteceu) para os vikings terem conseguido estar nove meses numa região que era o centro do condado do Porto. E a população? Limitou-se a fugir ou houve alguma forma de convivência? Repare-se que uma coisa é um ataque relâmpago, que consiste em chegar, pilhar e ir embora o mais depressa possível, não dando tempo para qualquer forma de convivência. Mas uma presença de nove meses obriga lados opostos a uma coexistência, mesmo que forçada, e que não tem de se resumir à violência ou medo. Bem pelo contrário, pode originar laços inesperados: talvez uma paixão, o amor pecuniário de senhoras com a profissão mais antiga do mundo ou uma troca de lados individual, até o desejo de rumar à aventura com os invasores. Isto pode parecer um exagero, mas tem-se um vislumbre histórico deste processo nos Anais de São Bertino, onde é dito que em França, no ano de 869, foi descoberto um monge apóstata num acampamento viking ${ }^{29}$. Está-se a falar de um clérigo cristão que mudou de religião e se juntou aos nórdicos, não se sabe por que motivo, se um episódio medieval da síndroma de Estocolmo, se outra causa. Eu não estou a dizer que houve apóstatas

\footnotetext{
${ }^{27}$ HERCULANO, 1868: 61, doc. 97.

${ }^{28}$ AZEVEDO, 1973: 91-3.

${ }^{29}$ NELSON, 1991: 163.
} 
entre os rios Douro e Ave, mas é um facto que a convivência prolongada, ainda que imposta, pode originar laços inesperados.

Outra pergunta que fica por responder é a localização da base de inverno. Porque se os nórdicos estiveram no que é hoje o norte de Portugal durante nove meses, do verão de 1015 até à primavera de 1016, então é certo que em algum lugar eles estiveram fortificados para poderem proteger os navios, guardar o saque, manter os cativos e ter defesas contra eventuais ataques portucalenses. E essa base seria mais facilmente localizada nas margens do Douro ou num afluente, porque caso contrário os vikings teriam de arrastar os navios por terra. Talvez tivesse uma muralha rudimentar, porventura uma paliçada, mas não se sabe por não haver qualquer descrição ou vestígios arqueológicos conhecidos ${ }^{30}$.

Vários meses depois do ataque entre os rios Douro e Ave, tem lugar o episódio de Vermoim, que é ainda mais problemático. A notícia é breve, podendo ser lida na chamada Crónica dos Godos, e diz apenas que a 6 de setembro de 1016 os vikings vieram ao castelo de Vermoim, que fica na província bracarense, e que, à época, era conde Alvito Nunes ou que ele estava na fortificação ${ }^{31}$. E isto é um pouco como dizer tudo sem dizer quase nada. Por exemplo, não é dito como é que os nórdicos chegaram ao castelo, se por terra ou subindo o rio Ave, que outros sítios atacaram ou não durante a viagem desde a costa e com que sucesso ou qual o desfecho da chegada a Vermoim. Tem-se só uma notícia telegráfica e sem qualquer contexto. Repare-se, aliás, que o texto diz apenas que eles veniunt ou foram até Vermoim; não diz como, porquê nem com que desfecho. Não é sequer certo que o conde Alvito Nunes tenha morrido a 6 de setembro e não meses mais tarde por outro motivo que não uma investida viking. E a falta de informação é tal que se pode até sugerir que tudo começou com um ataque costeiro malsucedido, no qual um grupo de nórdicos foi impossibilitado de regressar aos navios e obrigado a fugir para o interior, acabando por ir até Vermoim. Pura e simplesmente não há dados que permitam reconstruir os acontecimentos nos seus traços gerais e com um mínimo de certeza histórica.

Pelo mesmo motivo, deve-se também duvidar da teoria segundo a qual a notícia contida na Crónica dos Godos está mal datada em um ano, fundindo-se o episódio de Vermoim em 1016 com o dos rios Douro e Ave em 1015-16². O que não é impossível - os autores medievais também cometiam erros - mas não pode ser a primeira opção quando, conforme se disse ao início, tem-se apenas fragmentos de informação e não um registo completo da atividade viking. É portanto falacioso assumir uma relação entre ataques geográfica ou cronologicamente próximos, com base apenas nessa proximidade, mais ainda quando se conhece exemplos históricos de

\footnotetext{
${ }^{30}$ Mas veja-se o texto do professor Gareth Williams para exemplos de bases noutras partes da Europa.

${ }^{31}$ HERCULANO, 1856: 9.

${ }^{32}$ AZEVEDO, 1973: 88.
} 
investidas simultâneas em regiões adjacentes. Por exemplo, segundo os Anais de São Bertino, em 859 havia um grupo de nórdicos no rio Somme e outro um pouco mais a sul no Sena ${ }^{33}$. E como tal o mesmo pode ter acontecido a norte do Douro, com um bando de vikings em 1015-16 e outro, meses mais tarde, em 1016, sem necessidade de forçar a cronologia ou atribuir a um autor medieval um erro que ele pode não ter cometido. Quando há apenas fragmentos de informação e dado que a atividade viking era levada a cabo por bandos independentes e de forma descentralizada, não se pode pura e simplesmente fundir episódios sem indícios concretos nesse sentido.

Ainda no século XI, antes de 1024 houve pelo menos um ataque a Tui, o qual é objeto de uma lenda erudita segundo a qual a investida foi liderada por Óláfr Haraldsson, mais tarde rei e santo padroeiro da Noruega, e que ele teria navegado até junto do estreito de Gibraltar e portanto ao largo daquilo que é hoje a costa portuguesa. E eu chamo-lhe lenda erudita porque a base histórica para a suposta expedição ibérica do norueguês é escassa ou mesmo inexistente, tendo apenas a aparência de facto por ser sucessivamente repetida por autores e estudiosos que se citam uns aos outros desde há pelo menos um século ${ }^{34}$. Quando se analisa as fontes medievais de forma direta, as certezas desaparecem.

Por volta de 1026, pelos lados de Santa Maria da Feira, terá havido pelo menos um ataque, isto porque temos notícia da captura e resgate de duas mulheres, resgate esse que foi pago na presença de autoridades municipais e em géneros ${ }^{35}$. Em concreto, os nórdicos receberam um manto de pele de lobo, uma espada, uma camisa, três lenços, uma vaca e três módios de sal. O que é curioso, porque trata-se de um resgate bastante mais complicado de estabelecer do que simplesmente apresentar ouro e prata, pesar e fazer um sinal que autorize a libertação dos cativos. Está-se a falar de diferentes tipos de bens e em quantidades diversas, pelo que se impõe a questão: como é que se acordou o conteúdo do resgate? Uma hipótese é que foi formulado um pouco à la carte, com os géneros a serem apresentados, os nórdicos a levarem o que quisessem e alguém a registar por escrito de forma passiva. Outra possibilidade é que houve uma forma de regateio silencioso, talvez com os vikings a apontarem para o que queriam e a indicarem as quantidades com os dedos, enquanto um portucalense respondia da mesma forma até se chegar a um acordo. Ou então, naquilo que será a hipótese mais fascinante, houve uma negociação verbal, caso em que terá de se admitir a presença de intérpretes ou de um ou mais nórdicos que soubessem uma língua compreensível por ibéricos ocidentais. E de repente, vemo-nos um pouco naquela cena do filme $O$ Último Viking, com Antonio Banderas, em que um dos nórdicos sabe falar latim. Não é tão improvável quanto se poderia pensar, até

\footnotetext{
${ }^{33}$ NELSON, 1991: 90-1.

${ }^{34}$ PIRES, 2015: 318-23.

${ }^{35}$ HERCULANO, 1868: 161, doc. 261.
} 
porque, por alturas de 1026, os nórdicos contavam já com dois séculos de contacto direto com o ocidente e sul europeus, pelo que não é impossível que alguns tenham aprendido a comunicar com os nativos. E o facto de o resgate ter sido pago na presença de homens do município reforça a ideia de que não se está perante uma coisa feita ad hoc, mas mais formalizada e bem organizada.

Por último, talvez tenha havido um ou mais ataques na década de 1050, a julgar pelo menos pela versão coimbrã das atas do concílio de Coiança, que listam a fuga de investidas vikings como um dos motivos aceitáveis para viajar a um domingo ${ }^{36}$.

\section{ATAQUES PÓS-VIKINGS}

Na Península Ibérica, tal como na generalidade da Europa, o século XII é uma fase de transição do período viking, quando há ainda uma continuidade de algumas práticas, mas no contexto de uma Escandinávia cristianizada e inserida nas redes culturais e políticas da Europa continental. No contexto ibérico, o caso que melhor exprime essa transição é a expedição de Sigurðr Jórsalafari Magnússon, comonarca norueguês que, por volta de 1107, partiu do seu país em cruzada até à Terra Santa, navegando por isso ao longo do que é hoje a costa portuguesa. Segundo o poema Útfarardrápa, que terá sido composto no século XII por Halldórr skvaldri, os cruzados noruegueses atacaram três cidades no ocidente ibérico: Sintra, Lisboa e Alkasse, que será provavelmente Alcácer do $\mathrm{Sal}^{37}$.

Ora, há nisto um problema imediato: Sintra não é uma povoação localizada numa praia, mas separada do mar por cerca de nove quilómetros, numa zona onde o terreno é acidentado e a própria costa dominada por escarpas e penhascos. Por outras palavras e por assim dizer, não está à mão de semear para um exército que se deslocava de barco. E assim sendo, como e por que motivo os noruegueses atacaram Sintra? Uma resposta possível é que eles foram direcionados para o local, em concreto pelo conde D. Henrique ou por um dos seus homens como parte de um acordo com o rei Sigurðr. A ideia de que havia uma aliança entre os dois homens data pelo menos de meados do século $\mathrm{XX}^{38}$ e de facto há notícia na Crónica dos Godos de que o pai de Afonso Henriques tomou Sintra precisamente em $1109^{39}$, embora o texto não esteja isento de dificuldades. Mas assumindo-se a sua veracidade, a tese de um acordo perde força quando se olha para os detalhes do ataque a Lisboa, que se verá de seguida, havendo uma hipótese alternativa a considerar: a de desejo de retribuição. Isto é, que Sigurðr e os seus homens foram atraídos para terra após terem sido atacados por tropas locais.

\footnotetext{
${ }^{36}$ RODRIGUES, 1999: 753-60, doc. 567.

${ }^{37}$ GADE, 2009: 483-92.

${ }^{38}$ AĐALBJARNARSON, 1951: 242, n. 189.

${ }^{39}$ HERCULANO, 1856: 11.
} 
Há alguns indícios que podem ser usados para justificar essa teoria, a começar pela existência de uma rede de postos de vigia costeiros na região, que se conhece a partir da arqueologia ou toponímia ${ }^{40}$. Um desses postos encontrava-se junto à foz do Colares, hoje a Praia das Maçãs, que está também próximo de duas outras praias ou, se se duvidar da sua existência no início do século XII, de uma parte da costa sintrense onde o terreno é menos acidentado e por isso mais propício a um desembarque $^{41}$. Mas se estes dados permitem especular sobre o onde da ida a terra do exército norueguês, falta o porquê, questão cuja resposta talvez esteja nas fontes nórdicas. É que a narrativa dos compêndios de sagas de reis assenta no relato poético de Halldórr skvaldri e onde, pelo menos na ordenação das estrofes que chegou até hoje, o ataque a Sintra é precedido de uma batalha naval. A descrição críptica fornecida pelos versos fala de uma vitória norueguesa, a captura de oito galés e refere-se aos atacantes como "vikings», o que mostra bem como o termo era usado com o sentido lato de piratas e não como sinónimo de um povo à parte. Algo que, de resto, vai ao encontro de usos similares da palavra noutras fontes poéticas ${ }^{42}$. Assim sendo, não é impossível que os "vikings» que atacaram a frota de Sigurðr possam ter sido marinheiros ou piratas muçulmanos. E a isto junta-se a descrição, no Morkinskinna, de Sintra como uma base para ataques a cristãos ${ }^{43}$. O que é curioso, porque o papel militar da povoação ou do seu castelo seria acima de tudo defensivo, não dispondo das condições demográficas ou naturais de Lisboa ou Alcácer, cidades que estariam mais bem preparadas para serem bases ofensivas.

Com base nestes dados, eis a minha proposta de reconstrução hipotética dos acontecimentos: enquanto navegava para sul, ao aproximar-se da costa sintrense, a frota norueguesa foi avistada por um ou mais postos de vigia costeiros, que logo deram o alarme e levaram à saída, quem sabe se de Lisboa, de uma esquadra islâmica de pelo menos oito embarcações para fazer face aos nórdicos. Após a vitória nórdica, Sigurðr pode ter querido retribuir, virando-se por isso para um alvo relativamente fácil na costa local. Pontos como o posto de vigia junto à foz do Colares, o que pode ter levado a que os nórdicos subissem o rio, se não de barco por causa do assoreamento ou da maré baixa, pelo menos a pé até atingirem Sintra e, conforme descreve Halldórr skvaldri, tomarem a povoação e massacrarem a sua guarnição. O que explicaria, por um lado, o porquê do ataque a uma povoação a cerca de nove quilómetros do mar e numa zona pouco propícia a desembarques; e por outro, a descrição de Sintra como uma base para ataques a cristãos, que seria assim uma memória da experiência dos

\footnotetext{
${ }^{40}$ BORGES, 2012: 111-15.

${ }^{41}$ BORGES, 2012: 124.

${ }^{42}$ JESCH, 2008: 49-50.

${ }^{43}$ ANDERSSON \& GADE, 2000: 316.
} 
noruegueses ${ }^{44}$. E desse modo resolve-se também a dúvida que José Mattoso em tempos manifestou sobre os meios de D. Henrique para tomar Sintra ${ }^{45}$, uma vez que, após o saque norueguês e o massacre da guarnição, seria mais fácil conquistar a povoação.

Não é por isso preciso imaginar uma aliança entre o Sigurðr e o pai de Afonso Henriques. As coincidências, tal como o sonho, também são uma constante da vida e esta pode ter sido um exemplo, mas ainda quando se olha para os detalhes da narrativa poética acerca do ataque a Lisboa. Em concreto, o facto de, segundo os versos de Halldórr skvaldri, o rei norueguês ter combatido junto de Lisboa («við borg, pás kalla Lizibón») na praia ou local onde ele desembarcou («es lenduð at frón»), o que sugere um ataque relâmpago a um espaço extramuros, talvez até um dos bairros que estavam situados do lado de fora das muralhas da cidade e junto ao esteiro do Tejo - logo, na praia - e não um cerco ou ataque prolongado que tivesse permitido tomar Lisboa. E se assim foi, é legítimo perguntar o que é que aconteceu à hipotética aliança entre Sigurðr e Henrique. Serviu apenas para Sintra? Faltou coordenação ou houve uma falha de comunicação? O comonarca norueguês mudou de ideias ao ver Lisboa? Ou deve-se pura e simplesmente aceitar que não houve qualquer acordo entre os dois homens e que Sintra é o único episódio que requer uma explicação à parte? Afinal, as outras duas investidas - Lisboa e possivelmente Alcácer do Sal - são fáceis de justificar por serem ambas povoações ribeirinhas e junto a grandes estuários, fazendo delas alvos naturais para um exército que se deslocava de barco.

A respeito do ataque a Alkasse, o que é que as fontes nórdicas dizem ao certo? Os compêndios de sagas de reis citam duas meias estrofes, uma com o topónimo e outra que refere apenas a destruição de uma cidade anónima, e os autores do século XIII parecem ter acreditado que ambos os conjuntos de versos se referem ao episódio de Alkasse. Mas há que recordar o que se disse no início, que as coletâneas de sagas de reis distam um ou mais séculos dos poemas que lhes serviram de fonte e que os dois registos narrativos nem sempre coincidem; por vezes, nota-se mesmo um uso criativo dos versos por parte dos autores das sagas ${ }^{46}$. E isso dever-se-á em parte ao efeito do tempo sobre a transmissão de memória, neste caso que, cerca de cem anos após a sua composição, algumas passagens do Útfarardrápa podiam já não ser inteiramente claras. Assim, pode-se questionar os contornos exatos do episódio de Alkasse, para o qual a primeira meia estrofe fala apenas de uma batalha fora ou junto da povoação («út, pars heitir Alkasse»), enquanto o segundo conjunto de versos pode, porventura, referir-se a outra ação militar, bem mais violenta, mas num local hoje desconhecido. A leitura das duas passagens como sendo sobre um mesmo epi-

\footnotetext{
${ }^{44}$ PIRES, 2014: 181-4.

${ }^{45}$ MATTOSO, 1993: 34-5.

${ }^{46}$ FRANK, 2005: 176.
} 
sódio pode ser assim um erro dos autores das sagas de reis, incertos ou equivocados sobre o sentido dos versos.

\section{VESTÍGIOS}

No final, o que é que ficou de vestígios da actividade viking em território português? Acima de tudo, a memória, embora não de um modo tão vincado quanto na Galiza, onde há uma série de festividades locais evocativas do período. Ficou talvez o castelo de Guimarães, se bem que, já se disse, não seja claro quem eram os gentios do testamento de Mumadona Dias.

E quanto a traços nórdicos nas embarcações tradicionais portuguesas? Talvez não. Pode haver semelhanças e até influências de origem escandinava, mas isso não quer dizer que elas tenham sido deixadas pelos vikings, cuja época teve lugar não há dez ou cem anos, mas há cerca de um milénio. O que quer dizer que elas podem ser o produto de contactos posteriores com, porventura, os reinos de França e Inglaterra, espaços onde os nórdicos se fixaram nos séculos IX e X e onde foram assimilados, embora mantendo vestígios das suas origens setentrionais. Para dar um exemplo do que quero dizer, considere-se a palavra portuguesa «quilha», que tem origem remota no nórdico kjölr, mas que não chegou até nós por via dos vikings. Em vez disso, provém do francês quille e é um dos vestígios da colonização nórdica da Normandia, onde são vários os vocábulos e topónimos de origem escandinava ${ }^{47}$. E nos cerca de mil anos que nos separam da Idade Viking, esses vestígios podem ter entrado na cultura portuguesa em épocas posteriores, do século XII em diante, por via de contactos com reinos como Inglaterra e França e não por participação direta dos nórdicos na cultura ibérica.

Por último, talvez tenha ficado alguma toponímia, nomeadamente Lordemão, junto a Coimbra, uma vez que o nome faz lembrar lordemanos, que é um dos termos pelos quais os vikings eram denominados nas fontes ibéricas. Neste caso, o topónimo recua pelo menos ao século $\mathrm{XII}^{48}$ - embora o documento não seja o ideal ${ }^{49}$ - e apesar de não haver qualquer registo de um ataque nórdico a Coimbra ou sequer da presença de vikings no Mondego. Mas lá está, não se sabe tudo e só se tem fragmentos de informação sobrevivente. Talvez tenha acontecido algo cujo único vestígio seja o topónimo e assumindo que ele tem alguma coisa a ver com a presença de nórdicos no que é hoje território português.

\footnotetext{
${ }^{47}$ RENAUD, 2008: 456.

${ }^{48}$ AZEVEDO, 1958: 73-4, doc. 59.

${ }^{49}$ AZEVEDO, 1962: 577-8.
} 


\section{CONCLUSÃO}

O ocidente ibérico foi um cenário periférico da Idade Viking. Nunca teve a importância das ilhas Britânicas ou de França, até por uma questão de distância geográfica, e o impacto no panorama político, cultural ou religioso da península terá sido reduzido. Não levou à formação de um reino novo ou comunidade distinta, não gerou um ressurgimento pagão, não alterou os idiomas nativos e não se conhece nenhuma base de inverno que, à semelhança de Dublin, tenha evoluído para um grande centro urbano ou comercial. Quando muito, põe-se a possibilidade de a ameaça de ataques ter contribuído para o desenvolvimento dos espaços costeiros e da frota do Andaluz ${ }^{50}$.

Terá, portanto, sido essencialmente um fenómeno de pirataria, sem planos de conquista ou fixação, embora se possa especular que a expedição de Gunderedo e os nove meses de atividade entre os rios Douro e Ave podem ter tido objetivos mais duradoiros. Mas sem certezas, dado que não se sabe se o fim desses episódios se ficou a dever por inteiro a ações militares ibéricas ou se os nórdicos tinham intenções de partir. A informação é demasiado escassa para se poder determinar com certeza os contornos exatos desses episódios.

Para encerrar, se é verdade que o que é hoje o território galego-português foi um cenário periférico, não é impossível que durante alguns anos, nas décadas de $960 \mathrm{e}$ 970, o rumo dos acontecimentos noutras partes da Europa tenha tornado o ocidente ibérico num espaço circunstancialmente relevante no universo viking. A cronologia fornece o indício: entre 920 e 950, ocorreu a reconquista inglesa da Inglaterra nórdica ${ }^{51}$ e a expulsão dos vikings da Bretanha ${ }^{52}$; a partir de 980, após a subida ao trono do rei Æthelred, abre-se uma nova e violenta vaga de ataques nórdicos em Inglaterra ${ }^{53}$; e entre esses dois períodos, nas décadas de 960 e 970, é quando ocorrem os ataques de 966, a expedição de Gunderedo na Galiza em 968-9, a entrada nos vikings no rio Douro e a sua presença na costa ibérica em 971 e 972 . Ressalve-se, no entanto, que este padrão de recrudescimento e crescimento pode ser apenas aparente, resultado da sobrevivência aleatória de registos documentais. Talvez o número de ataques no que é hoje território português tenha sido mais ou menos estável ao longo do século $\mathrm{X}$, mas o facto de haver mais fontes para as décadas de 960 e 970 pode criar hoje a ilusão de que houve um aumento de investidas vikings. E essa é uma possibilidade que nunca se pode pôr de parte, dado que, conforme se disse no início, o nosso conhecimento é limitado, tendo-se apenas fragmentos de informação sobrevivente e não um registo completo e detalhado da atividade nórdica no ocidente ibérico. A nossa visão é e, a menos que surjam fontes novas, continuará a ser parcial.

\footnotetext{
${ }^{50}$ PICARD, 2000: 194-195.

${ }^{51}$ KEYNES, 2001: 69.

52 PRICE, 2010: 459.

${ }^{53}$ KEYNES, 2001: 73-74.
} 


\section{FONTES}

AĐALBJARNARSON, Bjarni, ed. (1951) - Heimskringla, volume 3, Íslenzk Fornrit 28, Reykjavík: Hið íslenzka fornritafélag.

ANDERSSON, Theodore M.; GADE, Kari Ellen, trad. (2000) - Morkinskinna. The earliest Icelandic chronicle of the Norwegian Kings (1030-1157), Islandica LI, Ithaca e Nova Iorque: Cornell University Press.

AZEVEDO, Rui Pinto de, ed. (1958) - Documentos Medievais Portugueses, volume 1, tomo 1: Documentos régios. Documentos dos condes portucalenses e de D. Afonso Henriques A. D. 1095-1185, Lisboa: Academia Portuguesa de História.

ed. (1962) - Documentos Medievais Portugueses, volume I, tomo II: Documentos régios. Documentos dos condes portucalenses e de D. Afonso Henriques A. D. 1095-1185: aditamentos, fontes e índices, Lisboa: Academia Portuguesa de História.

CHRISTIANSEN, Eric, trad. (1998) - Dudo of St. Quentin: History of the Normans. Woodbridge: Boydell Press.

COELHO, António Borges, Coord. (1972) - Portugal na Espanha árabe, volume 1, Paralelos, Lisboa: Seara Nova.

FERNÁNDEZ GONZÁLEZ, Francisco, trad. (1999) - Ibn Idari Al Marrakusi. Historia de Al-Andalus, Málaga: Ediciones Aljaima.

FERNÁNDEZ, Juan Gil; RUÍZ DE LA PEÑA, Juan Ignacio; MORALEJO, José L., ed. (1985) -Cronicas asturianas, Publicaciones del Departamento de Historia Medieval/ Universidad de Oviedo 11, Oviedo: Universidad de Oviedo, Departamento de Historia Medieval, Departamento de Filologia Clasica.

GADE, Kari Ellen (2009) - Halldórr skvaldri, Útfarardrápa. In GADE, Kari Ellen, ed. - Poetry from the Kings' Sagas 2: From c. 1035 to c. 1300. Skaldic Poetry of the Scandinavian Middle Ages 2. Turnhout: Brepols, p. 483-92. Disponível em http://skaldic.abdn.ac.uk/db.php?id=1273\&if=default\&table=text\&val=intro. [Consulta realizada em 18/01/2017].

GARCÍA GÓMEZ, Emílio, trad. (1967) - Anales Palatinos del califa de Córdoba Al-Hakam II, por Isa Ibn Ahmad Al-Razi: (360-364 H.=971-975 J.C.), Madrid: Sociedad de Estudios y Publicaciones.

GARMONSWAY, G. N., trad. (1984) - The Anglo-Saxon Chronicle. Londres e Melbourne: Dent.

HERCULANO, Alexandre, ed. (1856) - Portugaliae Monumenta Historica: a saeculo octavo post Christum usque ad quintumdecimum, Scriptores I, Olisipone : Typis Academicis.

ed. (1868) - Portugaliae Monumenta Historica: a saeculo octavo post Christum usque ad quintumdecimum, Diplomata et Chartae 1, Olisipone: Typis Academicis.

JAMES, David, trad. (2009) - Ibn Al-Qutiya. Early Islamic Spain: the History of Ibn Al-Qutiya. Londres e Nova Iorque: Routledge.

NELSON, Janet L., trad. (1991) - The Annals of St-Bertin: ninth-century Histories 1. Manchester: Manchester University Press.

MAKKI, Mahmud Ali; CORRIENTE, Frederico, trad. (2001) - Crónica de los emires Alhakam I y Abdarrahman II entre los años 796 y 847 [Almuqtabis II-1]. Zaragoza: La Aljafería.

PÁLSSON, Hermann; EDWARDS, Paul, trad. (1981) - Orkneyinga saga: the History of the Earls of Orkney. Londres: Penguin Books.

RODRIGUES, Manuel Augusto, ed. (1999) - Livro Preto: cartulário da Sé de Coimbra. Coimbra: Arquivo da Universidade. 


\section{BIBLIOGRAFIA}

ALMAZÁN, Vicente (1986) - Gallaecia Scandinavica: introducción ó estúdio das relacións galaicoescandinavas durante a Idade Media. Tradução de Cidrás Escáneo. Vigo: Galaxia.

ALSINA, Fernando López (2004) - La cristalización de Tui como espacio de poder señorial entre 1095 y 1157. In SOUTELO, Silvia González; FERNÁNDEZ, Marta Cendón, coord. - Tui, presente, pasado y futuro: I Coloquio de Historia de Tuy. Pontevedra: Diputación de Pontevedra, p. 57-95.

AZEVEDO, Rui Pinto de, (1973) - A expedição de Almançor a Santiago de Compostela em 997, e a de piratas normandos à Galiza em 1015-16. «Revista Portuguesa de História», Tomo XIV. Coimbra: Atlântida Editora, p. 73-93.

BORGES, Marco Oliveira (2012) - A defesa costeira do litoral de Sintra-Cascais durante o Garb al-Ândalus I: em torno do porto de Colares. In «História: Revista da FLUP», IV Série, volume 2. Porto: Universidade do Porto, p. 109-128.

FLÓREZ, Enrique (1798) - España Sagrada: theatro-geographico de da Iglesia de España, Tomo XXII. Madrid: Oficina de la viuda é hijo de Marin.

FRANK, Roberta (2005) - Skaldic Poetry. In CLOVER, Carol; LINDOW, John, coord. - Old NorseIcelandic Literature: a critical guide. Toronto: Toronto University Press, Medieval Academy of America, p. 157-196.

JESCH, Judith (2008) - Ships and Men in the Late Viking Age. The Vocabulary of Runic Inscriptions and Skaldic Verses. Woodbridge: Boydell Press.

KEYNES, Simon (2001) - The Vikings in England, c. 790-1016. In SAWYER, Peter, coord. - The Oxford Illustrated History of the Vikings. Oxford: Oxford University Press, p. 48-82.

LUND, Niels (2001) - The Danish Empire and the End of the Viking Age. In SAWYER, Peter, coord. - The Oxford Illustrated History of the Vikings. Oxford: Oxford University Press, p. 156-181.

MATTOSO, José (1993) - 1093-1325. In MATTOSO, José, coord. - História de Portugal 2: a Monarquia Feudal (1096-1480). Lisboa: Círculo de Leitores, p. 10-309.

PIRES, Hélio (2014) - Word from the south: a source for Morkinskinna?. «Viking and Medieval Scandinavia», vol. 10. Turnhout: Brepols, p. 172-186.

(2015) - Nem Tui, nem Gibraltar: Oláfr Haraldsson e a Península Ibérica. «En la España medieval», vol. 38. Madrid: Universidad Complutense de Madrid, p. 313-328.

PRICE, Neil (2010) - The Viking conquest of Brittany. In BRINK, Stefan; PRICE, Neil, coord. - The Viking World. Londres e Nova Iorque: Routledge, p. 458-61.

RENAUD, Jean (2010) - The Duchy of Normandy. In BRINK, Stefan; PRICE, Neil, coord. - The Viking World. Londres e Nova Iorque: Routledge, p. 453-457. 


\title{
INCURSÃO NORMANDA AO CASTELO DE VERMOIM: O ESPÍRITO DO TEMPO E DO LUGAR
}

\author{
ARMANDO COELHO FERREIRA DA SILVA*
}

\section{NOTA SOBRE O CONTEXTO HISTÓRICO DOS MEADOS DA IDADE MÉDIA NO QUADRO DA DEFESA, RECONQUISTA E REORGANIZAÇÃO DOS TERRITÓRIOS DO NOROESTE PENINSULAR}

Sabe-se, por uma breve notícia, que nos foi transmitida pela Chronica Gothorum, que o Castelo de Vermoim (Fig. 2: 18, 5), ora situado nessa freguesia do concelho de Vila Nova de Famalicão e, então, cabeça da Terra do mesmo nome, foi alvo de um ataque de piratas normandos, em 6 de setembro de 1016, segundo a correspondência do calendário romano ao da era cristã, quando aí se encontrava, certamente refugiado, o Conde de Portucale, Alvito Nunes:

Era MLIV viii idus septembris veniunt Lormanes ad castellum Vermudii, quod est in provincia Bracharensi. Comes tunc ibi erat Alvitus nuniz ${ }^{1}$.

\footnotetext{
* Professor catedrático jubilado da Faculdade de Letras da Universidade do Porto; Investigador do Centro de Investigação Transdisciplinar Cultura, Espaço e Memória (CITCEM; FLUP/FCT): Coordenador científico do Gabinete de Arqueologia de Vila Nova de Famalicão.

${ }^{1}$ HERCULANO, 1856: 9.
} 
Conforme observou Hélio Pires, na sua obra sobre as incursões normandas no ocidente ibérico ${ }^{2}$, a brevidade da fonte não nos permite conhecer nem os contornos do ataque, nem o percurso seguido e nem sequer o seu desfecho, que se presume, por outras informações, ter sido trágico. Mas, só o facto de o referir significará que não terá sido uma investida qualquer, mas certamente de uma incursão que terá penetrado mesmo no interior da região minhota e que terá, por isso, tido um impacto significativo, quando ainda ecoavam ressonâncias apocalípticas anunciadas pelos profetas do milenarismo.

Seja como for, tratar-se-á de uma das últimas investidas destes homens do norte, que durante dois séculos, a partir de 844, atacaram mais ou menos intermitentemente as costas do ocidente peninsular, e que agora, sediados junto de Portucale, desde julho de 1015, acossaram, durante nove meses consecutivos, a região entre Douro e Ave e levantaram ferro do porto do Douro em abril do ano seguinte.

Segundo Rui Pinto de Azevedo³, teria sido este o grupo responsável pelo ataque ao Castelo de Vermoim, concluindo, nestes termos, que tal só se poderia ter efetuado em setembro de 1015, e não no ano seguinte, não estando, assim, certa a data mencionada na Chronica Gothorum ${ }^{4}$, do que, por sua vez, discorda Hélio Pires, que a considera poder estar correta, sobrando duas hipóteses para o grupo que levou a cabo o ataque de 1016: «A primeira vai no sentido de algo que Rui Pinto de Azevedo também disse ${ }^{5}$, de se tratar do mesmo bando que esteve activo entre os rios Douro e Ave e que, após a sua partida em Abril de 1016, pelo menos parte seguiu para sul antes de regressar a norte no final do Verão, altura em que penetrou no território portucalense até Vermoim. A segunda hipótese é que se trata de um grupo distinto do qual nada mais se sabe», e justifica esta alternativa com outros casos conhecidos de ataques vikings, quase simultâneos e geograficamente próximos, mas levados a cabo por grupos distintos, como a entrada de piratas nórdicos no Somme, em 859, numa altura em que outro bando já se encontrava no Sena, nada obrigando, assim, a que uma incursão nórdica que avançou trinta quilómetros para o interior tenha de estar relacionada com outra que levou a cabo feito idêntico quase ao mesmo tempo ${ }^{6}$.

Foi este sobressalto precedido, cerca de meio século antes, em 968-969, pela incursão normanda de maior alcance no noroeste peninsular, comandada por Gunderedo, que provocou a devastação de vários centros religiosos na região de Santiago de Compostela, que se tornara, desde a miraculosa «invenção» do túmulo do Apóstolo, em 813 ou 814, no principal lugar de peregrinação do ocidente europeu,

\footnotetext{
2 PIRES, 2012: 175-177.

${ }^{3}$ AZEVEDO, 1974: 88.

${ }^{4}$ AMARAL, 2007: 98-99.

${ }^{5}$ AZEVEDO, 1974: 88.

${ }^{6}$ PIRES, 2012: 176-177.
} 
e, por ricochete, se transformou no alvo da ira dos infiéis, sejam eles gentios sejam muçulmanos.

Contra este centro da cristandade se dirigirá, justamente, a maior campanha de Almançor ${ }^{7}$ que, passando por cidades e mosteiros que destrói ou danifica, como as cidades de Coimbra e Braga e os mosteiros de Cete e Ganfei, chegou a Santiago em 11 de agosto de 997, onde saqueou e destruiu a Catedral, servindo-se das portas da igreja para construir navios e levando os sinos da torre para os colocar na Grande Mesquita de Córdova, como troféu da vitória.

Mas, se a catedral foi destruída e as relíquias do Apóstolo não foram, surpreendentemente, perturbadas por parte de Almançor, não terá sido ele movido, nesta guerra, por motivos exclusivamente religiosos, apesar do seu reconhecido fanatismo e da sua vontade em destruir completamente os estados cristãos, visando fazer do Califado de Córdoba o grande potentado peninsular?

Estes factos, como observou J. Rodrigues ${ }^{8}$, levam a pensar que a expedição empreendida contra Compostela terá sido mais uma tentativa para comprometer o inexorável avanço da reconquista cristã para sul, atacando aquele que era o seu principal centro religioso e símbolo e justificação do espírito de cruzada cristão, pretendendo, com esta ação, desmoralizar o ânimo da cristandade.

Ao não destruir o seu túmulo, porém, este gesto acabará em resultado contraproducente, uma vez que os cristãos veem reforçada a sua fé no Apóstolo, de tal forma poderoso, que nem o Almançor tinha conseguido - ou ousado - destruir o seu túmulo, as suas relíquias, que são, para os cristãos, a sua presença viva e o seu santuário um dos locais privilegiados, onde o Céu e a Terra se encontram, caminho simbólico para a salvação ${ }^{9}$.

Não podemos deixar de sinalizar, neste contexto, as diversas invocações a S. Tiago como oragos de uma série de freguesias da Terra de Vermoim, em S. Tiago de Antas, de Castelões, de Gavião, de Moldes (Cruz), de Mouquim, de Outiz, e da capela de Ninães (S. Silvestre de Requião), no concelho de Vila Nova de Famalicão, e de S. Tiago de Landim (Areias), concelho de Santo Tirso, e de Ronfe, concelho de Guimarães ${ }^{10}$, para mais tendo essa expedição seguido seguramente pela antiga via romana XVI do Itinerário de Antonino, que no concelho de Vila Nova da Famalicão se encontra bem testemunhada por uma série de marcos miliários que lhe definem o percurso desde a entrada na região da Trofa até às proximidades de Braga.

E sirva esta referência de vitalidade visível na organização religiosa da Terra de Vermoim como sinal do ambiente de maior segurança que se terá observado nos

\footnotetext{
${ }^{7}$ RODRIGUES, 2011.

${ }^{8}$ RODRIGUES, 2011: 103.

${ }^{9}$ RODRIGUES, 2011: 103.

${ }^{10}$ AMARAL, 2007: 710-711.
} 
territórios a norte do Douro após a presúria do Porto por Vímara Peres, em 868, não obstante as perturbações causadas pela violência das expedições de Almançor e dos piratas normandos, de que o ataque ao Castelo de Vermoim (Fig. 5) não pode deixar de se interpretar como um episódio relevante do protagonismo significativo assumido por Portucale na reorganização do poder regional e no reordenamento do espaço reconquistado sob a tutela de uma nobreza condal, que tivera como fundador o próprio presor Vímara Peres, mesmo que um seu descendente aí tenha encontrado um final menos feliz.

\section{SIGNIFICADO TOPONÍMICO DO LOCAL FACE À TRADITIO ARQUEOLÓGICA DA SUA OCUPAÇÃO E AO SUBSTRATO LINGUÍSTICO REGIONAL}

Entre as numerosas referências da documentação medieval sobre esta reorganização do território da diocese bracarense ${ }^{11}$, selecionámos três delas que se reportam a unidades paroquiais da Terra de Vermoim, dizendo respeito às atuais freguesias de Joane (datada de 1065: in villa Joannis subtus mons Kastro Vermui ${ }^{12}$ ), Requião (1114: in villa Requilani subtus castelo Vermudi territorium Bracarense discurrente ribulo Ageredi ${ }^{13}$ ) e Pousada de Saramagos (1194: villa que vocitant Pousada subtus mons Vermui território Bracarense discurrente rivulo Peelio ${ }^{14}$ ), que ainda mantêm a mesma designação.

Criadas, como dizem os textos, no sopé do monte, em zonas de exploração agrária, que lhe é assignada pela designação de villa, termo geral referente a uma propriedade rural, vinda dos tempos romanos, e, mais tarde, a uma aldeia ${ }^{15}$, todas se reportam ao Monte, Castro ou Castelo enquanto designativo da cabeça da Terra de Vermoim, hoje remanescente na designação paroquial e civil de Vermoim e mantendo a aura do prestígio medieval que deu nome a toda a plataforma montanhosa em que se enquadra.

Cita este antropónimo germânico o nome do seu possessor, que mais assinala a deslocação do centro de poder, que em época do domínio romano cremos estar localizado, em planície, no vicus de Perrelos ${ }^{16}$, para a periferia do Alto das Eiras, em sítio mais apropriado aos desígnios protetores do processo de «encastelamento» altimedievo, que ora substitui as funções do antigo «lugar central» dos finais dos tempos proto-históricos nesta zona do curso médio do Ave, a que se reporta o episódio, hoje comemorado, da Chronica Gothorum.

\footnotetext{
${ }^{11}$ COSTA, 1959; MARQUES, 2005; AMARAL, 2007; MARQUES, 2014.

12 COSTA 1959: 127.

${ }^{13}$ COSTA 1959: 37.

${ }^{14}$ COSTA 1959: 32.

${ }^{15}$ SAMPAIO, 1979a.

${ }^{16}$ SILVA et al., 2005: 46-47; SILVA 2007b: 133-135.
} 
Todas essas designações assumem, segundo J. Piel ${ }^{17}$, a forma peculiar dos topónimos qualificados como de proprietários, em que se reflete o nome de pessoa na forma do genitivo em -i, próprio dos antropónimos godos com terminação, no idioma de origem, em $-s$ e que foram latinizados em -us ${ }^{18}$ : Bermudus, Bermudi, com resultado moderno Vermoim, aqui registado em Vila Nova de Famalicão e no concelho da Maia (Vermudi), ou também Vermuy, na Maia, e Bermuy, na Corunha.

Não se tratará, assim, como muito bem observou Domingos A. Moreira a propósito de Vermoim, da Maia ${ }^{19}$, do nome pessoal Vermoino, enquanto diminutivo do nome pessoal germânico Vermudo, da série de nomes em Ver-dago, Ver-medus, Wer-aldo, etc., e de nomes em Mod/Mud como Floc-muda, Lare-mut, Milimut, Ricmod, etc., como cria J. Leite de Vasconcellos (Opúsculos, III-287), mas, seguindo J. Piel, simplesmente, do nome V/Bermudo, em genitivo, com deslocação da nasalidade para a última sílaba por via de uma hipercorreção erudita ou, talvez melhor, devido ao peso da tradição popular. Nestes termos, o genitivo -mudi teria evolucionado para -ui sob a ação da nasal, produzindo-se uma deslocação do acento para o segundo elemento do ditongo, como ocorre em português no adjetivo rúim/róim/ruím ${ }^{20}$.

Constitui este vocábulo, segundo o mesmo investigador ${ }^{21}$, um antropónimo bitemático, que quer dizer «valor do urso», $v{ }^{*}$ ber $<$ bair(a) 'urso' $+{ }^{*}$ mud $<\bmod$ 'valor', em gótico, vocábulo significando o segundo termo um uso metafórico, apropriado do sentido literal de 'castanho', desse temido animal selvagem, certamente por tabu, em consideração à perda da designação indo-europeia, como ursus, em latim, e arctos, em grego, que se regista nas línguas germânicas, assignando-se-lhe, deste modo, um especial caráter religioso.

Fica-lhe, assim, mais implícito o conceito de que o guerreiro tinha de dar provas de coragem e de valor, não temendo expor-se aos perigos, para poder ambicionar a vitória e, com ela, a paz, a proteção da comunidade e, daí, a fama e a glória. Afinal, o mesmo conceito de ideal de excelência que nos é dado perceber ter sido o dos guerreiros castrejos, cuja estatuária, mais de mil anos antes, imortalizou como heróis divinizados, e que igualmente se depreende dos registos de teor céltico que nos ficaram dos seus nomes transmitidos pela epigrafia latina, bem ajustados à ação e ao funcionamento mítico de chefaturas fundacionais, como entendemos ser a designação referente ao Castelo de Vermoim.

Mais manifestará esta versão o rasto de um substrato matricial indo-europeu, se observarmos a identidade de correspondência geográfica entre esse modo de for-

\footnotetext{
${ }^{17}$ PIEL, 1960b: 543.

${ }^{18}$ PIEL, 1960a: 9.

${ }^{19}$ MOREIRA, 1964: 73.

${ }^{20}$ PIEL, 1960a: 553-557.

${ }^{21}$ PIEL, 1960a: 438.
} 
mação linguística com o da área castreja do noroeste peninsular e o das isoglossas do galaico-português, sendo ele claramente delimitado às províncias galegas (Lugo, Corunha, Ourense e Pontevedra) juntamente com os distritos portugueses do Minho (Viana do Castelo e Braga) e Douro Litoral (Porto), que constituem o núcleo principal, apresentando um prolongamento progressivamente mais débil nas regiões limítrofes, principalmente nas províncias de Oviedo, de Trás-os-Montes e das Beiras (Litoral e Alta), com os distritos de Aveiro e Viseu ${ }^{22}$.

E cremos bem serem tais designações emblemáticas indiciadoras de uma indo-europeização cumulativa, iniciada com o começo da Idade dos Metais, bem organizada durante a proto-história com relações ao mundo céltico, dominadas pelo latim durante a romanização, para ressurgirem ao lado de outros protagonistas, germânicos, ao longo da Idade Média.

Uma leitura seletiva da carta arqueológica da região (Fig. 2) mais evidenciará a importância destes sítios e dos nomes destes lugares dos Montes de Vermoim (Fig. 1), que remontam às origens do seu povoamento, cujos primeiros testemunhos estão ligados à difusão do megalitismo na região, acompanhando os passos de um longo e complexo processo comum ao noroeste peninsular relacionado com uma profunda transformação económica, social e cultural que terá ocorrido durante cerca de dois mil anos a partir do V/IV milénio a. C.

Fenómeno estritamente dependente da mutação da própria estrutura da sociedade, a sua expansão corresponde à transição de sociedades predadoras para formas de economia de subsistência baseadas na produção de recursos alimentares por meio da agricultura e da criação de gado, ainda que com pervivência da caça e atividades recoletoras de frutos espontâneos da natureza.

Implantando-se sobretudo nas zonas planálticas da área mais litoral, marcando decisivamente a densidade de futuras ocupações, as expressões arqueológicas mais características são constituídas por monumentos com uma estrutura dolménica, como os que foram descobertos nos Montes de Vermoim, conferindo-lhes, deste modo, carácter fundacional.

Formando um conjunto de quatro mamoas muito próximas (Fig. 2: 1-4), três de grandes dimensões e uma mais pequena e baixa, duas delas que se destacam pela volumetria dos seus tumuli, estão na parte central da chã, ocupando uma destas, a mamoa de Mar de Água, pela sua monumentalidade e visibilidade, que a localização favorece, uma certa hierarquização dentro do agrupamento.

Assinalará este núcleo megalítico, localizado na freguesia de Vermoim, a existência de pequenas unidades sociais dispersas, dotadas de uma economia baseada em formas incipientes de agricultura, que se complementava com a recoleção e muito

22 PIEL, 1960b: 543. 
provavelmente com a criação de gado e a caça, segundo o modelo económico e social mais verosímil, também deduzido da capacidade de recursos propiciados pelo meio, que não difere substancialmente das suas congéneres nortenhas.

E se a construção de tão importantes monumentos funerários dos nossos primeiros agricultores não supõe um ordenamento social fortemente hierarquizado, implica, pelo menos, a utilização de formas de cooperação organizada para o cumprimento de tarefas que, no mínimo simbolicamente, assumiam um sentido coletivo.

A descoberta, nas proximidades, de vestígios característicos da Idade do Cobre no Monte do Facho (Fig. 2: 22), da freguesia do Calendário, poderá assinalar o advento do período calcolítico, que, nesta sequência, também se documenta na Bouça do Pique (Fig. 2: 6), em Pousada de Saramagos, onde foi encontrado um machado polido de quartzito e dois vasos cerâmicos inteiros de forma hemisférica e ornamentados segundo as técnicas e os padrões decorativos da cerâmica «tipo Penha», típica dos povoados de ar livre da fase final do megalitismo. Podem tais novidades considerar-se já como calcolíticas, em sentido amplo, pois, tanto podem contemplar populações que conheciam o metal como as que o manuseavam, em todo o caso, demonstrando o progressivo desenvolvimento económico da comunidade dos Montes de Vermoim, ora atestado pela introdução de uma nova série de artefactos de prestígio, que não poderemos deixar de associar a influências indo-europeias, segundo as mais plausíveis interpretações para o puzzle das origens dessa família linguística na região, ainda hoje pervivente, sobretudo, nos principais orónimos e hidrónimos regionais.

Não tendo sido identificado nenhum povoado relacionado com o fenómeno neolítico, são estes os primeiros lugares de habitat documentados na área do concelho de Famalicão, datáveis do começo da Idade dos Metais, período em que se iniciou a produção de objetos de cobre ao mesmo tempo que se continuaram a fabricar artefactos de pedra e, por isso, ser designado como Calcolítico.

Ter-se-á, então, assistido ao desenvolvimento da economia baseada na agricultura e criação de gado e à introdução das primitivas formas de metalurgia, que terão acentuado a divisão geral do trabalho, a acumulação de riqueza e o incremento de formas de intercâmbio, e que está unicamente documentado, na área do concelho de Famalicão, por uma lâmina de ouro de tiras, do Bronze Inicial ${ }^{23}$, cuja proveniência se atribui à freguesia de Sezures (Fig. 2: 8).

Constituindo este elemento mais um dado que testemunha a primeira etapa de um reconhecido desenvolvimento da ourivesaria pré-histórica no noroeste peninsular, cuja especificidade morfológica, técnica e funcional se manifesta no âmbito das relações que envolveram a fachada atlântica, do noroeste europeu ao ocidente mediterrânico, a partir dos inícios da Idade do Bronze, sinalizará este bem de prestígio a

${ }^{23}$ SILVA, 2007b: 156-157. 
emergência de um novo modo de produção, conformador das sociedades estratificadas e protoestatais da Idade do Bronze, que na área do concelho só se encontra representado na sua fase final por uma série de achados cerâmicos e metálicos indicadores do progresso havido durante mais de um milénio.

Perdido, com efeito, o rasto desses primeiros vestígios, não possuímos dados referentes às sequências culturais das etapas imediatas à introdução da metalurgia durante a Idade do Bronze Antigo e Médio, à primeira fase do Final da Idade do Bronze, datável entre 1250-1100 a. C., pertencerá o achado, ocorrido na freguesia do Bairro (Fig. 2: 9), de quatro vasos cerâmicos e uma bracelete de ouro maciço ${ }^{24}$, de provável contexto funerário de um enterramento de incineração, cuja novidade aponta para um relacionamento centro-europeu, por via de influências dos Campos de Urnas associáveis ao mundo céltico linguisticamente bem visibilizado na onomástica local e regional. Atribuível a um pequeno casal, testemunhará este sítio da Quinta da Bouça um padrão de povoamento antecedente ao dos povoados em altura, que vão caracterizar, de seguida, a fase originária da cultura castreja do noroeste peninsular.

Com efeito, é assinalável, nesta sequência, o conjunto de indícios referentes a um número considerável de sítios de povoamento (Fig. 2: 13-27), nomeadamente em altura, segundo critério seletivo que marcará, doravante, a estratégia de domínio e defesa territorial das comunidades indígenas ao longo do primeiro milénio a. C., denunciando a implantação de um novo modelo económico e social comum a toda a região do noroeste peninsular, que se conhece como resultado de um processo paulatino, que fez evoluir a mancha ocupacional do território desde pequenos aglomerados habitacionais do final da Idade do Bronze até ao aparecimento de grandes núcleos urbanos no final da Idade do Ferro.

Constituindo uma cultura arqueológica individualizada, cujo processo evolutivo nos é particularmente bem conhecido para o curso médio e final do $\mathrm{Ave}^{25}$, a sua especificidade encontra apoio material numa ergologia, particularmente especializada na artesania metalúrgica e cerâmica, e a organização da sociedade se reflete em formas protourbanas de ocupação e organização do espaço e singulares expressões simbólicas, de que o monumento para banhos iniciáticos do Alto das Eiras (Fig. 2: $17,3)$ se há como a peça mais emblemática, a que se deverão associar as referências onomásticas primordiais que nos foram sobretudo transmitidas pelos registos epigráficos latinos que nos fazem remontar a um substrato linguístico, que temos de reconhecer como de grande antiguidade.

Será porventura de sublinhar, neste passo, a importância da referência de povoamento indígena da comunidade castreja do curso médio do Ave, que teria estabelecido

\footnotetext{
${ }^{24}$ SILVA, 2007b: 158-161.

25 DINIS, 1993.
} 
o seu «lugar central» no "Alto das Eiras» (Fig. 2: 17, 3), donde dominava um vasto território nuclearizado em torno de uma série de povoados fortificados dependentes e que cremos identificada na inscrição dos Valabrigenses ${ }^{26}$ que, globalmente, entendemos ver, enquanto entidade administrativa, mas também identitária, o território que cerca de mil anos mais tarde vai ter por cabeça o Castelo de Vermoim (Fig. 2: 18, 5), donde houve nome a Terra que tutelava.

Assentou este castelo as suas bases, justamente, sobre as ruínas de um povoado castrejo, assim, conhecido como Castro de Vermoim (Fig. 2: 18, 4) ${ }^{27}$, localizado na mais imediata proximidade do Alto das Eiras, em privilegiada situação estratégica, ocupando uma proeminência em posicionamento topográfico de excelente visibilidade para o vale fértil do rio Pele, e que era dotado de um forte sistema defensivo, de que se reconhece um recinto definido por uma muralha que acompanha, grosso modo, a curva de nível dos $325 \mathrm{~m}$, reforçado do lado mais vulnerável, o norte, por um conjunto de três taludes e três fossos.

Identificado por Francisco Martins Sarmento em $1880^{28}$, apesar da sua monumentalidade, só foi objeto de escavações arqueológicas, dirigidas por Francisco Queiroga, entre 1982 e 1985, que evidenciaram a ocupação do sítio entre os séculos III/II a. C. e a época de Augusto, além da posterior ocupação medieval, comprovada historicamente pela Chronica Gothorum, que refere a incursão normanda, que hoje celebramos com uma reunião científica, transdisciplinar, sobre a sua memória ${ }^{29}$.

$\mathrm{E}$, ao sublinharmos as raízes deste sítio, mais uma vez relevamos a importância do substrato no processo de formação das Terras enquanto entidades administrativas, mas também identitárias, que, quanto a nós, não se torna inteligível sem o estudo da realidade proto-histórica que lhe está subjacente e lhes garantia uma profunda solidez de implantação.

\section{DAS REFERENCIAÇÕES HISTORIOGRÁFICAS À VALORIZAÇÃO PATRIMONIAL DOS MONTES DE VERMOIM}

Foi esta estruturação do território, precursora da fundação da nacionalidade, atingida por continuados movimentos de navegadores vikings que, desde o saque das ilhas britânicas, nos finais do século VIII, ligaram às costas escandinavas o destino da Irlanda, duma parte das ilhas britânicas, da Gronelândia, duma estreita banda costeira do Labrador, da Terra Nova, da «Nova Escócia» e da «Nova Inglaterra», implantando, no século XI, uma gigantesca talassocracia, cuja influência abrangia a maior parte do hemisfério norte até à Europa de Leste e à Ásia Central.

\footnotetext{
${ }^{26}$ SILVA, 2007a: 152-153.

${ }^{27}$ DINIS, 1993: 65-66.

${ }^{28}$ SARMENTO, 1989: 17-22.

${ }^{29}$ QUEIROGA, 1985: 56.
} 
A importância destas incursões de piratas normandos que, desde meados do século IX, durante o reinado de Ramiro I (842-850), começaram a infestar as costas do noroeste da Península, até ao século XI, foi oportunamente salientada por Alexandre Herculano na Introdução da História de Portugal ${ }^{30}$. Também Alberto Sampaio em As Póvoas Marítimas ${ }^{31}$, se refere a esta incursão ao Castelo de Vermoim e às principais dessas investidas em território peninsular e mais particularmente nas costas portuguesas aos danos por elas motivados e às precauções a que deram origem, mas sem que deixe de assinalar situações documentadas de convivência amigável, certamente beneficiada pelo parentesco dos padrões linguísticos e do sistema cultural, também de raiz indo-europeia, que poderia ter resultados de manifesta utilidade para a aprendizagem de conhecimentos da navegação atlântica.

Na sequência desta observação do famalicense Alberto Sampaio, torna-se-nos legítimo, hoje, apelar aos especialistas em história náutica que retomar as questões genericamente enunciadas por Jaime Cortesão ${ }^{32}$ e praticamente desativadas, entre nós, desde o estudo de O. Lixa Filgueiras ${ }^{33}$, sobre o contributo escandinavo para os descobrimentos portugueses, quando refere que a eles se deve a navegação à vela no Atlântico e um novo tipo de barco, adotado a seguir por todas as marinhas europeias, a ponto de as naves dos séculos XIII e XIV não passarem de barcas normandas, sobrecarregadas pesadamente com adições sucessivas. Contrariando a tradição mediterrânica atribuída ao seu carácter recurvo, mais acrescenta que certos barcos usados pelos pescadores do norte $\mathrm{e}$ do centro de Portugal, e muito especialmente na Caparica, parecem ter por veneráveis ascendentes os drakkar normandos, similares aos hodiernos barcos de pesca noruegueses.

Mais se apela a esta pesquisa, a propósito desta incursão ao Castelo de Vermoim, quando, nesta sequência, Jaime Cortesão invoca a iconografia dos capitéis da abside da igreja românica de Rio Mau (Fig. 6-7), situada no curso do Este, afluente do rio Ave, em relativa proximidade a qualquer dos percursos seguidos no ataque de 1016, representando, em sua opinião, o maior, um drakkar, e o mais pequeno, possivelmente um holker, cujo modelo aparece nas tapeçarias de Bayeux, e cuja existência poderá ser avalizada pela menção de embarcações com o nome de holoc, halocas e aloques em diversa documentação do século XIII.

E, a propósito desta referência, não podemos deixar de investigar os caminhos de intermediação de alguns termos náuticos que se conservam na língua portuguesa, igualmente presentes no francês moderno, e que poderão também ver-se como derivados do escandinavo antigo ${ }^{34}$.

\footnotetext{
${ }^{30}$ HERCULANO, 2007: 109 e ss.

${ }^{31}$ SAMPAIO, 1975b: 32-36.

${ }^{32}$ CORTESÃO, 2016: 192-193.

${ }^{33}$ FILGUEIRAS, 1965.

${ }^{34}$ RIDEL, 2009.
} 
Constituindo um conjunto particularmente coerente, nele se pode incluir a série de vocábulos rastreados, entre os termos marítimos, a palavra vaga $<^{*}$ vag, onda, movimento ondulatório que aparece à superfície de uma extensão líquida por ação do vento ou outros fatores ${ }^{35}$; várias designações de elementos da construção naval, como os vocábulos bordo < ${ }^{*}$ bord, prancha que recobre o exterior da coque do barco ${ }^{36}$, carlinga $<{ }^{\star}$ kerling, peça de madeira fixada à quilha, onde se vai implantar o mastro ${ }^{37}$ (Fig. 13), guindaste /guindar < * vindass, içar, em particular, uma vela, uma âncora, uma carga a bordo de um barco ${ }^{38}$ (Fig. 17), quilha < ${ }^{\star}$ kilir, ant, esc., pl. de kjölr, longa peça de madeira que constitui a peça mestra da carpintaria primitiva de um barco ${ }^{39}$; equipar $<{ }^{*}$ skipa, prover um navio em homens e material $=$ armar, aparelhar ${ }^{40}$ e frota $<{ }^{\star}$ floti, tropa, bando, rebanho ${ }^{41}$ ou armada naval que participa nas expedições vikings, por extensão toda a reunião de navios, de guerra ou comércio ${ }^{42}$, referentes ao equipamento; e ainda bolina < ${ }^{\star}$ bóglína, vela orientada de viés ${ }^{43}$, relativa às técnicas de navegação.

$\mathrm{E}$, com estes termos, se pretende concluir sobre a importância da realização deste colóquio que a Câmara Municipal de Vila Nova de Famalicão resolveu promover como a melhor forma de trazer para o presente tanto passado, tanto de interesse local, como nacional e internacional. E poderá usar, em breve, um verbo, também derivado do escandinavo antigo, e que foi assimilado, para exprimir casos de sucesso: poderá gabar-se $<^{*} g a b b a$, 'ufanar'-se, 'orgulhar'-se ${ }^{44}$, quando o conjunto arqueológico dos Montes de Vermoim for consagrado, como se espera, com a classificação de património monumental, assim, valorizando tão excecional riqueza ambiental, paisagística e cultural.

E cumprir-se-á o desígnio do oráculo deste lugar, quando, há mais de centena e meia de anos, alguém o consultou:

- Não tens uma história de feitiços que me contes? [...]

- Da crista do monte descobrem-se verdadeiros thesouros, fertilíssimas campinas, povoações a branquejarem entre florestas, bosques cercados pelas agulhas das torres, rios que serpenteiam por entre almargens e hervaçaes, enfim, o Minho, o espetáculo prodigioso que faz amar Portugal e pedir a Deus nos não deixe ir tão longe no caminho do progresso material que, ao cabo de contas, é a phrase própria, fiquemos sem pátria por amor do aperfeiçoamento da matéria ${ }^{45}$.

\footnotetext{
${ }^{35}$ RIDEL, 2009: 273.

${ }^{36}$ RIDEL, 2009: 178.

${ }^{37}$ RIDEL, 2009: 185-186.

${ }^{38}$ RIDEL, 2009: 220.

${ }^{39}$ RIDEL, 2009: 252.

${ }^{40}$ RIDEL, 2009: 198.

${ }^{41}$ RIDEL, 2009: 210.

42 RIDEL, 2009: 206-207.

${ }^{43}$ RIDEL, 2009: 179-180.

${ }^{44}$ RIDEL, 2009: 213-214.

${ }^{45}$ CASTELO BRANCO, Vinte horas de liteira apud OLIVEIRA, 2007: 212.
} 


\section{BIBLIOGRAFIA}

ADIGARD DES GAUTIERS, Jean (1954) - Les noms des personnes scandinaves de 911 à 1066. Lund: Carl Blum.

AMARAL, Luís Carlos (2007) - Formação e desenvolvimento do domínio da diocese de Braga no período da Reconquista (séc. IX-1137). Porto: Faculdade de Letras da Universidade do Porto. Tese de doutoramento.

AZEVEDO, Rui Pinto (1974) - A expedição de Almançor a Santiago de Compostela em 997 e a de piratas normandos à Galiza em 1015-1016. «Revista Portuguesa de História», 14. Coimbra: Faculdade de Letras da Universidade de Coimbra - Instituto de Estudos Históricos Dr. António de Vasconcelos, p. 73-93.

CASTELO BRANCO, Camilo (1964) - Vinte horas de liteira. Lisboa: Parceria A. M. PEREIRA, Lda.

CORTESÃO, Jaime (2016) - Os descobrimentos portugueses, 2. Lisboa: Expresso (INCM-Alêtheia Editores).

COSTA, Avelino Jesus (1959) - O Bispo D. Pedro e a organização da diocese de Braga. Coimbra: Faculdade de Letras da Universidade de Coimbra - Instituto de Estudos Históricos Dr. António de Vasconcelos, 2 vol.

DAVID, Pierre (1947) - Études historiques sur la Galice et le Portugal du VIe Siècle. Lisboa, Paris: Livraria Portugalia Editora, Les Belles Lettres.

DINIS, António Pereira (1993) - Povoamento proto-histórico no curso médio do Ave no I milénio a. C.. Porto: Faculdade de Letras da Universidade do Porto. Dissertação de mestrado, policop.

FILGUEIRAS, Octávio Lixa (1965) - Barcos da costa norte, sua contribuição no estudo de áreas culturais. Lucerna, 4. Porto: Centro de Estudos Humanísticos, p. 341-372.

HERCULANO, Alexandre (1856-1861) - Portugaliae Monumenta Historica a saeculo octavo usque ad quintumdecimum. Scriptores. 1. Lisboa: Academia das Ciências de Lisboa. (2007) - História de Portugal. Lisboa: Bertrand Editora.

MARQUES, André Evangelista (2014) - Da representação documental à materialidade do espaço: Território da diocese de Braga (séculos IX-XI). Porto: CITCEM.

MARQUES, José (2005) - A terra de Vermoim na Idade Média. In CAPELA, José Viriato, coord. - História de Vila Nova de Famalicão. Vila Nova de Famalicão: Quasi Edições, p. 61-107.

MATTOSO, José (1985) - Identificação de um país. Ensaio sobre as origens de Portugal 1096-1525. 1: oposição; 2: composição. Lisboa: Editorial Estampa - Imprensa Universitária.

MOREIRA, Domingos A. (1969) - Paisagem toponímica da Maia. Maia: Câmara Municipal da Maia.

OLIVEIRA, José Manuel (2007) - Martins Sarmento e o arqueólogo da alma. In SILVA, Armando Coelho Ferreira, coord. - Pedra Formosa. Arqueologia experimental. Vila Nova de Famalicão; Lisboa: Câmara Municipal de Vila Nova de Famalicão; Museu Nacional de Arqueologia, p. 213-215.

PIEL, Joseph M. (1960a) - Antroponimia germánica. In M. Alvar et alii (dir.), Enciclopedia lingüística hispánica, 1. Madrid: CSIC, p. 421-444.

(1960b) - Toponimia germánica. In M. Alvar et alii (dir.), Enciclopedia lingüística hispánica, 1. Madrid: CSIC, p. 531-560.

PIRES, Hélio Fernandes Vitorino (2012) - Incursões nórdicas no ocidente ibérico (844-1147). Lisboa: Faculdade de Ciências Humanas e Sociais da Universidade Nova de Lisboa. Tese de doutoramento.

QUEIROGA, Francisco Reimão (1992) - War and castros. New approaches to the northestern Portuguese Iron Age. Oxford: Oxford University (policop.).

RIDEL, Elisabeth (2009) - Les Vikings et les mots. L’apport de l'ancien scandinave à la langue française. Paris: Éditions Errance.

RODRIGUES, Jorge (2011) - Convivência e conflito no Califado de Córdova: do início da construção da Grande Mesquita à expedição de Al-Mansur (IBN AMIR). Cristãos e muçulmanos na Idade Média: Encontros e desencontros. Lisboa; Instituto de Arqueologia e Paleociências. 
SAMPAIO, Alberto Sampaio (1979) - Estudos históricos e económicos: As vilas do norte de Portugal,1. Lisboa: Editorial Veja.

(1979a) - Estudos históricos e económicos: As póvoas marítimas 2. Lisboa: Editorial Veja.

SARMENTO, Francisco Martins (1999) - Antiqua. Guimarães: Sociedade Martins Sarmento.

SILVA, Armando Coelho Ferreira (2007a) - A cultura castreja no noroeste de Portugal. $2^{a}$ ed. Paços de Ferreira: Câmara Municipal de Paços de Ferreira - Museu Arqueológica da Citânia de Sanfins.

SILVA, Armando Coelho Ferreira, coord. (2007b) - Pedra Formosa. Arqueologia experimental. Vila Nova de Famalicão - Lisboa: Câmara Municipal de Vila Nova de Famalicão - Museu Nacional de Arqueologia. SILVA, Armando Coelho Ferreira; DINIS, António Pereira; QUEIROGA, Francisco (2005) - Vila Nova de Famalicão do Neolítico à Idade Média. História de Vila Nova de Famalicão. Vila Nova de Famalicão: Quasi Edições.

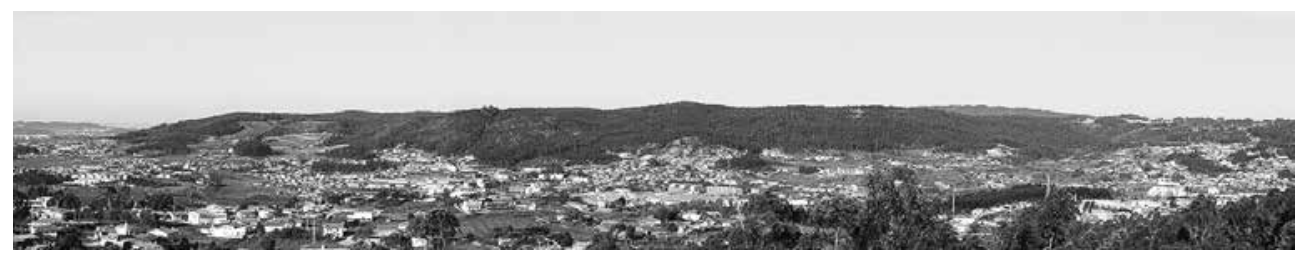

Fig. 1. Montes de Vermoim.

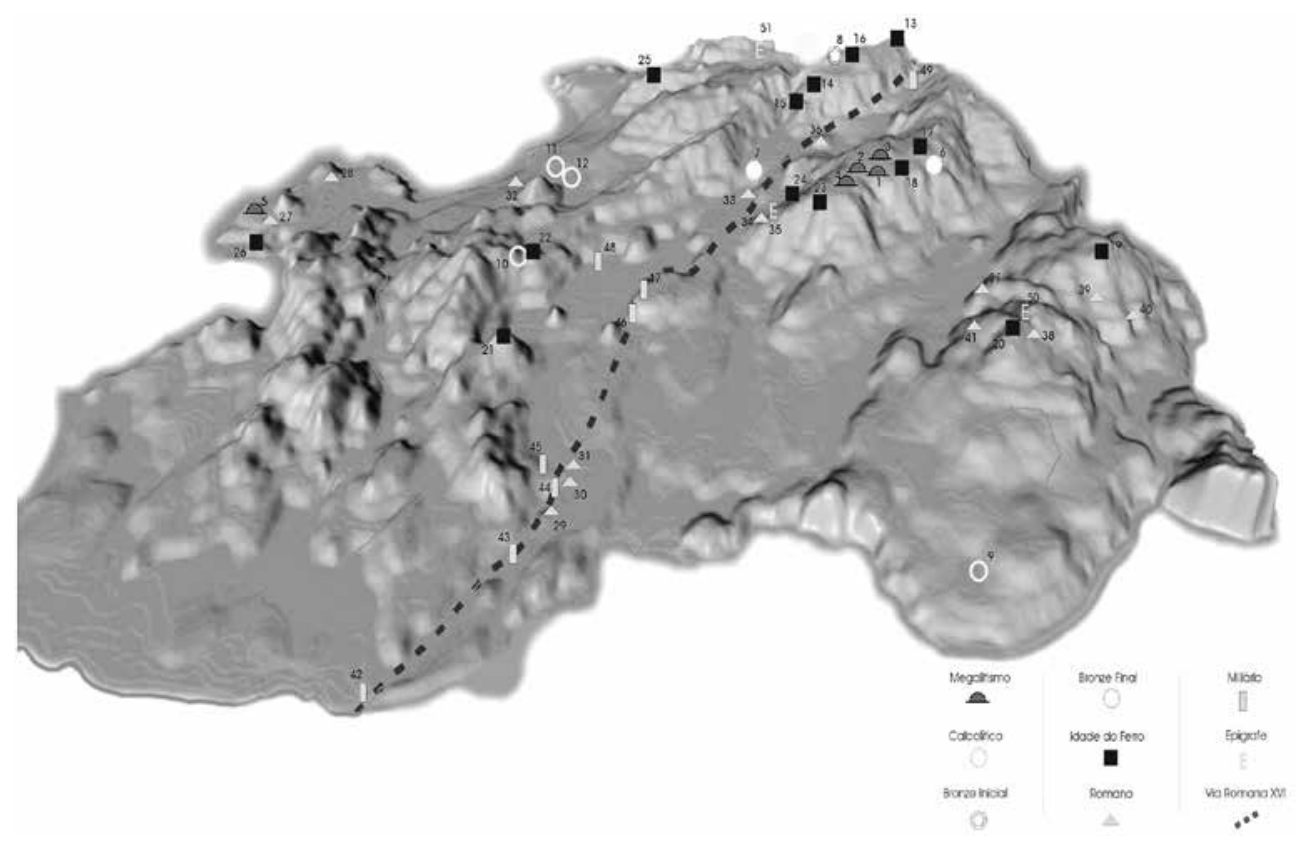

Fig. 2. Carta arqueológica do concelho de Vila Nova de Famalicão. 


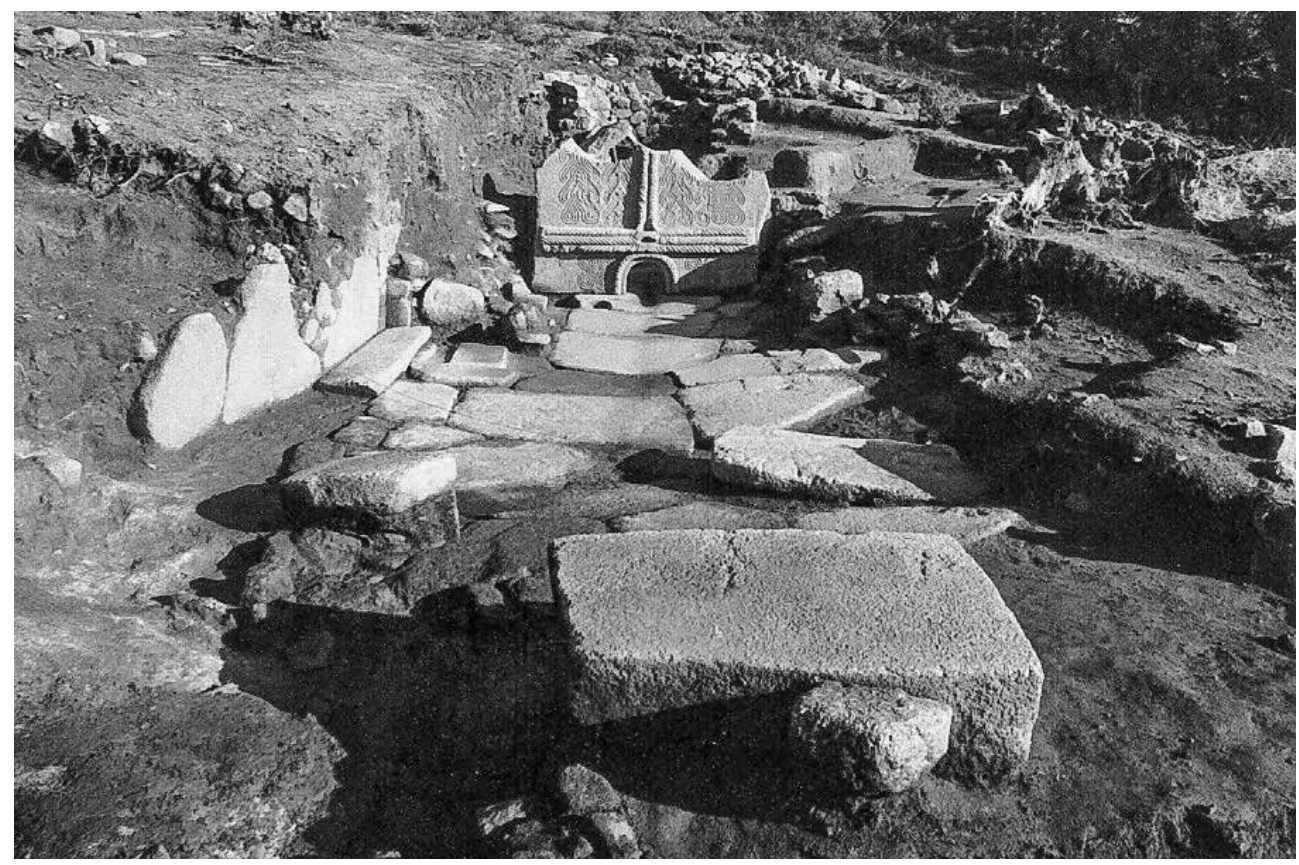

Fig. 3. Monumento balnear do Alto das Eiras (Escavações de F. Queiroga).

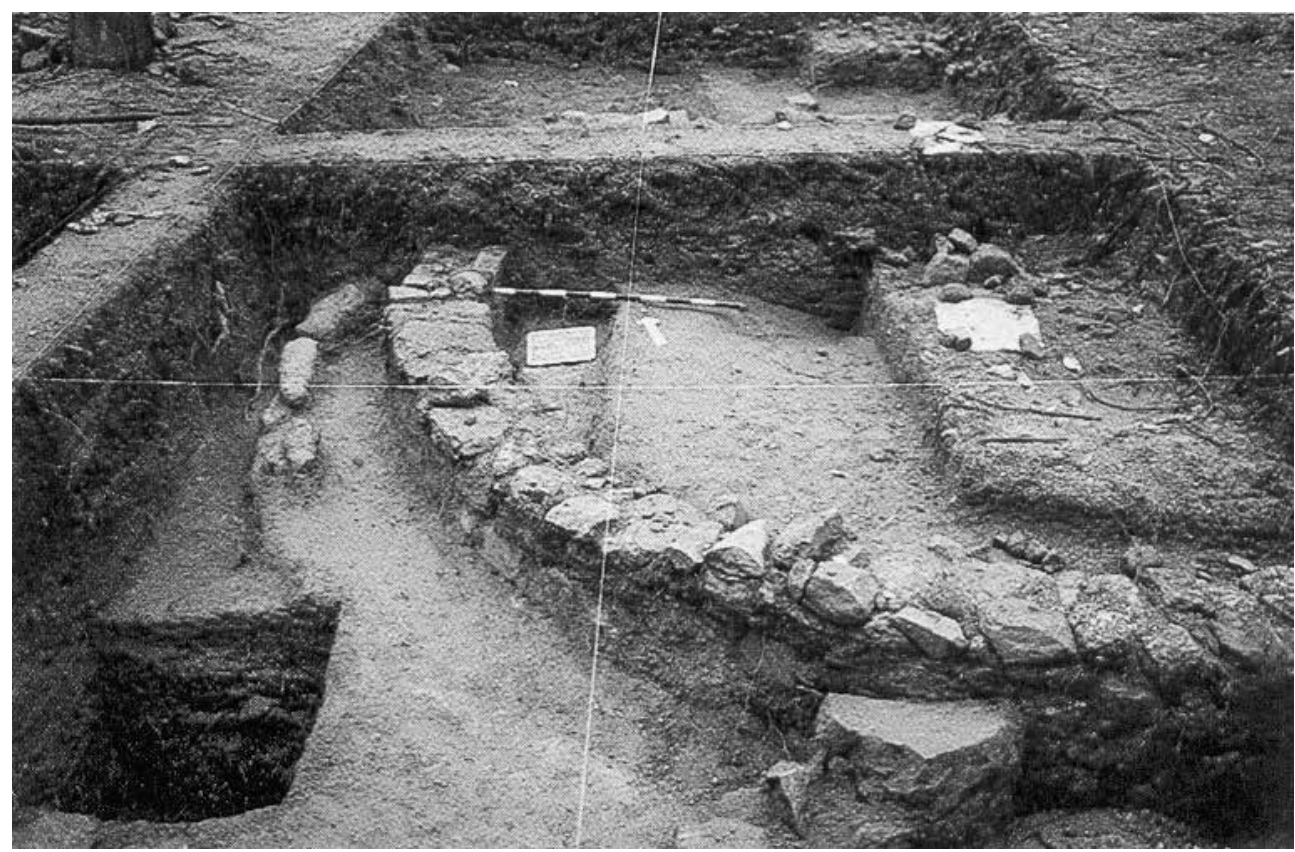

Fig. 4. Castro de Vermoim (Escavações de F. Queiroga). 


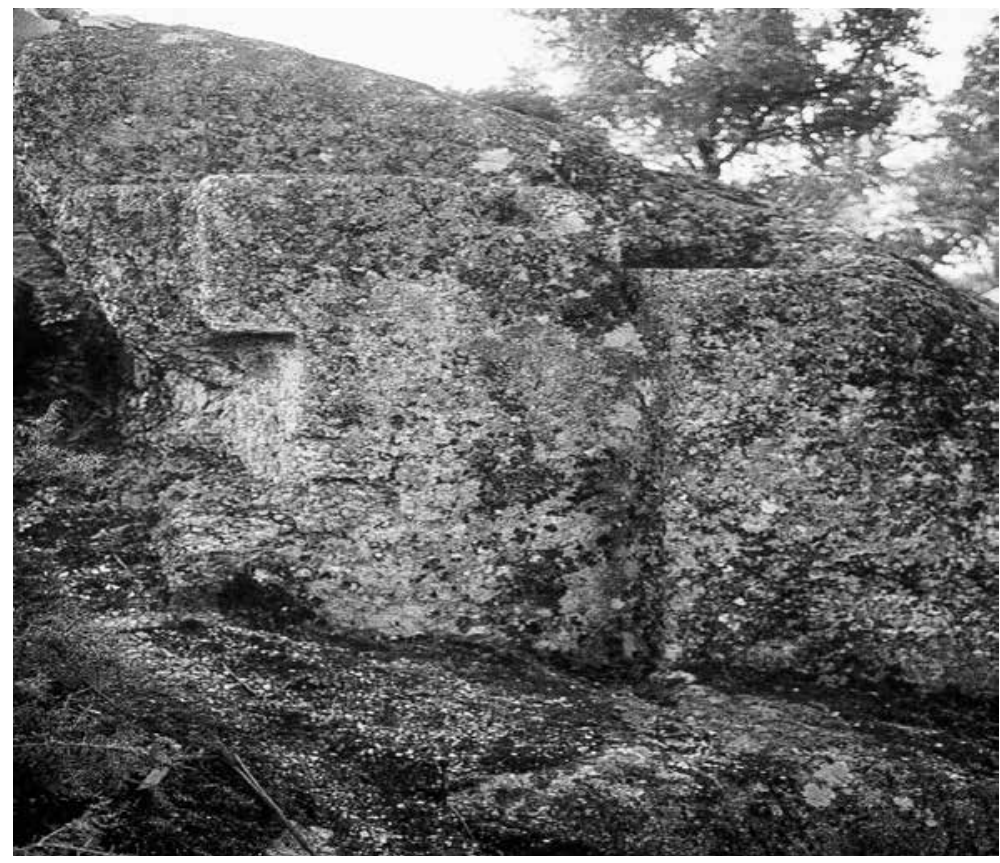

Fig. 5.

Castelo de Vermoim.
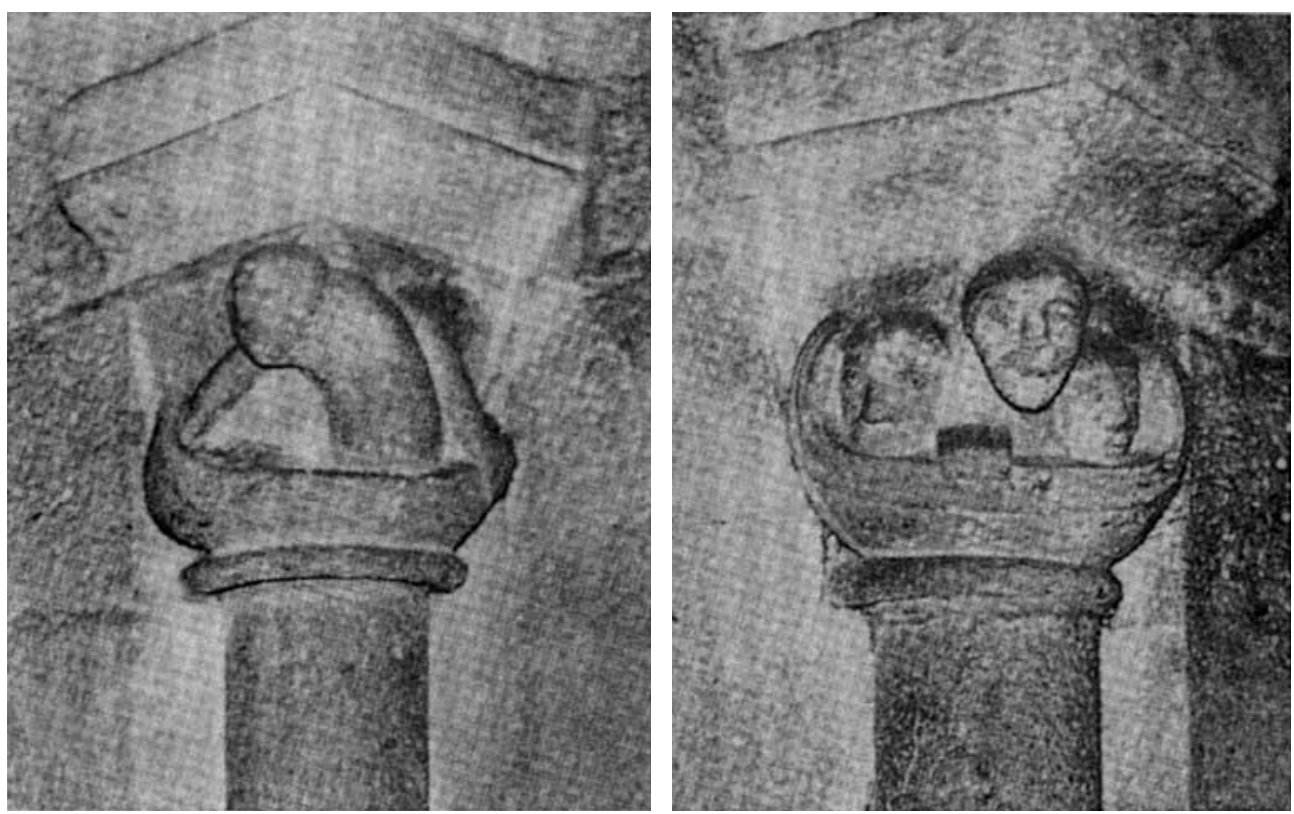

Figs. 6 e 7. Capitéis da Igreja românica de Rio Mau, Vila do Conde.

Fonte: CORTESÃO, 2016: 191. 



\title{
AS INCURSÕES VIKINGS NO NORTE DE PORTUGAL
}

\author{
ANDRÉ EVANGELISTA MARQUES* \\ MÁRIO JORGE BARROCA** \\ LUÍS CARLOS AMARAL****
}

\section{INTRODUÇÃO' ${ }^{1}$}

Escassas, avulsas, as mais das vezes breves e com informações não raro contraditórias, as notícias relativas às incursões de vikings ou normandos na Hispânia deixaram, ainda assim, um rasto perceptível, mais nas fontes documentais do que nas arqueológicas. E deve dizer-se, em abono da verdade, que a costa atlântica da Península Ibérica, do norte da Galiza até ao Algarve, está bastante presente nos relatos dessas investidas, sejam estes relatos latinos, árabes ou nórdicos ${ }^{2}$. Mais até do que Santiago de Compostela, Lisboa, a grande cidade da fachada ocidental da Península, e a sua área circundante (de Sintra a Alcácer do Sal) foram um alvo frequente das

\footnotetext{
* Bolseiro de pós-doutoramento (FCT); Instituto de Estudos Medievais, Universidade Nova de Lisboa; andre. omarques@gmail.com.

** Faculdade de Letras da Universidade do Porto; CITCEM-UP; mbarroca@letras.up.pt.

${ }^{* * *}$ Faculdade de Letras da Universidade do Porto; CITCEM-UP; CEHR-UCP; lcamaral@letras.up.pt.

${ }^{1}$ Por Luís Carlos Amaral e André Evangelista Marques. As siglas utilizadas em referências documentais ao longo do artigo vão desdobradas no final, em Fontes e Bibliografia.

${ }^{2}$ Para uma análise detalhada destas incursões (e respectivas fontes), v. PIRES, 2017. Trata-se de uma versão revista (e com alguns cortes) da tese de doutoramento do autor: PIRES, 2012. Para o conjunto do espaço ibérico, v. CHRISTYS, 2015; PRICE, 2012; e, num registo menos rigoroso, MORALES ROMERO, 2006. Sobre a ordenação das incursões à Península Ibérica em quatro vagas principais, v. CHRISTYS, 2015; cf. as reservas de PIRES, 2017: 222. A utilização que fazemos do qualificativo «viking» para caracterizar apenas as incursões que tiveram lugar antes de 1100 assenta no pressuposto de que a actividade de frotas nórdicas nas costas peninsulares durante o século XII pertence já a um outro contexto: v. ROESDAHL, 1998: 10; PIRES, 2017: 19-20.
} 
razias vikings logo desde 844 , data da primeira expedição conhecida ${ }^{3}$. De acordo com Ann Christys, Lisboa ter-se-á convertido no "primeiro objectivo dos vikings», sendo que também há notícias de ataques mais a sul, na costa alentejana e no Algarve ${ }^{4} \mathrm{O}$ Gharb al-Andaluz, com destaque para o entorno de Lisboa, e a Galiza, onde a primazia cabe à Ria de Arousa/Santiago, são os sectores referidos mais frequentemente nos relatos das incursões nórdicas ao Ocidente peninsular. Mas a verdade é que os vikings não deixaram de percorrer e de se interessar pela área intermédia do litoral atlântico, e em especial pela região do Entre-Douro-e-Minho.

O presente artigo ocupar-se-á deste território, correspondente ao espaço hoje português que permaneceu na esfera de influência da monarquia asturiana, a partir de meados do século IX, ao contrário do que aconteceu com a área a sul do rio Vouga, que, entre as décadas de 980-1000, voltou ao domínio muçulmano, na sequência das incursões de Almançor (978-1002) nos territórios de Coimbra, Viseu e Lamego, só recuperados definitivamente por Fernando I de Leão e Castela (1037-1065) entre 1057 e 1064. De facto, é em torno da embocadura do Douro e mais a norte, na zona de Guimarães-Famalicão, que se concentram as notícias de incursões vikings na terra portucalense. Por razões que se prendem sobretudo com a semelhança das fontes e dos contextos, estas incursões são mais facilmente relacionáveis com as numerosas intervenções vikings nas costas galegas ${ }^{5}$. Mas a verdade é que a tradicional divisão entre o "Norte cristão» e o "Sul muçulmano», que enforma muitas das concepções e das práticas historiográficas relativas a este período, revela-se demasiado rígida e pouco operativa também neste domínio.

Os textos árabes que nos informam sobre as incursões vikings no al-Andaluz traçam um quadro distinto do das fontes latinas do Norte, não só em termos da informação que veiculam - desde logo a cronologia atribuída a algumas incursões —, mas sobretudo no que respeita às interpretações que sugerem para enquadrar e construir o significado dessas incursões em contextos sociopolíticos locais e regionais específicos ${ }^{6}$. Mas não é possível separar as investidas num e noutro territórios. Elas integram-se, na maior parte dos casos, em expedições que, percorrendo a costa atlântica, tinham por objectivo conduzir as frotas vikings às ricas cidades do Sul muçulmano (do al-Andaluz ou do Magreb), quando não mesmo a outras paragens mais no interior do Mediterrâneo. Isto não significa, contudo, que não tenha havido

\footnotetext{
${ }^{3}$ BORGES, 2016: 69-72.

${ }^{4}$ CHRISTYS, 2015: 8. As primeiras (e únicas?) incursões documentadas na costa/zona de Beja e no Algarve (Silves) datam de 859 e 966, respectivamente: PIRES, 2017: 70-75, 83-85; CHRISTYS, 2015: 39, 49-50, 86-87.

${ }^{5}$ Para uma panorâmica das incursões galegas, v., para além da bibliografia citada na nt. 2, SÁNCHEZ PARDO, 2010. ${ }^{6} \mathrm{O}$ enfoque das fontes narrativas, tanto latinas como árabes, nos líderes políticos e militares que teriam assegurado a defesa face aos vikings foi já notado por CHRISTYS, 2015: 45, 92-93, 103. A autora chama a atenção para as construções propagandísticas que, tanto nos reinos cristãos como no al-Andaluz, procuraram converter essas acções de defesa em fontes de legitimação de determinados actores políticos (fontes latinas: p. 31, 43; fontes árabes: p. 40).
} 
uma reacção diferente face aos vikings por parte das populações (e elites) do Norte e do Sul; ou que os próprios navegadores e guerreiros nórdicos não tenham de alguma forma adaptado o seu comportamento, consoante o tipo de populações e de paisagens com que se confrontaram nas diferentes paragens que percorreram e onde, por vezes, estanciaram algum tempo.

Deste ponto de vista, as incursões vikings tornam-se mais do que uma simples justaposição de dois planos (ataque e defesa). Afiguram-se-nos antes como uma interacção, determinada por um tempo e um lugar concretos. É verdade que as fontes de que dispomos não dizem muito acerca do cenário que os vikings encontraram quando desembarcaram na costa ocidental hispânica ou entraram pelos seus estuários, nem sobre os tipos de interacção envolvida nos seus ataques, ou deles decorrente. Mas é chegado o momento de superar o enfoque tradicional sobre fontes de cariz narrativo, que tendem a apresentar as incursões vikings a uma luz exclusivamente político-militar, e de prestar maior atenção aos pequenos indícios que é possível extrair das fontes locais, que nos elucidam sobre o impacto destas incursões à pequena escala ${ }^{7}$. Se as fontes documentais deste género são escassas e de difícil interpretação, os dados arqueológicos são-no ainda mais, porque a investigação sobre a presença viking neste território só agora começa a dar os primeiros passos. Mas é importante sublinhar que só uma análise combinada dos registos documental e material, especialmente orientada para os contextos específicos de cada lugar e comunidade, permitirá compreender as reais implicações da presença na Península Ibérica de frotas vindas da Europa do Norte.

Recorrendo aos três principais tipos de fontes disponíveis (narrativas, mas sobretudo documentais e materiais), este artigo procura reavaliar a escassa informação conhecida sobre o território portucalense, por forma a responder a uma questão essencial: a violência e a pilhagem resumem toda a história dessa interacção? Para tal, desenvolveremos duas linhas de análise que irão sendo entrelaçadas. Por um lado, tentaremos caracterizar o cenário em que as incursões vikings tiveram lugar, procurando equacionar o problema do povoamento da faixa litoral, tradicionalmente tido como muito rarefeito, e perceber até que ponto esta imagem se deve sobretudo à cobertura geográfica da documentação conservada. Por outro lado, atentaremos nos vários tipos de relações entre vikings e populações locais, procurando perceber se, para lá dos ataques, das pilhagens, da tomada de cativos e consequentes resgates referidos nos documentos, terá havido lugar a algum tipo de assentamento, mais ou menos duradouro, por parte dos vikings. Antes, porém, de entrarmos na análise das fontes propriamente ditas, justifica-se reflectir, ainda que de forma breve, sobre

\footnotetext{
${ }^{7}$ Um impacto que é difícil de medir, em virtude das fontes de que dispomos, mas que foi real. A actividade viking na Península Ibérica «was probably small-scale, although perhaps more frequent than our sources admit» (CHRISTYS, 2015: 95).
} 
a imagem que a historiografia portuguesa construiu da presença viking no território portucalense e a utilização que dela fez, ou não, como factor explicativo da história desta região, entre os séculos IX e $\mathrm{XI}^{8}$.

A primeira coisa que podemos afirmar a este propósito é que a investigação nacional sempre considerou toda a problemática relacionada com as expedições de vikings ou normandos que assolaram as costas do futuro Portugal como um tema marginal e menor, e mesmo como uma espécie de um não tema. Ou seja, nunca foi atribuído a este assunto a relevância necessária para o integrar na panóplia de argumentos decisivos que esclareciam - e justificavam - o processo de independência e formação do reino. Elementos diversos e de fácil apreensão podem ser invocados para explicar esta situação. Destacaremos sobretudo três: antes de mais, (i) o facto de os vestígios documentais conhecidos e preservados serem manifestamente reduzidos e, em consequência, outrossim a investigação que sobre eles se debruçou, e ainda, salvo honrosas excepções, o generalizado desconhecimento, entre nós, da produção historiográfica oriunda de além-Pirenéus, pelo menos até meados do século XX; (ii) a circunstância de as empresas nórdicas apresentarem, por regra, uma dimensão limitada e a informação que delas temos cessar logo nas primeiras décadas do século XI, distando assim largos anos da criação do Condado Portucalense; e, por último, (iii) o domínio quase absoluto de uma visão historiográfica nacional centrada, de forma sistemática, num referente ideológico apoiado em construções que remontam, pelo menos, ao tempo da elaboração da Monarquia Lusitana $^{9}$ - e que foram amplamente reforçadas no decurso de Oitocentos - , e que poderíamos designar como o da crença apriorística em um «Portugal antes de Portugal», isto é, em um processo histórico que só se podia explicar e compreender através de si próprio, a partir de dentro e do seu «conteúdo».

Em face do exposto, não admira que a questão dos vikings apenas tivesse ocupado nos grandes textos de síntese, e não só, algumas linhas ou, na melhor das hipóteses, escassas páginas. De facto, quando em 1846 Alexandre Herculano publicou o volume inicial da sua celebrada História de Portugal ${ }^{10}$ - que, com inteira justiça, deve ser considerada como a primeira História geral de Portugal concebida em termos científicos - , limitou-se a fazer uma referência genérica e sem grande significado, inscrita na longa introdução programática com que abriu o referido volume. Ao falar sobre Ramiro I das Astúrias (842-850), escreveu: «Seguro no trono, [...] obteve várias vitórias dos muçulmanos e repeliu os piratas normandos que principiavam então a

\footnotetext{
${ }^{8}$ A simples enumeração dos principais autores e obras que estudaram as expedições nórdicas à Península Ibérica foi já realizada por: PIRES, 2017: 13-16.

${ }^{9}$ Os oito volumes que compõem esta obra foram inicialmente publicados em Alcobaça e Lisboa, entre 1597 e 1727.

${ }^{10}$ Os quatro volumes que compõem esta obra foram inicialmente publicados em Lisboa, em Casa da Viúva Bertrand e Filhos, entre 1846 e 1853.
} 
saltear as costas da Galiza» ${ }^{11}$. E por aqui se ficou. Já no século XX, na monumental História de Portugal dirigida por Damião Peres e Eleutério Cerdeira, dita de «Barcelos» ${ }^{12}$, cujo primeiro fascículo conheceu a luz do dia em Junho de 1928, o panorama herdado da centúria anterior manteve-se no essencial. Mais informações, sem dúvida. Mas sempre avulsas e breves e, invariavelmente, também sempre as mesmas, o que denota uma ausência total de investigação nova. Na década seguinte, o meticuloso Luís Gonzaga de Azevedo na sua História de Portugal dedicou igualmente vários parágrafos aos normandos/vikings, atribuindo-lhes mesmo a responsabilidade pelo assassinato do magnate portucalense Mendo Gonçalves (961-1008), neto da condessa Mumadona Dias (926-968?) ${ }^{13}$.

Acerca deste e de outros autores, apenas podemos dizer que a simples repetição de factos conhecidos, nem sempre apresentados de forma rigorosa, nada acrescentou ao que já se sabia. Em todo o caso, e como referimos antes, apercebemo-nos de que o fio condutor que orientava as passagens que integravam os dados relativos às expedições nórdicas, assentava num enquadramento único, a saber, o do binómio ataque/ defesa. Impõe-se registar que este verdadeiro "paradigma interpretativo», não exclusivamente português, andava muito próximo daquele que de forma mais recorrente era utilizado no estudo das relações entre cristãos e muçulmanos. Se acrescentarmos, por último, a predominância quase absoluta da perspectiva político-militar, teremos então delimitado o quadro historiográfico que enformou a abordagem do tema dos vikings, durante longo tempo.

O enorme crescimento e desenvolvimento que a investigação e a escrita da História conheceram também em Portugal no decurso da segunda metade do século XX, sobretudo a partir da década de Setenta, apesar de ter possibilitado como nunca o alargamento do campo conceptual, o apuramento metodológico e a acumulação de dados, não produziu imediatamente as desejáveis mudanças, tanto na matéria em apreço como em várias outras. Logo em 1959, no primeiro capítulo da obra que dedicou ao estudo das relações entre Portugal e a Liga Hanseática durante a época medieval, A. H. de Oliveira Marques pôde fazer uma espécie de breve síntese acerca das expedições normandas no Ocidente hispânico ${ }^{14}$. Apesar da clareza da exposição e da apresentação rigorosa dos factos, o autor não se coibiu de afirmar que «desde finais do século VIII que esses temíveis homens do Norte, impelidos por um desejo

\footnotetext{
${ }^{11}$ HERCULANO, 1980: 187.

${ }^{12}$ Composta inicialmente por oito volumes, foi publicada em Barcelos, pela Portucalense Editora, entre 1928 e 1938 . As referências às investidas dos normandos/vikings podem ler-se em: LOPES, 1928: 395; PERES, 1928: 441, 442, $456,460$. ${ }^{13}$ «O govêrno de Mendo Gonçalves não foi de longa duração, pois, quando no auge do poder e ainda na fôrça da vida, caíu assassinado, ao que parece, pelos normandos» (AZEVEDO, 1939: 117; v. também Apêndices, Nota X: 165). Os seis volumes que compõem a História de Portugal de Luís Gonzaga de Azevedo foram publicados postumamente em Lisboa, pela Edições «Bíblion», entre 1939 e 1944, numa edição organizada por Domingos Maurício Gomes dos Santos. ${ }^{14}$ MARQUES, 1993a: 25-28.
} 
de pirataria e de aventura, começaram a pôr em perigo a tranquilidade das costas do setentrião europeu» ${ }^{15}$. Deixando de lado os muito discutíveis juízos de valor, deveremos reconhecer no conjunto do texto a preocupação de articulação das empresas vikings com processos históricos mais vastos e de mais longa duração. Inversamente, na curta entrada do Dicionário de História de Portugal - sintomaticamente intitulada «Normandos, Ataques dos» ${ }^{16}$ - , Henrique Barrilaro Ruas limitou-se, uma vez mais, e de forma muito incompleta, a arrolar algumas das investidas nórdicas nas costas do actual Portugal. Bastaria atendermos na já então desactualizada bibliografia que apresenta, para nos inteirarmos da pouca importância atribuída ao assunto nesta obra maior da historiografia portuguesa contemporânea.

Por sua vez, Joaquim Veríssimo Serrão consagrou no primeiro volume da sua História de Portugal um pequeno mas autónomo ponto aos «Ataques dos Normandos a Portucale» ${ }^{17}$. Não trazendo nada de verdadeiramente novo, manifesta-se óbvia a vontade do autor de associar o «factor viking» não só ao quadro político-militar do Norte cristão peninsular, mas de forma mais específica às longínquas raízes da nacionalidade portuguesa. Afigura-se-nos hoje difícil subscrever as interpretações que formula, em particular no que respeita à segunda proposição. Ainda assim, é justo registar o seu esforço no sentido de superar a simples e costumeira enumeração das expedições nórdicas.

As novas perspectivas que o crescente conhecimento e recepção da bibliografia estrangeira e o paralelo desenvolvimento da investigação proporcionaram, acabaram por dar resultados significativos a partir da última década do século passado. As duas grandes obras de síntese então produzidas reflectem as mudanças em curso. De modos diversos, tanto na Nova História de Portugal dirigida por Joel Serrão e A. H. de Oliveira Marques ${ }^{18}$ como na História de Portugal dirigida por José Mattoso ${ }^{19}$, deparamo-nos com textos que procuram não só estabelecer de forma rigorosa os factos associados às empresas vikings, mas também apurar as consequências resultantes das mesmas. Por outras palavras, as investidas de normandos/vikings são articuladas num cenário alargado e convocadas como factores explicativos, quer do ordenamento político-militar, quer da organização social dos territórios distribuídos ao longo da fachada atlântica, desde a antiga Galécia até à estrema algarvia. Referindo-se especificamente à campanha inicial de 844, José Mattoso pôde escrever: «Foi a primeira intervenção normanda de que temos notícia precisa, mas elas repetiram-se depois com frequência até ao século XI, perturbando profundamente as zonas marítimas e

\footnotetext{
${ }^{15}$ MARQUES, 1993a: 25.

16 RUAS, 1990: 398-399.

${ }^{17}$ SERRÃO, 1977: 66.

${ }^{18}$ V.: MARQUES, 1993b: 125, 129, 245; BEIRANTE, 1993: 258-259, 261, 263, 273, 276, 313.

${ }^{19}$ MATTOSO, 1992: 532.
} 
as povoações situadas perto do curso dos rios. Foi necessário, então, construir fortificações nestas zonas e as povoações do litoral foram muitas vezes abandonadas» 20 .

No entanto, haveria que esperar até 2012 para se produzir, em Portugal, o primeiro estudo de fôlego dedicado inteiramente à temática das investidas vikings nas terras galegas e portuguesas ${ }^{21}$. Em definitivo, a expansão nórdica entre os séculos IX e XI passou a estar associada e a integrar o longo processo histórico de construção das monarquias ibéricas, no decurso da Plena Idade Média. Neste contexto, as expedições vikings foram, em simultâneo, sinais e sintomas daquilo a que, parafraseando Jaime Cortesão, poderíamos apelidar de «Atlantização», ou seja, a progressiva transformação das «comunidades» e dos «territórios» oceânicos em actores decisivos da História de Portugal.

\section{O REGISTO DOCUMENTAL ${ }^{22}$}

\subsection{Cenário: o povoamento litoral e as incursões vikings}

\subsubsection{Um povoamento periférico?}

O problema de base na abordagem tradicional do povoamento litoral durante a Alta Idade Média é a associação frequente entre silêncios documentais e vazios populacionais. A escassez e os condicionamentos geográficos e sociais dos documentos que chegaram até nós não autorizam este tipo de dedução. Que o mapa dos vestígios (escritos ou materiais) anteriores ao século XI registe um assinalável vazio em boa parte das zonas costeiras do Entre-Douro-e-Minho não significa que elas estivessem de facto escassamente povoadas, ou muito menos desertas. $\mathrm{O}$ mesmo se diga, ainda em maior grau, das zonas montanhosas. Num e noutro caso, estamos perante áreas periféricas face aos principais centros de poder da região, onde estavam localizadas as principais instituições produtoras de documentação ${ }^{23}$. Todas curiosamente situadas numa área central de maior potencial agrícola, correspondente ao que os geógrafos definiram como a área das "colinas e plainos minhotos», onde se concentravam os seus interesses patrimoniais ${ }^{24}$.

Não é fácil superar estas limitações que as fontes nos colocam, sobretudo enquanto não avançarmos mais no cruzamento da investigação histórica e arqueológica sobre o

\footnotetext{
${ }^{20} \mathrm{~V}$. nt. anterior.

${ }^{21}$ PIRES, 2012; PIRES, 2017. V. nt. 2.

${ }^{22}$ Por André Evangelista Marques.

${ }^{23}$ V. AMARAL, 2007.

${ }^{24}$ Sobre estes problemas, e as implicações que se levantam ao seu estudo no caso do Entre-Douro-e-Minho (e em particular do território da diocese de Braga), v. MARQUES, 2014: 10-25, 108-9. Sobre o povoamento da região minhota na Alta Idade Média, v. AMARAL, 2007: 15-200; MARQUES, 2008. Para a geografia da região, v., e.g., SILVA, 1983; RIBEIRO, 1995.
} 
território. Mas um dos caminhos obrigatórios para a correcta ponderação do registo escrito é o da análise da geografia documental. No estado actual da investigação, para uma perspectiva abrangente da região, capaz de a integrar no contexto mais amplo do Noroeste peninsular, temos de nos cingir ao mapa das instituições (todas eclesiásticas) que conservaram documentos datados até 1100 .

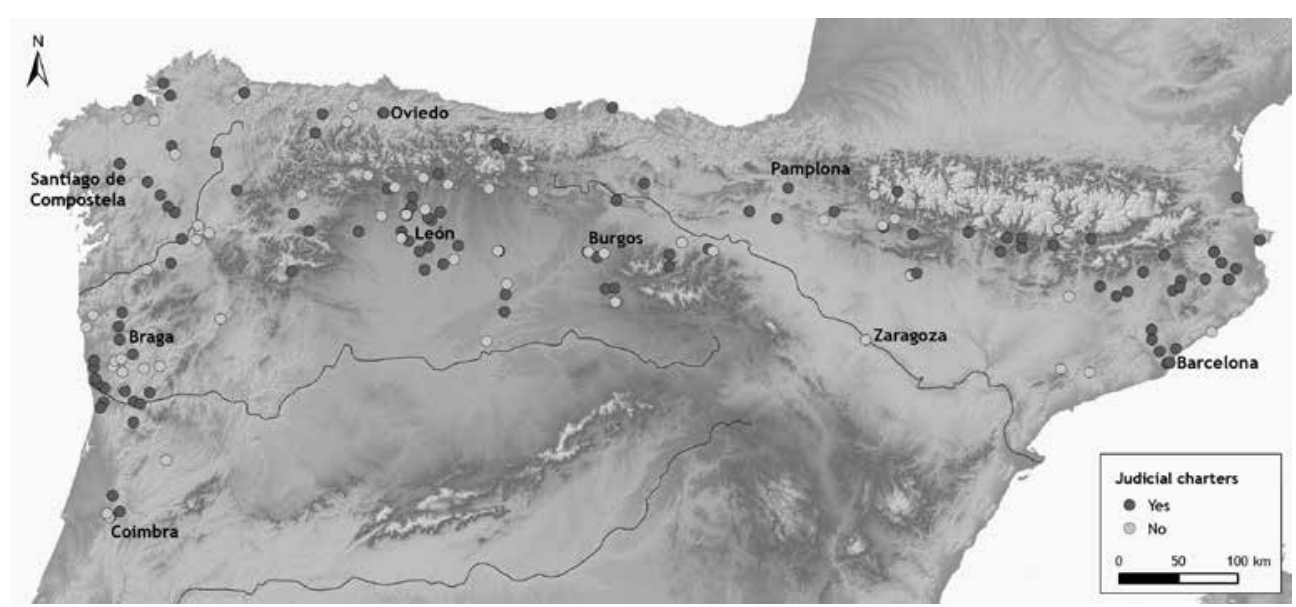

Mapa 1. Instituições do Norte peninsular que conservaram documentação datada até 1100.

Fonte: Projecto PRJ (http://prj.csic.es/) - IP: Isabel Alfonso. Mapa de Antonio Uriarte (Laboratorio de Arqueología del Paisaje y Teledetección. CSIC-Instituto de Historia. Madrid).

Trata-se de um mapa de instituições conservadoras, que omite muitas outras instituições efectivamente produtoras de documentação, introduzindo assim alguma distorção em matéria de cobertura geográfica. De qualquer forma, é evidente que a faixa costeira delimitada pelas bacias dos rios Douro, a sul, e Ave/Este, a norte, constitui a área de maior concentração de instituições junto ao litoral em todo o reino asturo-leonês. Sendo que não estamos apenas na presença de um número elevado de instituições, mas também de cartórios em que foi conservada uma massa significativa de documentação, como acontece nos casos dos mosteiros de Moreira da Maia, Junqueira, Pedroso, Grijó, Leça, Rio Tinto e Vairão, todos situados a menos de 10 km do mar. Estamos assim perante uma base de informação suficientemente ampla para podermos extrapolar uma densidade igualmente significativa para o povoamento desta área, onde um indicador importante como o casal - comummente definido como uma unidade familiar de povoamento - atinge uma densidade muito maior do que no sector litoral a norte do Ave (menos bem documentado, é certo) ${ }^{25}$. Atente-se na cartografia sistemática das menções documentais a casais no Entre-Douro-e-Lima até 1200.

${ }^{25}$ MARQUES, 2008: 78-111. 


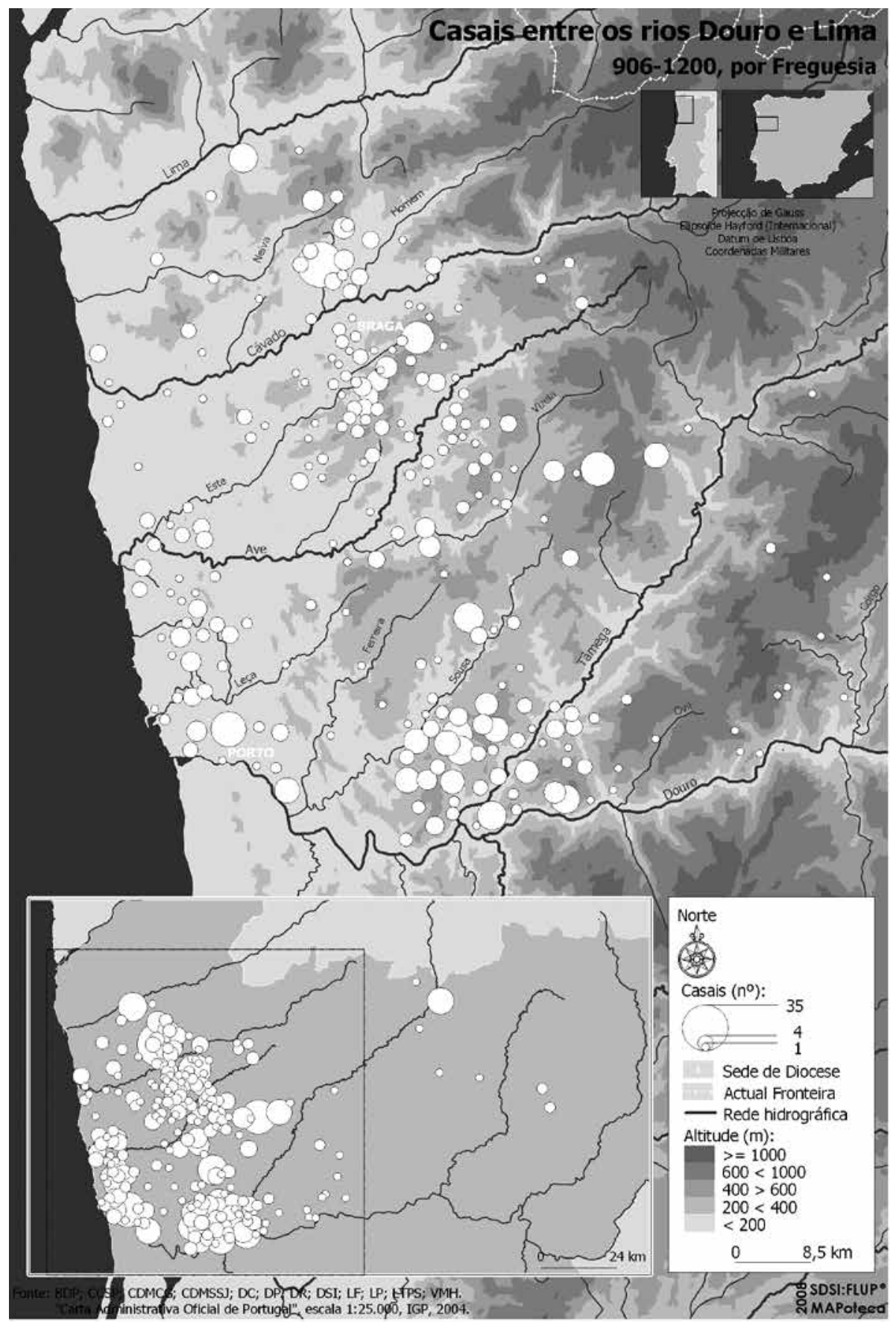

Mapa 2. Casais entre os rios Douro e Lima (906-1200), por freguesia.

Fonte: MARQUES, 2008: 75, mapa 1. Mapa de Miguel Nogueira (Oficina do Mapa, Faculdade de Letras da Universidade do Porto). 
Levada às últimas consequências, a análise da geografia documental implica cartografar todos os lugares referidos na documentação. $\mathrm{O}$ exercício não está feito, mas é possível obter uma imagem quase exaustiva para o território da diocese de Braga (entre os rios Ave e Lima), se atendermos à cartografia das unidades espaciais referidas na documentação dos séculos IX a XI contida nos principais cartulários da região - o Livro de Mumadona do mosteiro de Guimarães e o Liber Fidei da Sé de Braga - e numa lista de igrejas da diocese bracarense datável de finais do século XI (Mapa 3) ${ }^{26}$. É certo que uma boa parte dos lugares assinalados na faixa litoral corresponde a igrejas e mosteiros arrolados nesta lista mais tardia, embora deva ressalvar-se que só uma (pequena?) parte seria de fundação muito recente.

A principal conclusão a retirar deste mapa é que, mesmo a norte do Ave, o litoral minhoto está bastante longe de ser um deserto. $O$ povoamento seria certamente mais rarefeito do que nos vales centrais da região (e no litoral a sul do Ave), mas importa não esquecer o já referido efeito de subdocumentação das áreas periféricas, tanto litorais como montanhosas. A densidade registada na faixa costeira em redor do Porto demonstra que não se pode falar numa desertificação do litoral, supostamente causada ou agravada pelas ameaças de ataque por parte de frotas muçulmanas ou vikings, como tantas vezes se escreveu ${ }^{27}$.

O facto de a área envolvente do Porto ser especialmente rica, pela sua posição na embocadura de uma grande via de comunicação entre o litoral e o interior, já desde o período romano, e pela proximidade à fronteira com o al-Andaluz (sobretudo durante a primeira metade do século XI), explica uma maior densidade de ocupação ${ }^{28}$. De resto, é possível admitir que uma estrutura de poder mais hierarquizada e uma rede mais densa de fortificações possibilitassem uma melhor defesa nesta zona, logo uma

\footnotetext{
${ }^{26}$ LM; LF. A lista de igrejas, conhecida pelo nome de Censual de Entre-Lima-e-Ave, foi publicada por COSTA, 2000: 7-231. O editor atribui este documento ao episcopado de D. Pedro, mais concretamente ao intervalo [1085-1089/91], com base num conjunto de argumentos que não nos parece suficiente para excluir uma datação da primeira metade do século XII.

${ }^{27}$ É evidente aqui a influência de A. Sampaio, para quem o povoamento e a valorização económica do litoral minhoto, ainda incipientes no período romano, só teriam avançado significativamente a partir de finais do século XI, e sobretudo depois de a conquista de Lisboa (1147) ter criado condições de maior segurança, ao diminuir os ataques muçulmanos: SAMPAIO, 1979b: 9-10, 40, 52. Embora sublinhe os perigos da pirataria viking e muçulmana (SAMPAIO, 1979b: 32-36, passim), o autor alude também ao «assoreamento» para explicar o retraimento das populações litorais durante os séculos IX a XI (SAMPAIO, 1979b: 49). De resto, nota que o grande impacto dos ataques muçulmanos sobre as populações costeiras parece fazer-se sentir sobretudo a partir de finais do século XI (SAMPAIO, 1979b: 35, 75); e parece valorizar, acima de tudo, a iniciativa régia na dinamização do litoral, em especial de D. Sancho I (1179-1212) e seus sucessores (SAMPAIO, 1979b: 85, 87). No entanto, a conjugação entre a ameaça viking e a pirataria muçulmana continua a ser invocada por autores que defendem a rarefacção do povoamento litoral português e galego até ao século XII: e.g. RIBEIRO, 1990: 481; MATTOSO, 1992: 502, 532; ANDRADE, 2005: 65-66; GALÁN GÓMEZ, 2007: 74; SOLANO FERNÁNDEZ-SORDO, 2010: 60-61; contra PIRES, 2017: 224-25.

${ }^{28}$ Sobre a importância comercial da região, pelo menos até aos séculos V-VI, v. ALMEIDA, 1973-1974; ALARCÃO, 1988: 1-38; SILVA, 2000; LÓPEZ QUIROGA, 2004: 92-97, 180; SILVA, 2010: 223, 227-34; GOMES, 2011; MOREIRA \& SILVA, 2011; TEIXEIRA, 2011. Sobre a posição fronteiriça do território a sul do Douro, v. MATTOSO et al., 1989 : 30-32, $117-32$.
} 

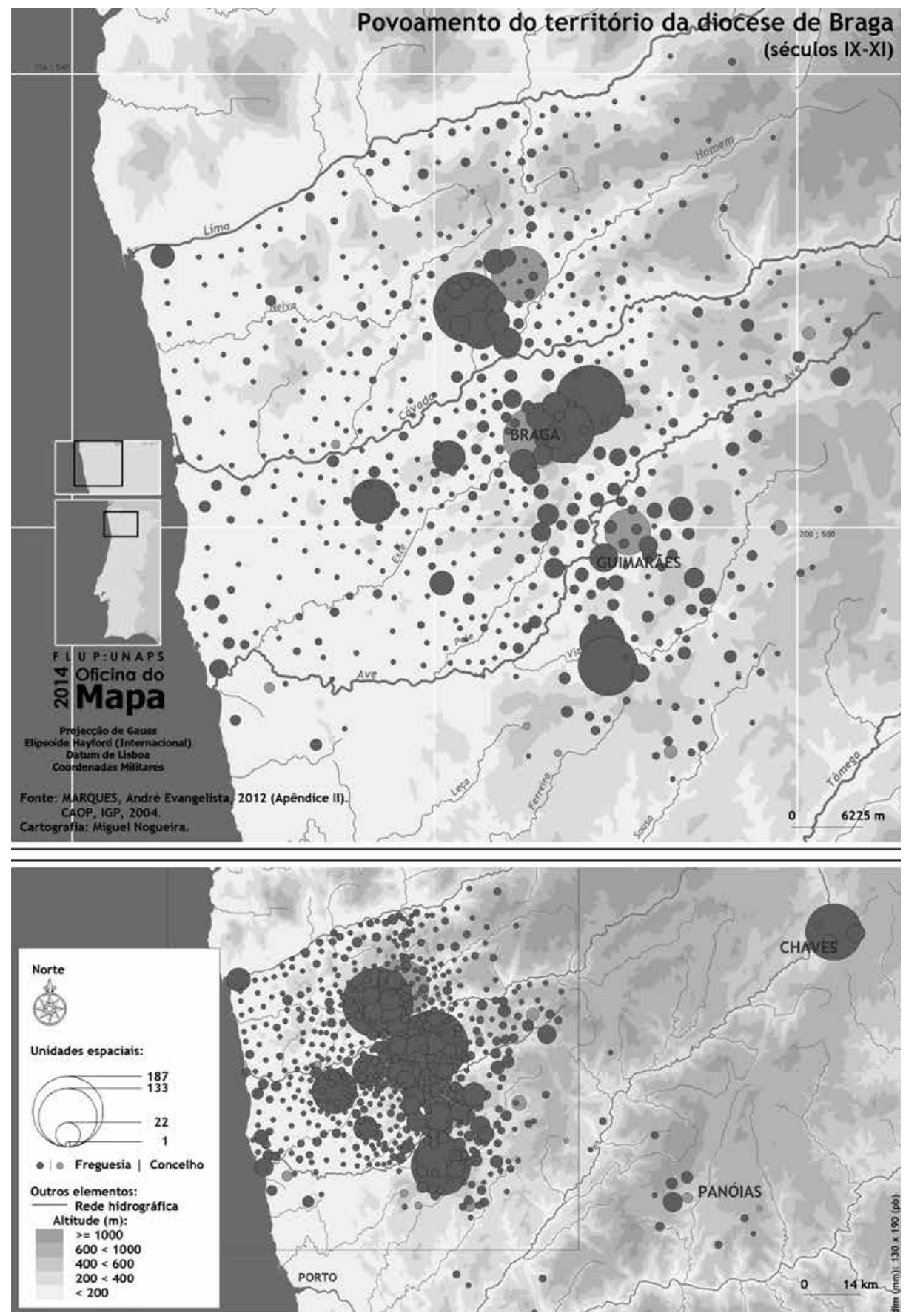

Mapa 3. Povoamento do território da diocese de Braga (séculos IX-XI).

Fonte: MARQUES, 2014: 18, mapa 2. Mapa de Miguel Nogueira (Oficina do Mapa, Faculdade de Letras da Universidade do Porto). 
maior atractividade para o povoamento ${ }^{29}$. A uma outra escala, são precisamente as diferenças de recursos e de organização política e militar que ajudam a explicar as respostas diferenciadas dadas pelo Norte cristão e pelo al-Andaluz à ameaça viking, com os segundos a conseguirem opor-lhes uma resistência mais eficaz do que os primeiros, naturalmente assente numa melhor organização dos territórios costeiros ${ }^{30}$.

O importante, contudo, é sublinhar que as características da faixa litoral entre os rios Ave e Vouga ajudam a explicar o que parece ter sido um maior interesse dos vikings por esta área, face à zona mais setentrional da costa minhota. Muito naturalmente, a sua atenção dirigiu-se a um território onde a densidade do povoamento e a abundância de riquezas ofereceriam razoáveis perspectivas para a pilhagem - desde logo de igrejas e mosteiros dotados de amplos patrimónios - e para a captura de escravos ou de pessoas capazes de pagar avultados resgates.

\subsection{2. $O$ impacto das incursões vikings}

Mas qual terá sido, afinal, o impacto das incursões vikings no litoral minhoto, e em particular nesta zona mais rica e densamente ocupada? A historiografia tende a avaliar esse impacto como sendo diminuto, tanto no conjunto dos reinos cristãos como no al-Andaluz ${ }^{31}$. Até porque, como já se disse, os ataques vikings foram transformados num topos, usado com evidentes propósitos propagandísticos de prelados e reis, no caso do reino asturo-leonês, e de califas omíadas e funcionários áulicos, no caso do al-Andaluz ${ }^{32}$. De resto, o Entre-Douro-e-Minho parece ter suscitado nos homens do Norte um interesse ainda menor do que os territórios mais a norte e mais a sul ${ }^{33}$.

É certo que as referências a incursões dirigidas à «Galiza», assim genericamente definida, podem, em teoria, abranger as costas de todo o Noroeste peninsular (incluindo o território portucalense), já que este corónimo era utilizado para designar toda essa

\footnotetext{
${ }^{29}$ Sobre a rede de fortificações do litoral entre os rios Ave e Douro, até meados do século XII, v. BARROCA, 2017.

${ }^{30}$ PIRES, 2017: 225-29. No Gharb al-Andaluz, é patente um reforço das estruturas defensivas (e provavelmente administrativas) da zona litoral logo a partir de meados do século IX, a par da montagem de uma força naval fundeada em Sevilha e encarregada de patrulhar a costa atlântica, onde utilizaria alguns portos: PICARD, 1997: 7, 20-25; que desenvolve uma ideia já avançada por SÁNCHEZ-ALBORNOZ, 1969: 408. Isto terá estimulado o povoamento litoral, desde logo nos principais centros urbanos em torno de Lisboa (Sintra, Almada, Palmela, Sesimbra, Alcácer do Sal), como sugeriu PICARD, 2000: 141-42, 209, 217. Já a Norte, Afonso III terá reagido aos ataques vikings do século IX ordenando a construção do castelo de Gauzón, junto ao mar, para proteger a sede régia de Oviedo (segundo o testemunho da Historia Silense), e das Torres do Oeste (ou de Catoira), em Padrón, para proteger o acesso a Santiago de Compostela, segundo SÁNCHEZ-ALBORNOZ, 1969: 405-7.

${ }^{31}$ PIRES, 2017: 223-29; CHRISTYS, 2015: 92-93, 95, 97; PRICE, 2012: 468; MORALES ROMERO, 2006: 13, 215-16; PORTELA SILVA, 2001: 129, nt. 326; SÁNCHEZ-ALBORNOZ, 1969: 408 (qualifica de «epidérmicas» as incursões do século IX) . Cf. LÓPEZ ALSINA, 2013: 234; SÁNCHEZ PARDO, 2010: 79-80, que sublinham o impacto das incursões vikings no território galego e na sua organização político-militar, sobretudo no século X.

${ }^{32}$ CHRISTYS, 2015: 103.

${ }^{33}$ Como reconheceu a historiografia portuguesa desde, pelo menos, os trabalhos de BARROS, 1947: 21-23; SAMPAIO, 1979b: 32-34; VASCONCELOS, 1982 [1958]: 19-20.
} 
área, desde logo nas fontes árabes ${ }^{34}$. Mas a verdade é que a esmagadora maioria das informações que possuímos sobre incursões vikings na Península Ibérica diz respeito ao território galego, na configuração restrita que hoje tem, e ao al-Andaluz (ainda que neste caso só durante os séculos IX e X). Hélio Pires avança duas razões que poderão explicar o maior interesse dos vikings pelo território galego-português, face ao território asturiano: as características do terreno (a costa é de mais fácil penetração) e a atractividade do grande centro de peregrinação que era Santiago ${ }^{35}$. No entanto, e apesar da proximidade geográfica, estas condições perdem força explicativa no caso do Entre-Douro-e-Minho. Aqui a costa é mais exposta e os estuários menos fáceis de penetrar ${ }^{36}$; por outro lado, não parece haver centros de peregrinação ou grandes núcleos urbanos (como os que existiam de Coimbra para sul) a oferecer a perspectiva de pilhagens muito lucrativas. Torna-se, portanto, evidente a menor atractividade do Minho para os piratas vikings, reflectida num corpus de informação mais restrito.

No conjunto dos ataques que é possível identificar na Península Ibérica entre os meados do século IX e a segunda metade do século XI (quando cessam os registos), as incursões que comprovadamente atingiram a costa minhota são poucas. No mínimo duas: a de Julho de 971 (que terá entrado no rio Douro) e a de 1015-1016 (que terá assolado o Entre-Douro-e-Ave). E no máximo quatro, se aceitarmos que a expedição liderada por Gunderedo em 968-969 (ou outra pouco anterior) chegou a Guimarães; e que houve de facto uma incursão na Terra de Santa Maria por volta de 1026, o que nos parece discutível, como veremos ${ }^{37}$.

Ainda assim, importa notar que todas estas incursões dirigiram-se para a já referida área de Entre-Douro-e-Ave, e possivelmente para a Terra de Santa Maria, a sul do Douro. A importância deste rio como via de penetração para o interior faz aumentar a estranheza pelo facto de a cidade do Porto nunca ser mencionada como alvo de ataque, como notou Pires, e obriga a admitir a hipótese de incursões anteriores (e posteriores) a 971 que não estão documentadas ${ }^{38}$. Por outro lado, é impor-

\footnotetext{
${ }^{34}$ Para uma panorâmica das referências ao território designado pelo termo árabe 'Yilliqiya', que muitas vezes designa o conjunto do reino asturo-leonês, v. CARBALLEIRA DEBASA, 2007.

${ }^{35}$ PIRES, 2017: 148-49 (cf. dúvidas expressas nas p. 222-23). O autor cita a interpretação de GARCÍA-GALLO, 1950: 603-4, para quem a maior exposição do ocidente peninsular às investidas vikings permite explicar o facto de o decreto VI.2 do concílio de Coyanza (1055) aludir - na versão copiada no Livro Preto da Sé de Coimbra, mas não na versão pelagiana incluída no Liber Testamentorum da catedral de Oviedo - aos ataques vikings (ou muçulmanos) como sendo uma das razões que permitem abrir uma excepção para a proibição de viajar ao domingo.

${ }^{36}$ Note-se, contudo, que o baixo calado dos barcos vikings (que atracavam e desatracavam à força de remos) permitialhe chegar a praias, por mais baixas que fossem, e subir rios, penetrando assim no interior dos territórios, como notam MORALES ROMERO, 2006: 48; BRINK \& PRICE, 2012: 4.

${ }^{37}$ Sobre estas incursões e respectivas fontes, v. PIRES, 2017: 87-97 (968-969), 97-101 (971), 118-26 (1015-1016), 143-46 (1026 ou antes).

${ }^{38}$ PIRES, 2017: 99, 123. CARRIEDO TEJEDO, 1998-1999: 332-33, sugere que a ausência de referências a bispos do Porto logo a partir da década de 960 (contrastando com as restantes dioceses portucalenses, em que o mesmo só se verifica a partir da década de 980) esteja relacionada com a incursão viking de 968, depois da qual não teria sido nomeado mais nenhum bispo até às primeiras décadas do século XI. É muito escassa a informação, tanto documental
} 
tante sublinhar que as incursões vikings não se limitaram à faixa costeira. Algumas chegaram a pontos mais interiores, atingindo áreas do mais denso povoamento em toda a região (caso de Vermoim e talvez Guimarães), pelo que terão obrigado a uma subida pelo rio Ave ou a uma progressão por terra ${ }^{39}$. Regista-se, contudo, uma quase total ausência de informação sobre o impacto local destas incursões mais interiores, por oposição a umas poucas notícias documentais sobre o seu impacto na faixa costeira. Vale a pena atentar nestas notícias, que se revestem de grande importância no contexto peninsular, pela informação invulgar e detalhada que veiculam.

\subsection{Interacções: ataques, cativos, resgates - e assentamento?}

Deixando de lado as fontes narrativas que nos informam sobre os ataques de 971 e de 1015-1016, passemos em revista os documentos que nos podem ajudar a avaliar as formas de interacção entre vikings e populações locais ${ }^{40}$. $\mathrm{O}$ confronto militar e os episódios de resgate de cativos são as únicas formas que a documentação explicita. Mas é muito provável, verosímil até, que esta interacção tenha revestido outras formas, como aconteceu noutras zonas da Europa alvo de incursões mais frequentes do que a Península Ibérica.

\subsubsection{Ataques}

\section{[1] LM 1b=PMH, DC 97 (968)}

Um documento relativo à construção do castelo de Guimarães poderá ser o primeiro em toda a documentação do território portucalense a sinalizar a presença viking nesta região. Trata-se de um codicilo à carta de dotação do mosteiro de Guimarães, outorgada por Mumadona Dias em $959^{41}$. Nesse codicilo, a fundadora confirma ao mosteiro a posse do castelo mas ressalva que os seus descendentes poderiam ter o controlo da fortificação ${ }^{42}$. Ao certo, o documento permite-nos apenas saber que esta

\footnotetext{
como arqueológica, sobre o Porto antes do século XII, embora deva ter sido um lugar importante, tanto do ponto de vista económico como militar e político: v. SOARES, 1935: 11-29; SILVA, 2000.

${ }^{39}$ V. infra as considerações feitas por Mário Barroca no ponto 2, a propósito da incursão de 1015-1016.

${ }^{40}$ Do ponto de vista das fontes, os ataques no Norte de Portugal podem dividir-se em três tipos: (i) os que são apenas mencionados em registos narrativos, como acontece com o ataque de 971, referido num texto da autoria de 'Isa ibn Ahmad al-Razi recolhido na secção relativa aos anos de 971-975 do Muqtabas, uma compilação historiográfica da autoria de Ibn Hayyan (GARCÍA GÓMEZ, trad., 1967: 50); (ii) os que são mencionados apenas em registos documentais, como acontece com os possíveis ataques a Guimarães em 968 (LM 1b=PMH, DC 97) e à Terra de Santa Maria c. 1026 (PMH, DC 261); e (iii) os que são mencionados em ambos os tipos de registos, como acontece com o ataque de 1015-1016, referido na Chronica Gothorum, uma das versões conhecidas da recensão longa dos Annales Portucalenses Veteres (DAVID, 1947: 295=PMH, Scriptores, vol. I: 9), e num documento datado de 1018 proveniente do mosteiro de S. Salvador de Moreira (AZEVEDO, 1974: 91-93, doc. 2).

${ }^{41} \mathrm{LM} 1 \mathrm{a}(=\mathrm{PMH}, \mathrm{DC} 76)$.

${ }^{42}$ É curioso o regime de tenência que Mumadona estabelece para este castelo, prevendo a sua continuação nas mãos dos filhos Gonçalo, Ónega e de outros seus descendentes, mas ressalvando que o deteriam sob a autoridade do mosteiro de Guimarães, e desde que se comprometessem a não o alienar; o que não deixa de ser sintomático da complexidade da relação patronal estabelecida entre a família e o cenóbio.
} 
terá sido construída por iniciativa de Mumadona Dias para protecção do mosteiro, na sequência de um ataque perpetrado por gentios (persecutium gentilium), que teve lugar "pouco depois» de Mumadona ter outorgado a carta de dotação do mosteiro (959) e antes de 968 (data do codicilo) ${ }^{43}$. A identificação destes «gentios» coloca problemas por não sabermos ao certo se o termo alude a vikings, a muçulmanos ou a ambos. Embora ressalvando sempre a dúvida, a maior parte dos autores portugueses tem-se inclinado para a identificação com um grupo viking (que no mesmo ano teriam saqueado a Galiza $)^{44}$.

Em 2012, H. Pires parecia inclinar-se também para esta identificação, invocando: (i) a distância à fonteira com os muçulmanos, que tornaria menos provável um ataque muçulmano a Guimarães (embora não esquecesse a incursão à Galiza de 953); (ii) a coincidência com a incursão de 968-969, chefiada por Gunderedo, que, tendo assolado boa parte da Galiza, poderia bem ter atacado Guimarães; e (iii) a conjuntura mais alargada de ataques vikings à Galiza nas décadas de 950-960, que desencadeou um movimento de construção de fortificações, em que Guimarães poderia integrar-se ${ }^{45}$. $\mathrm{Na}$ edição mais recente do seu trabalho, o autor limita-se a enunciar os dois últimos argumentos, sem excluir a possibilidade de se tratar de muçulmanos; e reafirma a sugestão de que «talvez o uso de um termo ambíguo [gentiles] seja propositado de forma a referir as duas ameaças numa única palavra» ${ }^{46}$. Independentemente das conotações étnicas que possamos atribuir-lhe, o termo "gentios» poderá, de facto, ter servido ao redactor deste documento para aludir aos «infiéis» de qualquer tipo que ameaçavam a segurança do mosteiro de Guimarães.

\footnotetext{
${ }^{43}$ CARDOZO, 1967: 296-98; PIRES, 2017: 107-8, 205-6. Dois dos autores do presente texto recuam a construção do castelo aos anos de 950-951: BARROCA, 2004: 190 (950-957); AMARAL, 2007: 674 (950-951). Esta interpretação parece-me assentar numa confusão entre o castelo e o monte em que ele foi construído (objecto de referências documentais anteriores) e contradizer o nexo estabelecido no codicilo entre a construção do castelo e o referido ataque de «gentios», como procurei explicar em MARQUES \& DAVID, 2013: Módulo Unidades, obs. à un. 1755; cf. infra o que M. Barroca escreve no ponto 2, onde está citado o texto do codicilo.

${ }^{44}$ ROCHA, 1730: 337-40; VITERBO, 1993, s.v. Laudomanes (cita Flórez - España Sagrada, XL, fl. 403); BARROS, 1947: 22, nt. 1; SAMPAIO, 1979b: 33; VASCONCELOS, 1982 [1958]: 19. É também esta a opinião de M. Barroca (v. infra o ponto 2), para quem o termo «gentios» não era por norma aplicado a muçulmanos (um argumento já invocado por ROCHA, 1730: 339; contra v. SAMPAIO, 1979b: 33, 108). É curioso notar, em apoio desta interpretação, que as primeiras fontes irlandesas a aludirem aos vikings, no século IX, lhes chamam também gentiles (BRINK \& PRICE, 2012: 5). No entanto, a Vita Sancti Rudesendi Episcopi (a. 1172) apelida também os sarracenos que teriam atacado o território portucalense no tempo em que S. Rosendo fora bispo de Iria-Santiago de paganos: DÍAZ Y DÍAZ et al., 1990: 130-33, \$18-19.

${ }^{45}$ PIRES, 2012: 134-35, 144, 253. O autor admitia duas hipóteses relacionadas com a incursão liderada por Gunderedo: «A primeira é a de que, após a vitória contra o Bispo de Iria-Compostela, os nórdicos tenham chegado a Guimarães, antes de serem derrotados em 969 ou depois desse momento, com pequenos grupos de sobreviventes do exército de Gunderedo a dispersarem-se pelo território. A segunda é estarmos perante um bando vikingue do qual nada mais sabemos» (p. 135). O bispo Sisnando II de Iria-Santiago (bispo entre 952-968), responsável pelo reforço de estruturas defensivas em Lanzada e na própria cidade de Santiago, acabaria por ser morto pelos vikings, segundo os testemunhos da Crónica de Sampiro, da Historia Compostellana e do Chronicon Iriense: CHRISTYS, 2015: 83-84.

${ }^{46}$ PIRES, 2017: 107-8, 205-6 (citação na p. 206); no mesmo sentido desta última observação: CHRISTYS, $2015: 76$.
} 
A confirmar-se a identificação com os homens do Norte, esta seria a mais antiga referência a uma incursão viking no Entre-Douro-e-Minho. Mas, independentemente da identificação dos "gentios» com vikings ou muçulmanos, não é necessário que a construção do castelo respondesse a um ataque concreto a Guimarães nos anos anteriores à doação de Mumadona Dias. Pode ter sido antes uma resposta à percepção de ameaça provocada por incursões (vikings ou muçulmanas) em zonas vizinhas, como também notou Pires ${ }^{47}$. O importante é sublinhar que, a uma escala menor do que acontece no al-Andaluz, as incursões vikings podem ter actuado, directa ou indirectamente, como estímulo para o reforço das estruturas defensivas também no Entre-Douro-e-Minho.

\subsubsection{Cativos e resgates}

Um segundo domínio - este mais claramente documentado - em que se manifestou a interacção entre vikings e populações locais foi o da captura e resgate de cativos $^{48}$. Para além de um conjunto numeroso de referências cronísticas, tanto em fontes latinas como árabes, este fenómeno está bem retratado em dois documentos habitualmente citados, dada a sua singularidade no contexto ibérico ${ }^{49}$.

\section{[2] AZEVEDO, 1974: doc. 2 (1018)}

O primeiro documento, datado de 1018, relata indirectamente a captura de três irmãs, no contexto da incursão de 1015-1016 pela zona de Entre-Douro-e-Ave, e os esforços do pai, Amarelo Mestaliz, para as resgatar ${ }^{50}$. Três anos depois, Amarelo, já doente, vende a Froila Trutesendes parte dos seus bens em Guilhabreu (freguesia do concelho de Vila do Conde), com a condição de este cuidar dele até à morte, por um preço pago em géneros (um lenço, uma camisa e um boi) e como pagamento da dívida de 15 soldos que Froila lhe emprestara para o resgate das filhas. O documento é sobejamente conhecido e os seus comentadores têm sublinhado a informação invulgarmente detalhada que ele fornece. Desde logo sobre o episódio da captura e

\footnotetext{
${ }^{47}$ PIRES, 2012: 134.

${ }^{48}$ Segundo CHRISTYS, 2015: 11, na Península Ibérica a tomada de cativos parece revestir-se de maior importância para os vikings do que o saque e destruição de igrejas (que é excepcional).

${ }^{49}$ Entre as fontes latinas, refira-se, por exemplo, a passagem da Historia Silense relativa à incursão de 968 na Galiza, chefiada por Gunderedo; entre as fontes árabes, a passagem da História da Conquista do al-Andalus de Ibn al-Qutiya (que cobre o período entre 756-961) relativa à incursão de 844 no território de Sevilha (apud CHRISTYS, 2015: 83-84 e 34-35, respectivamente). AZEVEDO, 1939: 117, 165, cita um terceiro documento, que considera indiciar a possibilidade do pagamento de um resgate aos vikings (PMH, DC 197, de 1008). A interpretação proposta parece-nos, contudo, abusiva; e nada permite relacionar os factos referidos neste texto com os vikings, como já observou PIRES, 2017: 117-18. O mesmo se diga da hipótese avançada por BALIÑAS PÉREZ, 2014: 28, nt. 77, para quem o resgate referido em PMH DC 81 (de 960), pago com bens que o autor situa na área de Ponte de Lima (sem que o texto permita afirmá-lo claramente), está relacionado com cativos tomados por vikings e não por muçulmanos.

${ }^{50}$ Sobre este documento, v. AZEVEDO, 1974: 85-88; PIRES, 2017: 118-23; CHRISTYS, 2015: 96; MORALES ROMERO, 2006: 206.
} 
resgate das três irmãs, mantidas em cativeiro e libertadas mediante o pagamento de um resgate de 15 soldos em prata ${ }^{51}$; mas também sobre a própria incursão de 1015 1016: entrada dos vikings no Douro em Julho de 1015, seguida da pilhagem das terras de Entre-Douro-e-Ave durante nove meses ${ }^{52}$.

O que não foi até agora sublinhado é que este documento, sendo na aparência uma mera venda de propriedades, tem subjacente uma disputa dentro do próprio grupo familiar de Amarelo, um notável local («homem-bom») da zona de Guilhabreu ${ }^{53}$. Este conflito está patente na recusa das filhas em aceitar a proposta do pai para que cuidassem dele na doença, com a contrapartida de virem a herdar os seus bens ${ }^{54}$. A referência ao resgate das irmãs parece assim ter uma evidente intenção retórica, de sublinhar a dívida (material e moral) das filhas para com Amarelo, num claro contraste com o abandono a que votavam o pai. Não é apenas a informação veiculada por este documento que é excepcional. O próprio contexto em que se alude ao episódio da captura e resgate das filhas de Amarelo é excepcional e deixa adivinhar que outros casos de tomada e "venda» de cativos pelos vikings não mereceriam, por si só, ser objecto de registo, como acontece desde logo com a transacção de propriedades. $\mathrm{O}$ que não significa que não tenham ocorrido, talvez até em número significativo, como este texto parece dar a entender.

\section{[3] PMH, DC 261 (1026)}

O segundo documento conhecido sobre o resgate de cativos das mãos de vikings nesta região alude também indirectamente ao facto ${ }^{55}$. Trata-se de uma carta datada de 1026, pela qual Meitilli «vende» a Octicio um conjunto de bens em Cabanões

\footnotetext{
${ }^{51}$ Ibi captiuarunt tres filias de me ipso Amarelo et remansi mesquino, pasarunt Leodemanes illos catiuos a uindere toto, ipsas filias de Arnarelo [...] pro tale actio aueruaui com Froila Tructesindiz que li dedise ea per carte et dedi mici que misi pro filias meas, et sacaui eas de captiuitate [...] Isto mici placuit et illos XV solidos argenzdeos que iam de uos pressi pro in illa catiuitate (AZEVEDO, 1974: doc. 2).

${ }^{52}$ In Era M L iija mense Iulio ingressi fuerunt filius et neptis Lotnimis (sic, por lotmanes) multis in Doiro, predans et captiuans de Doiro in Aue per viiije menses (AZEVEDO, 1974, doc. 2). Rui de Azevedo sugeriu que o ataque a Vermoim, datado pela Chronica Gothorum de Setembro de 1016, tenha tido lugar antes em 1015, supondo que ele estaria integrado na incursão de 1015-1016 relatada por este documento de 1018 e que haveria um erro de uma unidade na era que lhe é atribuída por aquele texto analístico; mas não deixa de admitir que este ataque possa ter ocorrido de facto em Setembro de 1016, aquando de um suposto regresso ao Norte do mesmo bando viking, depois de ter andado por paragens mais setentrionais entre Abril e Setembro desse ano (AZEVEDO, 1974: 87-88). PIRES, 2017: 125-26, considera a primeira hipótese admissível, mas não necessária, sublinhando que podemos até estar perante ataques de dois bandos distintos. ${ }^{53}$ Amarelo Mestaliz aparece referido num conjunto de três documentos: PMH, DC 163 (991), PMH; DC 216 (1011) e Azevedo, 1974, doc. 2 (1018). A sua condição de proprietário local foi sublinhada por AZEVEDO, 1974: 85-86.

${ }^{54}$ Dum uenimus ad anno pleno integro cadiuit ego Amarelo in mesquinitate et in infirmitate per annos malos et non aueua in meo iure pan nec aligo genere causa que aprestamo ominis est per que uiuere fecissem a meas fillias carta que partissent mea ereditate in tercias post mea morte pro que eram de singulas matres et pro it (sic) dedissent mici uictum et uestitum et curiassent me et seruissent in mea uita, et non abuerunt (sic, por abnuerunt?) unde, et deleisciarunt me mal in mea infirmitate (AZEVEDO, 1974: doc. 2).

${ }^{55}$ Sobre este documento, v. VITERBO, 1993, s.v. kemiso; VASCONCELOS, 1982 [1958]: 21; CARDOSO, 1929: 53-56; PIRES, 2017: 143-47; MORALES ROMERO, 2006: 207-8; CHRISTYS, 2015: 96.
} 
(freguesia de Ovar (S. Cristóvão), concelho de Ovar), como contrapartida por este ter pago o resgate do(a) próprio(a) Meitilli e de sua filha Goncinha, no valor total de 70 moios (divididos entre uma espada, uma camisa, três lenços, uma vaca e três moios de sal) ${ }^{56}$. São várias as questões que este documento levanta.

Em primeiro lugar, não indica a data dos factos, pelo que é bem possível que estejam relacionados com a incursão de 1015-1016, como defenderam Gama Barros e Rui de Azevedo, e como deixa subentender o uso do pretérito (eram) na referência aos homens que terão supervisionado o pagamento do resgate ${ }^{57}$. O documento pode assim não aludir a um ataque independente ocorrido em «1026 ou antes», nem é necessário que esse suposto ataque tenha ocorrido na zona de Santa Maria da Feira, como pretende Pires, ao tomar a identificação das propriedades transaccionadas como um indicador da origem dos cativos, logo do lugar do ataque ${ }^{58}$. Importaria perceber melhor o estatuto social dos intervenientes, mas tanto aristocratas como membros das elites camponesas podiam mover-se num raio geográfico que ultrapassa a esfera local. De qualquer forma, continuamos sem sair da área envolvente da embocadura do Douro, onde vimos ser mais activa a presença viking, tanto quanto a documentação nos permite saber.

Há depois um conjunto de problemas em torno do resgate propriamente dito. Pago em géneros, ao contrário do que vimos acontecer em 1018, este resgate compreende um conjunto de bens (incluindo uma espada!) que caberiam numa qualquer transacção banal. De facto, é esta a impressão que se colhe do documento, até porque o resgate é explicitamente classificado como uma «compra» ${ }^{59}$. Que esta não foi uma transacção banal deduz-se, contudo, do facto de o pagamento do resgate ter sido feito na presença de três homens que «habitavam» numa "casa de Sta. Maria da Cividade» (actual concelho de Santa Maria da Feira). Gonzaga de Azevedo supôs que estes homens seriam autoridades locais coniventes com os vikings, a quem seria devida uma parte do resgate ${ }^{60}$. Mas Pires sugere antes que essa presença poderia ter a função de «organizar ou sancionar o resgate, reforçando assim a sugestão de que houve uma negociação, neste caso sob os auspícios das autoridades locais» ${ }^{61}$.

Era, de facto, comum que transacções com um carácter excepcional fossem celebradas na presença de autoridades (ou mesmo assembleias) locais que, mais do

\footnotetext{
${ }^{56}$ pro que comparastes nobis de kaptibo mici meitilli cum filia mea guncina et sakastes nobis de barcas de laudomanes et dedistis pro nobis uno manto lobeno et una spada et Io kamisso et III lenzos et una uaka et III modios de sal finto sub uno LXX modios ante ipsos domnos que abitantes eram in cassa de sancta maria de ciuitate tedon galindici et fredenando gundissalbici et ero tellici et de pretio abut uos non remansit pro dare (PMH, DC 261).

${ }^{57}$ BARROS, 1947: 23; AZEVEDO, 1974: 87.

${ }^{58}$ PIRES, 2017: 143-44.

${ }^{59}$ Já em 1018 Amarelo Mestaliz dizia que os vikings tinham «vendido» os cativos entre os quais estavam as suas filhas (AZEVEDO, 1974: doc. 2).

${ }^{60}$ AZEVEDO, 1939: 165.

${ }^{61}$ PIRES, 2017: 145.
} 
que intermediar, davam força ao negócio. E não será de excluir a possibilidade de estes homens estarem presentes para assegurar a protecção de quem pagava o resgate face aos próprios vikings ${ }^{62}$. O documento parece indicar que os cativos seriam mantidos nos próprios barcos (sinal da curta duração do cativeiro). Mas também se pode admitir que o fossem em alguma base viking, que podia mesmo aproveitar construções pré-existentes ${ }^{63}$.

A captura de cativos e o pagamento de resgates devem ser entendidos no contexto das necessidades de abastecimento das frotas vikings, que na maior parte das vezes estariam apenas de passagem, não tendo o Entre-Douro-e-Minho como destino final $^{64}$. Os cativos seriam assim moeda de troca por mantimentos ${ }^{65}$, com destaque para o sal. Mas também é possível relacionar a captura de cativos com o tráfico de escravos feito pelos vikings ${ }^{66}$. Havia, aliás, na Península Ibérica deste período, e em especial nos territórios de fronteira, uma dinâmica intensa de captura e resgate de cativos, que não só alimentava o mercado de escravos, seja nos reinos cristãos seja

\footnotetext{
${ }^{62}$ Cabe ainda perguntar se os três homens (habitantes in cassa de sancta maria de civitate) não seriam antes eclesiásticos. O documento é escrito por um abade (Aba uasculum notuit), que poderia ser membro da dita casa de sancta maria, caso aceitemos que o termo casa alude aqui a uma instituição monástica; ou mesmo abade do mosteiro de Pedroso, onde foi conservado o documento (embora este mosteiro tenha sido fundado entre 1017-1026, não é conhecido o nome de nenhum abade antes de 1072: MATTOSO, 2002: 31). Mas a verdade é que o termo casa aparece a designar não só mosteiros mas também centros dominiais (tanto monásticos como aristocráticos): MARQUES, 2014: 248, 302-3. ${ }^{63}$ PIRES, 2017: 145; MORALES ROMERO, 2006: 216.

${ }^{64}$ Estas necessidades estão patentes nos relatos de fontes de diversa cronologia. Entre as mais antigas está a já referida História da Conquista do al-Andalus de Ibn al-Qutiya: atacados pelas forças andaluzas no lugar de Quintas de Moafer, dois dos bandos vikings que atacaram Sevilha em 844 foram forçados a fugir para os seus barcos, parando apenas no caminho para trocar os cativos que tinham feito por tecidos e provisões (apud CHRISTYS, 2015: 34-35). Um segundo exemplo encontra-se no relato feito pela Morkinskinna e outras fontes nórdicas da passagem da frota de Sigurd pela Galiza, algures entre 1107-1110 (apud PIRES, 2017: 162-63). Tendo invernado na «terra de Santiago», onde chegou em Outubro, Sigurd negociou com o governante do território o estabelecimento de um mercado onde a sua frota pudesse abastecer-se. Posto em causa este abastecimento por altura do Natal, o exército norueguês atacou o castelo do dito governante e recolheu um abundante saque, antes de voltar a partir. A mesma tentativa de montagem de um mercado local para abastecimento é referida na Orkneyinga Saga, a propósito da passagem pela Galiza de uma frota chefiada por Rögnvaldr Kali Kolsson, jarl das Ilhas Orkney, também a caminho de Jerusalém (apud PIRES, 2017: 16466, que sugere que o relato relativo à expedição de Sigurd possa ter-se inspirado na versão poética original do relato da expedição de Rögnvaldr Kali Kolsson, só mais tardiamente recolhida na Orkneyinga Saga).

${ }^{65}$ V. um exemplo em CHRISTYS, 2015: 35. O sal é uma das mercadorias referidas no pagamento do resgate de $\mathrm{PMH}$, DC 261. Não deve, contudo, exagerar-se a sua importância na explicação das incursões vikings à Península Ibérica, como mostrou PIRES, 2017: 51.

${ }^{66}$ Sobre a relação entre a tomada de cativos na Península Ibérica e o tráfico de escravos operado pelos vikings, v. CHRISTYS, 2015: 11-12, 56-57; MORALES ROMERO, 2006: 166, que aludem ambos à venda de escravos oriundos do Magreb em Dublin logo na década de 860, registada por uma fonte tão problemática como os Fragmentary Annals irlandeses. Embora escassamente documentado, o tráfico de escravos (tanto eslavos, trazidos pelos vikings, como ibéricos e magrebinos, por eles levados para o Norte) poderá ter sido mais importante do que Christys sugere, ao considerar que a tomada de cativos estava relacionada sobretudo com a exigência de resgates. A importância dos vikings no abastecimento de escravos ao al-Andaluz no período omíada foi sublinhada por COLLINS, 1995 : 192. Mas as notícias da existência de cativos a bordo de frotas vikings envolvidas em incursões no território português podem ser interpretadas como indícios da captura de cativos em paragens anteriores ao longo da mesma costa, como sugere PIRES, 2012: 130, a propósito da indicação de Ibn Idhari de que havia prisioneiros a bordo dos navios vikings derrotados pela frota muçulmana que os atacou ao largo de Silves em 966.
} 
no al-Andaluz, como acabava por enquadrar uma parte significativa das trocas de outros produtos entre o Norte e o Sul da Península.

Chamando a atenção para a dupla possibilidade de resgate ou venda dos cativos como escravos, Amancio Isla notou já o paralelo entre o modus operandi dos vikings e o dos muçulmanos no que toca à tomada de cativos ${ }^{67}$. Deve por isso admitir-se a possibilidade, já sugerida por Pires, de as negociações envolvidas no resgate de cativos - sobretudo nos casos em que se teriam prolongado por alguns meses, como aconteceu com Amarelo Mestaliz - terem ocasionado o estabelecimento de trocas comerciais entre vikings e locais ${ }^{68}$. Aliás, aquelas negociações poderiam revestir-se de uma dimensão bem mais amistosa, ao ponto de os vikings ajudarem homens do Norte peninsular a fugir da sua própria terra, como terá acontecido com um asturiano vítima da ira do rei Afonso V, que terá fugido ad alias terras in barcas de Lodmanos nos inícios do século XI ${ }^{69}$.

A verdade, porém, é que não há provas claras, desde logo no registo numismático, de um comércio regular entre os vikings e as populações ibéricas ${ }^{70}$. Se alguma coisa se pode saber ao certo dos dois documentos analisados é que o pagamento de ambos os resgates terá deixado os próprios cativos (ou os seus familiares) endividados ao ponto de terem de alienar propriedade para pagar essas dívidas. Trata-se, portanto, de transacções a todos os títulos excepcionais. A impressão que fica destes

${ }^{67}$ ISLA FREZ, 1992: 102. O autor confronta o referido documento de 1026 aqui comentado (PMH, DC 261) com um outro caso de resgate que supõe ser pago a muçulmanos, embora o documento não explicite a identidade de quem o recebeu (PMH, DC 239, de 1018) - a sugestão do autor dever-se-á ao facto de o resgate ser intermediado por judeus? ${ }^{68}$ PIRES, 2017: 122; a mesma sugestão foi feita, a propósito do al-Andaluz, por PRICE, 2012: 464-65.

${ }^{69}$ et abia ila villa [de Erias] Felix ea de nos per karta, et tenente ila villa in suo iure venit ili a Felix iram de Rex domno Adefonso et exibit de terra et fuit ad alias terras in barcas de Lodmannos [...]: FLORIANO LLORENTE, 1968: 72-74, n. ${ }^{\circ}$ XXX (de 1028). FERNÁNDEZ CONDE \& TORRENTE FERNÁNDEZ, 2007: 190, sugerem que Félix poderá ter traído o rei colaborando com os próprios vikings, mas a verdade é que desconhecemos os motivos que o levaram a incorrer na ira régia, como notou MORALES ROMERO, 2006: 205. Já é excessiva afirmação deste autor quando sugere que «El hecho de que Félix Agelazi utilizase para su fuga los barcos de los vikingos parece indicar la presencia más o menos permanente de una flota nórdica en aguas del Cantábrico y las costas de Galicia» (MORALES ROMERO, 2006: 205). ALONSO RODRÍGUEZ, 2009: 185-86, chama a atenção para a aquisição pelo dito Félix, no seu regresso, e através de um escambo com a rainha Vesquita, de uma villa e de um porto a ela associado, que poderia constituir uma infra-estrutura destinada à actividade comercial.

${ }^{70}$ KROMANN, 1988; MORALES ROMERO, 2006: 112-14, 224-25, que chamam a atenção para a escassez de moeda de origem hispano-muçulmana (apenas 39 numismas) entre os mais de 60.000 dinares de diversas proveniências encontrados na Escandinávia; destacam a importância de um pequeno tesouro descoberto em Heligholmen (uma ilha sueca, a sul da ilha de Gotland), composto por 24 moedas provenientes do al-Andaluz, datadas entre 778-779 e 1012-1013; e Morales alude ainda a «un determinado número de monedas con carácteres cúficos halladas en tesorillos noruegos del período [que] eran de procedencia andalusí y probablemente llegaron a Noruega vía Irlanda» (MORALES ROMERO, 2006: 168). O tesouro de Heligholmen tem sido interpretado, por estes e outros autores, como resultado de um contacto directo (por via do comércio ou do saque) entre a Península Ibérica e a Escandinávia. A cronologia das moedas pode mesmo sugerir que teriam sido levadas na sequência da incursão de 1015-1016 ou de outra posterior, mas não há nenhuma certeza quanto à sua origem. Em suma, é mínima a evidência de moedas ibéricas na Escandinávia, em manifesto contraste com a enorme abundância de moeda árabe proveniente do Oriente, encontrada sobretudo na Suécia (CHRISTYS, 2015: 6, 8). Os Fragmentary Annals irlandeses, que apresentam informação detalhada sobre a Península Ibérica e o Magreb, podem denunciar contactos mais ou menos frequentes já no século IX, mas não são suficientes para sugerir a existência de trocas regulares (v. CHRISTYS, 2015: 56-57; cf. p. 24). 
textos é a de um carácter episódico da interacção entre vikings e populações locais no Entre-Douro-e-Minho. Terá havido certamente mais episódios de ataques e tomada de cativos, e a presença dos vikings no território portucalense terá sido mais prolongada do que normalmente reconhecemos ${ }^{71}$. Mas será possível afirmar que esta presença deixou alguma vez de ser ocasional?

\subsubsection{Assentamento? \\ Colonos}

Segundo H. Pires, tanto os contactos entre vikings e locais com vista ao resgate de cativos como a possível captura dos primeiros pelos segundos, na sequência de derrotas que algumas fontes registaram, podem ter ocasionado o assentamento de alguns vikings neste território, como «colonos». Que este seja «um fenómeno passível de ser ignorado pelas principais fontes escritas ou de deixar poucos ou mesmo nenhum vestígio material» explicar-se-ia pelo facto de ter ocorrido a uma escala muito menor do que noutras zonas da Europa, como a Normandia ou as Ilhas Britânicas; ainda que a intensidade dos ataques entre c. 950-1066 seja considerável ${ }^{72}$. Mas a verdade é que nenhum dos indicadores normalmente invocados (a toponímia e as supostas influências vikings na construção naval peninsular) fornece prova material suficiente; o que leva o autor a concluir que, a ter existido, essa colonização «não foi nem de grande dimensão nem, pelo que sabemos, intensa na generalidade do território galego-português» ${ }^{73}$.

Não é este o lugar para discutir os indícios antroponímicos e toponímicos da presença viking no Noroeste peninsular; discussão que, em todo o caso, compete antes de mais aos filólogos. Mas importa arrolar aqui as escassas referências documentais que permitem admitir - mas não confirmam - a hipótese de um assentamento mais estável ${ }^{74}$. Trata-se de um conjunto certamente incompleto, mas que inclui um ou outro dado que os autores citados não referem.

No domínio da antroponímia, importa citar três documentos que aludem a possíveis vikings (ou seus descendentes) já instalados no território hoje português,

\footnotetext{
${ }^{71}$ Até porque, como notou MORALES ROMERO, 2006: 88, «los ataques vikingos a la Península Ibérica no son episodios aislados, sino que se producen como consecuencia de la ampliación del radio de acción de las bandas vikingas que operaban en el Canal de la Mancha y el Mar de Irlanda».

72 PIRES, 2012: 257-58; PRICE, 2012: 468: «The intensity of these attacks [entre 951 e 1066] against the Spanish Christians may imply some kind of attempt at settlement or even conquest: the assaults of 968-71 and 1047-66 seem to have been virtually military campaigns. The documentary sources are unfortunately too meagre to draw any firm conclusions, and in the absence of new archaeological evidence the motivations behind the latter Viking raids on northern Spain remain obscure».

${ }^{73}$ PIRES, 2012: 263; o autor tratou este problema da colonização viking de forma mais breve e ainda mais prudente na última versão da obra: PIRES, 2017: 209-16; v. tb. p. 122-23.

${ }^{74}$ Esta hipótese parece ser aceite, para a Galiza, por LÓPEZ ALSINA, 2013: 234, nt. 340.
} 
mais concretamente na área litoral em torno do Porto, que vimos ser aquela em que está documentada uma maior presença viking:

[4] PMH, DC 185=LP 522 (1001): testamento de um tal Donaciano, entre cujas testemunhas está um Fromarigu Leodemariz. Trata-se de um documento sem qualquer referência toponímica, pelo que não é possível situá-lo no território.

[5] PMH, DC 295=LP $362=511(1037)^{75}$ : venda de uma propriedade em Real (concelho de Matosinhos), feita pelo conde Gonçalo Forjaz a um Halaf. O conde recebera essa propriedade de um servo seu, Godesteo, filho de Leodemaro; sendo que entre as testemunhas do documento está um Victenando Leodemarizi (irmão de Godesteo?) $)^{76}$.

[6] RIBEIRO, 1857-1896, I, Ap. n. 15 (1046) ${ }^{77}$ : doação feita por Transtina Pinioliz a sua irmã Sancha Pinioliz de um amplo conjunto de propriedades (dispersas por vários lugares a sul e a norte do Douro), entre as quais: nostras ganatas, que ganavimus ic in Palmacianos, ubi avita Leodemaro ${ }^{78}$.

No que diz respeito à toponímia (tanto de base antroponímica como etnonímica) que remete para pessoas ou grupos oriundos do Norte da Europa, são normalmente referidos três lugares em todo o Noroeste peninsular, dos quais apenas um está situado no actual território português, ainda que já fora da área aqui em estudo ${ }^{79}$ :

(i) Lordemanos (Cimanes de la Veja, Tierra de Campos, León), cujo topónimo aparece referido num documento de 1064, como elemento confinante com a villa em que se localizavam as propriedades transaccionadas ${ }^{80}$.

(ii) Lordemão (concelho de Coimbra), cujo topónimo aparece referido na doação de uma propriedade aí situada, feita pela rainha D. Teresa a Gonçalo Aluane algures entre 1121 e $1125^{81}$.

\footnotetext{
${ }^{75}$ Documento proveniente do cartório do mosteiro de Leça.

${ }^{76}$ O patronímico consta apenas de LP 511 [C]; em LP 363 [B] está tão-somente: Victenando ts. Sobre estas referências antroponímicas e a proximidade de Real ao lugar da Mota de Adaúlfo (Perafita, Matosinhos), possivelmente relacionada com os vikings, v. infra as considerações de Mário Barroca no ponto 2.

${ }_{77}$ Documento proveniente do cartório do mosteiro de Pedroso.

${ }^{78}$ É possível acrescentar outros documentos produzidos fora do território portucalense, alguns dos quais não estão necessariamente relacionados com vikings, mas com «normandos», no sentido amplo de homens vindos do Norte, como poderá ser o caso de um presbítero de nome Lormano referido numa constituição do bispo D. Diego de León datada de 1120 (CL(V) 1367).

${ }^{79}$ CHRISTYS, 2015: 16; MORALES ROMERO, 2006: 87-88. A generalidade dos autores sugere que estes lugares corresponderiam a assentamentos. Embora reconhecendo que a interpretação dos três topónimos é pouco clara, PRICE, 2012: 465, sugere que eles poderiam corresponder a «sites where Scandinavians came regularly to barter». ${ }^{80}$ CL(IV) 1128: de una parte termino de Lordomanos. Segundo PIRES, 2017: 97, este topónimo pode «indiciar um local onde os vikings estiveram ou se fixaram».

${ }^{81}$ DMP, DR 59: hereditate quam habui in termino de Colimbrie in loco qui dicitur Lordomam; comentado por PIRES, 2017: 212-13.
} 
(iii) Por fim, há um terceiro documento, datado de 979, que alegadamente refere uma "cidade dos Lodimanos» na demarcação de uma propriedade situada nas proximidades do rio Ulla, na zona de Pontevedra (Galiza); embora deva sempre admitir-se a hipótese de o texto aludir a uma base de inverno e não a um assentamento permanente ${ }^{82}$.

Haverá talvez outros exemplos ainda não identificados, mas a verdade é que aqueles que conhecemos são insuficientes para confirmar uma presença estável de vikings no Noroeste peninsular, e muito especialmente no Entre-Douro-e-Minho.

\section{Acampamentos}

Mais força parece ter a hipótese, defendida por H. Pires num contexto desligado do problema da "colonização», de terem sido construídas no território portucalense bases de inverno vikings, semelhantes a outras instaladas em vários pontos das costas britânica e francesa a partir da década de $840^{83}$. Esta hipótese vem ao encontro de alguma evidência toponímica e arqueológica que sugere a permanência de vikings durante breves períodos de invernagem noutras zonas da Península ${ }^{84}$. Note-se, contudo, que estas bases, a existirem, teriam uma duração curta, destinando-se apenas ao apoio logístico durante incursões mais prolongadas (algumas estendendo-se por vários meses). Aliás, poderiam ter servido de ponto de partida para ataques a cidades do al-Andaluz, mais ricas e fortificadas do que os pequenos núcleos populacionais do litoral portucalense. Seja como for, dificilmente a sua existência seria tolerada por muito tempo pelos poderes locais, por constituírem uma ameaça permanente. E, por isso, dificilmente podem ter dado origem a povoações estáveis; o que não significa que se deva negar qualquer forma de assentamento viking neste território. São duas as bases de inverno que Pires sugere terem existido nesta região.

A primeira estaria situada na zona de Entre-Douro-e-Ave e seria indiciada pela longa duração da incursão de 1015-1016, que começou em Julho de 1015 e terá durado nove meses, durante os quais a zona foi saqueada. $\mathrm{O}$ autor avança esta hipótese com base em dois argumentos principais: (i) a necessidade que os vikings teriam de acampar, armazenar mantimentos e assegurar a defesa dos próprios navios

\footnotetext{
${ }^{82}$ LUCAS ÁLVAREZ, 2003: 169-70, doc. 8; apud LÓPEZ ALSINA, 2013: 234, nt. 340 (que considera este lugar um assentamento «estável»); MORALES ROMERO, 2006: 87-88; CHRISTYS, 2015: 81 (cita erradamente a edição de Lucas Álvarez). Note-se que esta referência consta apenas de um resumo do século XVII (onde o documento está datado de 966). O documento original está hoje muito mutilado e só deixa ler o protocolo final. O autor do resumo, parafraseando talvez o texto original, dá claramente a entender que este assentamento viking já não existiria no momento em que o documento foi escrito: «Ordoño Laurencio dona al monasterio de San Martín la heredad que tenía en la villa de Campaña [...] cerca del río Ulla, como se demarcan por el río Louro y con Cordeiro y Valga, y hasta donde estuvo la ciudad de los Lodimanos» (apud LÓPEZ ALSINA, 2013: 234, que data erradamente o documento de 996).

${ }^{83}$ Paralelos assinalados em PIRES, 2012: 88-89, 96, 114, 173-74; PIRES, 2017: 51, 55, 71.

${ }^{84}$ CHRISTYS, 2015: 6.
} 
(uma frota/exército que teria provavelmente alguma dimensão), a propósito do que invoca paralelos conhecidos arqueologicamente nas costas inglesas; (ii) o episódio do cativeiro das filhas de Amarelo Mestaliz, que pressupõe um intervalo de tempo e uma logística de cativeiro e resgate que indiciam a existência de lugares de detenção dominados pelos vikings ${ }^{85}$.

A segunda base de inverno estaria situada na Terra de Santa Maria e o autor deduz a sua existência da negociação de um resgate de cativos com as supostas autoridades desta civitas, relatada na já referida carta de $1026^{86}$. Tal negociação pressuporia um intervalo de tempo mínimo para a presença dos vikings nesta zona, uma certa proximidade com as ditas autoridades e «no mínimo, um acampamento no local de desembarque, passível de ser identificado como o ponto onde os piratas se encontravam e, com eles, as pessoas cativas» ${ }^{87}$. Como vimos, é discutível a ideia de negociação em torno do pagamento do resgate e sobretudo a tese de que seriam autoridades locais os intermediários da negociação do resgate; já para não falar da atribuição deste episódio ao ano de 1026, associando-o a um suposto ataque que teria versado especificamente a área costeira a sul do Douro. Tudo isto torna bastante estreita a margem para aceitar a hipótese de uma base viking na zona de Santa Maria da Feira.

Em suma, ataques, tomada e resgate de cativos e assentamento (provavelmente de carácter não permanente) terão sido as principais formas de relacionamento entre os vikings e as populações do território portucalense, segundo o registo documental. É discutível a frequência e o grau de proximidade que esse relacionamento atingiu em cada uma das formas. Mas a interacção não pode ser negada, mesmo se a informação de que dispomos é tão escassa e não nos permite documentar mais do que contactos episódicos.

\section{O REGISTO ARQUEOLÓGICO 88}

Apesar de, como acabamos de ver, a interacção entre vikings e populações peninsulares, nomeadamente do Noroeste da Península, ter ocorrido em diferentes momentos entre os meados do século IX e o primeiro quartel do século XI, são muito escassos os testemunhos arqueológicos que se podem relacionar seguramente com a presença de vikings no espaço ibérico. Assinalemos, a este propósito, uma pequena caixa em haste de cervo ou de rena, com $44 \mathrm{~mm}$ de altura e $33 \mathrm{~mm}$ de diâmetro, provavelmente destinada a guardar fichas de jogo (certamente o Hnefatafl, jogo de tabuleiro viking). Em momento não determinado, foi incorporada na Colegiada de

\footnotetext{
${ }^{85}$ PIRES, 2012: 91, 172-74; PIRES, 2017: 121: avança a hipótese de uma localização nas margens do Douro, admitindo que pudesse haver mais do que uma base; cf. a localização junto da foz do Ave sugerida por Mário Barroca no ponto 2.

${ }^{86} \mathrm{PMH}, \mathrm{DC} 261$.

${ }^{87}$ PIRES, 2012: 189; PIRES, 2017: 145.

${ }^{88}$ Por Mário Barroca.
} 
León, onde passou a servir de lipsanoteca, resguardando relíquias. É possível que tenha feito parte da grande doação de 1063, feita por Fernando I, o Magno, e por D. Sancha à Colegiada de San Isidoro aquando da sua fundação, mas o certo é que a caixa não é mencionada entre as peças discriminadas no diploma da doação régia. Esta pequena caixa, que hoje pertence ao Tesouro da Colegiada de San Isidoro, em León, foi publicada pela primeira vez por Manuel Gómez Moreno, que registou a sua singularidade, sugerindo ser obra de arte saxónica ${ }^{89}$. Pouco depois foi estudada por Adolph Goldschmidt, que a classificou de origem «sueca» e a datou à volta do Ano $\mathrm{Mil}^{90}$. Depois destas duas referências pioneiras, a caixinha de León permaneceu esquecida durante várias décadas. Em 1990 foi de novo estudada e valorizada por Eduardo Morales Romero e pelos investigadores dinamarqueses Jan Skamby e Keld Hansen. Eduardo Morales Romero publicou-a em 2004, atribuindo-a à segunda metade do século $\mathrm{X}^{91}$. O mais recente estudo foi consagrado em 2010 por Else Roesdahl, que sugeriu a possibilidade de ter sido expressamente criada para servir de píxide ou de lipsanoteca cristã, dada a ausência de paralelos rigorosos no mundo escandinavo, atribuindo a peça ao século X e ao estilo Mammsen ${ }^{92}$. Curiosamente, na Colegiada de San Isidoro conservam-se outras lipsanotecas que resultam da adaptação de peças eborárias concebidas para outras funções, como é o caso da Caixa das Lebres, obra muçulmana (ou, quando muito, moçárabe) que, depois de incorporada na Colegiada, passou igualmente a servir de lipsanoteca ${ }^{93}$, e de outras pequenas caixas, algumas com legendas árabes, que cumpriram idênticas funções ${ }^{94}$. A presença destas peças de luxo em instituições religiosas espelha uma prática relativamente corrente nas monarquias cristãs emergentes: a de se assinalar e agradecer a protecção divina em vitórias militares entregando uma peça emblemática à Igreja. Mas elas também podem resultar de ofertas, reflectindo contactos e relações entre as várias comunidades. É o que sugeriu Ángel Galan y Galindo para o Cofre muçulmano da Sé de Braga, que era usualmente datado de [1004-1008] e interpretado como resultado de saque de guerra, e que aquele investigador espanhol sugeriu poder ser antes uma oferta do próprio Abd al-Malik ao conde portucalense, D. Mendo Gonçalves, em 1004, quando Abd al-Malik arbitrou uma querela entre o conde Sancho Garcia e o conde portucalense em torno da tutela do jovem rei leonês, Afonso $\mathrm{V}^{95}$. Poderia a caixa de León também resultar de uma oferta diplomática, desta vez viking?

\footnotetext{
${ }^{89}$ GÓMEZ MORENO, 1925: (1) 195; (2) fig. 195 e 196.

${ }^{90}$ GOLDSCHMIDT, 1926: 57 (N. $\left.{ }^{\circ} 298 \mathrm{a}-\mathrm{b}\right)$.

${ }^{91}$ MORALES ROMERO, 2006: 115-122.

92 ROESDAHL, 2010: 157-159.

${ }^{93}$ GALÁN Y GALINDO, 2005: 70-72.

${ }^{94}$ GÓMEZ MORENO, 1925: (1) 163-165.

${ }^{95}$ GALÁN Y GALINDO, 2005: (2) 53-55. Do ponto de vista cronológico, este autor recua a execução do Cofre bracarense para o período de [994-1002].
} 
Para além da pequena caixa de León não se conhecem mais exemplos seguros de testemunhos vikings em solo peninsular. O duplo báculo de San Pelayo, do século IX-X, que se conserva na Catedral de León e que durante algum tempo foi apontado como sendo viking (em boa medida por uma errada identificação da sua matéria-prima), foi afastado do rol das peças de origem nórdica. Resta apenas a notícia, veiculada pela imprensa espanhola, do aparecimento de restos de um drakar viking, atribuído ao século IX, encontrado em Agosto de 2008 no rio Bidasoa (Vera de Bidasoa, Guipúzcoa) e que foi relacionado com a incursão viking de 858 sobre Pamplona. O achado aguarda, no entanto, estudo monográfico que o caracterize de forma mais fundamentada e segura.

Portanto, e como se pode verificar, os testemunhos materiais relacionados com os vikings em solo ibérico são escassíssimos. Mas podemos recuperar outros dados.

Com efeito, é provável, como foi antes referido, que a fundação do Castelo de Guimarães e a sua doação ao mosteiro vimaranense (em 968) tenham sido respostas às ameaças vikings que se faziam sentir por essa altura. O castelo, construído entre os penedos do Mons Latito (Monte Largo), resultou de iniciativa condal e, na nossa opinião, deve ter sido erguido por volta de 950 . Com efeito, julgamos que o primeiro documento que o refere, ainda que de forma indirecta, é um diploma do Livro de Mumadona que, na recente edição daquele cartulário, recebeu a datação crítica de [d. 950, Julho, 24 - a. 951, Janeiro, 5]. Nele se refere o «cenobio nuncupato Vimaranes que est fundata ad radice montis Latito inter duas amnes Aue et Auizella urbium Bracarensis ${ }^{96}$. A expressão ad radice, que alterna na nossa documentação com a expressão subtus mons, revela, na nossa opinião, uma relação de dependência militar. Depois deste primeiro diploma, o Monte Latito volta a ser referido em 26 de Janeiro de 959 (ab alpe Latito) ${ }^{97}$, em 20 de Julho de 959 (territorio Lattito) $^{98}$, em 10 de Março de 961 (subtus monte Latito) ${ }^{99}$ e a 10 de Dezembro de 968 (subtus alpe Latitus $)^{100}$. Mas a nossa interpretação de que estas referências documentais ao Monte Largo são, de uma forma indirecta, testemunho da existência de um castelo não é consensual. André E. Marques, neste mesmo texto, afasta este tipo de referências e aceita que o castelo de Guimarães apenas se documenta a partir de 968. Mas, quer tenha sido fundado c. 950, quer pouco antes de 968, o que importa para este nosso estudo é o teor do conhecido diploma de 4 de Dezembro de 968, pelo qual a condessa Mumadona Dias doou o castelo aos monges e monjas do mosteiro de

\footnotetext{
${ }^{96} \mathrm{LM} 49=\mathrm{PMH}, \mathrm{DC} 71 ; \mathrm{VMH}, 8$.

${ }^{97} \mathrm{LM} 1 \mathrm{a}=\mathrm{PMH}, \mathrm{DC} 76 ; \mathrm{VMH}, 9$.

${ }^{98}$ LM 54 = PMH, DC 77; VMH, 341.

${ }^{99} \mathrm{LM} 62$ = PMH, DC 82; VMH, 12.

${ }^{100}$ LM 67 = PMH, DC 99; VMH, 15.
} 
Guimarães. Nessa doação a Condessa declara expressamente que o fazia por receio do ataque dos gentios:

Post non multo vero temporis quod hunc series testamenti in conspecto $m[u]$ ltorum est confirmatum persecutio gentilium irruit in hujus nostre religionis [sic] suburbium et ante illorum metum laborauimus castellum quod vocitant Sanctum Mames in locum predictum alpe Lat<i>to quod est super huius monasterio constructum et post defensaculo huius sancto cenobio concedimus eum fratribus et sororibus ipso monasterio persistentibus [... $]^{101}$.

A expressão usada - persecutio gentilium —, já acima abordada e valorizada por André E. Marques, é muito interessante. Obviamente refere-se a povos que não professavam a religião cristã. Mas, na nossa documentação, os muçulmanos não costumam ser tratados como "gentios». São normalmente designados «mouros». Parece, portanto, haver alguma intencionalidade no uso desta expressão: designar outras ameaças não cristãs, embora não muçulmanas. Ora, nesta altura, o espaço controlado pela monarquia leonesa estava sobretudo sujeito a duas ameaças: a dos povos do Sul, os muçulmanos; e a dos povos do Norte, do Mar, os vikings. Parece-nos ser lícito, portanto, supor que esses gentios fossem, afinal, vikings.

Sensivelmente coeva da doação do Castelo de Guimarães, de 968, temos a incursão de Gunrød ou, como as fontes cristãs memorizaram, Gunderedo sobre a Galiza. Ocorrida entre 968 e 969, a expedição de Gunderedo parece ter incidido na Galiza, começando pela ria de Arousa, subindo o rio Ulla e internando-se na zona de Iria Flávia e de Compostela, mas não é de excluir que possa ter também atacado zonas a sul do rio Minho, uma região que estava, para mais, fragilizada por recentes razias muçulmanas. Para além do mais, tratava-se de uma zona densamente povoada, bem agricultada, dotada de uma rede de mosteiros, tudo condições ideais para a obtenção de bons lucros, quer por saque, quer por resgate.

$\mathrm{Na}$ Vida de S. Rosendo refere-se estes tempos conturbados, assinalando-se a ausência do rei, Sancho I de Leão, a invasão normanda da Galiza, na qual morreu o bispo Sisnando, e as devastações muçulmanas sobre o Entre-Douro-e-Minho. É certo que o texto é de produção tardia, não anterior à segunda metade do século XII (talvez por volta de 1172$)^{102}$, e, portanto, muito afastado dos acontecimentos descritos. Provavelmente estes foram referidos com um propósito hagiográfico preciso: o de

\footnotetext{
${ }^{101}$ LM 1 b (= PMH, DC 97; VMH, 14). Na tradução de Manuel Ramos (a quem agradecemos): «Ora, não muito tempo depois que o conteúdo do testamento foi confirmado na presença de muitos, a perseguição dos pagãos (gentilium) atacou o subúrbio desta nossa região e, por causa do medo que deles tínhamos, construímos acima o castelo a que chamam de São Mamede no referido lugar de Alpe Latito, o qual (castelo) foi construído acima do mosteiro e depois para defesa deste santo cenóbio, concedemo-lo aos frades e freiras que residem no mosteiro».

102 DÍAZ Y DÍAZ, 1993: 686.
} 
enaltecer a figura do bispo Rosendo face a outras figuras mais próximas do tempo de redacção da Vita, nomeadamente o poderoso arcebispo Diego Gelmírez, celebrizado, entre outras coisas, pelo combate à pirataria, como nos sublinhou André E. Marques nos comentários que trocámos a propósito de este texto. A Historia Compostellana $(\mathrm{I}, 2)$ alude a S. Rosendo (que trata de forma elogiosa) no mesmo parágrafo em que fala da invasão normanda que vitimaria o bispo Sisnando (que é tratado de forma muito crítica), muito embora omita qualquer intervenção de Rosendo no combate aos normandos. Em todo o caso, a Vita Sancti Rudesindi Episcopi et Confessoris, redigida por Ordonho, monge de Celanova, regista:

Eo tempore quo beatus Rudesindus Hyriensem ecclesiam regebat, ut asseritur, cum Gallecia iam fere tota inuaderetur a Normanorum multitudine, et Portugalensium prouincia uastaretur a Sarracenorum fortitudine [... $]^{103}$.

E as mesmas informações são confirmadas na chamada «segunda» versão da Vita, atribuída comummente a Estêvão, também monge de Celanova, mas que, segundo Manuel C. Díaz y Díaz deverá resultar, na redacção que hoje conhecemos, de uma construção do século XVI ${ }^{104}$. Nela se refere, de forma mais sucinta, mas certamente inspirada no primeiro relato: «Hoc tempore absente rege Galecia a Normannis inuadebatur, et Portugalia a Mauris deuastabatur[...]»105.

A construção de estruturas militares motivadas pelas ameaças das incursões normandas - por vezes mais latentes e psicológicas do que reais - não foi um acontecimento isolado. Com efeito, nos primeiros anos do século X, Afonso III empreendeu duas obras militares para responder às ameaças vikings: a construção do Castelo de Gauzón (Castrillón, Astúrias) e do Castelo de Oviedo. O primeiro ficaria imortalizado por ter sido o local onde, em 908, foi feita a Cruz de la Vitória, que Afonso III ofereceu, depois, à Catedral de Oviedo ${ }^{106}$. O segundo, datado por epígrafe do ano de 905, foi construído para proteger a Catedral de Oviedo, porque, explica-nos o letreiro coevo, «costumavam chegar por mar os gentios com o seu exército de piratas» (DVM NAVALI GENTILITAS PIRATO SOLENT EXERCITV PROPERARE) ${ }^{107}$. Sublinhe-se que, nesse ano de 905, não se conhece qualquer referência a incursão viking. Tratava-se de resposta a uma ameaça latente ou seria ela motivada por alguma incursão de que não ficou memória? Sublinhe-se, igualmente, a forma como o monarca se refere aos vikings, classificando-os como gentios.

\footnotetext{
${ }^{103}$ DÍAZ Y DÍAZ et al., eds., 1990: $₫ 18,130$-133. Uma tradução para português encontra-se em PEREIRA, $1970: 45$.

${ }^{104}$ DÍAZ Y DÍAZ et al., eds., 1990: 282-291.

${ }^{105}$ DÍAZ Y DÍAZ et al., eds., 1990: 295. Uma tradução para português encontra-se em PEREIRA, 1970: 23.

106 GARCIA ALVAREZ-BUSTO e MUÑIZ LÓPEZ, 2005, 2010a, 2010b e 2010c.

${ }^{107}$ MIGUEL VIGIL, 1987: Insc. nº 3, Lam. I; DIEGO SANTOS, 1994: Insc. No 7.
} 
O mesmo temor dos devastadores e violentos ataques vikings levou o Bispo Sisnando, de Iria Flávia, a reforçar, em 961, as defesas do pequeno burgo de Santiago de Compostela, cujo templo estava a cativar cada vez mais peregrinos, gozando já de fama além-Pirenéus. Nesse sentido, manda rodear o santuário de muro dotado de torres e de um profundo fosso. Para completar as defesas de Santiago, manda ainda construir os castelos de Lanzada e de Cedofeita.

É também nessa lógica que se deve inscrever a construção das Torres de Oeste (Catoira, Caldas de Reis) - o Castelli Honesti da Historia Compostellana - erguidas para a defesa da ria de Arousa e da foz do rio Ulla, zona que facultava o acesso directo a Iria Flávia e a Santiago de Compostela. Quem conhece a ria de Arousa compreende que era um dos locais privilegiados para fundear uma frota. Foi, de resto, e como vimos, esta a zona escolhida por Gunderedo para estabelecer a base do seu ataque em 968. A importância desta zona já tinha levado os romanos a erguerem as Turris Augusti, referidas por Pompónio Melo. Sobre as suas ruínas foi construído o Castelli Honesti, que Afonso V de Leão, no Sínodo de Compostela, reunido em 1024, haveria de doar a Vistruário, Bispo de Iria Flávia ${ }^{108}$.

A construção e a doação, em 968, do Castelo de Guimarães - também designado Mons Latito ou Castelo de S. Mamede - pode inscrever-se, portanto, neste movimento de reforço das estruturas militares cristãs, procurando responder de forma mais eficaz às razias vikings ou normandas, não esquecendo, como é óbvio, a ameaça muçulmana, igualmente latente. Repare-se que a geografia dos primitivos castelos portugueses, desde os primeiros exemplos (c. 870-900) ${ }^{109}$ até à viragem de milénio, revela uma distribuição muito significante: a maioria dos castelos conhecidos encontra-se entre o Ave e o Vouga, não se afastando muito da geografia das instituições monásticas produtoras de documentação, a que André E. Marques já teve oportunidade de se referir neste estudo. Mas verifica-se uma significativa concentração em torno de dois vales: o vale do Douro (naturalmente...) e a foz do Ave. Esta última concentração, que já sublinhámos noutros estudos nossos ${ }^{110}$, revela-se muito interessante, por denunciar o reforço das defesas do estuário de um rio que, não sendo navegável em profundidade, garantia contudo o acesso às vias de comunicação terrestres que conduziam, directamente, ao coração político do Condado Portucalense. Sublinhemos, igualmente, uma densa e estruturada rede de fortificações costeiras,

\footnotetext{
${ }^{108}$ Sobre as Torres de Oeste, e de entre uma numerosa bibliografia, veja-se NAVEIRO LÓPEZ, 2004.

${ }^{109}$ Aquele que consideramos ser o primeiro diploma a referir um castelo - o Mons Cauallus - tem uma data expressa de 11 de Fevereiro de 870, mas encerra problemas cronológicos, tendo recebido a datação crítica de [873-910], Fevereiro, 11 (LM 65 = PMH, DC 5; VMH, 1). Sobre o significado deste diploma para a Castelologia veja-se BARROCA, $2004: 184$. 110 BARROCA, 2004: 186; BARROCA, 2017: 200-201 e 214 e ss.
} 
que se implantavam numa faixa litoral, quer a Norte do Douro (entre o Cávado e o Douro $)^{111}$, quer a Sul do Douro, até ao vale do Vouga ${ }^{112}$.

Se o arranque do processo de encastelamento no Entre-Douro-e-Minho não pode ser separado da incorporação deste espaço no âmbito da monarquia ovetense e da reorganização territorial e militar de matriz asturiana - corolário de um processo que arranca com as presúrias do Porto (868), de Chaves (872) e de Coimbra (878) - , também é certo que esse movimento secundou, em poucos anos, as primeiras incursões vikings sobre o Noroeste Peninsular (844 e 859-862). Este processo de encastelamento incrementou-se claramente a partir dos meados do século X, ou seja, por coincidência ou não, numa altura em que o Noroeste peninsular estava a ser alvo de uma segunda vaga de ataques vikings, na qual se destaca a marcante expedição de Gunderedo (968-969). De resto, e como referimos, não só o incremento do número de castelos, no terceiro quartel do século X, é coevo das incursões vikings, como a área de distribuição, com uma clara concentração no espaço entre o Ave e o Douro, coincide com as zonas aparentemente mais fustigadas por essas expedições.

Por isso, a construção do Castelo de Guimarães, e a sua sequente doação ao cenóbio fundado pela família condal portucalense, não podem deixar de ser relacionadas com as incursões vikings, mesmo que tenha sido uma resposta a um temor, mais do que a uma razia efectiva (que a documentação da época olvidou ou que nunca se chegou a concretizar).

Passado meio século, a mesma zona geográfica seria de novo alvo dos vikings. Com efeito, em 1015-1016, uma grande expedição atacou o coração do Entre-Douro-e-Minho, entre o Ave e o Douro e, provavelmente, a partir da foz do rio Ave. Esta expedição prolongou-se por nove meses e é conhecida por duas vias documentais: por intermédio de uma notícia analística, exarada nos Annales Portugalenses Veteres e por um diploma de 1018, publicado por Rui Pinto de Azevedo.

A notícia dos Annales, sucinta como todas as que compõem este tipo de registos, diz apenas:

Era 1054, $8^{\circ}$ idus septembris veniunt Lormanes ad Castellum Vermudii quod est in Prouincia Bracharensi; comes tunc ibi erat Aluitus Nuniz ${ }^{113}$.

A «vinda» dos normandos ao Castelo de Vermoim revela-nos que o exército nórdico terá aportado na foz do Ave, fixando acampamento em terra nas suas imediações e depois rumado para o interior. O rio Ave não era navegável em profundidade, e por isso o exército viking optou pela via terrestre. A via que saía de Vila do Conde

\footnotetext{
${ }^{111}$ BARROCA, 2017: 197-243.

112 CARMO, 2016.

113 DAVID, 1947: 295 (= PMH, Scriptores, vol. I: 9).
} 
e rumava ao interior, passando por Famalicão, permitia aceder à zona de Guimarães. Era este o objectivo das forças vikings: cercar a «sede» do Condado Portucalense e procurar obter um rico saque ou, depois de negociações, um copioso resgate ${ }^{114}$. Não sabemos se o conde portucalense, Alvito Nunes (985-1016) já se encontrava no Castelo de Vermoim ou se, sabendo da aproximação das forças vikings, decidiu avançar até essa fortificação. Em todo o caso, o ataque de 6 de Setembro de 1016 revela que, aos olhos do conde, ela era uma das estruturas mais seguras de que dispunha na região. O minucioso estudo de Francisco Queiroga, que se publica neste volume, revela que o castelo era, realmente, uma estrutura dotada de boas condições defensivas. Aqui o conde foi cercado e, muito provavelmente, encontrou a morte. Com efeito, e como José Mattoso sublinhou, a notícia de 1016 é a derradeira referência documental que possuímos para este conde portucalense ${ }^{115}$. No ano seguinte, em 1017, já se documenta seu filho, Nuno Alvites (1017-1028), no exercício de funções condais. Não é, portanto, demasiado arrojado supor que, quando o redactor dos Annales Portugalenses Veteres referiu que o conde que aí estava era Alvito Nunes, ele quisesse na realidade registar que o conde portucalense encontrara aí a morte. Não tendo sido erguido para dar resposta às incursões vikings ou normandas, o Castelo de Vermoim acabou por se ver directamente envolvido nelas...

Há, portanto, dois factores que ajudam a compreender o ataque normando a Vermoim: (i) a implantação do castelo junto da via medieval que, da orla litoral, facultava acesso a Guimarães; e (ii) a presença do conde portucalense no seu interior, com o seu séquito, o que garantia de um generoso resgate.

As incursões vikings implicavam, por vezes, a permanência em terra durante vários meses. Com efeito, a lógica de actuação destas comunidades era substancialmente distinta da que orientava os exércitos muçulmanos. Os vikings aproveitavam as rias e a foz dos rios mais importantes, que ofereciam proteção contra as intempéries, para acostar e desembarcar. A partir daí, e durante alguns meses, fustigavam a região com raides e incursões, procedendo ao saque e à tomada de cativos que eram, depois, negociados e libertados a troco de resgates. Este processo negocial implicava que a incursão viking não fosse um acontecimento rápido, mas que as forças permanecessem algum tempo nos locais. Implicava, em suma, a construção de estruturas de habitat, ainda que temporárias. Podemos apontar vários exemplos. Quando, no âmbito da primeira incursão em espaço peninsular, em 844, os vikings decidiram atacar Sevilha (4 de Outubro de 844), o seu acampamento estaria localizado na Isla Menor, nas margens do Guadalquivir, a escassos quilómetros do cobiçado alvo ${ }^{116}$.

\footnotetext{
${ }^{114}$ Se o objectivo fosse atacar Braga, certamente que o exército viking teria preferido subir o Cávado que, segundo Oliveira Marques, era navegável quase 30 quilómetros para interior (MARQUES, 1987: 128).

115 MATTOSO, 1980: 112.

116 PRICE, 2008: 464.
} 
E a incursão de 968-969, que incidiu sobre a Galiza e, talvez, o Norte de Portugal, assentou a sua base terrestre principal na foz do rio Ulla, junto às Torres de Oeste ${ }^{117}$.

Conhecem-se vários acampamentos temporários erguidos pelos vikings, que não têm necessariamente de adoptar a forma circular do conhecido acampamento de Trelleborg (Slagelse, Dinamarca), criado por volta de 980-981 d.C.. Invoquemos, por exemplo, o acampamento viking na margem do rio Vance (Saint Sulliac, Ille-et-Vilaine, França) ${ }^{118}$ ou o Camp de Péran (Pléran, Saint-Brieuc, França) ${ }^{119}$.

Existiram acampamentos vikings em Portugal? A resposta é afirmativa: é forçoso que tenham existido. Temos, de resto, alguns topónimos significativos como é o caso, já abordado, de Lordemão (Santo António dos Olivais, Coimbra), derivado de Leodemanus > Lordemanus > Lordemão. A mesma evolução que deu origem ao topónimo leonês de Lordemanos (Cimanes de la Veja, Tierra de Campos), na fronteira entre as terras de León e de Zamora. A estes dois topónimos, e à «cidade dos Lodimanos», nas imediações do rio Ulla, já se referiu anteriormente André E. Marques. Mas também podem ser significativos os topónimos derivados de Madjuz, a forma muçulmana de designar os homens do Norte, que esteve na origem de topónimos como Magos (Rossas, Vieira do Minho), Paúl de Magos e Salvaterra de Magos (Salvaterra de Magos, Santarém). Devemos confessar, no entanto, que em nenhuma destas áreas encontramos testemunhos arqueológicos de eventuais acampamentos.

E no Norte de Portugal, existiram acampamentos vikings? Apesar da ausência de vestígios arqueológicos claros e seguros, também não temos dúvidas em responder afirmativamente. Houve, seguramente, acampamentos vikings. $\mathrm{O}$ caso da incursão de 1016 é particularmente significativo. Penetrando na foz do Ave, a frota viking deve ter fundeado pouco acima, sensivelmente em frente do Castro de S. João, o monte hoje coroado pelo Convento de Sta ${ }^{\mathrm{a}}$. Clara de Vila do Conde. A zona encontra-se profundamente humanizada, o que dificulta a identificação de vestígios arqueológicos. Mas o rio Ave não era navegável para navios, mesmo de média dimensão ${ }^{120}$. A sua navegabilidade ficava comprometida por pedras, que criavam rápidos, por açudes e por azenhas. Com a via fluvial comprometida, restava a opção terrestre. E isso significa que o acampamento viking não estaria muito longe da margem sul do Ave. Sabemos, pelo já mencionado documento de 1018, que a incursão viking atacou o espaço entre o Ave e o Douro e demorou-se nestas paragens por nove meses: «In era M L iija Mense Iulio ingressi fuerunt filius et neptis Lotnimis multis in Doiro, pre-

\footnotetext{
117 PRICE, 2008: 467. Veja-se também o contributo de Fernando Alonso Romero, «La navegación e itinerário del ejército normando de Gunderedo (968-969)», publicado neste volume.

${ }^{118}$ CASSARD, 1996: 64-66.

${ }^{119}$ NICOLARDOT \& GUIGON, 1991: 123-157; CASSARD, 1996: 66-70.

${ }^{120}$ Tenha-se em atenção a dimensão dos barcos recuperados e musealizados no Museu dos Barcos Vikings de Roskilde (Dinamarca) ou no Museu dos Barcos Vikings de Oslo (Suécia).
} 
dans et captivans de Doiro in Ave per viiijo menses» $^{121}$. O suficiente para organizar a expedição terrestre, tomar cativos, negociar resgates e passar o Inverno em segurança. $\mathrm{Na}$ ausência de outros vestígios arqueológicos seguros, terá o acampamento viking assentado no Castro Celouria (Retorta, Vila do Conde)? Trata-se do único monte da margem sul do Ave, situado nas proximidades da área de fundeação, que apresenta condições defensáveis. Este monte, apesar das suas privilegiadas condições de defesa, tem uma ocorrência relativamente tardia e esporádica na documentação medieval: é apenas mencionado em $1100^{122}$ e em $1110^{123}$, tendo sob sua alçada as povoações de Retorta e de Pindelo ${ }^{124}$. Estas duas povoações - as duas únicas de um território mal definido - surgem referidas, noutros diplomas, sob alçada de Castro Boi (Capela de St ${ }^{\circ}$. Ovídio, Crasto, Vairão, Vila do Conde). Serão estas referências documentais, de 1100 e 1110, a memória de este ponto ter recebido estruturas defensivas, mesmo que efémeras, num passado não muito distante? E seriam elas as fortificações criadas pelas forças vikings para aí permanecerem no Inverno de 1015-1016?

Gostaríamos, por fim, de chamar a atenção para um último aspecto que pode estar, de alguma forma, relacionado com as incursões vikings no Noroeste peninsular: a difusão das motas. Como se sabe, as motas eram montes artificiais sobre os quais se instalava uma estrutura militar dotada de paliçada e torreão central, ambas construídas em madeira. Os mais antigos exemplos conhecidos remontam ao século X (Mota de Doué-la-Fontaine, Maine-et-Loire, França), e multiplicam-se de forma crescente a partir do Ano Mil. A difusão destas estruturas foi um fenómeno que esteve associado à expansão viking ou normanda. Com efeito, fora da sua área geográfica de origem (a zona compreendida entre o vale do Loire e o curso terminal do Reno), as motas mais antigas surgem em Inglaterra e na Sicília. Nos dois casos foram introduzidas pelos normandos: com a conquista de Inglaterra por Guilherme o Conquistador (em 1066) e com a ocupação da Sicília e do Sul de Itália pelos normandos e a criação do Reino Normando da Sicília.

Entre nós, a identificação de motas é um acontecimento relativamente recente e os exemplos são limitados. A primeira a ser publicada foi a Mota de Eiró (Rio Douro, Cabeceiras de Basto), que foi estudada por Luís Fontes ${ }^{125}$. A ela podemos acrescentar a Lomba Mourisca (Cimo de Vila, Caíde de Rei, Lousada), mencionada nas Inquirições de 1258 no Julgado de Santa Cruz, nos limites entre Caíde de Rei e Travanca - ... ad lumbam maurisca quomodo partit Caydi cum Travanca... - , cujo

\footnotetext{
121 AZEVEDO, 1974: 91.

122 PMH, DC 932.

${ }^{123}$ DMP, DP (3), 350.

124 BARROCA, 2017: 222-223.

${ }^{125}$ FONTES, 1999: 325-329.
} 
montículo foi identificado e publicado em 2008 ${ }^{126}$. E, por fim, a Mota de Adaúlfo (Perafita, Matosinhos), a estrutura que mais directamente nos interessa.

A Mota de Adaúlfo encontra-se mencionada num diploma de 1038: «[...] in villa quos vocitant Petra Ficta in terminum de Ataulfi territorio Portugalensi subtus Mamola de Adaulfi et ave iacentia inter Recemundi et Adaulfi ipsa ereditate [...]» ${ }^{127}$. Como já referimos, este tipo de expressão - subtus mons, subtus alpe, etc. - espelha relações de dependência militar e é muito comum nos documentos dos séculos X e XI, sendo um dos veículos privilegiados para o estudo do processo de encastelamento ${ }^{128}$. No caso de Perafita, em 1038 a vila é referida subtus mamola Adaulfi. E, como se sabe, «mamoa» é uma expressão popular utilizada para designar um monte ou montículo artificial. Na maior parte dos casos corresponde a monumentos megalíticos ${ }^{129}$. Mas nem sempre. O diploma de 1038 chamou a atenção de Carlos Alberto Ferreira de Almeida, que o associou a uma eventual «mota», hipótese que acabou por descartar ${ }^{130}$. Em 1990-91 tivemos oportunidade de recuperar este exemplo, associando o diploma de 1038 a um outro, datado de 1047, onde a mesma zona de Perafita era localizada «[...] in villa Petraficta in illo agro que dicent de Martina subtus Mamola de Lumbelo terridurio Portugalensis subtus Castro Quifiones discurrente ribulo Leza prope litore maris $[\ldots]{ }^{131}$. Estas duas referências documentais, pela sua singularidade no panorama dos diplomas portugueses, por serem referentes à mesma zona (Perafita) e por corresponderem a um curto período de tempo, levaram-nos a colocar de novo a hipótese de se tratar de uma mota ${ }^{132}$. A Mamola de Adaulfi ou Mamola de Lumbello, procurada por nós durante anos, foi finalmente identificada em 2008 pelos Serviços de Arqueologia da Câmara Municipal de Matosinhos (Joel Cleto, José Manuel Varela e Maria Conceição Pires). Localiza-se em Madoufe (Perafita, Matosinhos) e tem as seguintes coordenadas geográficas (em graus decimais):

\section{Lat. $41.227103^{\circ}$}

Long. $-8.690387^{\circ}$

A sua implantação é extraordinária porque, não se elevando muito (atinge apenas uma altitude absoluta de 50 metros), permite um notável domínio da linha de costa, da qual dista, em linha recta, apenas 2,5 quilómetros.

\footnotetext{
${ }^{126}$ PMH, Inq., 608; BARROCA, 1990-91: 99; NUNES, SOUSA \& GONÇALVES, 2008: 96.

${ }^{127} \mathrm{PMH}, \mathrm{DC} 303$.

${ }^{128}$ BARROCA, 2017: 201-206.

${ }^{129}$ SAMPAIO, 1979a: 43, nota 2.

${ }^{130}$ ALMEIDA, 1978: 52.

${ }^{131}$ PMH, DC 351.

132 BARROCA, 1990-91: 99; BARROCA, 2003: 101-103; BARROCA, 2017: 231-233.
} 
O caso da Mota de Adaúlfo é, ainda, um notável exemplo de petrificação toponímica: em redor da Mota encontramos a Rua de Madoufe, a Travessa de Madoufe e a Viela de Madoufe, evidentes corruptelas do antropónimo Adaúlfo, referido nos diplomas do longínquo século XI. E até um outro microtopónimo referido em 1038 conseguiu sobreviver até aos nossos dias: Recemundi é hoje Rassamonde...

O antropónimo Adaúlfo deriva do germânico Athawolf $>$ Athaulfus $>$ Adaulfus $>$ Adaulfo, composto por $=$ Athal $($ nobre $)+$ Wolf $($ lobo $)$, o mesmo que dá origem ao nome próprio Adolfo ou a outros topónimos, como Adaúfe ${ }^{133}$.

No caso de Perafita, parece claro que se tratava de uma estrutura de posse individual. Este Adaúlfo está documentado na zona por outros diplomas: em 1021 temos a referência ao casal de Adaulfo ${ }^{134}$ e em 1040 a uma hereditate de casal de Adaulfo ${ }^{135}$.

Sublinhemos, ainda, que esta estrutura se implanta numa área onde existem outros testemunhos de povoamento antigo: em Montedouro, junto a Pampelido Velho, onde Almeida Fernandes pretendia localizar uma das paróquias do Parochiale Suevum, temos um pequeno núcleo de sepulturas escavadas na rocha. E toda esta zona, que se prolonga entre Pampelido Velho e Lavra, tem testemunhos de ocupação intensa no período tardo-antigo e alto-medieval.

Resta saber se a Mota de Adaúlfo foi erguida por populações autóctones ou por comunidades forâneas. Analisemos as diferentes implicações de cada uma destas perspectivas. Se foi erguida pelas primeiras, ela terá servido para complementar a defesa desta linha de costa - protegida por castelos como os de Castro Boi, Monte Pedras Rubras, Castro de Guifões ou Monte Custóias - de eventuais ataques por via marítima, perpetrados por muçulmanos ou por vikings. Atente-se à cronologia das referências documentais, que coincidem com uma época em que se conhecem várias notícias de ataques vikings, a começar pelo de 1015-1016, que aqui comemoramos. Se, pelo contrário, ela foi introduzida por populações forâneas poderia ser mais um caso de "exportação» de uma forma castelar bem conhecida dos normandos. E a opção por uma mota, que se ergue facilmente, com os recursos materiais da zona e sem requerer mão-de-obra especializada, adaptava-se bem a uma situação deste tipo. Acrescente-se que há alguns indícios de presença, nesta zona, de populações vikings ou, pelo menos, com contactos nórdicos. Um diploma do Livro Preto da Sé de Coimbra, datado de 14 de Março de 1037, referente a Real (Matosinhos), que já foi referido por André E. Marques, documenta-nos a venda de uma propriedade pelo conde Gonçalo Forjaz a um Halaf. O conde D. Gonçalo Forjaz revela que a recebera do servo Godesteo, filho de Leodemaro. E o diploma é testemunhado por um Victenando Leodemarizi. Três antropónimos de origem nórdica...

\footnotetext{
${ }^{133}$ MACHADO, 1984: s.v. Adolfo, (1) 51; s.v. Adaúfe, (1) 47.

134 PMH, DC 248.

135 PMH, DC 310; LP 513.
} 
Se, pelo contrário, aceitarmos que a Mota de Adaúlfo foi erguida por populações autóctones, então estaremos perante mais um caso de necessidade de defesa de um espaço demasiado exposto ao mar. Quiçá a opção pela mota, estrutura de construção rápida, espelhe uma necessidade urgente de defesa.

Não podemos, obviamente, optar por uma ou por outra hipótese, sem o contributo da Arqueologia. Mas elas revelam que, afinal, a interacção entre vikings e populações locais pode ter sido bem mais dinâmica do que conseguimos entrever pela simples análise da documentação da época que chegou até nós.
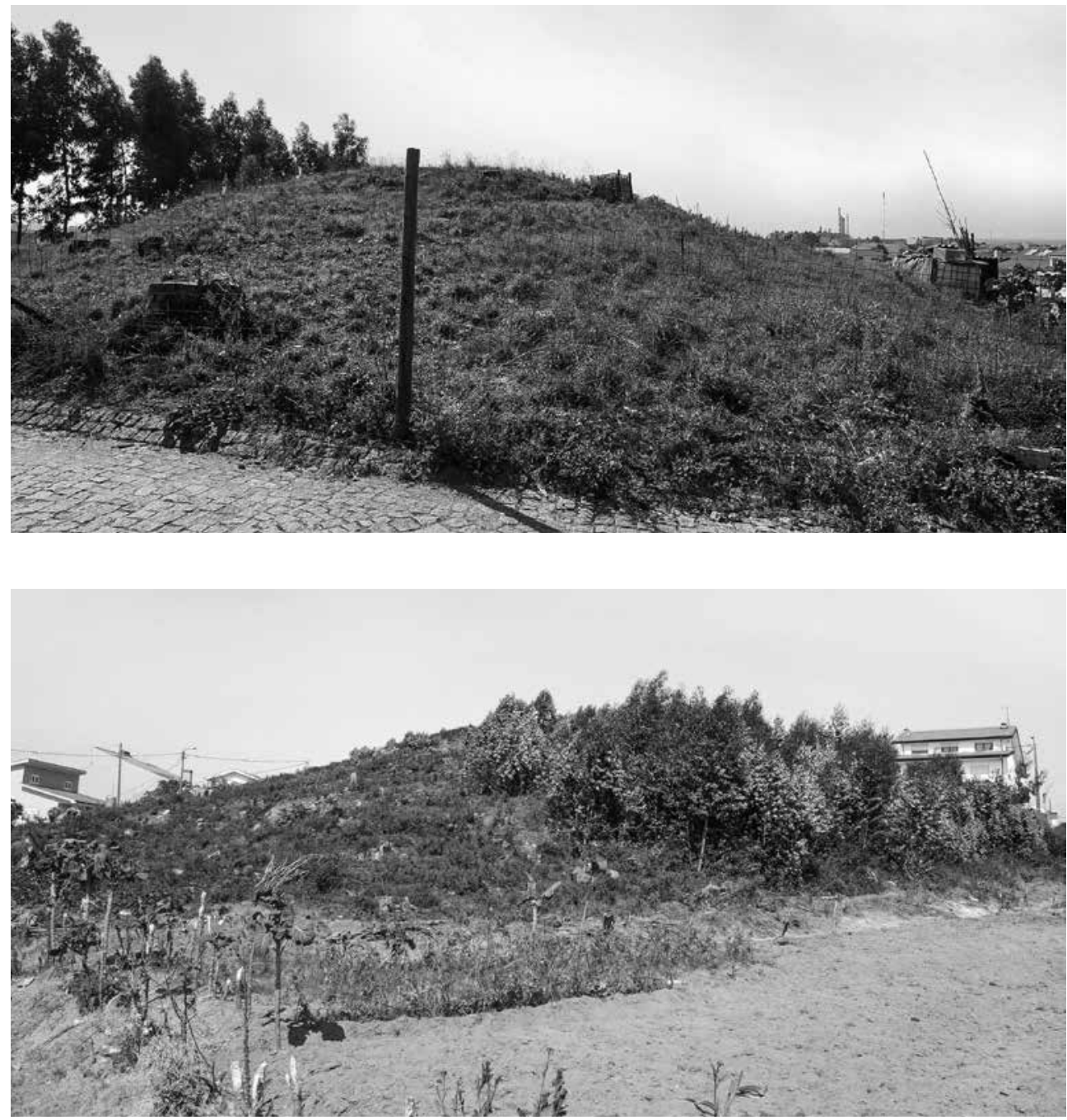

Figs. 1 e 2. Mota de Perafita. Fonte: Foto do autor. 


\section{FONTES}

CL: Colección Documental del Archivo de la Catedral de León (775-1230), vol. IV (1032-1109). Ed. de José Manuel Ruiz Asencio; vol. V (1109-1187), ed. de José María Fernández Catón. León: Centro de Estudios e Investigación «San Isidoro», Caja de Ahorros y Monte de Piedad, Caja España de Inversiones, Archivo Histórico Diocesano de León, 1990.

DMP, DP: Documentos Medievais Portugueses. Documentos Particulares, vol. III (A.D. 1101-1115). Ed. de Rui Pinto de Azevedo. Lisboa: Academia Portuguesa da História, 1940.

DMP, DR: Documentos Medievais Portugueses. Documentos Régios. Ed. de Rui Pinto de Azevedo. Lisboa: Academia Portuguesa da História, 1958-1961, 2 vols.

FLORIANO LLORENTE, Pedro, ed. (1968) - Colección diplomática del Monasterio de San Vicente de Oviedo. I Parte 1 (Años 781-1200). Oviedo: Instituto de Estudios Asturianos.

GARCÍA GÓMEZ, Emilio, trad. (1967) - Anales palatinos del Califa de Córdoba al-Hakam II, por 'İsá ibn Ahmad al-Rāzī (360-364 H. = 971-975 J.C.) [Ibn Ḥayyān, Muqtabas (971-975)]. Madrid: Sociedad de Estudios y Publicaciones.

LF: Liber Fidei Sanctae Bracarensis Ecclesiae. Ed. crítica de Avelino de Jesus da Costa, reed. melhorada e ampliada por José Marques, Maria Teresa Nobre Veloso e Joaquim Tomás da Silva Pereira. Braga: Arquidiocese de Braga, 2017, 2 vols.

LM: Livro de Mumadona: Cartulário do Mosteiro de Guimarães. Edição crítica. Coord. de Luís Carlos Amaral. Lisboa: Academia das Ciências de Lisboa, 2016 [publicado em 2018]. (Portugaliae Monumenta Historica, Nova Série).

LP: Livro Preto: Cartulário da Sé de Coimbra. Ed. crítica de Manuel Augusto Rodrigues e Avelino de Jesus da Costa. Coimbra: Arquivo da Universidade de Coimbra, 1999.

PMH, DC: Portugaliae Monumenta Historica: a saeculo octavo post Christum usque ad quintumdecimum. Diplomata et chartae, vol. I. Lisboa: Academia das Ciências de Lisboa, 1867-1873.

PMH, Inq.: Portugaliae Monumenta Historica: a saeculo octavo post Christum usque ad quintumdecimum. Inquisitiones, vol. I, partes I e II. Lisboa: Academia das Ciências de Lisboa, 1888-1977.

PMH, Scriptores: Portugaliae Monumenta Historica a saeculo octavo post Christum usque ad quintumdecimum. Scriptores. Lisboa: Academia das Ciências de Lisboa, 1856-1861.

VMH: Vimaranis Monumenta Historica. A saeculo nono post Christum usque ad vicesimum. Guimarães: Senado de Guimarães, vol. I (2a ed.), 1941; vol. II, 1929.

\section{BIBLIOGRAFIA}

ALARCÃO, Jorge de (1988) - Roman Portugal. Vol. II, fasc. I (1. Porto, 2. Bragança, 4. Viseu). Warminster: Aris \& Phillips.

ALMEIDA, Carlos Alberto Ferreira de (1973-1974) - Necrópole galaico-romana de Vila do Conde. «Revista da Faculdade de Letras - História», vol. 3-4, p. 209-222. (1978) - Castelologia Medieval de Entre-Douro-e-Minho. Das origens a 1220. Porto: Ed. Policopiada.

ALONSO RODRÍGUEZ, Nicolas (2009) - Nuevas aportaciones sobre un poblamiento con restos romanos y ocupación medieval en Asturias: el valle de Eres y su porto de Bañugues (Gozón). In QUIRÓS CASTILLO, Juan Antonio, ed. - The archaeology of early medieval villages in Europe. Vitoria: Servicio Editorial de la Universidad del País Vasco, p. 181-190.

AMARAL, Luís Carlos (2007) - Formação e desenvolvimento do domínio da diocese de Braga no período da Reconquista (séc. IX-1137). Porto: Ed. Policopiada. Dissertação de doutoramento em História Medieval apresentada à Faculdade de Letras da Universidade do Porto.

ANDRADE, Amélia Aguiar (2005) - A estratégia régia em relação aos portos marítimos no Portugal medieval: o caso da fachada atlântica. In ARÍZAGA BOLUMBURU, Beatriz; SOLÓRZANO 
TELECHEA, Jesús Ángel, eds. - Ciudades y villas portuarias del Atlántico en la Edad Media: Encuentros Internacionales del Medievo, Nájera, 27-30 de julio de 2004. Logroño: Instituto de Estudios Riojanos, p. 57-90.

AZEVEDO, Luís Gonzaga de (1939) - História de Portugal. Edição de Domingos Maurício Gomes dos Santos. Lisboa: Edições Bíblion, vol. 2.

AZEVEDO, Rui Pinto de (1974) - A expedição de Almançor a Santiago de Compostela em 997, e a de piratas normandos à Galiza em 1015-1016 (Dois testemunhos inéditos das depredações a que então esteve sujeito o Território Portugalense entre Douro e Ave). «Revista Portuguesa de História», vol. 14, p. 73-93.

BALIÑAS PÉREZ, Carlos (2014) - El territorium saliniense y los orígenes altomedievales de la comarca de Arousa. In MONTERROSO MONTERO, Juan M.; GUEDES CASTRO, Augusto, eds. - Arousa medieval y románica: I Simposio de Historia y Patrimonio Cultural de Vilagarcía de Arousa. Vilagarcía de Arousa: Concello de Vilagarcía de Arousa, 2014, p. 1-35.

BARROCA, Mário Jorge (1990-1991) - Do Castelo da Reconquista ao Castelo Românico (Séc. IX a XII). «Portvgalia», Nova Série, vol. 11-12, p. 89-136.

(2003) - Da Reconquista a D. Dinis (1096-1325). In MATTOSO, José, coord. - Nova História Militar de Portugal. Lisboa: Círculo de Leitores, vol. 1, p. 21-161

(2004) - Fortificações e povoamento no Norte de Portugal (séc. IX a XI). «Portvgalia», Nova Série, vol. 25, p. 181-203.

(2017) - Prope litore maris: O sistema defensivo da orla litoral da Diocese do Porto (séc. IX a XII). In AMARAL, Luís Carlos, ed. - Um poder entre poderes: nos 900 anos da restauração da Diocese do Porto e da construção do Cabido Portucalense. Porto: Centro de Estudos de História Religiosa - Universidade Católica Portuguesa, p. 197-243.

BARROS, Henrique da Gama (1947) - História da administração pública em Portugal nos séculos XII a XV. Edição de Torquato de Sousa Soares. Lisboa: Livraria Sá da Costa Editora, vol. IV.

BEIRANTE, Maria Ângela (1993) - A «Reconquista» Cristã. In SERRÃO, Joel; MARQUES, A. H. de Oliveira, eds. - Nova História de Portugal. Vol. II: Portugal, das Invasões Germânicas à «Reconquista». Lisboa: Editorial Presença, p. 251-365.

BORGES, Marco Oliveira (2016) - A defesa costeira no distrito de Lisboa durante o Período islâmico. I - A área a Ocidente da cidade de Lisboa. In FONTES, João Luís Inglês, et al., eds. - Lisboa Medieval: Gentes, Espaços e Poderes. Lisboa: IEM - Instituto de Estudos Medievais, p. 67-104.

BRINK, Stefan and PRICE, Neil, eds. (2012) - The Viking World. London: Routledge. (The Routledge worlds).

CARBALLEIRA DEBASA, Ana María (2007) - Galicia y los gallegos en las fuentes árabes medievales. Madrid: Consejo Superior de Investigaciones Cientifícas, Xunta de Galicia. (Cuadernos de Estudios Gallegos, Anexos, vol. 36).

CARDOSO, Aguiar (1929) - Terra de Santa Maria: Civitas Sanctae Mariae. Coimbra: Imprensa da Universidade de Coimbra.

CARDOZO, Mário (1967) - O testamento de Mumadona, fundadora do Mosteiro e Castelo de Guimarães na segunda metade do século X. «Revista de Guimarães», vol. 77, n. ${ }^{\circ} 3-4$, p. 279-298.

CARMO, Tiago João Alves (2016) - Os castelos no Baio-Ferrado (Séc. X-XII). Contributo para o estudo dos sistemas defensivos na Orla Litoral a Sul do Douro. Dissertação de Mestrado. Porto: Ed. Policopiada.

CARRIEDO TEJEDO, Manuel (1998-1999) - Los episcopologios portugueses en los siglos IX y X, a través de dos obispos de Oporto, Froarengo (890-918) y Hermogio (923-927), y su situación a comienzos del siglo XI. «Bracara Augusta», vol. 48, n. ${ }^{\circ}$ 101-102 (114-115), p. 311-401.

CASSARD, Jean-Christophe (1996) - Le siècle des Vikings en Bretagne. S.l.: Editions J.-P. Gisserot. 
CHRISTYS, Ann (2015) - Vikings in the South: Voyages to Iberia and the Mediterranean. London: Bloomsbury. (Studies in early medieval history).

COLLINS, Roger (1995) - Early Medieval Spain: Unity in Diversity, 400-1000. New York: St. Martin's Press. (New studies in medieval history).

COSTA, Avelino de Jesus da (2000) - O Bispo D. Pedro e a Organização da Arquidiocese de Braga. Vol. II: Censuais e Documentos. Braga: Irmandade de S. Bento da Porta Aberta.

DAVID, Pierre (1947) - Annales Portucalenses Veteres. In Études historiques sur la Galice et le Portugal du VIe au XIIe siècle. Lisboa: Institut Français au Portugal, p. 257-340.

DÍAZ Y DÍAZ, Manuel C., et al., eds. (1990) - Vida y milagros de San Rosendo. La Coruña: Fundación Pedro Barrié de la Maza.

DÍAZ Y DÍAZ, Manuel C. (1993) - Vita Rudesindi. In LANCIANI, Giulia; TAVANI, Giuseppe, org. e coord. - Dicionário da Literatura Medieval Galega e Portuguesa. Lisboa: Editorial Caminho, p. 686.

DIEGO SANTOS, Francisco (1994) - Inscripciones Medievales de Asturias. Oviedo: Principado de Asturias - Consejeria de Educacion, Cultura y Deportes.

FERNÁNDEZ CONDE, Francisco Javier; TORRENTE FERNÁNDEZ, Isabel (2007) - Los orígenes del monasterio de San Pelayo (Oviedo): aristocracia, poder y monacato. «Territorio, Sociedad y Poder», vol. 2, p. 181-202.

FONTES, Luís (1999) - O sítio fortificado tipo 'Mota' de Eiró, Rio Douro (Cabeceiras de Basto). In BARROCA, Mário Jorge, coord. - In Memoriam Carlos Alberto Ferreira de Almeida. Porto: Faculdade de Letras da Universidade do Porto, vol. 1, p. 325-329.

GALÁN GÓMEZ, Tania (2007) - Xénese do espazo urbano en Galiza. Noia, A Coruña: Toxosoutos. (Trivium, 22).

GALÁN Y GALINDO, Ángel (2005) - Marfiles Medievales del Islam. Córdoba: CajaSur Publicaciones, 2 vols.

GARCIA ALVAREZ-BUSTO, Alejandro; MUNIZ LOPEZ, Iván (2005) - El Castillo de Gauzón: Analisis arqueológico de una fortaleza asturiana. In Actas del III Congreso de Castellologia Ibérica. Madrid: Asociación Española de Amigos de los Castillos; Guadalajara: Diputación Provincial de Guadalajara, p. 93-106.

(2010a) - El Castillo de Gauzón y Alfonso III: La formación del Reino de Asturias a través de una fortaleza. In GARCIA LELA, Alfonso; GUTIERREZ GONZALEZ, Ramón; e PRIETO ENTRIALGO, Clara Elena, coord. - MC Aniversário de la Muerte de Alfonso III y de la Tripartición del território del Reino de Astúrias, vol. I, Oviedo, p. 45-68.

(2010b) - El Castillo de Gauzón (Castrillón, Astúrias). Campañas de 2007-2009. El processo de feudalización entre la Antigüedad Tardia y la Edad Media a través de una Fortaleza. «Territorio, Sociedad y Poder», vol. 5, p. 81-121.

(2010c) - El Castillo de Gauzón (Astúrias, España) y el processo europeo de feudalización entre la Antigüedad Tardia y la Edad Media a través de una fortificacion. «Munibe», nº 61, p. 289-328.

GARCÍA-GALLO, Alfonso (1950) - El concilio de Coyanza: Contribución al estudio del derecho canónico español en la alta Edad Media. "Anuario de Historia del Derecho Español», vol. 20, p. 275-633.

GOLDSCHMIDT, Adolph (1926) - Die elfenbeinskulpturen aus der romanischen Zeit XI.-XIII. Jahrhundert. Berlim: Bruno Cassirer, vol. 4.

GOMES, Paulo Dordio (2011) - Os mosaicos da Casa do Infante e o contexto urbano na zona ribeirinha do Porto. In O mosaico romano nos centros e nas periferias: originalidades, influências e identidades. Actas do X Colóquio Internacional da Associação Internacional para o Estudo do Mosaico Antigo (AIEMA), Museu Monográfico de Conímbriga, 2005. Lisboa: Instituto dos Museus e da Conservação, p. 837-847. 
GÓMEZ MORENO, Manuel (1925) - Catalogo Monumental de España. Provincia de León (1906-1908). 2 vols., Madrid: Ministério de Instruccion Pública y Bellas Artes.

HERCULANO, Alexandre (1980) - História de Portugal desde o começo da monarquia até o fim do reinado de Afonso III. Edição de José Mattoso. Lisboa: Livraria Bertrand, tomo 1.

ISLA FREZ, Amancio (1992) - La sociedad gallega en la Alta Edad Media (siglos IX-XII). Madrid: CSIC. (Biblioteca de historia, vol. 12).

KROMANN, Anne (1988) - Finds of Iberian Islamic coins in the northern lands. In METCALF, David Michael and GOMES MARQUES, Mário, eds. - Problems of Medieval Coinage in the Iberian Area 3. Santarém: Sociedad Numismática Scalabitana, Instituto de Sintra, p. 243-253.

LOPES, David (1928) - O Domínio Árabe. In PERES, Damião; CERDEIRA, Eleutério, eds. - História de Portugal. Barcelos: Portucalense Editora, vol. I, p. 389-431.

LÓPEZ ALSINA, Fernando (2013) - La ciudad de Santiago de Compostela en la Alta Edad Media. 2. ${ }^{\text {a }}$ ed., Santiago de Compostela: Consorcio de Santiago, Universidade de Santiago de Compostela.

LÓPEZ QUIROGA, Jorge (2004) - El final de la Antegüedad en la "Gallaecia". Transformación de las estructuras de poblamiento entre Miño y Duero (siglos $V$ al X). La Coruña: Fundación Pedro Barrié de la Maza.

LUCAS ÁlVAREZ, Manuel (2003) - El Monasterio de San Martiño Pinario de Santiago de Compostela en la Edad Media. Sada, A Coruña: Ediciós do Castro. (Publicacións do Seminario de Estudos Galegos. Galicia Medieval: Fontes, vol. 6).

MACHADO, José Pedro (1984) - Dicionário Onomástico Etimológico da Língua Portuguesa. Lisboa: Editorial Confluência.

MÄKELER, Hendrik (2005) - Wikingerzeitlicher Geldumlauf im Ostseeraum: Neue Perspectiven. "Quaestiones Medii Aevii Novae», vol. 10, p. 121-149.

MARQUES, André Evangelista (2008) - O casal: uma unidade de organização social do espaço no EntreDouro-e-Lima (906-1200). Noia (A Coruña): Toxosoutos. (Trivium, vol. 26).

(2014) - Da representação documental à materialidade do espaço: território da diocese de Braga (séculos IX-XI). Porto: CITCEM, Afrontamento. (Teses universitárias, vol. 6).

MARQUES, André Evangelista; DAVID, Gabriel (2013) - Paisagem e Povoamento (diocese de Braga, Séculos IX-XI) [Base de dados]. Repositório Aberto da U. Porto: http://hdl.handle.net/10216/69259 [Consulta realizada em 09/09/2018].

MARQUES, A. H. de Oliveira (1987) - Portugal na Crise dos Séculos XIV e XV. Lisboa, Editorial Presença. (1993a) - Hansa e Portugal na Idade Média, 2. ${ }^{\text {a }}$ ed. corrigida e aumentada. Lisboa: Editorial Presença [1. ${ }^{\mathrm{a}}$ ed.: 1959].

(1993b) - O «Portugal» Islâmico. In SERRÃO, Joel; MARQUES, A. H. de Oliveira, eds. - Nova História de Portugal. Vol. II: Portugal, das Invasões Germânicas à «Reconquista». Lisboa: Editorial Presença, p. 117-249.

MATTOSO, José (1980) - A Nobreza Medieval Portuguesa. A família e o poder. Lisboa: Editorial Estampa. (1992) - Portugal no reino asturiano-leonês. In MATTOSO, José, ed. - História de Portugal. Vol. 1: Antes de Portugal. Lisboa: Círculo de Leitores, p. 438-565.

(2002) - O monaquismo Ibérico e Cluny. Rio de Mouro: Círculo de Leitores (Obras Completas de José Mattoso, vol. 12) [ed. original: 1968].

MATTOSO, José, et al. (1989) - O castelo e a Feira: a Terra de Santa Maria nos séculos XI a XIII. Lisboa: Editorial Estampa. (Imprensa Universitária, vol. 74).

MIGUEL VIGIL, Ciriaco (1987) - Asturias Monumental, Epigrafica y Diplomática, 2 vols., Oviedo: Principado de Asturias - Consejeria de Educacion, Cultura y Deportes, 2a ed., 1987 [ed. original: 1887]. 
MORALES ROMERO, Eduardo (2006) - Historia de los vikingos en España: ataques e incursiones contra los reinos cristianos y musulmanes de la Península Ibérica en los siglos IX-XI. 2. a ed. Madrid: Miraguano Ediciones, 2006 (Libros de los Malos Tiempos, Serie mayor).

MOREIRA, Álvaro de Brito; SILVA, Armando Coelho Ferreira da (2011) - O Rio da Memória: a romanização do vale do Leça. In VARELA, José Manuel; PIRES, Conceição, eds. - O Rio da Memória. Arqueologia no Território do Leça. Matosinhos: Câmara Municipal de Matosinhos, p. 125-197.

NAVEIRO LÓPEZ, Juan L. (2004) - Torres de Oeste. Monumento Histórico e Xacemento Arqueolóxico. Pontevedra: Diputación de Pontevedra.

NICOLARDOT, Jean-Pierre; GUIGON, Philippe Guigon (1991) - Une forteresse du Xe siècle; le Camp de Péran à Plédran (Côtes d’Armor). «Revue Archéologique de l'Ouest», tomo 8, p. 123-157.

NUNES, Manuel; SOUSA, Luís; GONÇALVES, Carlos (2008) - Carta Arqueológica do Concelho de Lousada: Lousada: Câmara Municipal de Lousada.

PEREIRA, Maria Helena da Rocha, ed. (1970) - Vida e Milagres de São Rosendo. Porto: Junta Distrital do Porto.

PERES, Damião (1928) - A Reconquista Cristã. In PERES, Damião; CERDEIRA, Eleutério, eds. - História de Portugal. Vol. I. Barcelos: Portucalense Editora, p. 433-479.

PICARD, Christophe (1997) - La mer et les musulmans d'Occident au Moyen Age, VIIIe-XIIIe siècle. Paris: Presses Universitaires de France (Islamiques).

(2000) - Le Portugal musulman, VIIIe-XIIIe siècle: l'Occident d'al-Andalus sous domination islamique. Paris: Maisonneuve et Larose.

PIRES, Hélio (2012) - Incursões Nórdicas no Ocidente Ibérico (844-1147): Fontes, História e Vestígios. Lisboa: Ed. Policopiada. Dissertação de doutoramento em História Medieval apresentada à Faculdade de Ciências Sociais e Humanas da Universidade Nova de Lisboa.

(2017) - Os Vikings em Portugal e na Galiza: As Incursões Nórdicas no Ocidente Ibérico. Sintra: Zéfiro.

PORTELA SILVA, Ermelindo (2001) - García II de Galicia: el rey y el reino (1065-1090). Burgos: La Olmeda (Corona de España, vol. 34).

PRICE, Neil (2012) - The Vikings in Spain, North Africa and the Mediterranean. In BRINK, Stefan; PRICE, Neil, eds. - The Viking World. London: Routledge, 462-469.

RIBEIRO, João Pedro (1857-1896) - Dissertações chronologicas e criticas sobre a historia e jurisprudencia ecclesiastica e civil de Portugal. 2. ${ }^{\mathrm{a}}$ ed. Lisboa: Academia das Ciências de Lisboa, 1857-1896, 5 vols.

RIBEIRO, Orlando (1990) - Povoamento. In SERRÃO, Joel, ed. - Dicionário de História de Portugal. Vol. 6. Porto: Livraria Figueirinhas, 1990, p. 466-485 [1. a ed.: 1963-1971]. (1995) - Uma região portuguesa do norte e do litoral: o Minho. In Opúsculos Geográficos. Vol. VI: Estudos Regionais. Lisboa: Fundação Calouste Gulbenkian, p. 259-302.

ROCHA, Fr. Manoel da (1730) - Portugal renascido: Tratado historico-critico-chronologico. Lisboa: Oficina de Joseph António da Silva.

ROESDAHL, Else (1998) - The Vikings. London: Penguin. (2010) - Viking art in European churches (Cammin - Bamberg - Prague - León). In KLÆSØE, Iben Skibsted, ed. - Viking Trade and Settlement in Continental Western Europe. Copenhaga: Museum Tusculanum Press, p. 149-164.

RUAS, Henrique Barrilaro (1990) - Normandos, Ataques dos. In SERRÃO, Joel, ed. - Dicionário de História de Portugal. Vol. IV. Porto: Livraria Figueirinhas, 1990, p. 398-399 [1. ${ }^{a}$ ed.: 1963-1971].

SAMPAIO, Alberto (1979a) - Estudos históricos e económicos. Vol. I: As vilas do Norte de Portugal. Lisboa: Vega. (Documenta Historica).

(1979b) - Estudos históricos e económicos. Vol. II: As Póvoas Marítimas. Lisboa: Vega. (Documenta Historica). 
SÁNCHEZ PARDO, José Carlos (2010) - Los ataques vikingos y su influencia en la Galicia de los siglos IX-XI. «Anuario Brigantino», vol. 33, p. 57-86.

SÁNCHEZ-ALBORNOZ, Claudio (1969) - Invasiones normandas a la España cristiana durante el siglo IX. In I normanni e la loro espansione in Europa nellalto medioevo (Settimane di studio del Centro italiano di studi sullalto medioevo, XVI). Spoleto: Centro Italiano di Studi sull'Alto Medioevo, p. 367-408.

SERRÃO, Joaquim Veríssimo (1977) - História de Portugal. Vol. I: Estado, Pátria e Nação (1080-1415). Lisboa: Editorial Verbo.

SILVA, António Manuel S. P. (2010) - Ocupação da época romana na cidade do Porto. Ponto de situação e perspectivas de pesquisa. "Gallaecia», vol. 29, p. 213-262.

SILVA, Armando Coelho Ferreira da (2000) - Origens do Porto. In RAMOS, Luís A. de Oliveira, ed. História do Porto. Porto: Porto Editora, p. 44-117.

SILVA, Rosa Fernanda Moreira da (1983) - Contraste e Mutações na Paisagem Agrária das Planícies e Colinas Minhotas. «Estudos Contemporâneos», vol. 5, p. 9-115.

SOARES, Torquato de Sousa (1935) - Subsídios para o Estudo da Organização Municipal da Cidade do Porto durante a Idade Média. Barcelos: Companhia Editora do Minho.

SOLANO FERNÁNDEZ-SORDO, Álvaro (2010) - Historia urbana en la Galicia medieval. Balance y perspectivas. «Cuadernos de Estudios Gallegos», vol. 123, p. 59-90.

TEIXEIRA, Ricardo (2011) - Idade Média: dados e perspectivas arqueológicas sobre o território do Leça no período medieval (sécs. IX-XIV). In VARELA, José Manuel; PIRES, Conceição, eds. - O Rio da Memória: arqueologia no território do Leça. Matosinhos: Câmara Municipal de Matosinhos, p. 199-232.

VASCONCELOS, José Leite (1982) - Etnografia portuguesa. Vol. IV. Lisboa: Imprensa Nacional-Casa da Moeda, 1982 [ed. original: 1958].

VITERBO, Frei Joaquim de Santa Rosa (1993) - Elucidário das palavras, termos e frases que em Portugal antigamente se usaram e que hoje regularmente se ignoram. Edição de FIÚZA, Mário. 2 vols. Porto: Livraria Civilização Editora. 


\title{
O CASTELO DE VERMOIM, NOTAS SOBRE A SUA ESTRUTURA E IMPLANTAÇÃO
}

\author{
FRANCISCO M. V. REIMÃO QUEIROGA*
}

\section{INTRODUÇÃO}

No quadro da evocação da incursão viking ao castelo de Vermoim, passado que é um milénio sobre o evento, não podemos deixar de olhar para a fortificação, para a sua estrutura e função, assim como para o seu período de vida e de domínio sobre a terra e os seus habitantes. Cabe-nos apresentar os dados arqueológicos disponíveis sobre o castelo, tendo como base a parca evidência de superfície visível no local, e as impressões e observações recolhidas em várias visitas que fomos efectuando, desde 1977 ao presente, uma vez que neste sítio nunca foi efectuada nenhuma escavação arqueológica.

O castelo de Vermoim sempre esteve presente na mente de todos os habitantes do seu entorno, a maioria dos quais desconhecendo o seu significado, é certo, mas olhando sempre este local, bastante isolado e rodeado de uma aura telúrica, como referência de um imaginário que se foi alimentando ao longo de gerações.

Com efeito, este imaginário pode ilustrar-se numa lenda que é local, mas cujos contornos são comuns a outras regiões do país ${ }^{1}$. Reza esta lenda que existe uma moura residente dentro do amplo afloramento granítico sobre o qual se implanta o castelo, e guarda zelosamente durante o dia um tesouro considerável. Quando é chegada a

\footnotetext{
* Professor Associado, Universidade Fernando Pessoa, Porto; investigador agregado ao CLEPUL (Centro de Literaturas e Culturas Lusófonas e Europeias da Faculdade de Letras da Universidade de Lisboa).

${ }^{1}$ BASTOS, 1988.
} 
meia-noite, o penedo abre-se ao meio e a moura vem para a sua entrada fiar. Por vezes, a moura transforma-se em cobra e desce às aldeias dos vales circundantes para beber o leite das vacas ou, se as não encontra, vai beber o leite das mulheres com crianças de berço, surpreendendo-as no sono. Para que estas não acordem, coloca a cauda na boca das crianças, à laia de chupeta, enquanto suga o leite das mães. Ouvimos vários habitantes das redondezas garantirem ter visto uma cobra enorme e escura, com madeixas longas de cabelo, a esgueirar-se pelas folhagens do monte, numa clara alusão a esta entidade mítica em estado de transmutação incompleto, que é justificado pelo seu avistamento diurno, portanto extemporâneo com o ritual, pois com o nascer do Sol todas as entidades nocturnas se recolhem.

Esta curiosidade etnográfica justifica também, em parte, a depredação a que o castelo terá sido votado ao longo dos tempos, na ânsia de encontrar o tesouro. Recordamo-nos vivamente da primeira escavação realizada no castro, em 1982, a cerca de vinte metros do rochedo do castelo, durante a qual fomos visitados quase todos os dias por grupos de pessoas que, invariavelmente, perguntavam se já tinha aparecido algum ouro. Referiam também que era comum virem a esse local na base do rochedo - onde existe uma depressão que abaixo comentaremos - à meia-noite, e com o livro de S. Cipriano, tecer um esconjuro para aceder ao tesouro que o rochedo guarda. Esta prática de buscar ouro nos rochedos do castelo de Vermoim foi também relatada por Camilo Castelo Branco ${ }^{2}$, cuja descrição nos ilustra a magnitude que esta prática terá atingido, talvez a partir do século XVI, quando se intensificam os rituais de categorização e de exorcização dos espaços, no quadro das lutas contra as bruxarias na Europa ${ }^{3}$. Contudo, se este fenómeno foi muito atenuado no noroeste peninsular devido às idiossincrasias do seu povo ${ }^{4}$, desta época ficaram-nos muitas cruzes e gravuras diversas ${ }^{5}$ dispersas pelos montes, por vezes apostas sobre arte rupestre de épocas anteriores. De resto, cremos que será devido a esta lenda da moura que foi neste local, e não no vizinho cabeço das Eiras, que as comunidades circunvizinhas decidiram erigir o cruzeiro que hoje vemos sobre o rochedo.

As razões para a continuada degradação do castelo dividem-se, portanto, entre a busca de pedra aparelhada no passado para a construção das casas e dos muros das redondezas, a acção dos caçadores de tesouros que foram escavando por todo o lado mas sobretudo no "penedo da moura» e, no presente, os desportistas, mormente ciclistas e motociclistas, que o têm vindo a incluir nos seus traçados e assim contribuem para a degradação galopante dos já escassos vestígios de muralha existentes.

\footnotetext{
${ }^{2}$ CASTELO BRANCO, 1985: 1050-1056.

${ }^{3}$ BURNS, 2003.

${ }^{4}$ LISÓN TOLOSANA, 1987: 363 segs.

${ }^{5}$ ALMEIDA, 1981: 7-9.
} 


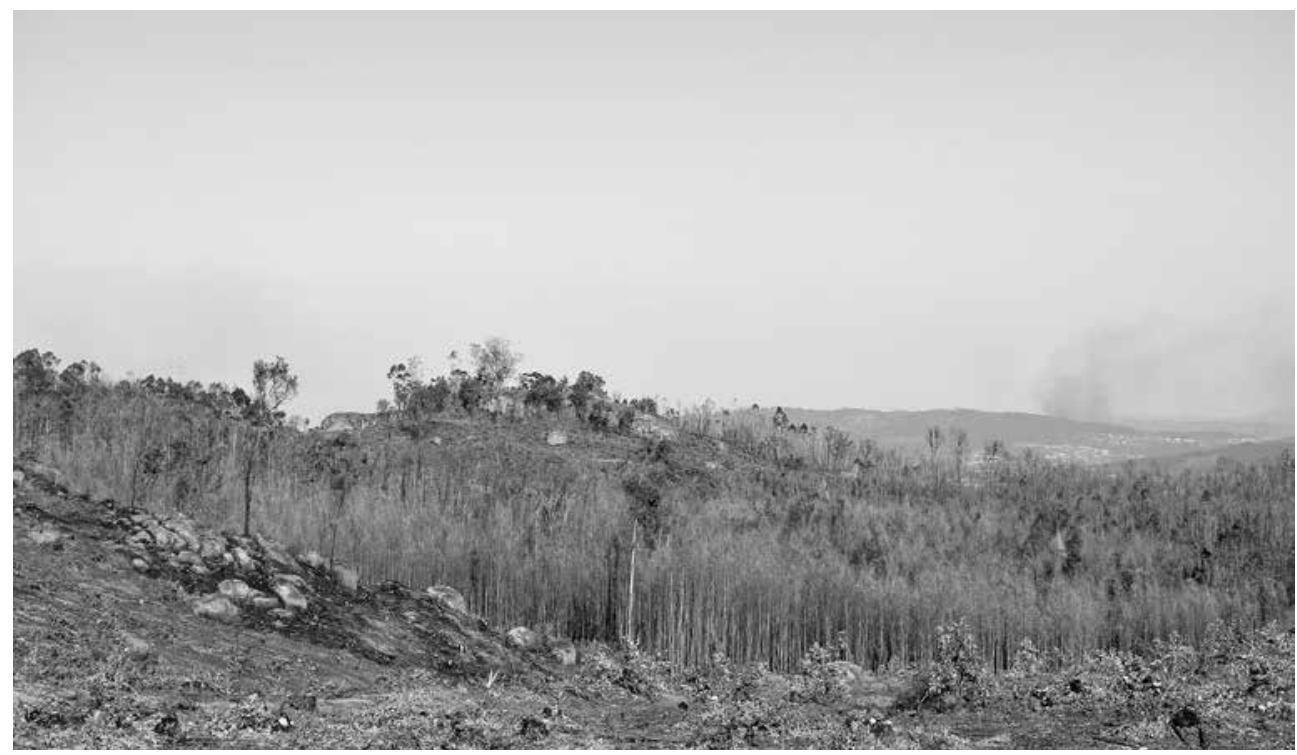

Fig. 1. Vista do monte do castelo, a partir do poente, do castro de Sta. Cristina.

\section{ENQUADRAMENTO GEOGRÁFICO E HISTÓRICO}

O castelo de Vermoim está implantado num relevo alongado no sentido nascente-poente, com encostas de pendor acentuado, e sendo a coroa dominada por rechãs e cabeços de contornos suaves (Fig. 1), entrecortados por elevações de grandes batólitos graníticos situados na sua periferia, portanto voltadas aos vales que o relevo domina. São os vales aluvionares do rio Pelhe, a norte, e o rio Pele, do lado sul, ambos ligados à bacia do rio Ave, cujo curso corre a sudoeste do relevo.

Talvez a particular implantação geográfica deste relevo seja uma das razões da ampla diacronia da sua ocupação, e da densidade populacional que chegou a atingir. Com efeito, ao longo dos cumes suaves do seu extremo poente, conhecemos três monumentos megalíticos, a juntar a três povoados castrejos. Um destes povoados é o castro das Eiras, cujos dados indicam ser de fundação augústea, e se configura como uma das maiores citânias conhecidas no noroeste peninsular. A concentração de sítios e de população nesta área, por volta do câmbio de Era, permite classificá-la como uma verdadeira «área metropolitana», da qual a urbe das Eiras, ou colónia como referiu Estrabão, seria o lugar central.

O local de implantação do castelo foi anteriormente ocupado pelo que designamos como castro de Vermoim. Este povoado, no qual se efectuaram sondagens em 1982 e $1983^{6}$, teve origem pelos inícios do primeiro milénio a. C., e terá sido desocupado com a romanização. 


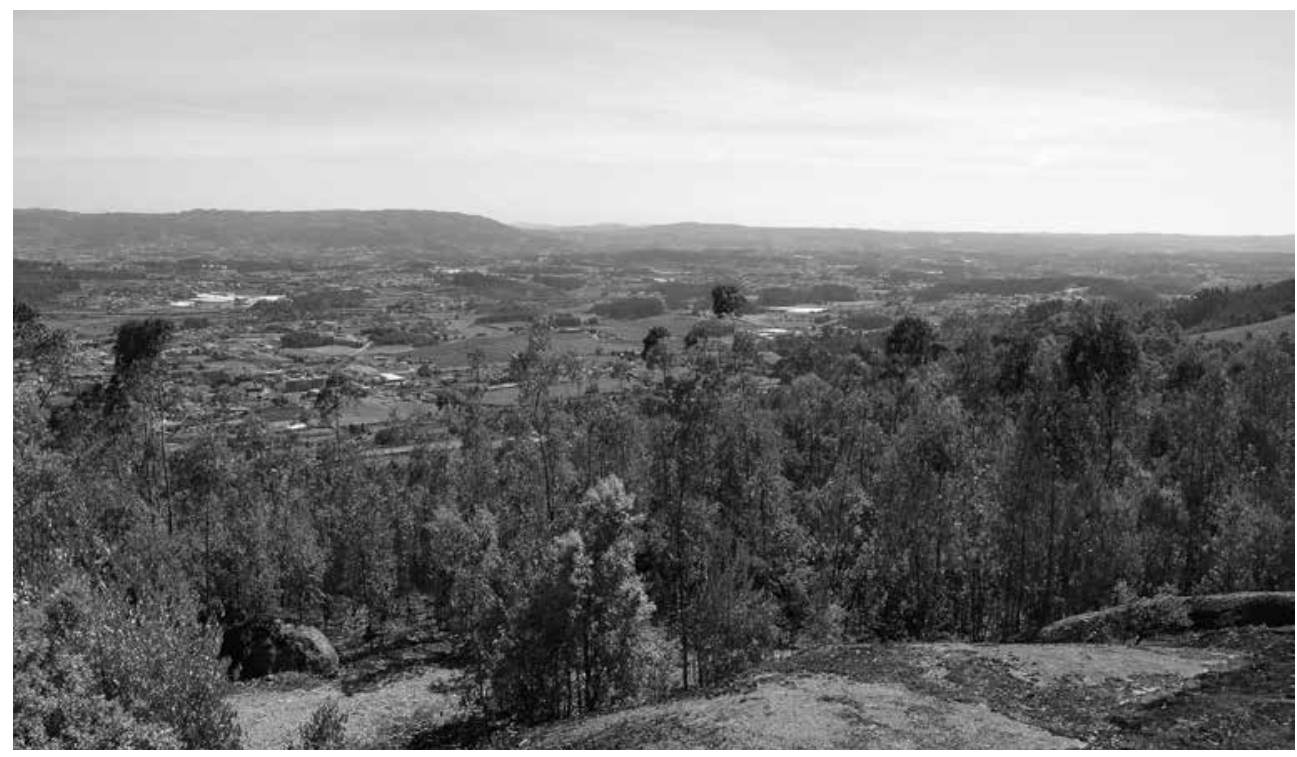

Fig. 2. Paisagem para sul do castelo, sobre o amplo vale do Ave.

O alto do castelo beneficia de um amplo domínio sobre a paisagem circundante (Fig. 2), e igualmente de contacto visual com as fortificações coevas, estas também localizadas em pontos altaneiros, se bem que menos estratégicos. Desta interacção visual salientamos a partilhada com o Monte Redondo, sobranceiro à importante via romana que desde o império ligava Cale a Bracara e, no quadrante sul, nos vales do Pelhe e Ave, com os castelos de Custóias, Sabroso e S. Miguel-O-Anjo.

A área envolvente está pejada de topónimos de raiz medieval, como torre, paço quintão, a juntar às agras que abundam nos vales adjacentes.

O monte do castelo e o relevo no qual se situa constituem espaço periférico das aldeias circunvizinhas; espaço de monte, ermo, de caçadores, lenhadores e pastores, mas também de malfeitores, como refere Camilo Castelo $\mathrm{Branco}^{7}$, que viveu na vizinhança e a ele alude em algumas ocasiões. Dos seus escritos confirmamos a impressão já colhida de Francisco Martins Sarmento, de que por esta época já nada restava do castelo, nem mesmo as ruínas da muralha.

Como nota de curiosidade, e talvez reminiscência do seu quotidiano histórico, constatamos que por toda a área de implantação do castelo abunda o trovisco (Daphne gnidium L.), arbusto que tão frequentemente é referido nas Inquirições, por ter sido utilizado na prática da pesca fluvial na Idade Média, sendo a sua recolha uma das obrigações que os habitantes tinham perante o senhor da terra. 


\section{O CASTELO E A SUA ESTRUTURA}

A presente análise fundamenta-se exclusivamente na observação superficial dos vestígios visíveis de momento no castelo de Vermoim, elementos somados ao que recordamos ter visto nas visitas efectuadas ao local há mais de vinte anos. Como tal, ressalvam-se as devidas cautelas na interpretação das estruturas, cuja visão parcelar e limitada pode facilmente ser desmentida por trabalhos arqueológicos programados, que esperamos venham a ser realizados no futuro.

As ilações que se vão produzindo são apoiadas pelos vestígios materiais visíveis à superfície do terreno, e documentados nas fotos em anexo, as quais são referenciadas no decurso da descrição. A observação do castelo e seu espaço envolvente beneficiou de uma circunstância infeliz que foi o incêndio que lavrou na quase totalidade deste amplo relevo no Verão de 2016, e foi seguido do corte de todo o arvoredo para aproveitamento da madeira. Desta forma, o terreno apresentava uma visibilidade que até então nunca tínhamos presenciado, e foi aproveitada para a elaboração de um modelo digital de superfície gerado a partir de imagens digitais obtidas por voo de drone $^{8}$. No registo fotogramétrico optou-se por uma resolução de cerca de 10 centímetros por pixel, a qual se entendeu ser a mais adequada, atendendo à amplitude da área representada e às características do estudo.

\subsection{Implantação e acessos}

O castelo implanta-se sobre o que teria sido a acrópole do castro de Vermoim, que então já estaria desabitado há muitos séculos. A partir da análise dos vestígios de superfície, e mormente das irregularidades do terreno, a única que nos é permitida de momento, não é fácil distinguir o que faz parte da estrutura do castelo do que é reminiscência da ocupação castreja. É natural que o cabeço rochoso onde se implanta o castelo tenha possuído estruturas habitacionais desta época mais antiga, as quais, entretanto, a ocupação medieval obliterou, podendo igualmente existir vestígios desta época enterrados nos níveis inferiores, e que futuras escavações permitam detectar. Mantemos em mente a possibilidade de algum dos vários entalhes nos rochedos pertencer a esta fase mais antiga, pelo que se redobram as cautelas na análise destes vestígios, e mormente da sua coerência relativa face à planta do castelo.

A presente observação, e interpretação das ruínas, teve ainda em conta outro factor importante, que é a dinâmica do seu processo de erosão e destruição, a qual condiciona sobremaneira a percepção da realidade arqueológica.

No contexto da degradação que as ruínas foram sofrendo ao longo dos tempos, devemos salientar uma ocupação, aparentemente insólita, que nos é relatada

\footnotetext{
${ }^{8} \mathrm{O}$ registo e tratamento da informação foi realizado pela empresa GEOSITE, sendo o serviço custeado pelo CLEPUL. Muito agradecemos a Renato Henriques, docente da Universidade do Minho, a consultoria técnica e adequação das representações tridimensionais.
} 
por Francisco Martins Sarmento, na descrição de uma sua visita ao castelo de Vermoim, no dia 24 de Abril de 1880. Relata-nos ${ }^{9}$ que «Mas é de notar que no alto do morro do Castelo houve um antigo telégrafo, e muita telha que por lá vi é decerto moderna e da casa do telegrafista». Desta informação podemos inferir que em 1880 já não existiriam ruínas da referida construção, nem alicerces que certamente não escapariam ao olhar arguto de Martins Sarmento. Ora, o telégrafo implementa-se em Portugal a partir do início da segunda metade do século XIX ${ }^{10}$ (1856), sendo então gradualmente vulgarizado pelo país, e a telegrafia sem fios, ou rádio, só será introduzida décadas após o relato de Martins Sarmento. Se não se pode deixar de estranhar a escolha de um local elevado, tão isolado e pouco acessível, para instalar um retransmissor de um sistema de comunicações que funciona por cabo, também parece pouco credível que no espaço tão curto de duas décadas este equipamento tivesse sido implementado, utilizado e completamente obliterado do local. A ser verdade esta informação que Martins Sarmento recolheu de habitantes locais, poderia mais provavelmente tratar-se de uma forma de telégrafo visual, método de comunicação que se vulgarizou no decurso da Guerra Peninsular ${ }^{11}$, e que dependia naturalmente de domínio visual sobre amplos espaços.

Ajuizando pela descrição de Francisco Martins Sarmento, cremos que nesta altura já não deveria ser visível o traçado da muralha do castelo, pois não lhe é feita qualquer referência, sendo bem provável que a depredação da estrutura se tenha iniciado logo após o seu abandono, e rapidamente exaurido o acervo de boas pedras aparelhadas que a constituíam. Martins Sarmento não teria certamente deixado de fazer uma referência ao pano de muralha do castelo, caso tivesse divisado ainda que um pequeno tramo.

Um outro momento de perturbação das estruturas é promovido pela lenda da Moura Encantada, acima referida, como resultado do impacto que produziu no imaginário local. Do lado poente, e junto à base do rochedo, nota-se uma ampla e profunda depressão (Fig. 3), juncada com abundante pedra de calibres variados. Não existindo nas redondezas qualquer contexto semelhante, estamos certos que neste local se terão concentrado todos os episódios de escavação em busca do tesouro escondido, quer aqueles com a magnitude relatada por Camilo Castelo Branco ${ }^{12}$, quer os realizados pelos habitantes das redondezas.

O rochedo onde se implanta o castelo é de configuração alongada, orientado sensivelmente no sentido norte-sul. Em todo o seu redor se orientam estruturas defensivas

\footnotetext{
${ }^{9}$ SARMENTO, 1999: 131.

${ }^{10}$ Mormente pela acção reformadora de Fontes Pereira de Melo, e privilegiando as ligações insulares e intercontinentais com o Brasil.

${ }^{11}$ LUNA et al., 2008.

${ }^{12}$ CASTELO BRANCO, 1985: 1050-1056.
} 


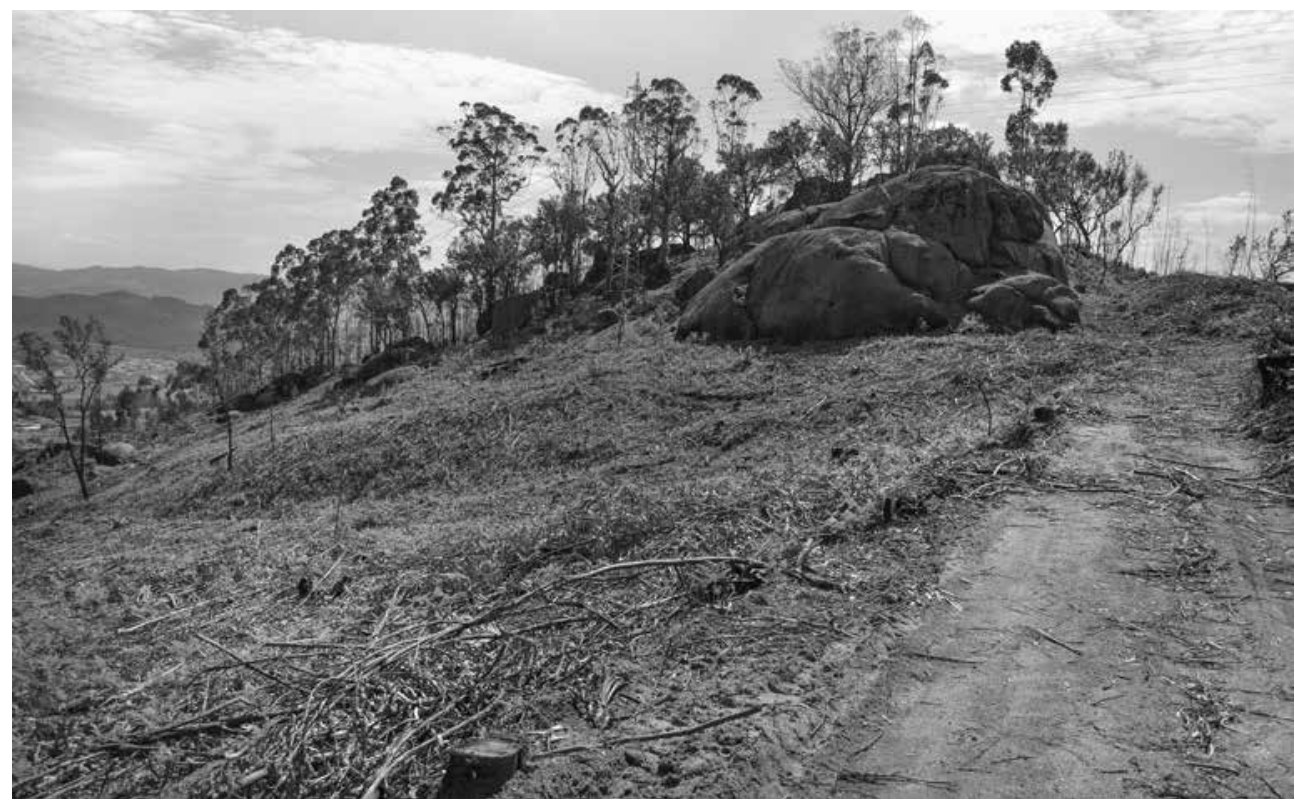

Fig. 3. Extremo norte do monte do castelo, vendo-se o talude e fosso de época castreja que se esbate pela encosta abaixo.

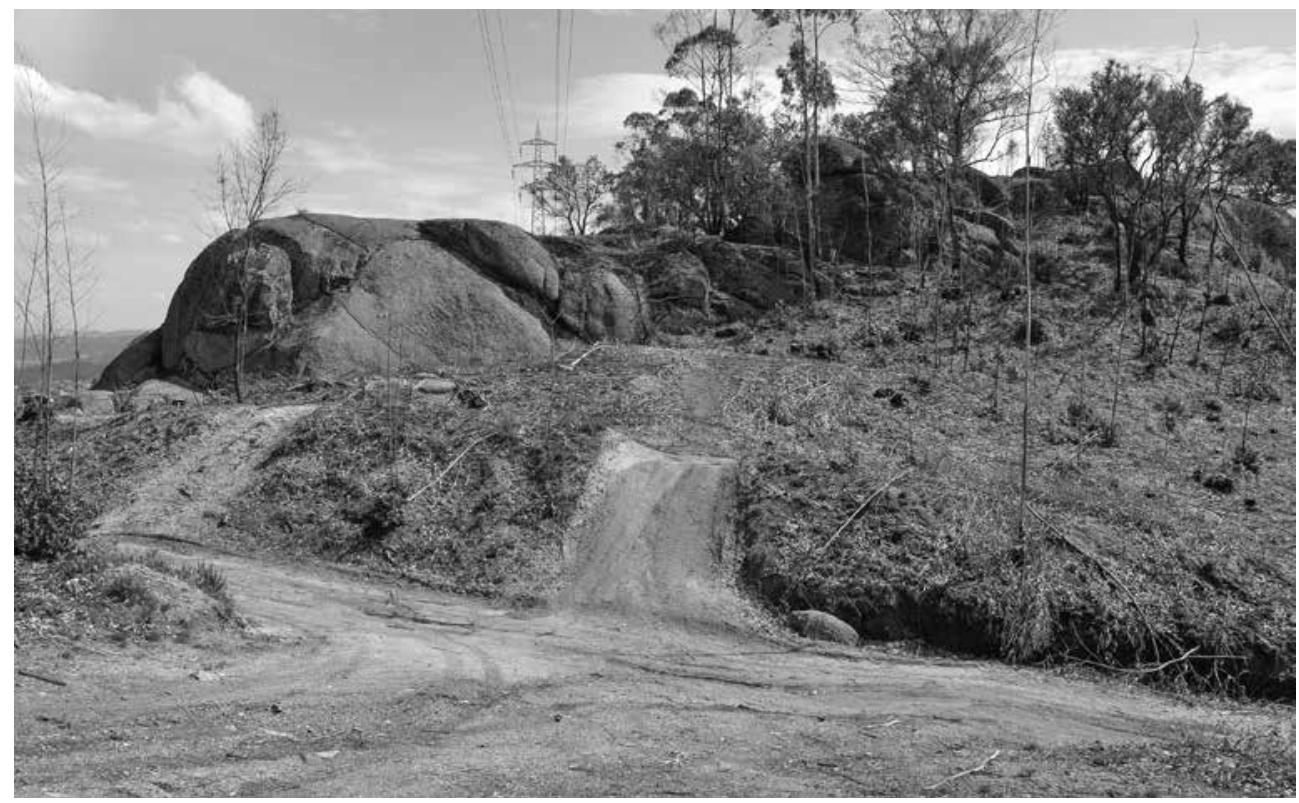

Fig. 4. Monte do castelo visto de poente. Notam-se os taludes e fossos de época castreja, já muito degradados, e o grande afloramento granítico sobranceiro ao acesso ao castelo. 


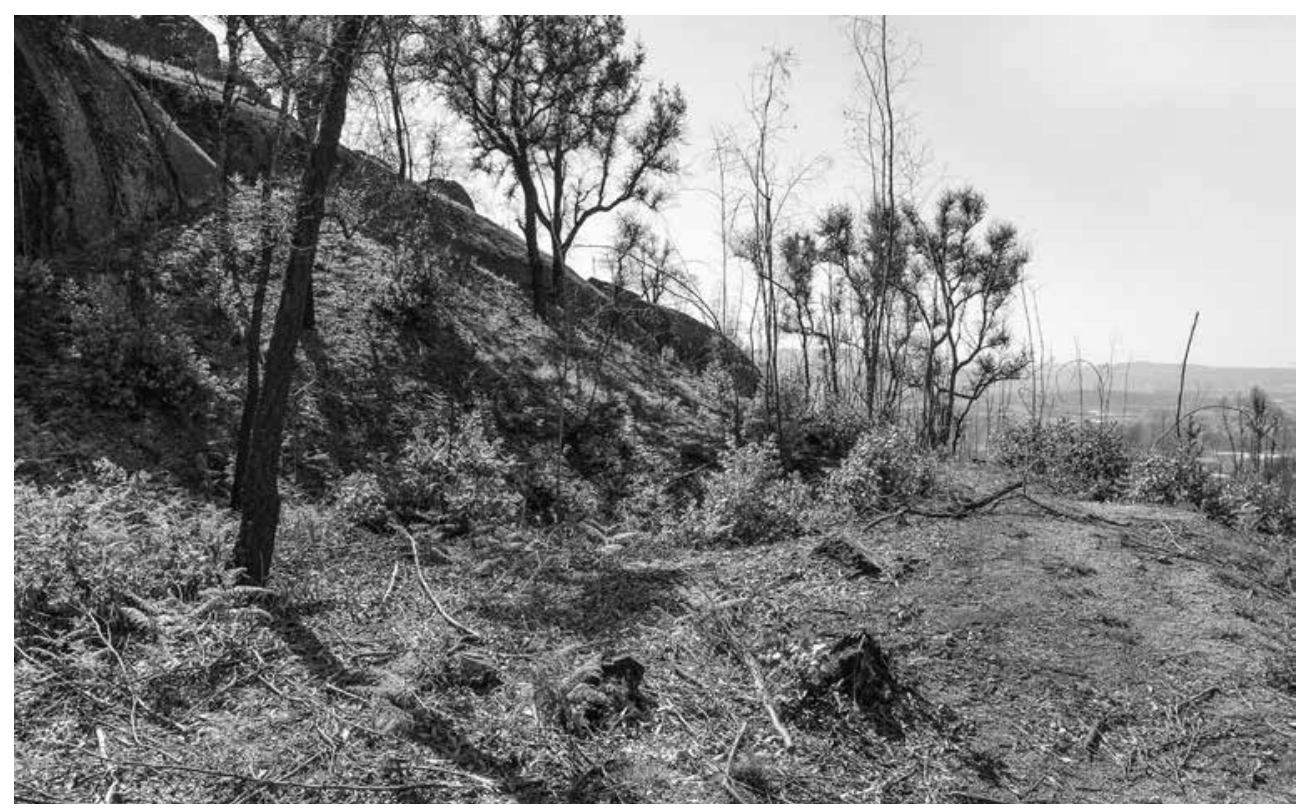

Fig. 5. O «buraco da moura», na base do penedo do castelo. Junto com a profunda depressão, e dos materiais dela provenientes, nota-se um volumoso escorrimento da plataforma do castelo.

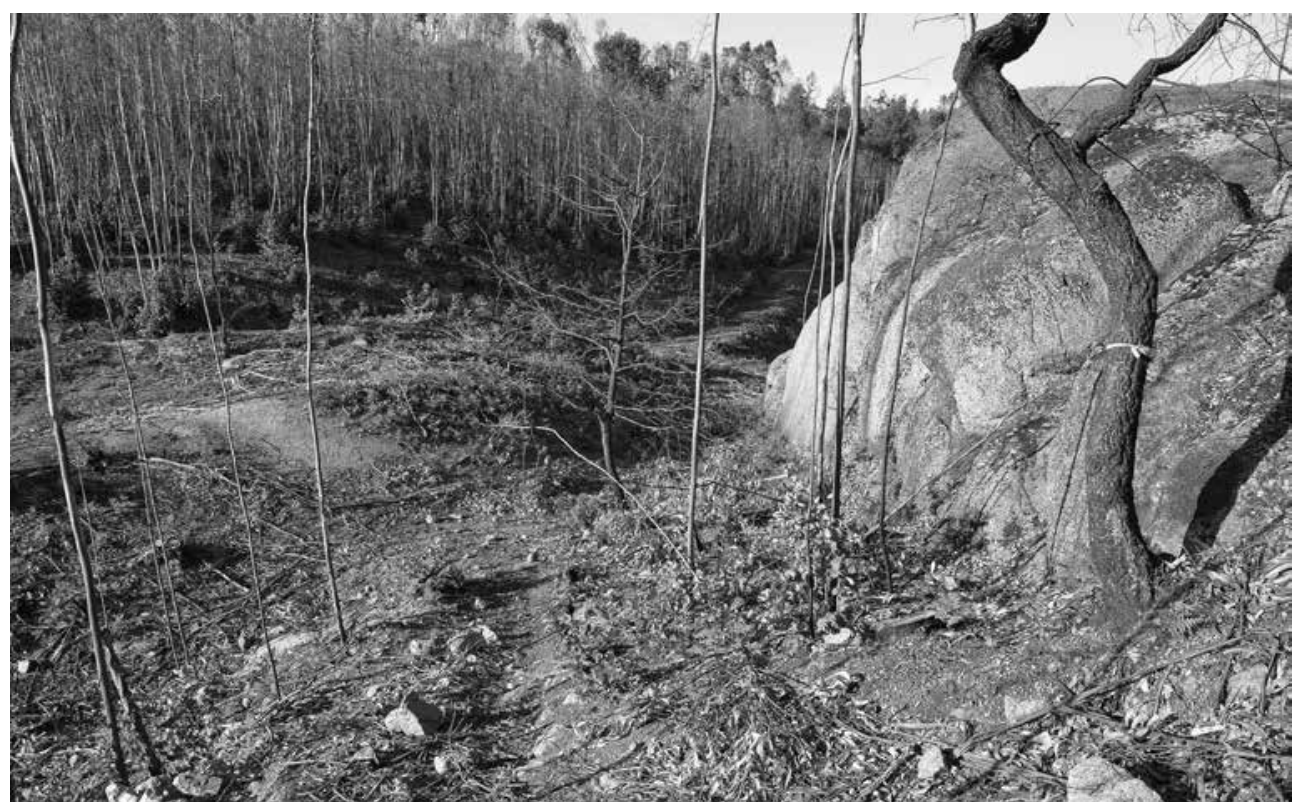

Fig. 6. O caminho de acesso ao castelo, aproveitando uma depressão entre o rochedo e as defesas de época castreja. 


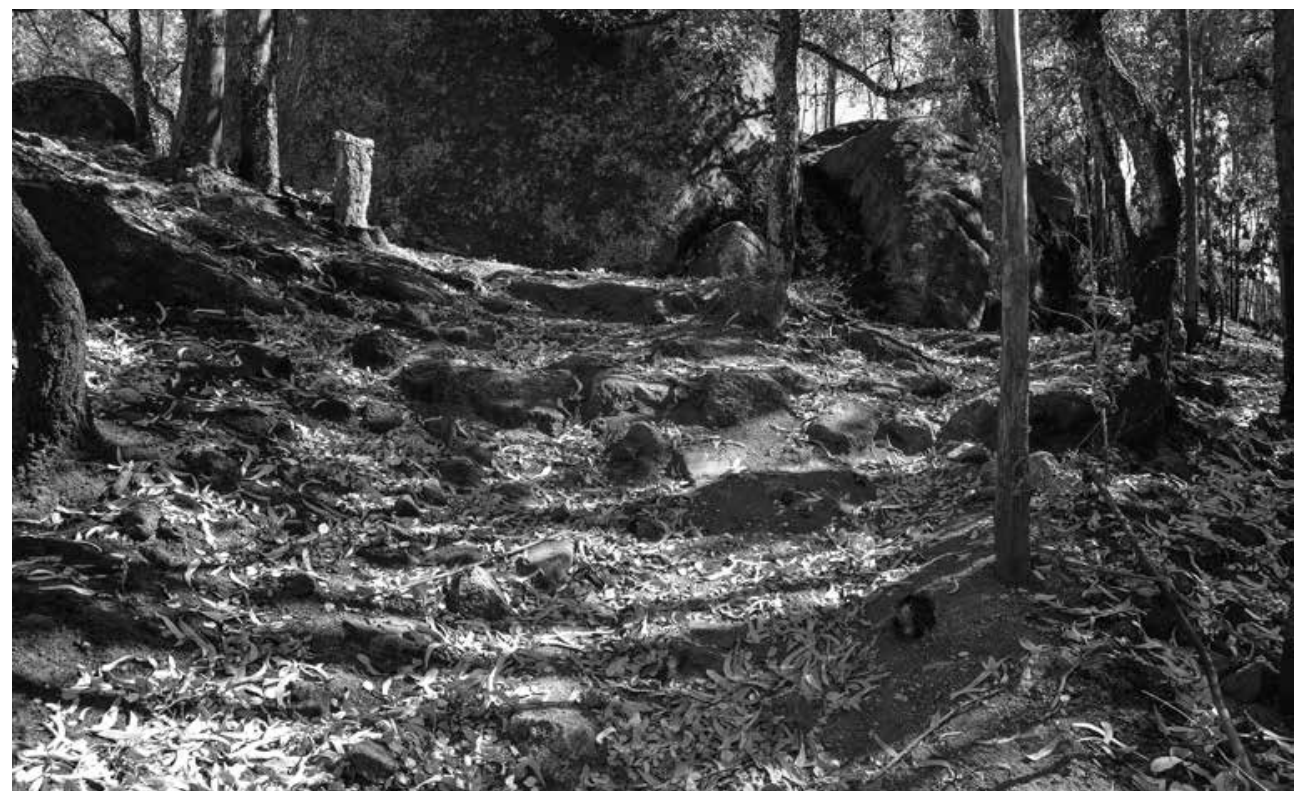

Fig. 7. A parte superior do acesso ao castelo, onde são aproveitados como degraus os restos da muralha de época castreja que aqui conflui.

e muros de socalcos do período castrejo, razão pela qual temos alguma dificuldade em descortinar se alguma das pequenas plataformas visíveis do lado nascente será desta época mais recuada, ou então reminiscência de uma fase mais tardia do castelo.

Ao lado noroeste do rochedo confluem dois taludes, e os respectivos fossos (Fig. 4), que são comprovadamente de época castreja, aos quais acresce um outro talude exterior (Fig. 3), que os contorna por todo o lado norte. Entre os taludes e o rochedo existe uma ligeira depressão alongada, que interpretamos como caminho de acesso ao castelo (Fig. 6), expondo quem entrava à posição sobranceira dos defensores. Vencido este tramo, temos vestígios de degraus em pedra (Fig. 7), parte dos quais integra certamente o reaproveitamento da face exterior do paramento da muralha castreja, que vai encostar ao penedo (Fig. 4). Neste ponto clarifica-se a defesa natural, e o acesso é cerceado por um imponente batólito granítico do lado direito, e a superfície rochosa delimitada por pendor acentuado, do lado esquerdo (Fig. 10).

Atingida a superfície mais aplanada do rochedo, e tendo sempre o grande batólito granítico do lado direito, encontramos um derrube de pedras, algumas das quais definindo alinhamentos recortados com pouca clareza, contexto que poderia indiciar uma pequena estrutura de defesa, do tipo torreão (Fig. 8). Este espaço encontra-se bastante remexido, e apresenta uma depressão que poderá ser resultante do corte de pedra em épocas mais recentes, actividade que está patente nos buracos de guilhos que o rochedo ainda ostenta. 


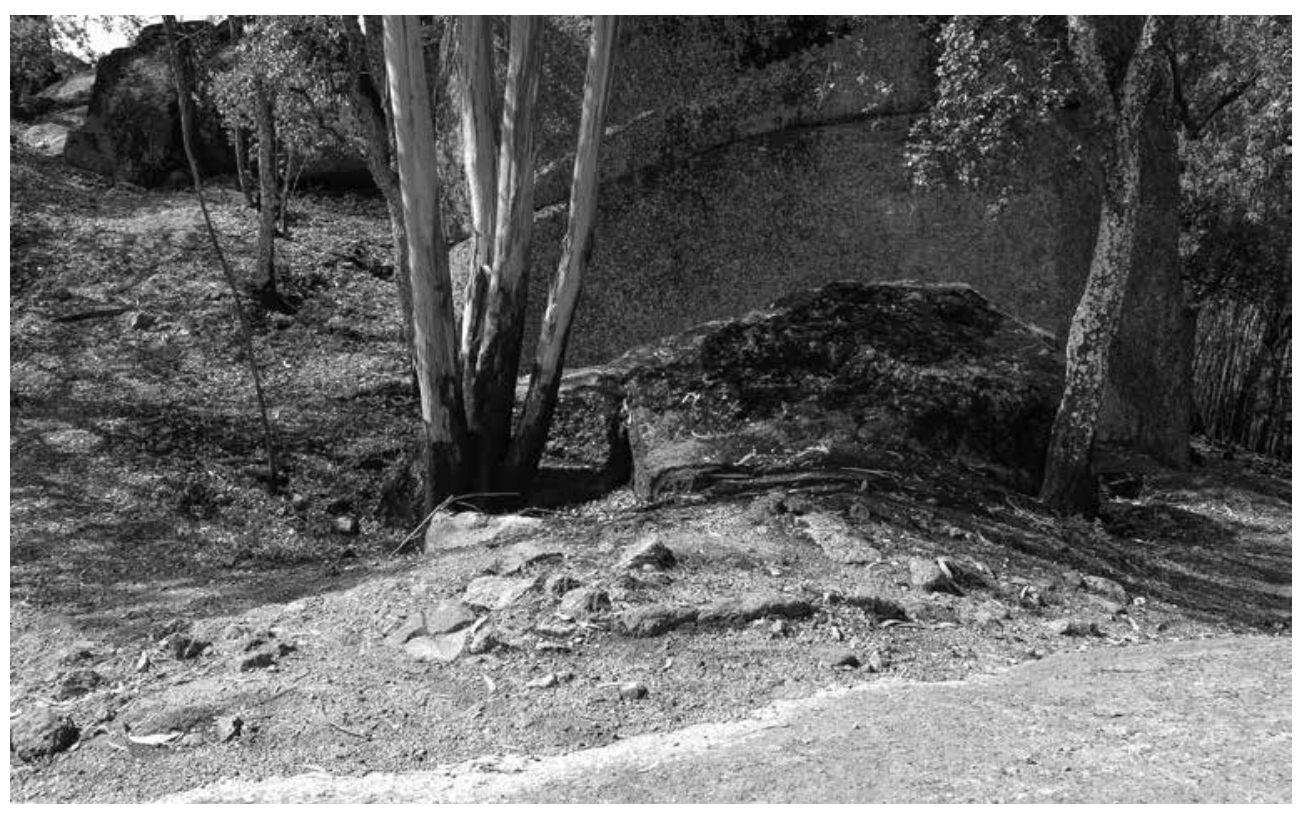

Fig. 8. Na plataforma superior são visíveis restos de construções que podem configurar algum tipo de estrutura defensiva no acesso ao castelo.

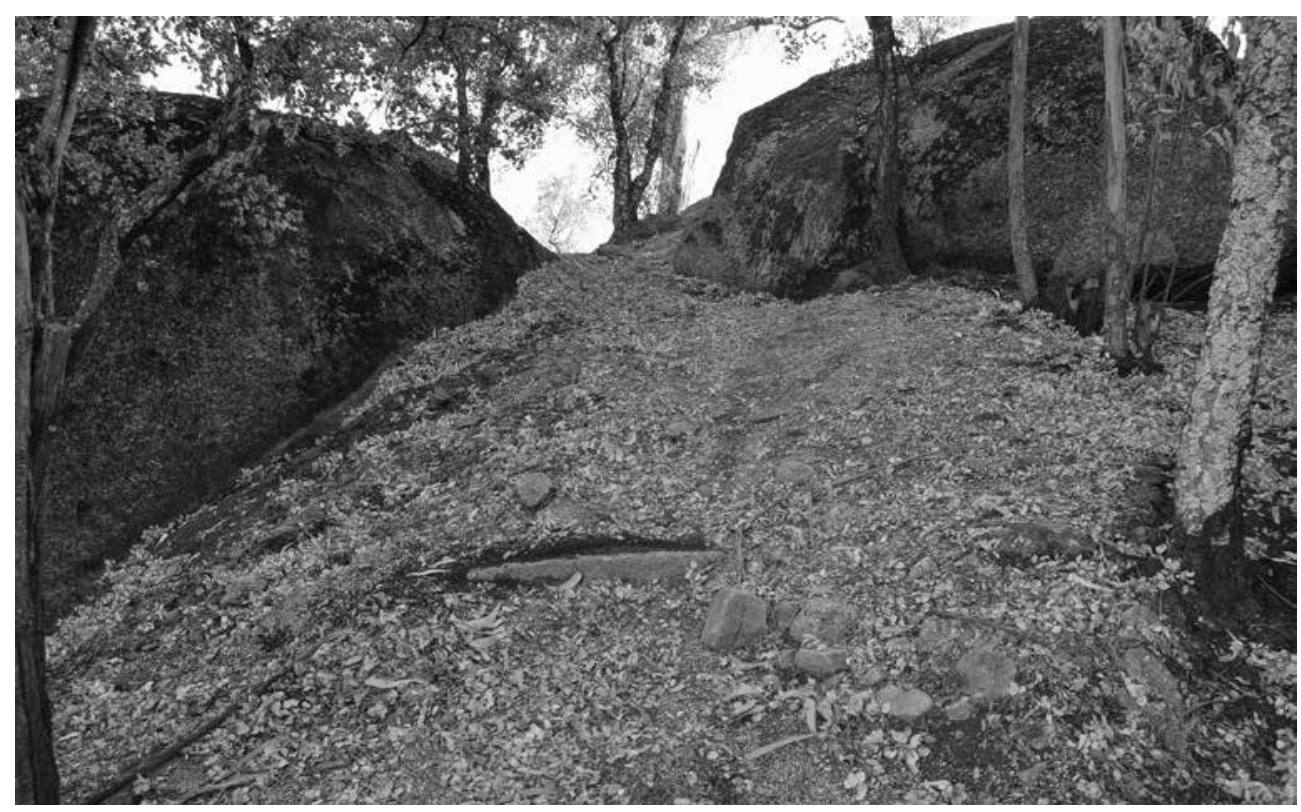

Fig. 9. Acesso à entrada do castelo, entre grandes batólitos. Do solo emerge o topo de uma pedra de degrau, elemento do que terá sido uma escadaria. 


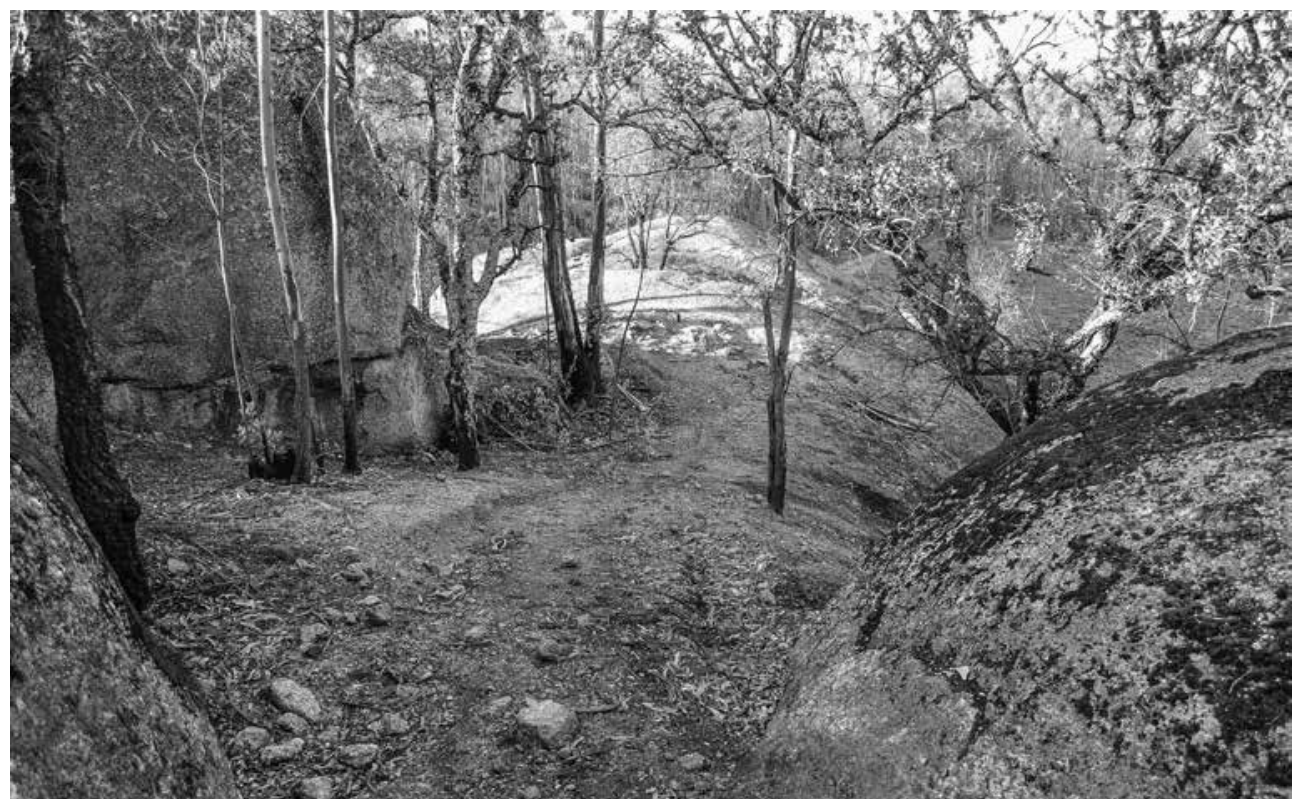

Fig. 10. Vista, do lado da porta do castelo, do «corredor» de acesso, que estaria delimitado por um muro, do lado direito, entre os afloramentos, formando corredor.

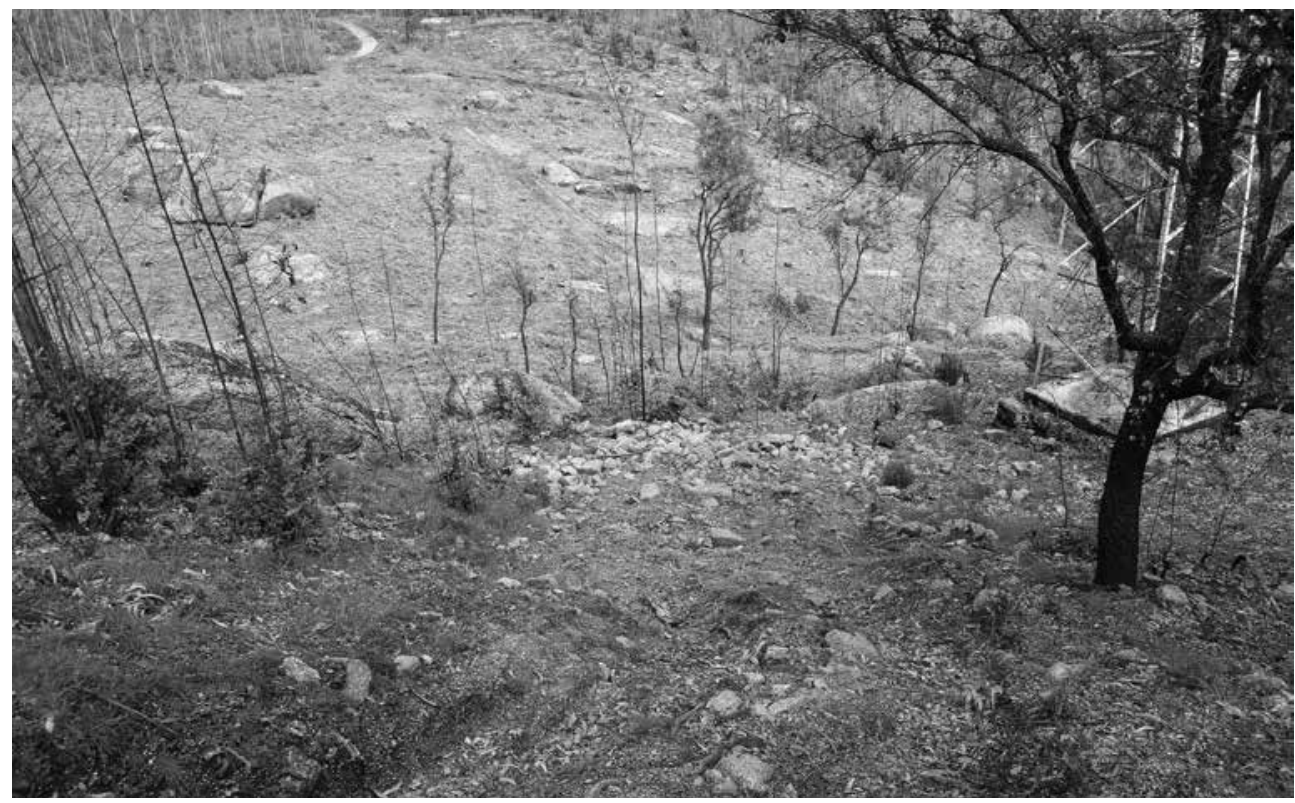

Fig. 11. Extenso derrube de pedras que indicia a existência do muro que delimitava a rampa de acesso ao castelo. 
A partir deste ponto configura-se com maior clareza o percurso de acesso ao castelo, que continua a ser limitado no seu lado poente por grandes batólitos (Fig. 10), cujos espaços intermédios se nos afigura terem sido preenchidos por segmentos de muro, dos quais ainda vemos reminiscências. Do lado oposto, a nascente, abre-se um espaço entre afloramentos, seguido de grande pendor, e que também seria limitado por um muro, do qual vemos vestígios de alicerce, e ao qual parece pertencer o denso derrube arrastado pela encosta (Fig. 11). Em função deste conjunto de vestígios, presumimos que teria existido uma entrada em corredor entre a base do rochedo, junto aos taludes de época castreja, e a porta do recinto fortificado. Este tramo, entre o primeiro torreão e a entrada do castelo era vencido por degraus, dos quais temos um exemplo visível à superfície (Fig. 9) junto à estrutura de porta.

\section{O RECINTO AMURALHADO}

Temos então o que será a evidência mais emblemática do conjunto dos vestígios que este castelo ainda possui: a estrutura da porta principal. Parte da soleira e da ombreira do lado poente da porta do castelo foram entalhadas na rocha (Fig. 12), legando-nos assim uma indicação preciosa sobre a sua estrutura e funcionamento.

Da observação dos entralhes constatamos a existência de um batente lateral generoso. Na parte inferior do batente temos uma ligeira depressão com perfil redondo indiciando que a porta teria girado sobre gonzos. O desgaste do fulcro do gonzo é muito reduzido (Fig. 13), pois notam-se as irregularidades do pico, e a secção da depressão é de perfil ovalizado, vendo-se uma mancha circular acastanhada, talvez devido à agregação de óxidos de ferro sobre a rocha. Somos tentados a presumir que ou os gonzos seriam em madeira, ou sendo em ferro terão tido muito pouca utilização. Na base da porta temos numa canelura profunda e larga, que suscita algumas dúvidas. O nível dos seus lados é igual, não se divisando o batente de soleira, facto irregular a não ser que tivesse existido uma pedra/degrau no exterior suficientemente sobreelevada para cumprir essa função. Falta-nos evidência sobre a configuração da ombreira do lado nascente, o que não permite concluir se a porta teria uma ou duas peças, sendo esta segunda hipótese mais coerente, pois quanto mais estreita fosse a folha da porta menor carga faria sobre o gonzo. De resto, tanto as características do acesso à porta como as do espaço disponível do lado interior, e a ela contíguo, sugerem que esta seria comparativamente estreita, adequada à passagem de pessoas e animais de tiro, mas não de veículos. Com base nestes pressupostos, e em exemplos coevos, aventamos que a sua largura se deveria situar entre 120 e 160 centímetros.

A parte superior do rochedo apresenta evidência importante sobre a configuração da muralha, uma vez que ostenta alguns entalhes de embasamento do seu tramo do lado poente. No alinhamento do batente da porta temos um entalhe que define o 
pano exterior da muralha, o qual aqui teria cerca de 70 centímetros de largura (Fig. 14). Do lado interior da porta, um outro entalhe indicia que a muralha se alargaria mais um metro para este lado, perfazendo assim um total de cerca de um metro e setenta. Neste plano, situa-se ainda um rebaixe com cerca de 12 centímetros de largura, o qual servia para apoio da tranca transversal de bloqueio da porta (Figs. 12 e 14). A largura total da muralha neste curto tramo junto à porta, que teria pelo menos 1,70 $\mathrm{m}$, é consentânea com a existência de uma plataforma, ou adarve, na parte superior. A posição da porta, na parte média da muralha, conferia-lhe alguma protecção face ao desgaste provocado pelas intempéries. A abertura de entrada seria certamente suportada por uma solução em arco, cuja forma não nos é possível determinar.

Defronte da porta de entrada temos um rochedo que sobreleva a cota do lado poente (Figs. 12 e 14), pelo que o acesso ao interior do castelo deveria aqui inflectir para a esquerda, em rampa. O desnível acentuado, que ainda hoje vemos do lado direito da entrada, só poderia ter sido vencido com recurso a degraus, se bem que pareça mais lógico a existência de um murete de suporte, do qual temos um possível vestígio na base do rochedo da porta (Figs. 12 e 14), e vedaria o acesso por este lado.

A configuração do pano de muralha do lado norte é definida claramente pela estrutura da porta, e o cunhal da intersecção deste com o alinhamento da muralha no lado nascente do castelo situa-se sobre um pequeno batólito que, em nossa opinião, teria sido mais fácil remover do local do que integrar na construção. Neste

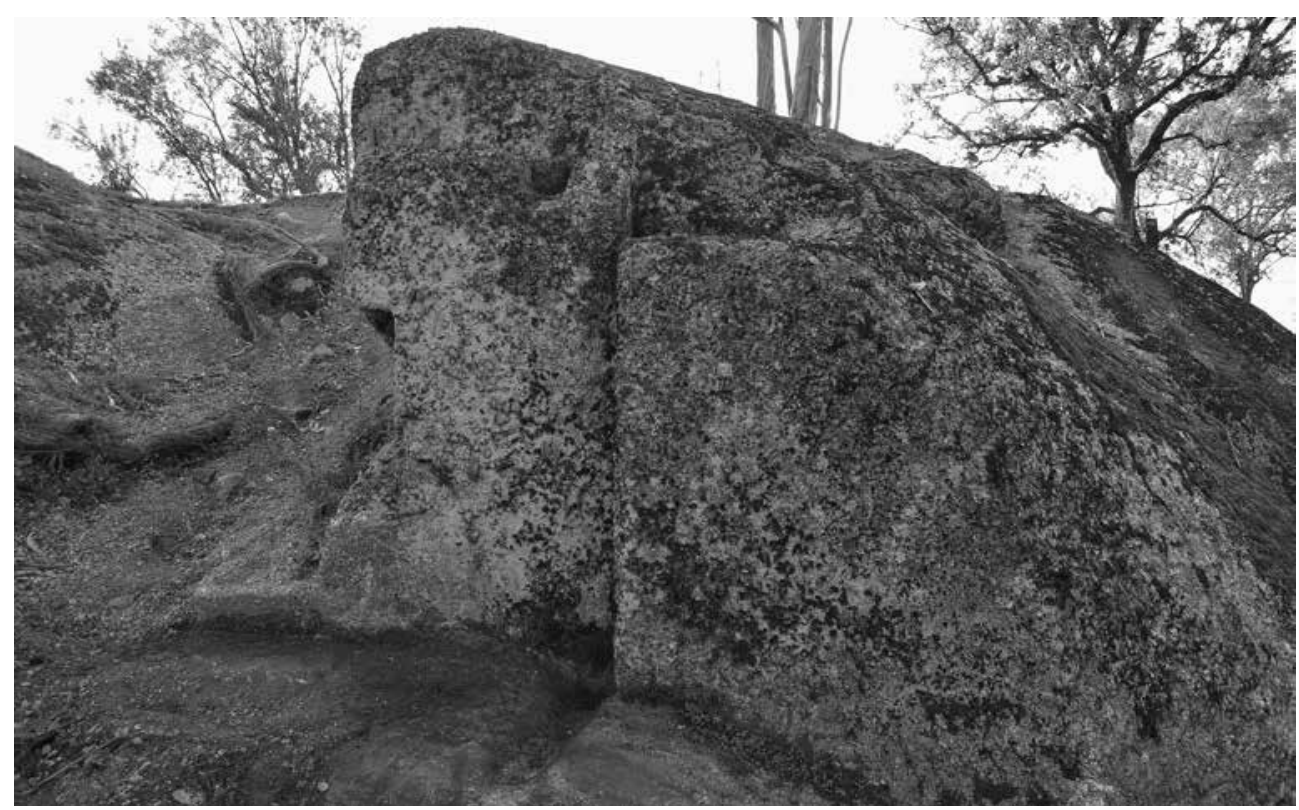

Fig. 12. A estrutura da porta do castelo, documentada pelos entalhes escavados na rocha. 


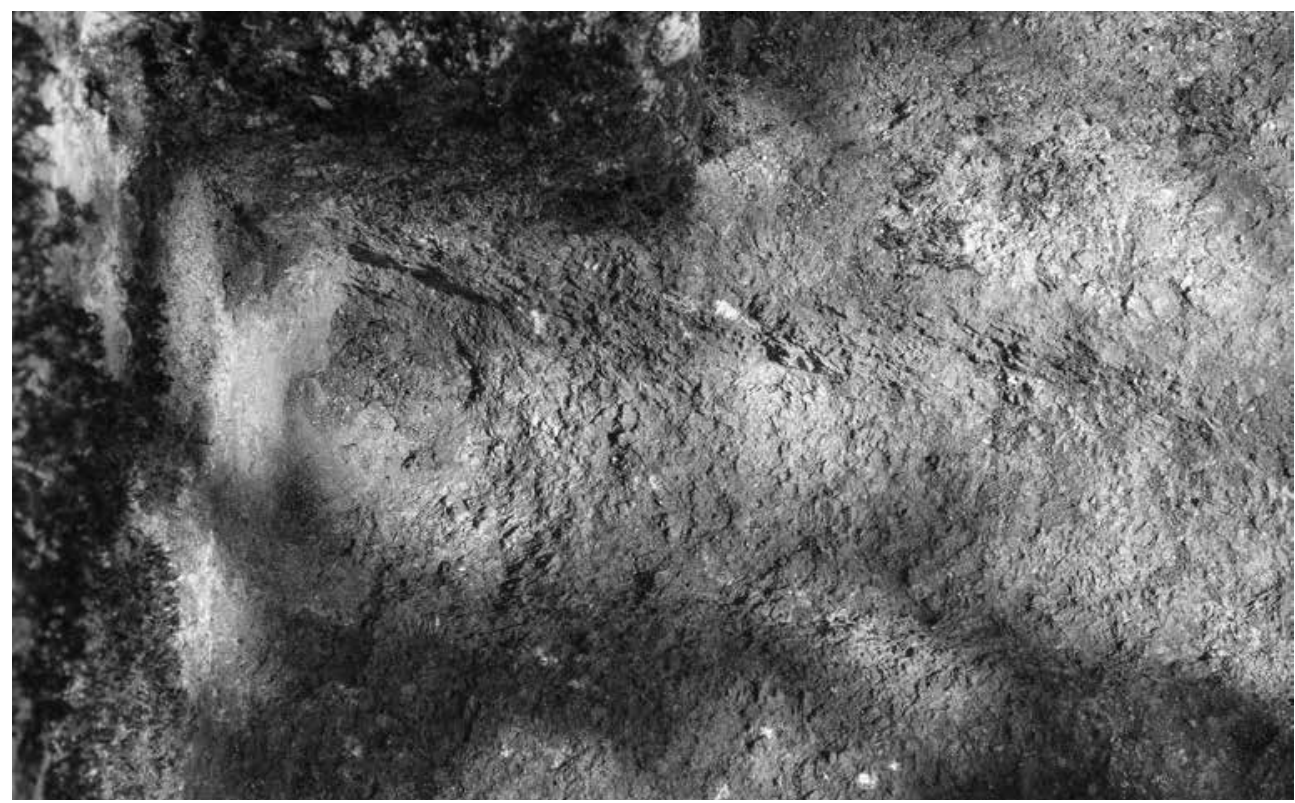

Fig. 13. Pormenor da canelura da soleira e do orifício do gonzo, do lado poente da porta de entrada do castelo.

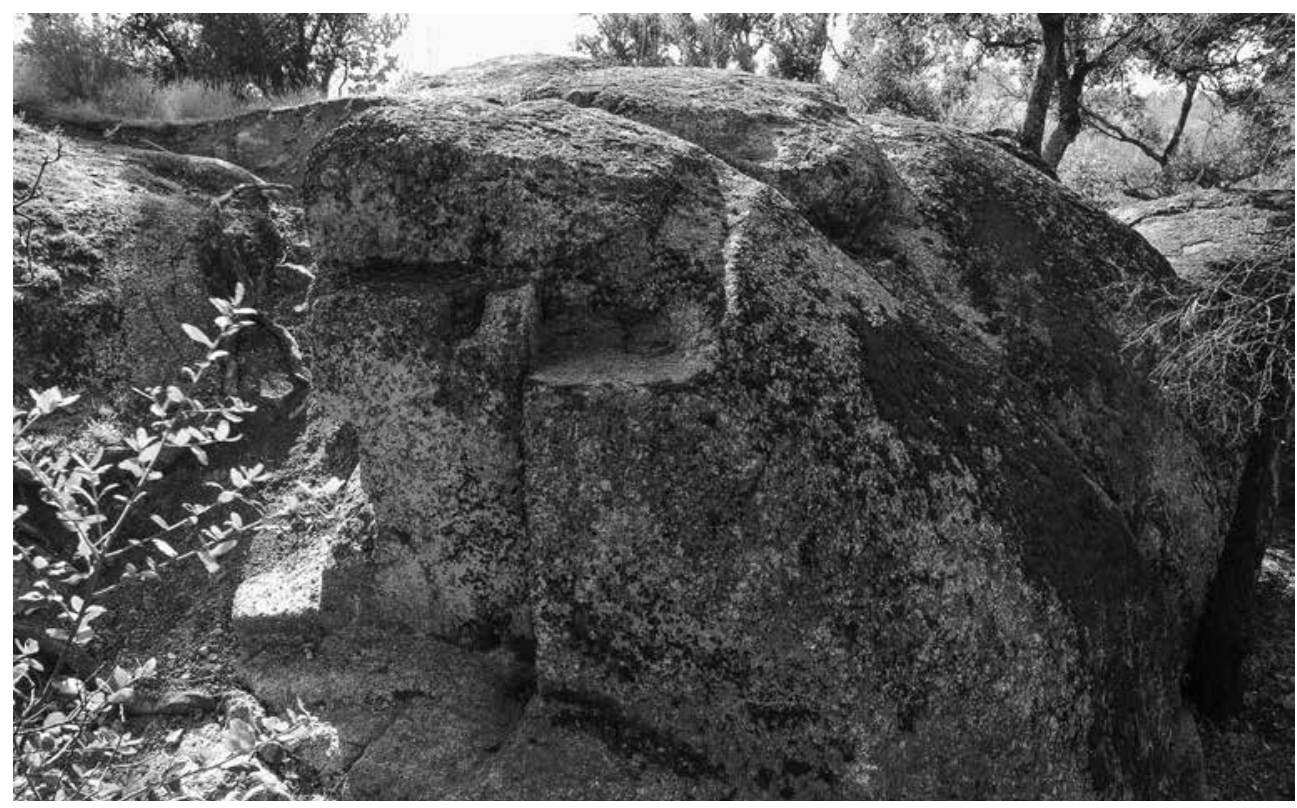

Fig. 14. Vista superior da estrutura da porta, notando-se os entalhes do desenvolvimento da muralha para o lado poente. Nota-se ainda o desnível do terreno no interior do recinto, devido à presença do afloramento granítico. 
lado a configuração do afloramento rochoso é bastante mais entrecortada, criando espaços com vãos angulosos, em tudo semelhantes a linhas de água. Estes espaços de instabilidade estrutural obrigaram a criar alicerces, ou "sapatas», que se alongam para o exterior do alinhamento da muralha conforme indiciam as escassas pedras que ainda sobrevivem in situ, configurando uma solução do tipo alambor semelhante ao que vemos junto à porta norte do castelo de Guimarães.

Os dados disponíveis sobre o posicionamento da muralha, que oscilam entre uma ou outra pedra de alicerce e os entalhes nos rochedos, parecem definir uma planta bastante regular para este tipo de construção. Com efeito, e como documenta a Fig. 15, cerca de metade do traçado do lado nascente é rectilíneo, entre o entalhe no

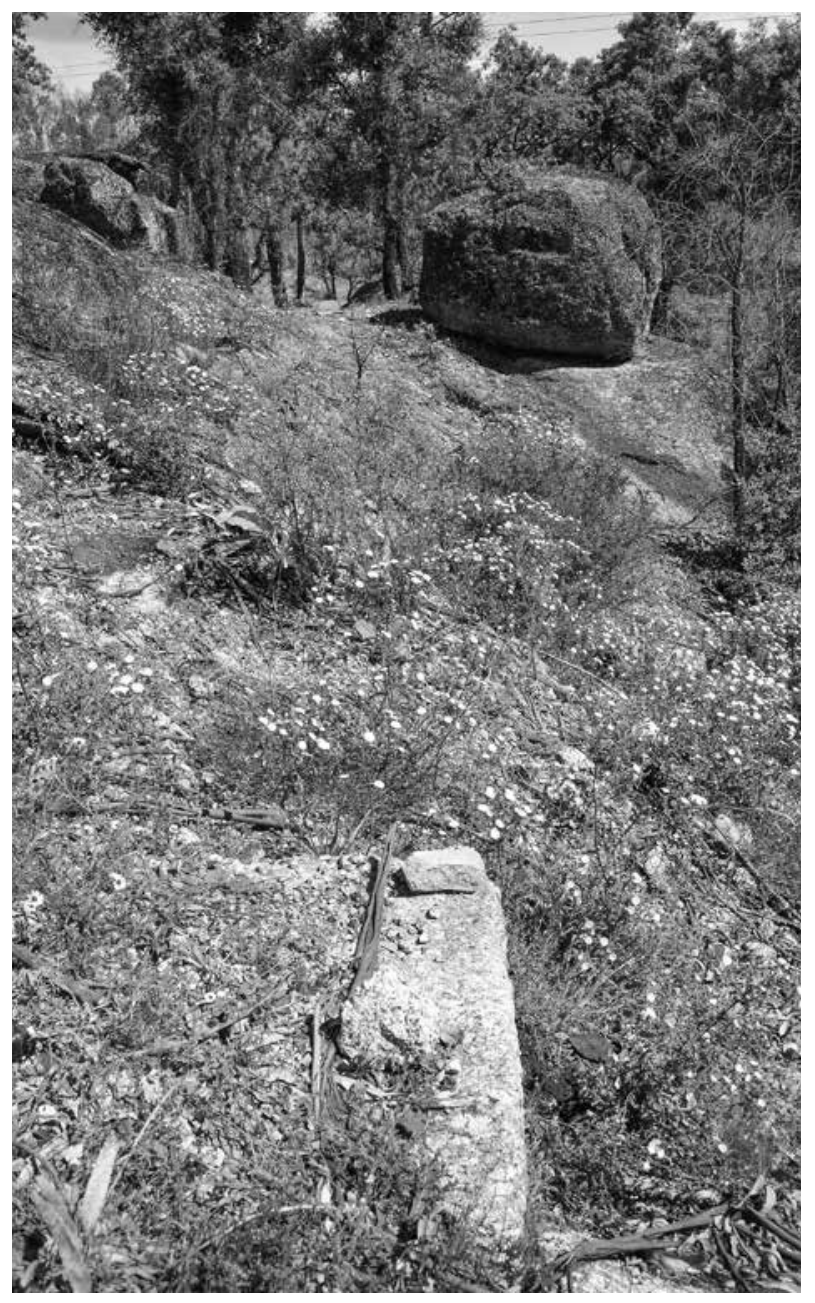

Fig. 15.

Alinhamento da muralha do lado nascente, em zona débil de afloramento rochoso. Nota-se em primeiro plano uma boa pedra aparelhada, a qual alinha com o entalhe no penedo, ao fundo, no qual também se infere a largura da muralha. 


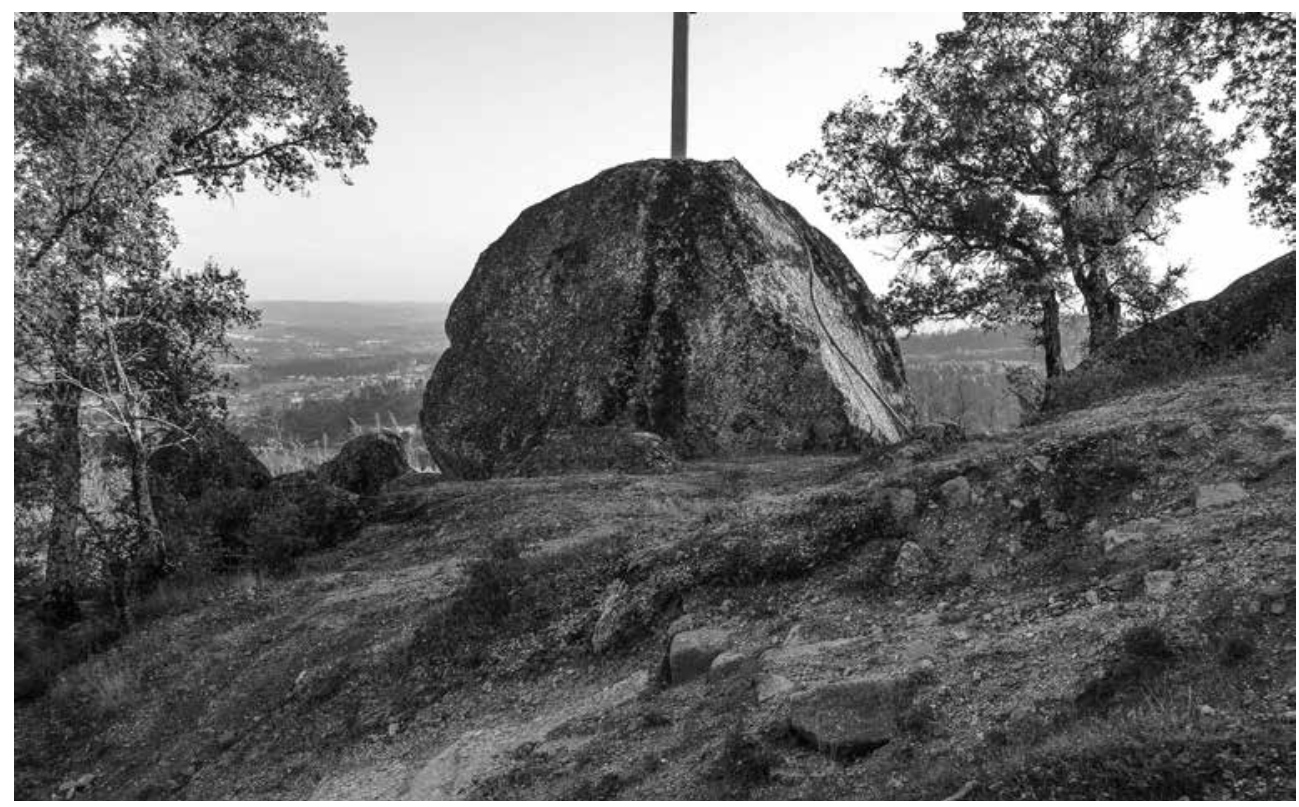

Fig. 16. Vista do traçado da muralha nascente, para o seu extremo sul. A pedra de alicerce, sobre o rochedo, alinha com a base do cruzeiro, onde temos um entalhe de apoio de cunhal.

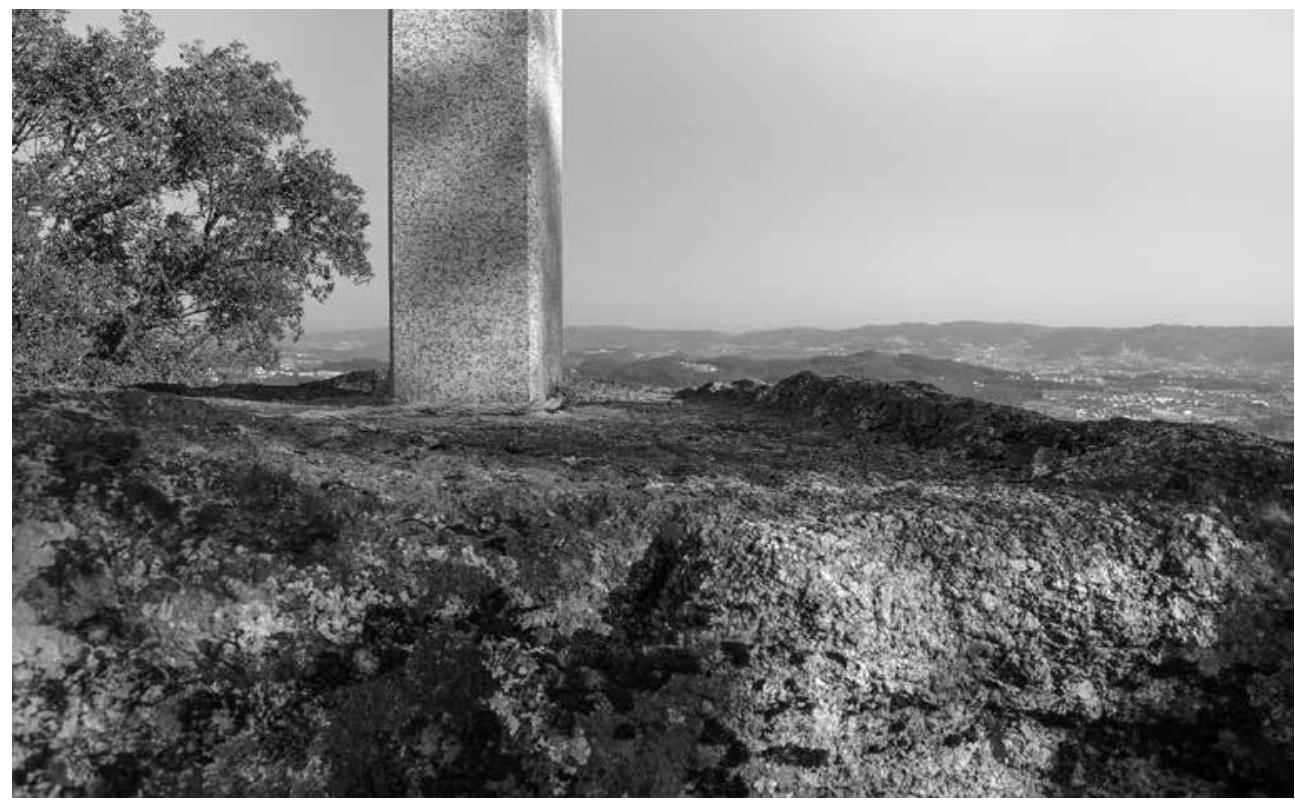

Fig. 17. Parte superior do rochedo com entalhe de apoio da muralha. O rebordo lateral inflecte em ângulo, indicando tratar-se do cunhal. 


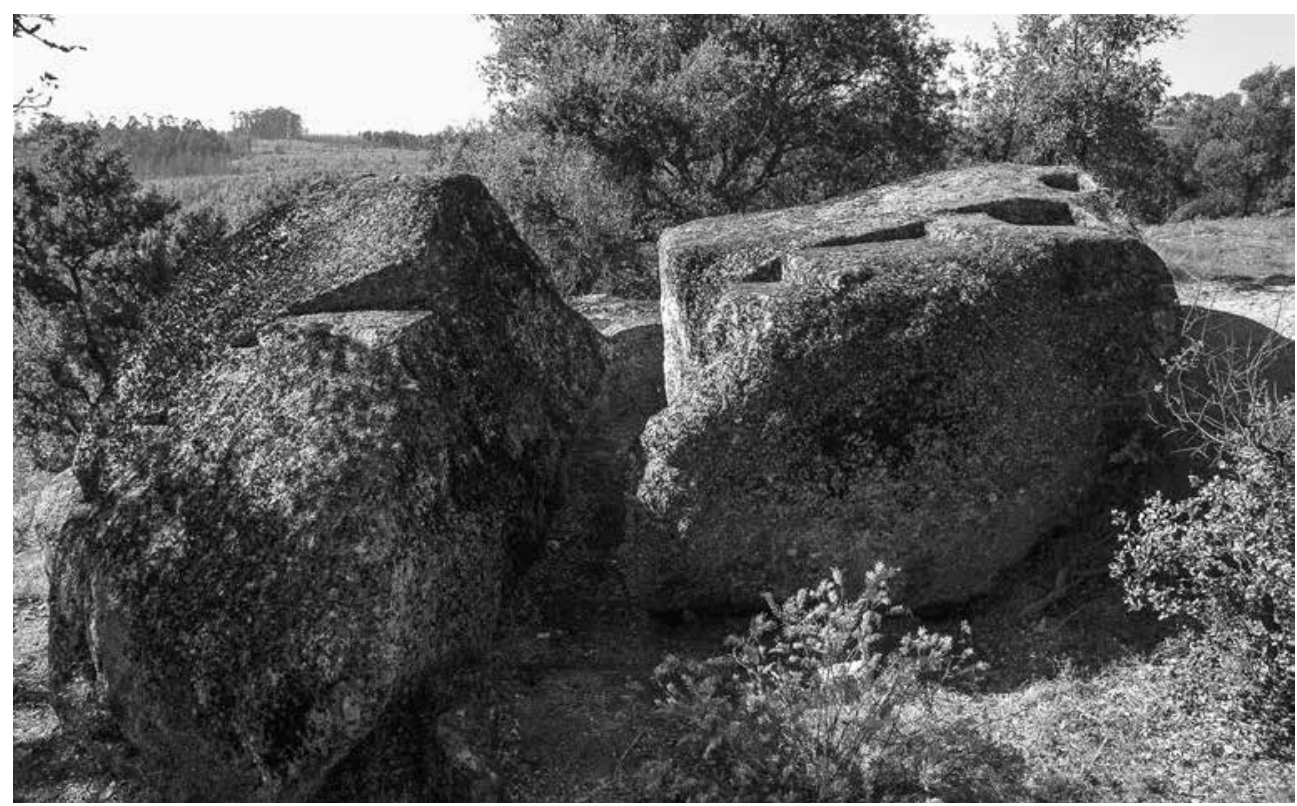

Fig. 18. Magnífica sequência de entalhes na rocha, que clarificam a configuração do que se presume ser uma torre.

rochedo e uma boa pedra de alicerce, podendo inflectir ligeiramente ao aproximar-se do seu extremo sul, onde subsiste evidência de alicerce (Fig. 16) na falha do rochedo.

No extremo sul temos indicação clara sobre o traçado da muralha, mercê de um conjunto de entalhes sobreelevados sobre dois batólitos graníticos. Neste local, a muralha vai apoiar sobre o enorme batólito, no qual se erigiu um cruzeiro em pedra, e no topo do qual se nota o entalhe de embasamento. Este mostra claramente a configuração de um cunhal (Fig. 17), indicando que a partir de aqui a muralha inflecte em ângulo próximo dos $90^{\circ}$ para poente. Neste local, o alicerce da muralha encontra-se a cerca de 4,5 metros acima do nível do maciço rochoso (Fig. 16).

O alinhamento interrompe-se pouco depois pela confluência de uma magnífica série de entalhes (Fig. 18), cuja configuração parece definir um pequeno recinto quadrangular (Fig. 19) que só conseguimos interpretar como torre de menagem, ideia que parece ser reforçada pela altura que o alicerce atinge no rochedo onde se situa o cruzeiro.

Naturalmente que os parcos dados disponíveis, e mesmo confirmando-se esta interpretação, não permitem aduzir se esta estrutura corresponderá à planta original do castelo, ou se será uma adição posterior aos meados do século XI, já do período românico, a partir do qual aparecem as torres de menagem ${ }^{13}$ nos castelos roqueiros.

\footnotetext{
${ }^{13}$ BARROCA, 1990-91: 91.
} 


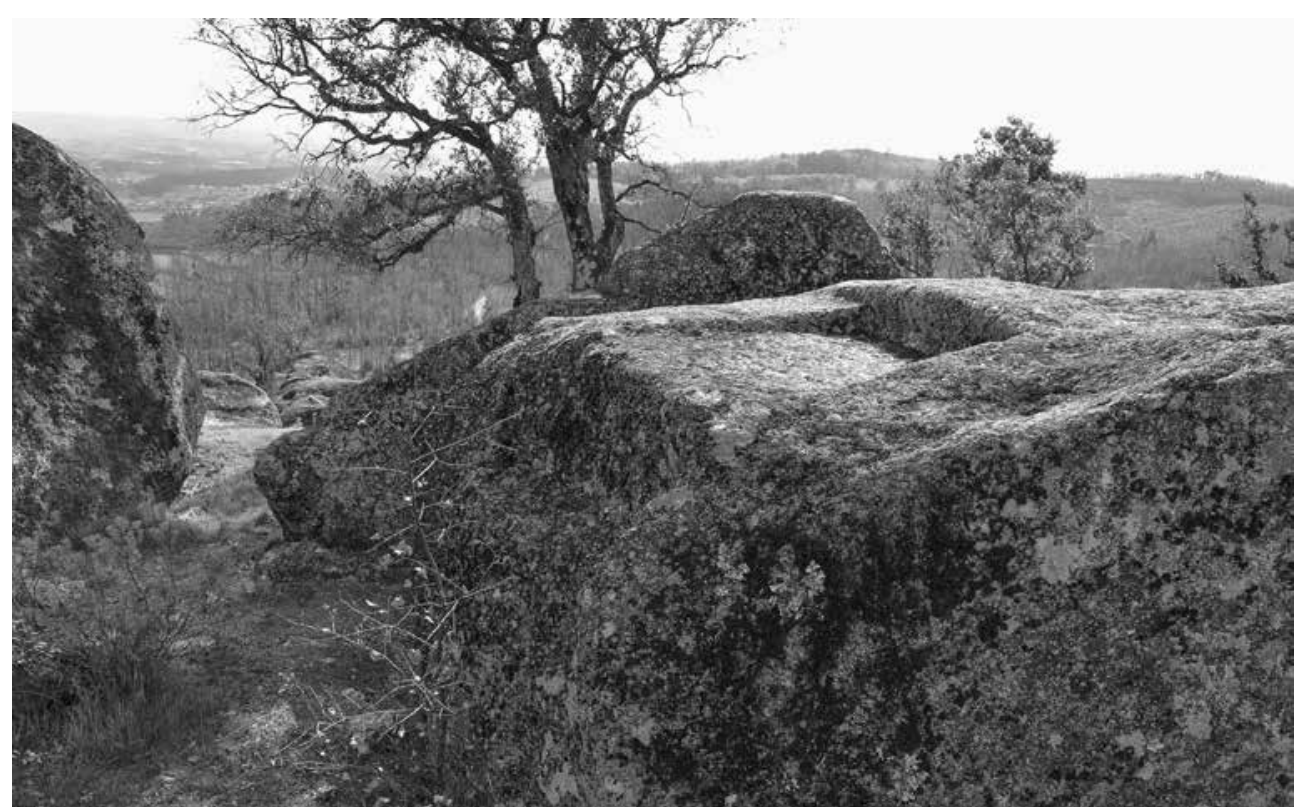

Fig. 19. Detalhe da vista anterior, onde se salienta o entalhe que documenta a planta quadrangular da torre.

Em todo o caso, estranha que os construtores do castelo tenham decidido passar a muralha sobre um obstáculo tão proeminente, tendo em mente os esforços de adaptação dos aparelhos a este rochedo de configuração circular, e também à sua cota particularmente elevada.

O tramo poente da muralha arranca da intersecção deste muro norte da presumível torre de menagem inflectindo e acompanhando a curvatura do rochedo, até alinhar quase que rectilíneo sobre três conjuntos de entalhes rupestres (Fig. 21), e vai encaixar na secção da muralha onde se situa a porta de entrada.

Os dados disponíveis, e acima apresentados, indicam que a planta desta fortificação aparenta seguir um traçado talvez excessivamente rectilíneo, comparativamente com alguns outros exemplos coevos, que conhecemos da região ${ }^{14}$, nos quais o alinhamento é bastante mais entrecortado. Contudo, deve ter-se em consideração a regularidade da plataforma rochosa na qual se implanta, a qual pode ter propiciado esta configuração mais rectilínea da planta.

A largura da muralha parece não ter excedido os 80 centímetros, segundo o que nos é indiciado pelos entalhes nas rochas que temos vindo a referenciar, salvo no tramo da porta principal, onde poderá ultrapassar 1,7 metros, como acima se referiu. Estas dimensões das paredes não permitiriam desenvoltura na circulação

\footnotetext{
${ }^{14}$ FONTES \& REGALO, 1997: figura 4.
} 


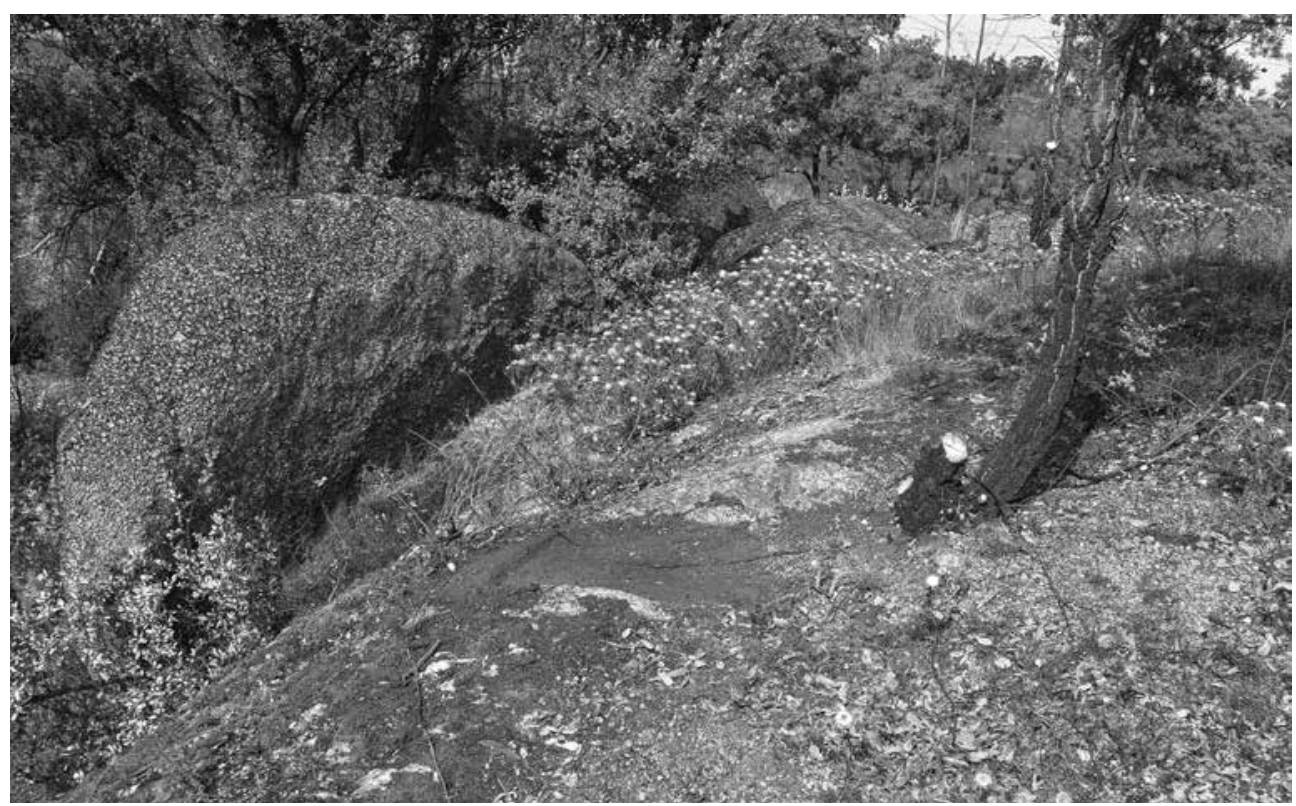

Fig. 20. Entalhe quadrangular sobre o rochedo, do lado poente do castelo.

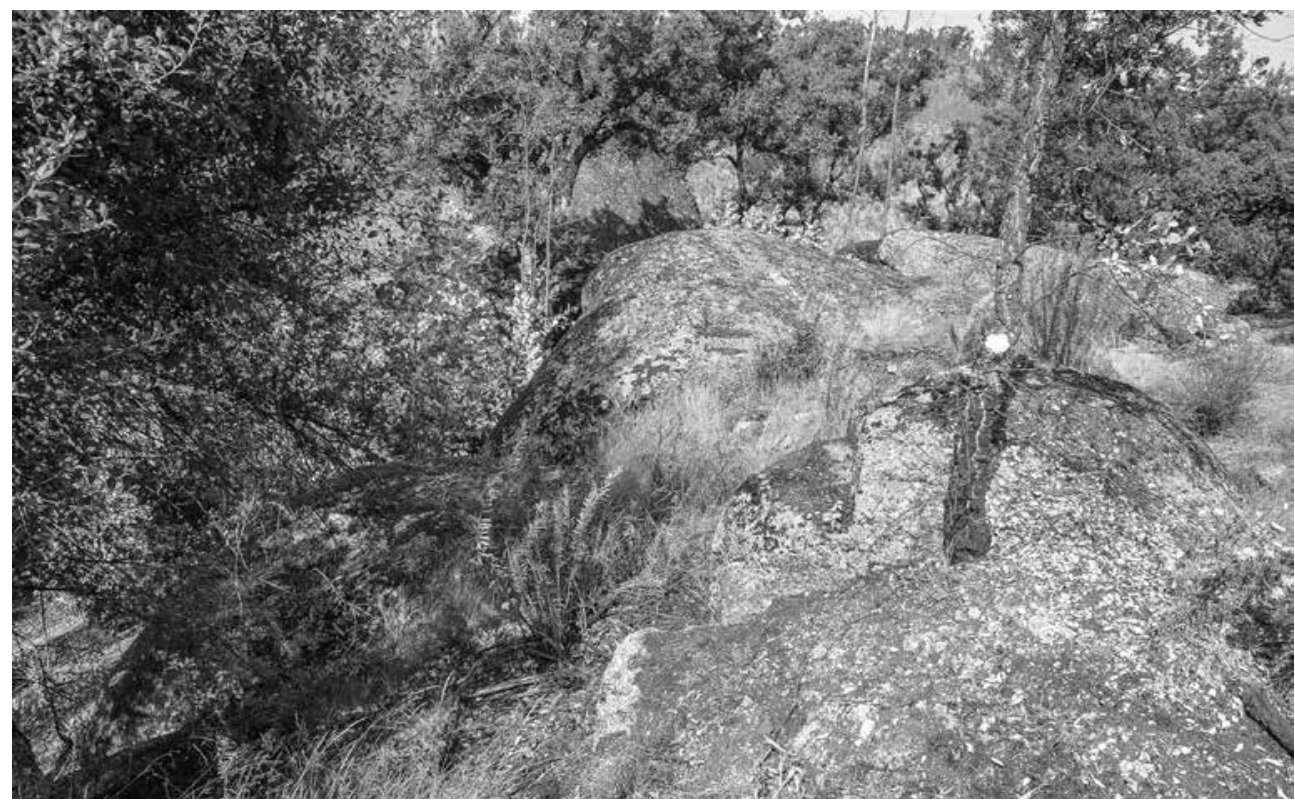

Fig. 21. Vista de dois entalhes na rocha, do lado poente do castelo. O entalhe em primeiro plano delimita a face interior da muralha, enquanto o outro, ao fundo, é perpendicular ao seu traçado. 


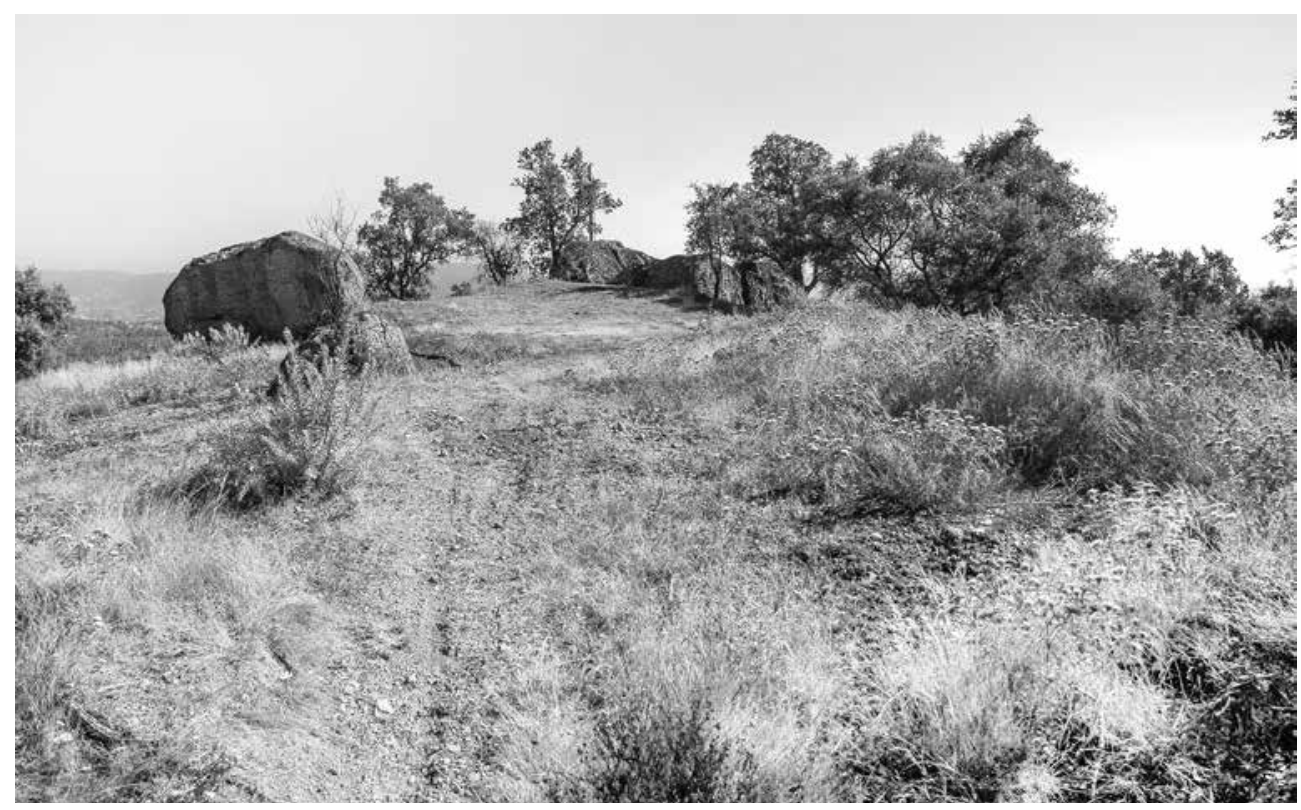

Fig. 22. Vista geral da plataforma interior do castelo, na direcção sul. Em primeiro plano, uma planta de trovisco.

sobre a sua parte superior, na tarefa de defesa da fortificação. A confirmarem-se estes dados sobre a espessura dos tramos nascente e poente da muralha do castelo, em futuras escavações arqueológicas, só resta aventar a possibilidade de as construções que existiram no seu interior, quer em pedra quer em madeira, terem servido de apoio a um passadiço em madeira que permitisse a circulação em torno da muralha, propiciando a defesa destes sectores. Trata-se, como se salientou, de uma conjectura que caberá a futuros trabalhos esclarecer.

Algumas pedras aparelhadas que se encontram dispersas em derrubes ao longo da encosta sugerem que a muralha teria tido um aparelho do tipo isódomo, o que conferiria alguma solidez à estrutura, compensando em parte a sua reduzida espessura. A estimativa sobre a altura apenas é sugerida pelo batólito onde assenta a suposta torre de menagem, local onde é lícito presumir que a muralha teria pelo menos seis metros de altura.

O interior do recinto era amplo e aplanado (Fig. 22), e teria, naturalmente, algumas construções de apoio aos residentes, mormente à guarnição, posto que nesta época os castelos não eram residência quotidiana da nobreza. Dormitório, cozinha, estábulo e forja parecem ser espaços indispensáveis à vida do castelo. Se os primeiros dois são de senso comum, já para documentar os segundos temos o achado de dois fragmentos de escória, e um pequeno fragmento de ferradura (Fig. 23) junto com um cravo, ambos em ferro, encontrados à superfície numa das últimas visitas ao local. 


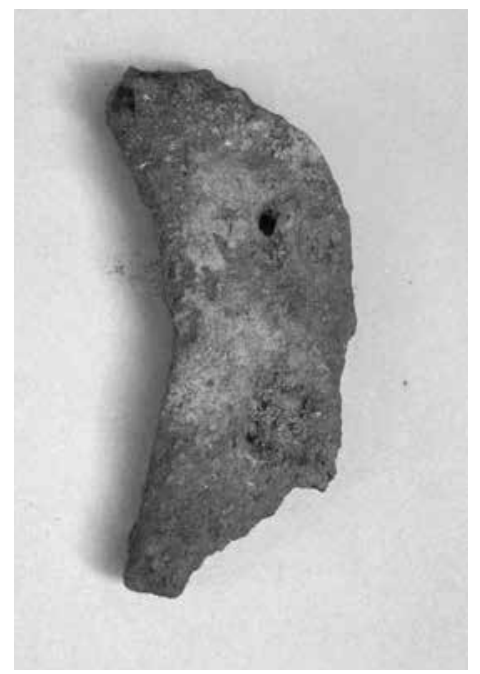

Fig. 23. Fragmento de uma ferradura, encontrada em derrube superficial, junto à entrada do castelo.
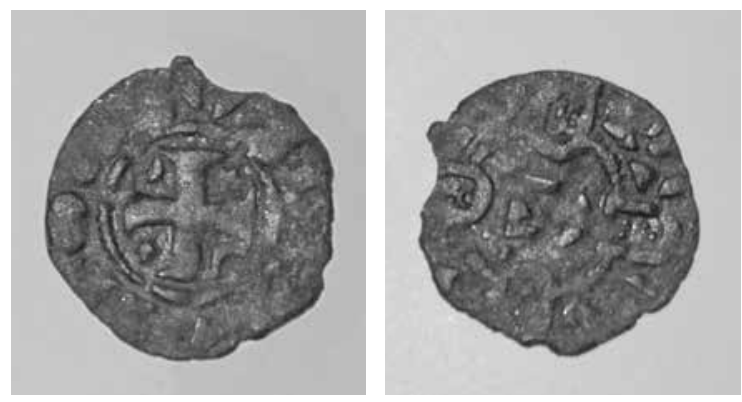

Fig. 24. Dinheiro de D. Afonso III encontrado em derrube superficial junto da entrada do castelo.

Ambos fundamentam tanto a prática metalúrgica como a presença de equídeos no quotidiano desta fortificação.

A superfície do terreno revela indícios de muretes, cuja configuração por ora não é possível descortinar, mas pelo menos um deles parece alinhar em paralelo ao lado poente da muralha, sugerindo assim a possibilidade de as construções estarem adossadas aos seus lados nascente e poente, criando um espaço do tipo corredor entre a porta e o extremo sul. De resto, a ocupação quotidiana está documentada por outros achados de superfície em zonas de escorrimentos, que recordamos ter visto no local ${ }^{15}$, como fragmentos de várias formas cerâmicas de cozinha e de armazenamento, e ainda uma importante moeda (Fig. 24), um dinheiro de D. Afonso III ${ }^{16}$, datável de 1248-79.

Do conjunto das cerâmicas encontradas à superfície no local já só guardamos memória. Recordamos fragmentos de alguidar com fundo em disco e bordo denteado, de panela com decoração em fio ondulado na parte superior da pança, e os bordos com lóbulo em bisel e curvatura esvasada. Contudo, o que mais chamou então a atenção foram alguns fragmentos com parede pouco espessa, pasta bem cozida, e com a particularidade de uma superfície anormalmente irregular em ambas as faces, pejada com marcas de dedos nas quais eram ainda visíveis as impressões digitais do

\footnotetext{
${ }^{15}$ Em visita feita em 1978 na companhia de Orlando Sousa, sendo então ambos alunos da Faculdade de Letras e já muito interessados por este castelo, por contágio do Prof. Carlos Alberto Ferreira de Almeida.

${ }^{16}$ Agradecemos a Mário Barroca a classificação deste numisma, feita já há cerca de duas décadas.
} 
oleiro. Trata-se de cerâmica de fabrico claramente medieval, pela pasta e pela cozedura, mas na manufactura da qual parece não ter sido usado o torno, circunstância que, de resto, não explica a sua excessiva rusticidade ${ }^{17}$.

As características construtivas do castelo parecem indiciar a sua edificação por iniciativa condal ${ }^{18}$, o que viria também a dar sentido ao protagonismo que esta fortificação teve nos episódios e circunstâncias que aqui evocamos, justificando a sua preferência pelo conde Alvito Nunes. A estrutura deste tipo de fortificações começa a ser mais bem conhecida, mercê de intervenções arqueológicas na região ${ }^{19}$ que nos vão revelando plantas e técnicas construtivas, ao que esperamos agora dar contributo.

Entre as muitas dúvidas que ficam por esclarecer, salientamos a da eventual evolução da estrutura do castelo, nomeadamente se a muralha foi reparada ou refeita, ou mesmo se houve ampliação por altura da sua ascensão a cabeça de terra, não sendo igualmente claro se a torre, que teria existido no seu extremo sul, pertencerá a esta fase. Os vestígios escrutinados salientam, contudo, a notável individualidade na adaptação das estruturas defensivas aos condicionalismos locais. O carácter local destas construções castelares menores, pela adaptação às configurações particulares de cada monte, e pela sensibilidade própria dos seus construtores, deveria saldar-se numa grande diversidade de soluções ${ }^{20}$, na configuração da planta e nos aparelhos de pedra utilizados, assim como na organização funcional dos espaços interiores e dos acessos.

\section{O CASTELO E O TERRITÓRIO ENVOLVENTE}

No território envolvente ao castelo de Vermoim possuímos uma série de evidências, somando as arqueológicas e documentais, da existência de povoamento estruturado em torno de alguns cabeços proeminentes, e na maioria dos quais tinha havido ocupação da Idade do Ferro ${ }^{21}$. Estes montes (mons), que as fontes documentais tão repetidamente referem a partir do século XI, serão locais com defesas naturais, possuindo reminiscências de muralhas castrejas, ou alguns muros incipientes então edificados, dentro dos quais se refugiam as populações em épocas de instabilidade. A sua construção será de iniciativa local ${ }^{22}$, fruto do labor, da técnica e das necessi-

\footnotetext{
${ }^{17}$ Os fragmentos cerâmicos foram então mostradas ao Prof. Carlos Alberto Ferreira de Almeida, que nos indicou serem datáveis genericamente dos séculos XI-XIII.

${ }^{18}$ BARROCA, 1990/91: 94.

${ }^{19}$ FONTES \& REGALO, 1997; FONTES \& RORIZ, 2010.

${ }^{20}$ BARROCA, 1990/91: 98.

${ }^{21} \mathrm{Na}$ escavação do castro de Penices, em Gondifelos, encontrou-se evidência de ocupação medieval (sécs. XI-XIII) nas camadas superficiais, e ainda cerâmicas datáveis desta época no enchimento do fosso adjacente à muralha. Saliente-se que este castro se situa num cabeço pouco proeminente junto ao vale do rio Este. Cremos que o recurso pelas populações à segurança conferida por estes castros, então abandonados, terá sido muito mais generalizado do que a documentação deixa transparecer, e só um olhar atento da arqueologia irá lentamente evidenciar no futuro este padrão.

22 BARROCA, 1990-91: 91.
} 
dades dos habitantes, a ela sendo alheia a intervenção condal, o que poderá explicar a sua rusticidade e caducidade. A amplitude deste «encastelamento» que se iniciará no século $\mathrm{X}^{23}$ está representado neste entorno por um número significativo de casos (Planta 1$)^{24}$, se bem que referidos no século XI e seguinte. O simples facto de serem utilizados como marco de referência já atesta a sua importância, e se na documentação não são referidos como castelos é porque talvez o não sejam, na maioria dos casos, por não possuírem uma estrutura própria, antes aproveitando e reforçando as defesas preexistentes. E também se enquadram num espaço ainda não estruturado, isto é, não organizado defendido e disciplinado ${ }^{25}$ por uma tutela condal, situação que a criação das «terras» virá colmatar ${ }^{26}$.

A propósito da distribuição destes mons na paisagem circundante a Vermoim (Planta 1), consubstancia-se nesta área a sugestão de Carlos Alberto Ferreira de Almeida da sua relação com as vias de circulação ${ }^{27}$, e mormente as de penetração costa-interior, e de ligação entre as cidades de maior importância.

A existência dos topónimos vila, casal, e também portela, espalhados pelo entorno do castelo, sugere um espaço povoado e organizado, e em tudo compatível com os ritmos de povoamento conhecidos nesta região ${ }^{28}$ na viragem do milénio.

A presença do conde Alvito Nunes no castelo de Vermoim, e consequentemente a sua escolha para resistir à incursão normanda, parecem ser indiciadores do destaque que esta fortificação teria, devido tanto à robustez da sua estrutura como ao seu papel jurisdicional. Presume-se que os tenentes do castelo não o habitariam normalmente ${ }^{29}$, por desconfortável e isolado, nele residindo apenas uma pequena guarnição de homens de armas, como acima se sugeriu. Talvez, e à semelhança de

\footnotetext{
${ }^{23}$ ALMEIDA, 1978: 24 segs., 48-9; ALMEIDA, 1989: 47.

${ }_{24}$ Com efeito, e restringindo-nos às imediações, evocamos os casos de prováveis cercas amuralhadas que serviriam de defesa temporária às populações locais em momentos de instabilidade:

- Castelo de Beati, em Mouquim, cuja localização precisa se desconhece, poderia ficar na parte alta de Santiago da Cruz, e controlar o vale do Rio Pelhe, e a estrada para Braga, ou então no cabeço da Santa Filomena, ou no das Ermidas, com controle visual sobre a extensa veiga do rio Este;

- Cossourado, em Guisande (D.C. 540, L.F. 465);

- Monte de S. Miguel, Delães (L.F. 137, de 1085);

- Outino, Sande, Guimarães (D.C. 168 de 994; 587 de 1080);

- Castelo de Frogeva, Leitões, Guimarães (L.F. 369, de 1108);

- Tiedeiras, Leitões, Guimarães (L.F. 223, de 1065; e 224 de 1075);

- Castelo de Custoias, em Calendário, no Monte de S. Miguel-O-Anjo (Avelino Jesus Costa 1959, II, p. 44);

- Sabroso, Oliveira Sta. Maria (D.C. 278, de 1033);

- Monte Córdoba, Santo Tirso;

- Monte de Santa Cristina, Brito, Guimarães (L.F. 384 de 1113).

${ }^{25}$ ALMEIDA, 1978.

${ }^{26}$ LIMA, 1993.

${ }^{27}$ ALMEIDA, 1978: 44.

${ }^{28}$ AMARAL, 2009: 125-125.

${ }^{29}$ BARROCA, 1990/91: 91.
} 


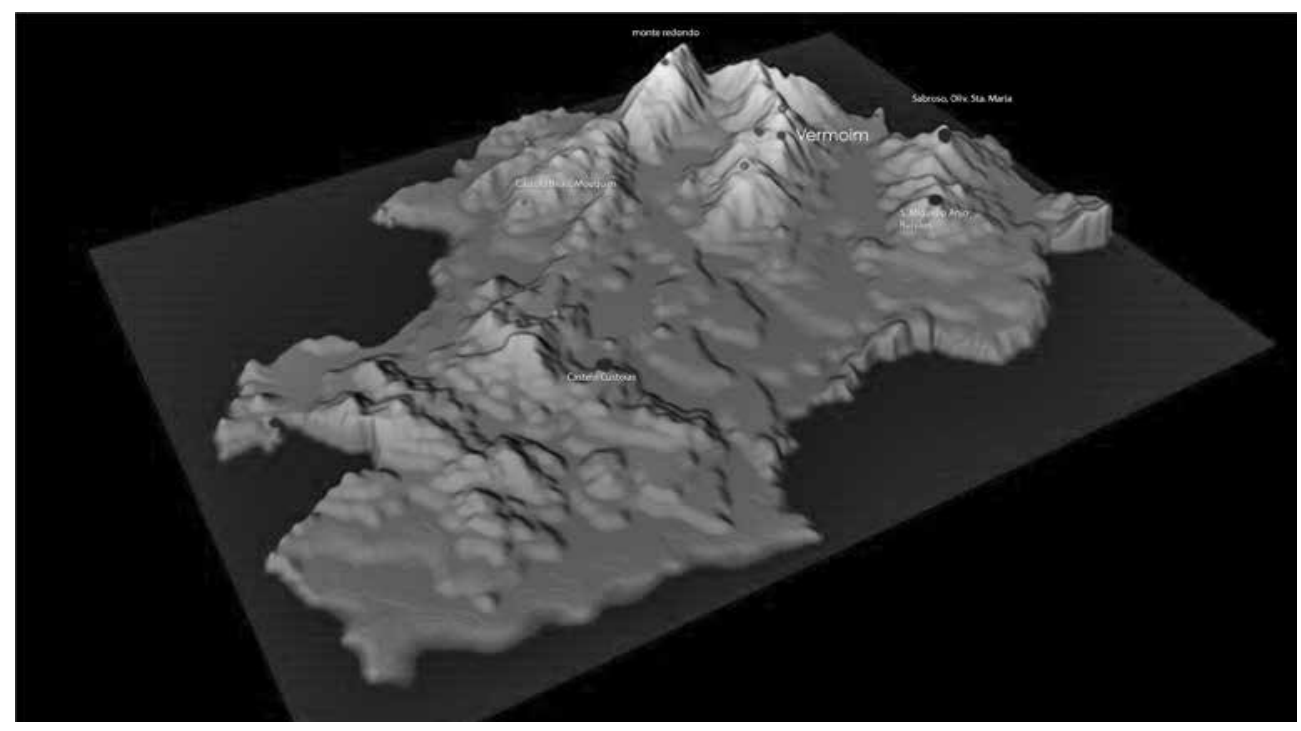

Fig. 25. Modelação de superfície assinalando a azul a localização dos castelos, mons, e castros onde se documentou reocupação medieval.

Planta do castelo de Vermoim, com proposta de traçado da muralha documentada pela evidência disponível.

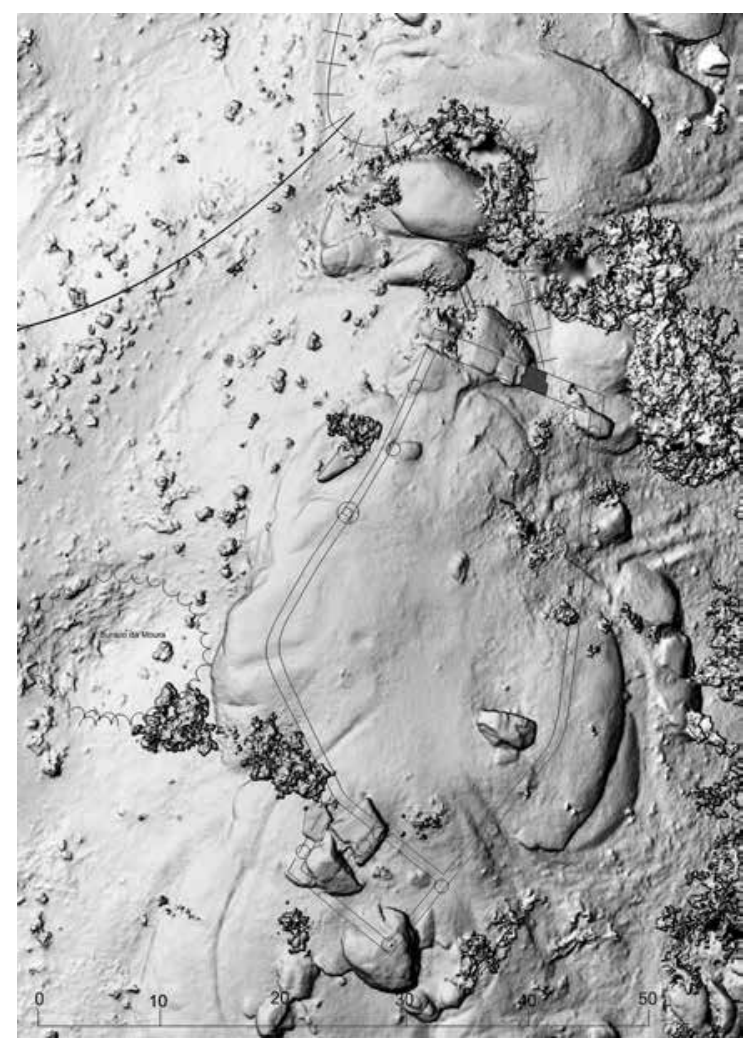



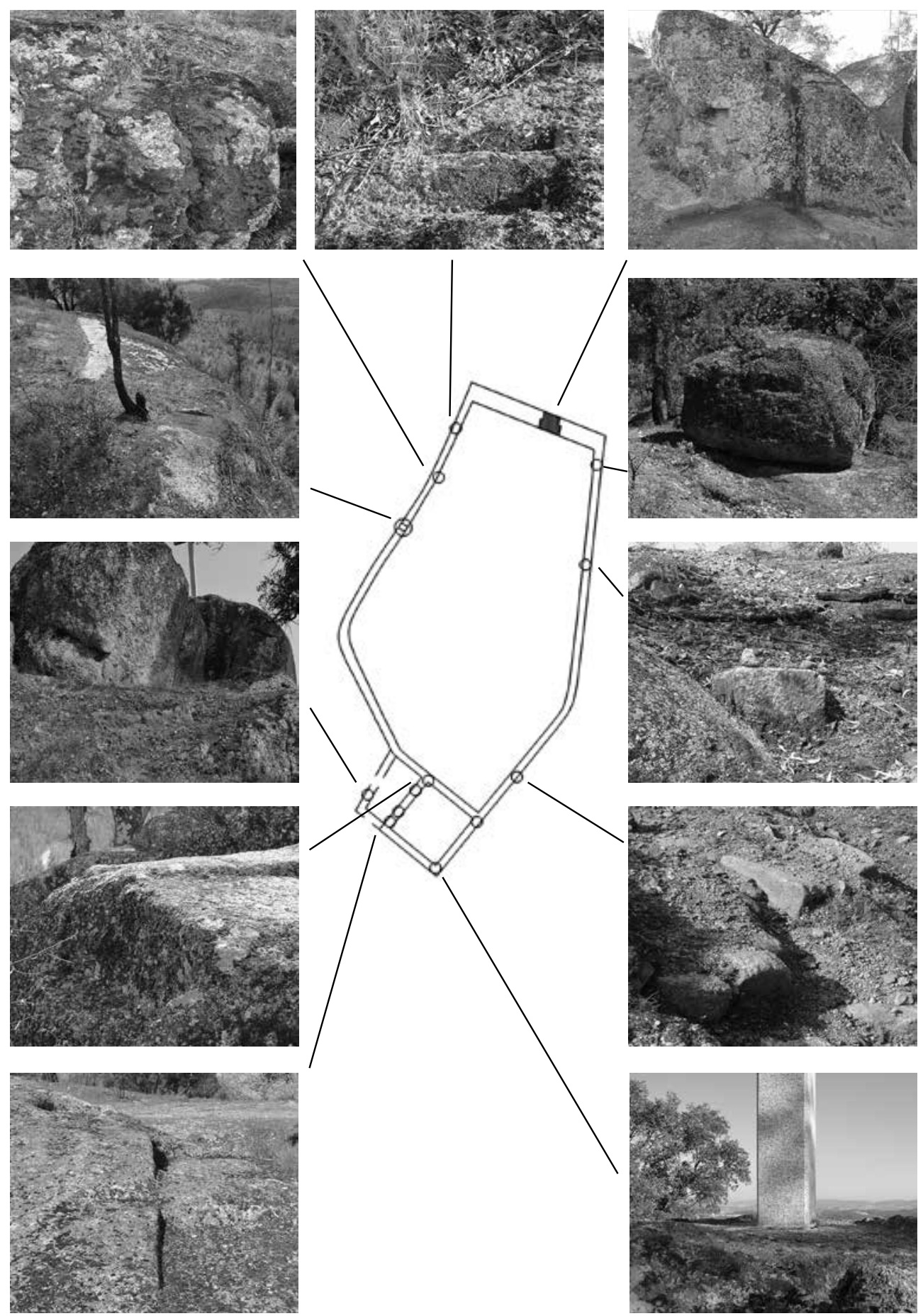

Fig. 27. Apresentação detalhada dos indícios de implantação e traçado da muralha. 


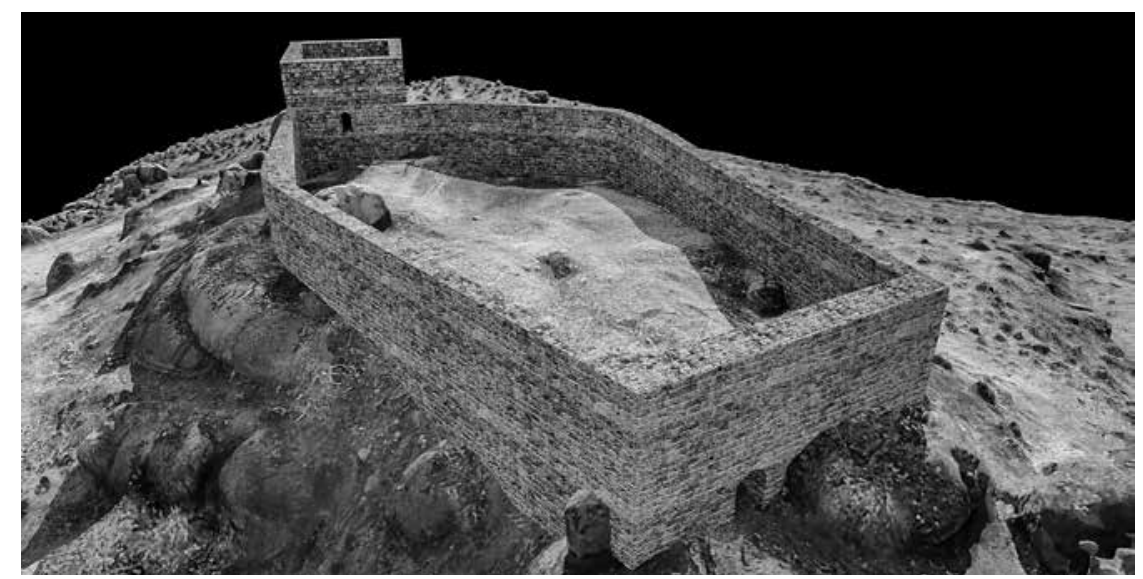

Fig. 28. Proposta de reconstituição 3D do Castelo de Vermoim.

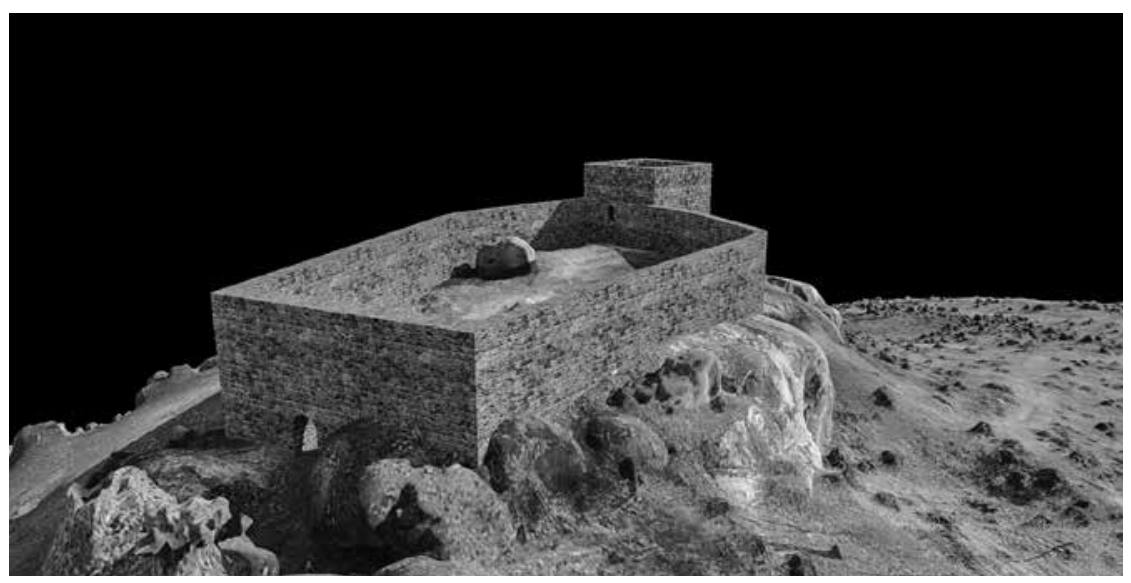

Fig. 29. Proposta de reconstituição 3D do Castelo de Vermoim.

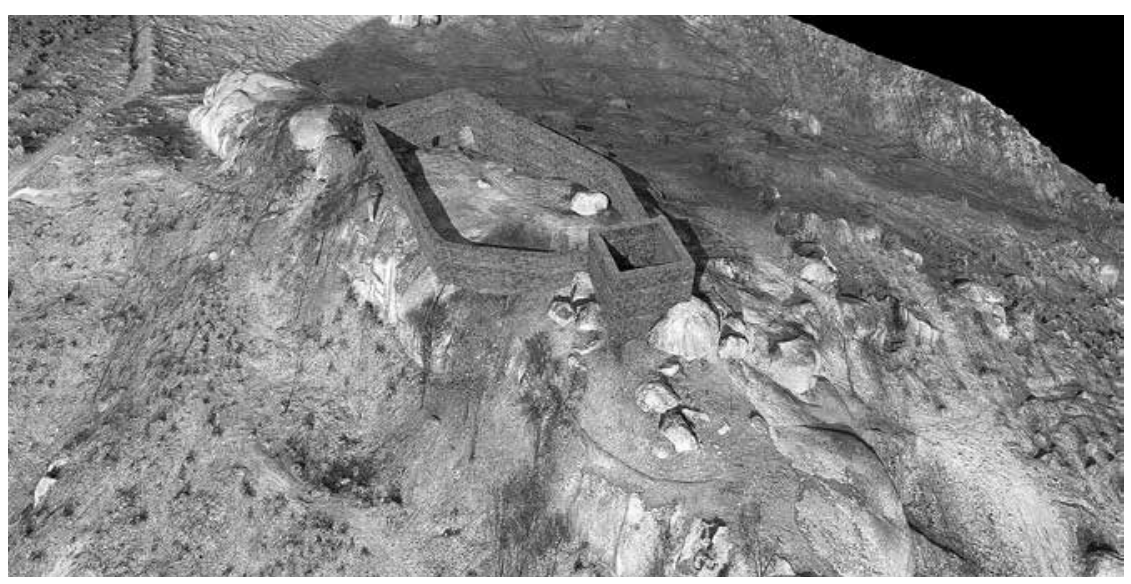

Fig. 30. Proposta de reconstituição 3D do Castelo de Vermoim. 
outras regiões ${ }^{30}$ o conde tenha estabelecido residência numa torre na periferia do vale, topónimo que podemos ainda identificar em mais que um local nas proximidades.

\section{CONSIDERAÇÕES FINAIS}

As técnicas construtivas detectadas nas estruturas do castelo, tanto ao nível dos alicerces como nos entalhes nos rochedos, indiciam um nível de especialização do trabalho de cantaria que não é compatível com o sistema de cooperação vicinal, que parece ter caracterizado a construção dos sítios de refúgio referidos na documentação, alguns nomeados como mons, dos quais listámos acima um conjunto dos situados nas redondezas de Vermoim. Estamos perante trabalho de cantaria especializada, a mesma que vemos nas obras de prestígio de época pré-românica, como na igreja de S. Torquato e nos castelos de Guimarães e de Lanhoso. Estes indícios parecem sugerir que a construção deste castelo foi obra de equipe de canteiros/assentadores, que só a iniciativa condal teria posses para financiar, pela monta do empreendimento, o que o colocaria numa posição hierárquica dominante já nos finais do século $\mathrm{X}$ e inícios do século XI. De resto, sabe-se que a construção dos castelos mais importantes desta época é de iniciativa condal ${ }^{31}$, fenómeno do qual temos o exemplo próximo do castelo do Mons Latito, o futuro castelo de Guimarães, de iniciativa da condessa Mumadona Dias, e com o objectivo manifesto de melhor resistir às incursões. Se esta hipótese vier a ser confirmada pela investigação futura, e nomeadamente por escavações arqueológicas no local, então algumas outras questões poderão ficar esclarecidas. A primeira é o protagonismo deste castelo na defesa da incursão normanda, ou pelo menos o facto de as fontes o terem registado como associado ao evento, a juntar à presumível presença do conde por altura do ataque, e também o facto de este castelo vir a ascender a cabeça da Terra de Vermoim.

O castelo de Vermoim possui um amplo domínio visual do espaço visual dos dois quadrantes a sul, nomeadamente sobre o tramo de todo o vale dos rios Pele e Ave que lhe ficam adjacentes, sendo, por sua vez, visível a quem esteja dentro desta área. Talvez o ataque dos normandos que vinham $a$ viking em 6 de Setembro de 1016 não deva ser considerado fortuito. A expedição, que provavelmente teria arribado à embocadura do rio $A v e^{32}$, penetrou em direcção ao interior pelas vias naturais das veigas adjacentes ao seu curso, e o curso do rio Pele, alinhadas com o traçado das vias que então ligavam ao interior ${ }^{33}$, e na rota dos núcleos monacais que já então se estendiam em número considerável pelo vale do rio Ave acima, até Guimarães ${ }^{34}$.

\footnotetext{
${ }^{30}$ BARROCA, 1984: 124; 1988: 163.

${ }^{31}$ BARROCA, 1990/91: 94.

${ }^{32}$ AMARAL, 2009: 125.

${ }^{33}$ ALMEIDA, 1968: 82-83.

${ }^{34}$ MARQUES, 1988.
} 
O castelo chamaria inevitavelmente a atenção dos invasores, pela ameaça militar que constituía, por qualquer tentativa que a sua guarnição terá efectuado no sentido de repelir a incursão, e que os textos não referem, e naturalmente também porque um dos objectivos primários do raide era o de obter bens e reféns de valor, para negociação de resgate ${ }^{35}$, e neste caso a captura do conde Alvito Nunes, a concretizar-se, seria particularmente rentável.

A escassez das fontes escritas sobre este episódio, que é laconicamente referido na Chronica Gothorum ${ }^{36}$, obriga-nos a auscultar outras evidências que apoiem as nossas dúvidas e interpretações sobre esta incursão. Contudo, o facto de Alvito Nunes, então governador do condado portucalense, ter encabeçado a resistência organizada a estes ataques-relâmpago, e ter escolhido o castelo de Vermoim para o fazer, sugere não só a atenção que o poder condal conferia a estes focos de instabilidade, como também o facto de o castelo possuir solidez tida como suficiente para resistir ao ataque. De resto, pelo que acima se referiu, consideramos que o castelo de Vermoim continha capacidades de defesa para enfrentar ataques deste teor, isto é, sem recurso a armas de cerco.

Quanto à rota de penetração, colocamos algumas reservas quanto à possibilidade de o rio Ave nos inícios do mês de Setembro possuir então caudal, e, portanto navegabilidade, compatíveis com a progressão de barcos, mesmo sendo estes tão extraordinariamente ligeiros e versáteis como os drakkar, que pouco ultrapassavam um metro de calado, salvo talvez no seu curso inferior, com limite na zona Trofa/ Santo Tirso. Recordamos que se vivia então um período de óptimo climático com temperaturas e precipitações superiores às actuais ${ }^{37}$, que só o início da designada «pequena idade do gelo» viria a alterar cerca de dois séculos depois. Por esta razão, somos tentados a defender que a incursão terá seguido uma rota terrestre, talvez pelas vias existentes ao longo dos vales dos rios Ave e Pele.

\section{BIBLIOGRAFIA}

ALMEIDA, Carlos A. Ferreira de (1968) - Vias medievais de Entre Douro e Minho. Porto: Faculdade de Letras da Universidade do Porto (polic.).

(1978) - Castelologia medieval de Entre-Douro-e-Minho. Porto: [s. n.] (polic.).

(1981) - Território Paroquial no Entre-Douro-e-Minho. Sua sacralização. «Nova Renascença 2», vol.1, Porto: Livraria Bertrand, 202-12.

de (1987) - Muralhas Românicas e Cercas Góticas de algumas cidades do centro e do norte de Portugal. A sua lição para a dinâmica urbana de então. Cidades e História, Lisboa: Fundação Calouste Gulbenkian, 137-41.

\footnotetext{
35 PIRES, 2011.

${ }^{36}$ HERCULANO, 1856: 9.

${ }^{37}$ FAGAN, 2002: 75.
} 
(1989) - Castelos e cercas medievais, séculos X a XIII. In MOREIRA, Rafael, edit. - Portugal no Mundo. História das Fortificações Portuguesas no Mundo. Lisboa: Publicações Alfa, 38-54.

(1992) - Castelos Medievais do Noroeste de Portugal. In ACUÑA CASTROVIEJO, F., ed. - Finis Terrae: Estudios en Lembranza do Prof. Dr. Alberto Balil, Santiago de Compostela: 371-85.

(1993) - Os castelos medievais do norte de Portugal. In Primeiras Xornadas Históricas e Arqueolóxicas da 'Mariña Lucense'. Lugo: Disputación Provincial de Lugo, 51-101.

AMARAL, Luís Carlos (2009) - O povoamento da terra bracarense durante o século X. «Revista da Faculdade de Letras - História», III série, vol. 10. Porto: Faculdade de Letras da Universidade do Porto, p. 113-27.

AZEVEDO, Rui Pinto de (1973) - A expedição de Almançor a Santiago de Compostela em 997, e a de piratas normandos à Galiza em 1015-16. «Revista Portuguesa de História», 14. Coimbra: Faculdade de Letras da Universidade de Coimbra, p. 73-93.

BASTOS, J. G. P. (1988) - A mulher, o leite e a cobra. Lisboa: Edições Rolim.

BARROCA, Mário J. (1984) - Notas sobre a ocupação medieval em Baião. Porto: «Arqueologia», 10, p. 116-36.

(1988) - A ocupação Medieval em Castelo de Matos. Primeira abordagem. Porto: «Arqueologia», 17, p. 159-71.

(1990-91) - Do castelo da reconquista ao castelo românico (Séc. IX a XII). «Portvgália», 11-12, p. 89-126.

(2004) - Fortificações e Povoamento do Norte de Portugal (Séculos IX a XI). «Portvgália», 25, p. 181-203.

BURNS, William E. (2003) - Witch Hunts in Europe and America: An Encyclopedia. Westport: Greenwood Press.

CASTELO BRANCO, Camilo (1985) - Vinte horas de liteira. Obras Completas, Volume 5, Porto, Lello \& Irmão Editores.

CUNHA, A. R. (1975) - Trepando aos montes. «O Distrito de Braga», 1 (1-4), p. 485-535.

DINIS, António Pereira; SILVA, Armando Coelho F. da; OLIVEIRA, Felisbela; QUEIROGA, Francisco M.V.R. (2005) - Vila Nova de Famalicão, do neolítico à romanização. In Capela, José Viriato et al., edits. - História de Vila Nova de Famalicão, Vila Nova de Famalicão: Câmara Municipal, p. 11-61.

FAGAN, Brian (2002) - The Little Ice Age: How Climate Made History 1300-1850. New York: Basic Books.

FIGUEIRAL, Isabel M. A. C. R.; QUEIROGA, Francisco (1988) - Castelo de Matos, 1982-86. «Arqueologia», 17, p. 137-50.

FONTES, Luís F. O.; RORIZ, Ana (2010) - O Castro - Castelo de Vieira (Cantelães, Vieira do Minho). Relatório. Braga: Trabalhos Arqueológicos da UAUM. (Memórias 9).

FONTES, Luís Fernando de Oliveira; REGALO, Henrique Jorge L. de Araújo (1997) - O «Castelo» de Penafiel de Bastuço, Paços S. Julião, Braga. Elementos para o seu estudo. «Arqueologia Medieval», 5, p. 199-220.

LIMA, António M. de Carvalho (1993) - Castelos Medievais do Curso Terminal do Douro (Séc. IX a XII). Porto: Universidade do Porto (polic.).

(2010/11) - Povoamento e Organização do Território do Baixo Douro na época da Monarquia Asturiana. «Portvgália», 31-32, p. 83-114.

LISÓN TOLOSANA, Carmelo (1987) - Brujería, estructura social y simbolismo en Galicia. Madrid: AKAL. LUNA, Isabel; SOUSA, Ana Catarina; LEAL, Rui Sá (2008) - Telegrafia visual na Guerra Peninsular 1807-1814. «Boletim Cultural», Mafra: Câmara Municipal de Mafra, p. 67-141.

MARQUES, José (1988) - A Arquidiocese de Braga no séc. XV. Lisboa: Imprensa Nacional. 
(2005) - A Terra de Vermoim na Idade Média - Identificação do território, instituições, vida e declínio. Alguns aspectos. In Capela, José Viriato et al., edits. - História de Vila Nova de Famalicão. Vila Nova de Famalicão: Câmara Municipal, p. 63-107.

PIRES, Hélio F. Vitorino (2011) - Money for Freedom: Ransom Paying to Vikings in Western Iberia. «Viking and Medieval Scandinavia Journal» 7. Turnhout: Brepols Publishers, p. 125-130. (2012) - Incursões Nórdicas no Ocidente Ibérico (844-1147): Fontes, História e Vestígios. Lisboa: FCSH Universidade Nova de Lisboa (polic.).

PORTUGALIAE Monumenta Historica. Diplomata et Chartae. Lisboa: 1867.

QUEIROGA, Francisco M.V.R. (1983) - Património Histórico de Vila Nova de Famalicão. «Boletim Cultural da Câmara Municipal de Vila Nova de Famalicão», 4, p. 47-51. (1985) - Vila Nova de Famalicão. Castro de Vermoim - 1982. «Informação Arqueológica 5», 56. (2015) - As cabanas do Castro de Penices, e a evolução da arquitectura doméstica dos castros. «Portvgalia», 36, p. 263-276.

RODRIGUES, Ana Maria S. A. (2006) - A Formação da rede paroquial no Portugal medievo. In Estudos em Homenagem ao Professor Doutor José Amadeu Coelho Dias. Porto: Faculdade de Letras da Universidade do Porto, vol. I., p. 71-84.

SARMENTO, F. Martins (1999) - Antíqua, Apontamentos de Arqueologia. Guimarães: Sociedade Martins Sarmento.

VEIGA, Augusto Botelho da Costa (1939) - Estudos de História Militar Portuguesa (2 vols.). Lisboa: Tipografia Henrique Torres. 


\section{MIL ANOS DA INCURSÃO NORMANDA AO CASTELO DE VERMOIM}

COORD.

MÁRIO JORGE BARROCA

ARMANDO COELHO FERREIRA DA SILVA

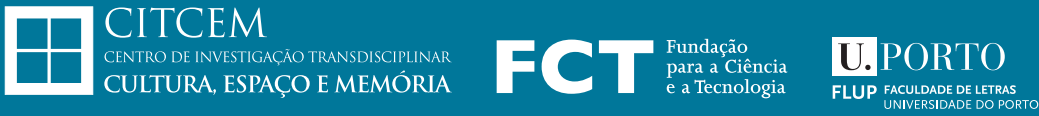

Cofinanciado por:

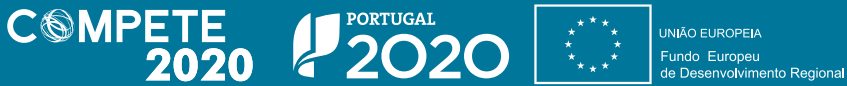

